In cooperation with the Texas Department of Transportation

\title{
Atlas of Depth-Duration Frequency of Precipitation Annual Maxima for Texas
}

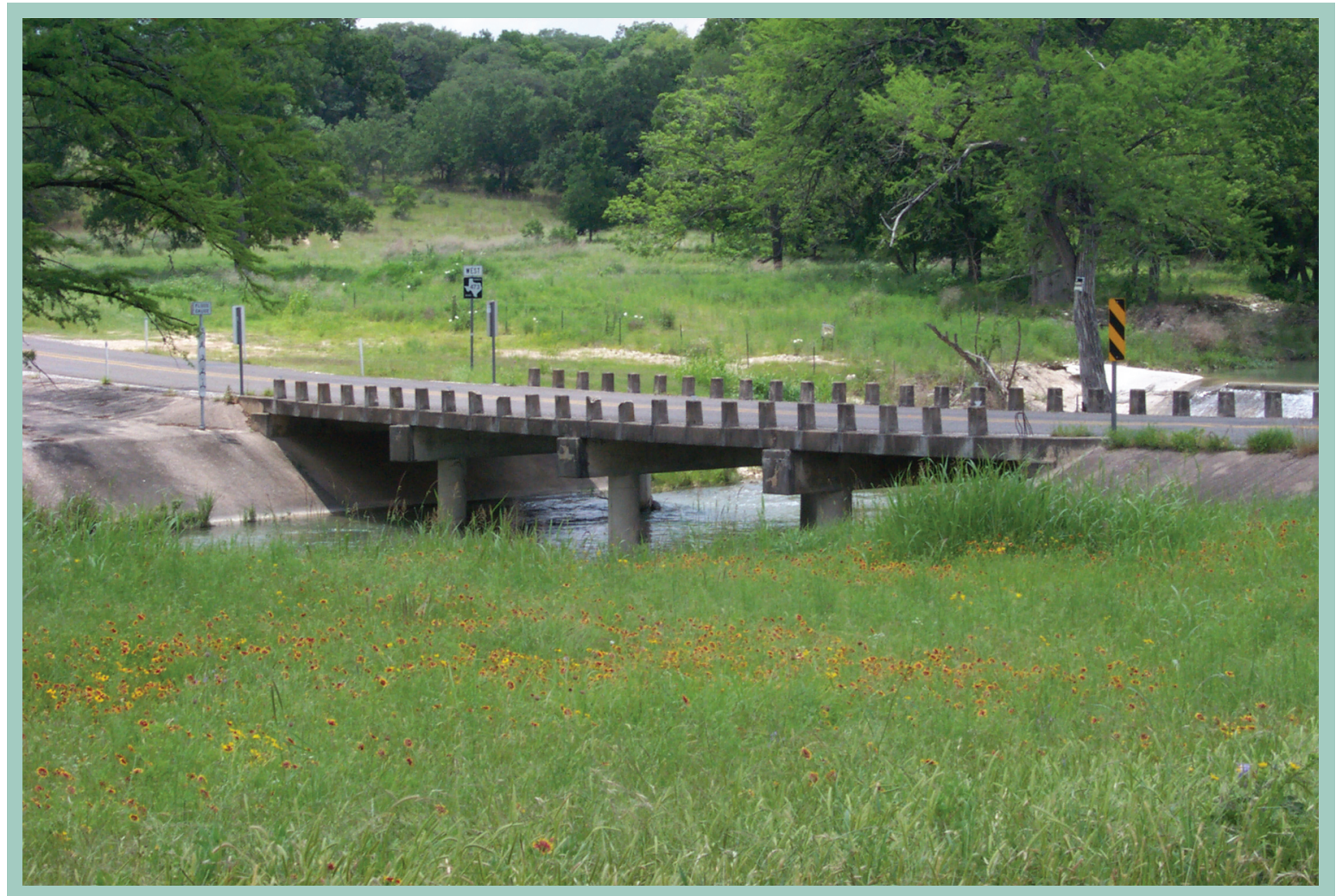

Scientific Investigations Report 2004-5041

(TxDOT Implementation Report 5-1301-01-1) 
Technical Report Documentation Page

\begin{tabular}{|c|c|c|c|}
\hline $\begin{array}{l}\text { 1. Report No. } \\
\text { FHWA/TX-04/5-1301-01-1 }\end{array}$ & 2. Government Accession No. & \multicolumn{2}{|l|}{ 3. Recipient's Catalog No. } \\
\hline \multicolumn{2}{|l|}{ 4. Title and Subtitle } & \multicolumn{2}{|l|}{$\begin{array}{l}\text { 5. Report Date } \\
\text { June } 2004\end{array}$} \\
\hline \multicolumn{2}{|c|}{$\begin{array}{l}\text { ATLAS OF DEPTH-DURATION FREQUENCY OF } \\
\text { PRECIPITATION ANNUAL MAXIMA FOR TEXAS }\end{array}$} & \multicolumn{2}{|l|}{ 6. Performing Organization Code } \\
\hline \multicolumn{2}{|c|}{$\begin{array}{l}\text { 7. Author(s) } \\
\text { William H. Asquith and Meghan C. Roussel }\end{array}$} & \multicolumn{2}{|c|}{$\begin{array}{l}\text { 8. Performing Organization Report No. } \\
\text { SIR 2004-5041 }\end{array}$} \\
\hline \multirow{2}{*}{\multicolumn{2}{|c|}{$\begin{array}{l}\text { 9. Performing Organization Name and Address } \\
\text { U.S. Geological Survey } \\
\text { Water Resources Division } \\
8027 \text { Exchange Drive } \\
\text { Austin, Texas } 78754\end{array}$}} & \multicolumn{2}{|l|}{ 10. Work Unit No. (TRAIS) } \\
\hline & & \multicolumn{2}{|l|}{$\begin{array}{l}\text { 11. Contract or Grant No. } \\
\text { Project 5-1301 }\end{array}$} \\
\hline \multirow{2}{*}{\multicolumn{2}{|c|}{$\begin{array}{l}\text { 12. Sponsoring Agency Name and Address } \\
\text { Texas Department of Transportation } \\
\text { Research and Technology Implementation Office } \\
4000 \text { Jackson Ave., Bldg. } 1 \\
\text { P.O. Box } 5080 \\
\text { Austin, TX } 78731\end{array}$}} & \multicolumn{2}{|c|}{$\begin{array}{l}\text { 13. Type of Report and Period Covered } \\
\text { Research from } 2003 \text { to } 2004\end{array}$} \\
\hline & & \multicolumn{2}{|l|}{ 14. Sponsoring Agency Code } \\
\hline \multicolumn{4}{|l|}{$\begin{array}{l}\text { 15. Supplementary Notes } \\
\text { Project conducted in cooperat }\end{array}$} \\
\hline \multicolumn{4}{|l|}{$\begin{array}{l}\text { 16. Abstract } \\
\text { Ninety-six maps depicting the s } \\
\text { presented. The recurrence inter } \\
15 \text { and } 30 \text { minutes; } 1,2,3,6 \text {, ar } \\
\text { parameter maps of probability } \\
\text { magnitude and frequency of pre } \\
\text { depth-duration frequency of pre }\end{array}$} \\
\hline \multicolumn{2}{|c|}{$\begin{array}{l}\text { 17. Key Words } \\
\text { Precipitation, Depth duration frequency, Annual precipitation maxima, } \\
\text { L-moments, Texas }\end{array}$} & \multicolumn{2}{|l|}{$\begin{array}{l}\text { 18. Distribution Statement } \\
\text { No restrictions. }\end{array}$} \\
\hline $\begin{array}{l}\text { 19. Security Classif. (of report) } \\
\text { Unclassified }\end{array}$ & $\begin{array}{l}\text { 20. Security Classif. (of this pa } \\
\text { Unclassified }\end{array}$ & $\begin{array}{l}\text { 21. No. of pages } \\
106\end{array}$ & $\begin{array}{l}\text { 22. Price } \\
\$ 4.00\end{array}$ \\
\hline
\end{tabular}

Form DOT F 1700.7 (8-72)

Reproduction of completed page authorized

\section{Cover:}

West Sister Creek near Sisterdale, Texas, on FM 473, Kendall County, May 10, 2004. 


\section{Atlas of Depth-Duration Frequency of Precipitation Annual Maxima for Texas}

By William H. Asquith and Meghan C. Roussel

In cooperation with the Texas Department of Transportation

Scientific Investigations Report 2004-5041

(TxDOT Implementation Report5-1301-01-1) 


\title{
U.S. Department of the Interior Gale A. Norton, Secretary
}

\author{
U.S. Geological Survey \\ Charles G. Groat, Director
}

\section{U.S. Geological Survey, Reston, Virginia: 2004}

For sale by U.S. Geological Survey, Information Services

Box 25286, Denver Federal Center

Denver, CO 80225

For more information about the USGS and its products:

Telephone: 1-888-ASK-USGS

World Wide Web: http://www.usgs.gov/

Any use of trade, product, or firm names in this publication is for descriptive purposes only and does not imply endorsement by the U.S. Government.

Although this report is in the public domain, permission must be secured from the individual copyright owners to reproduce any copyrighted materials contained within this report.

The contents of this report do not necessarily reflect the official view or policies of the Texas Department of Transportation (TxDOT). This report does not constitute a standard, specification, or regulation.

Suggested citation:

Asquith, W.H., and Roussel, M.C., 2004, Atlas of depth-duration frequency of precipitation annual maxima for Texas: U.S. Geological Survey Scientific Investigations Report 2004-5041, 106 p. 


\section{CONTENTS}

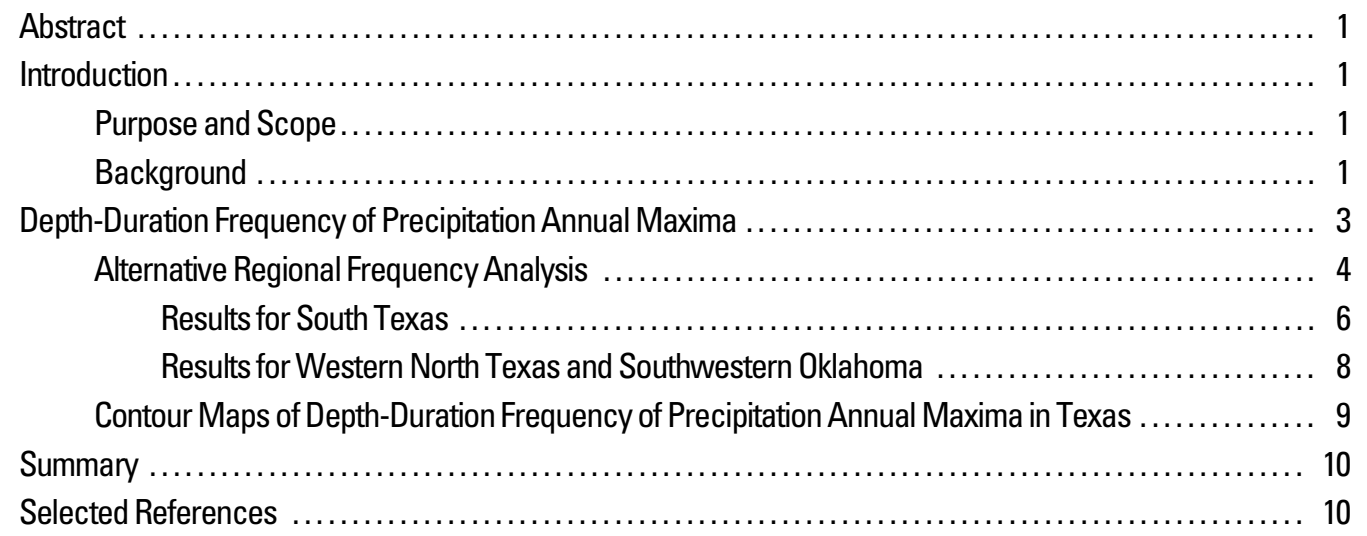

\section{FIGURES}

1. Graphs showing L-moment ratio diagrams for selected storm durations in Texas .............. 2

2. Flowchart showing components of the process to generate a depth-duration frequency of

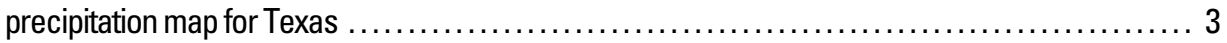

3. Map showing National Weather Service hourly precipitation stations in the South Texas, western North Texas, and southwestern Oklahoma regions ........................... 5

4-15. Maps showing depth of precipitation for 2-year storm for:

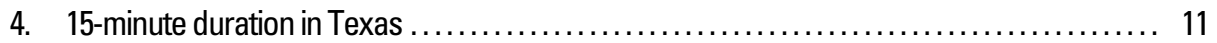

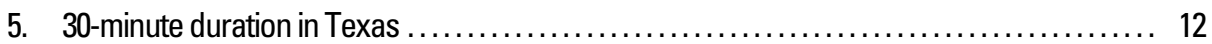

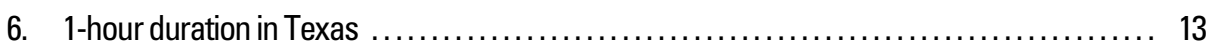

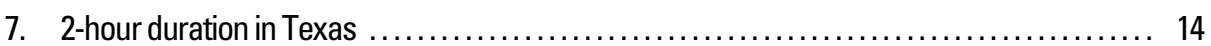

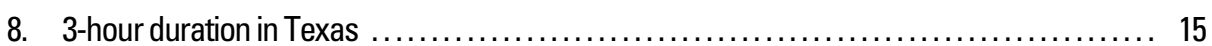

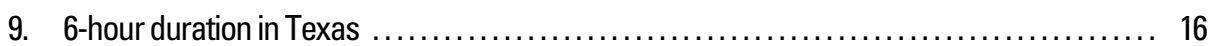

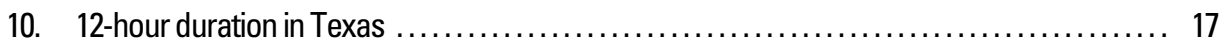

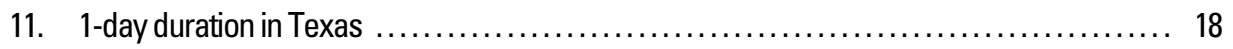

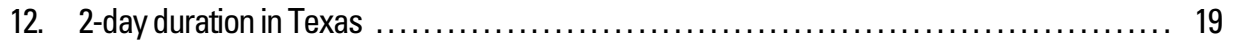

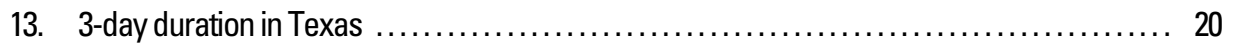

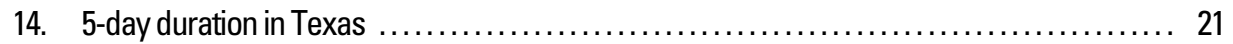

15. 7-day duration in Texas.................................................. 22

16-27. Maps showing depth of precipitation for 5-year storm for:

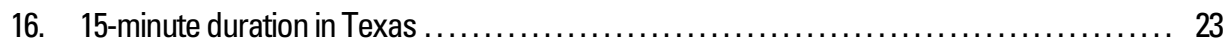

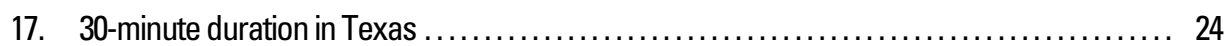

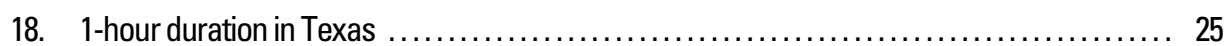

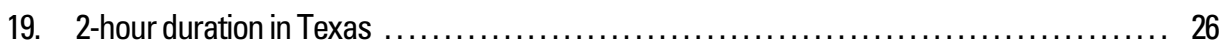

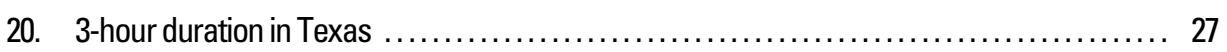

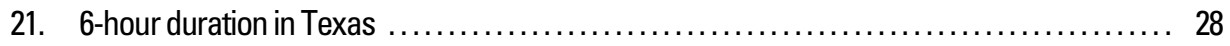

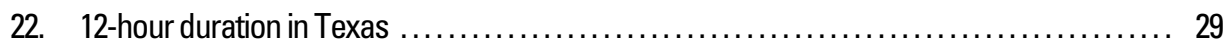

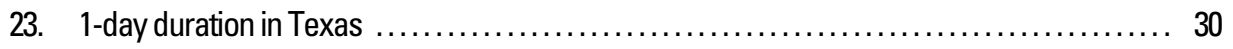

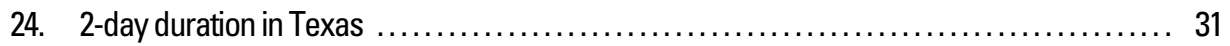

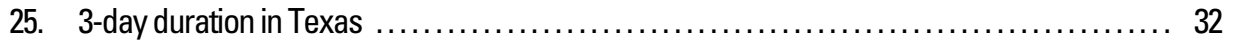

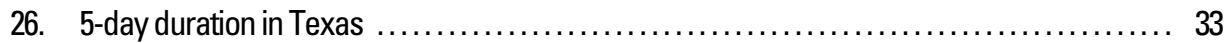

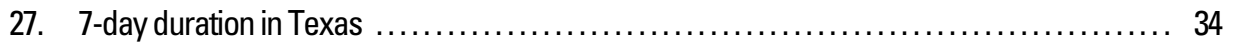


28-39. Maps showing depth of precipitation for 10-year storm for:

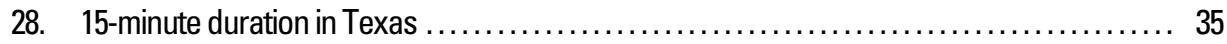

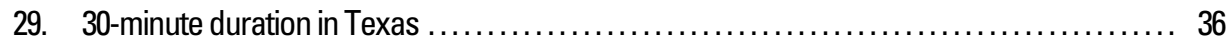

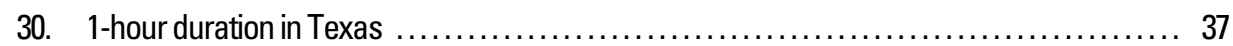

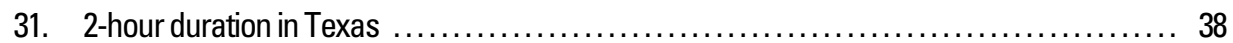

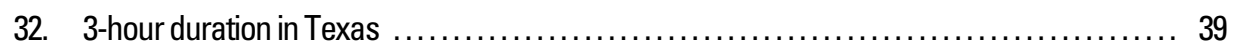

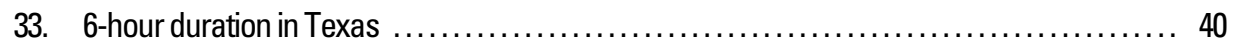

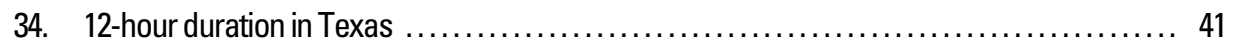

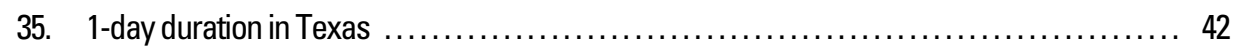

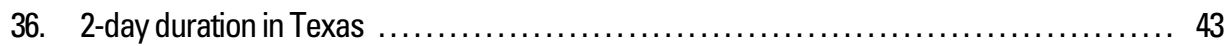

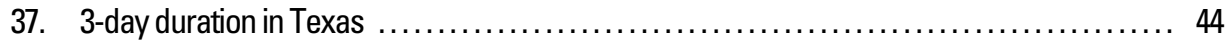

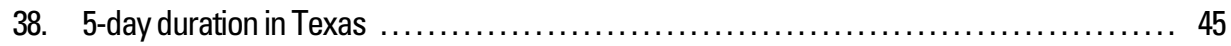

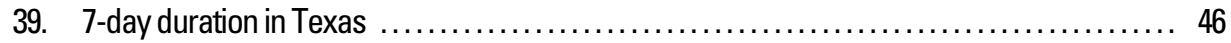

40-51. Maps showing depth of precipitation for 25-year storm for:

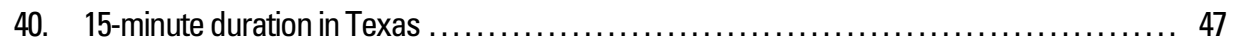

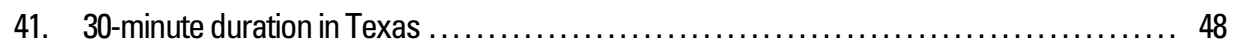

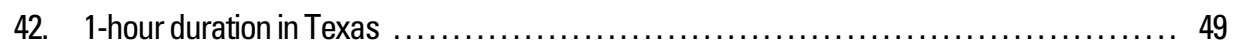

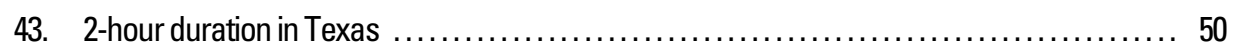

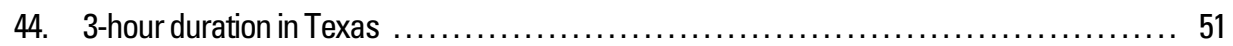

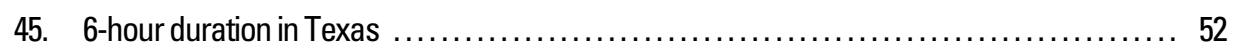

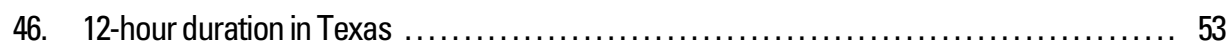

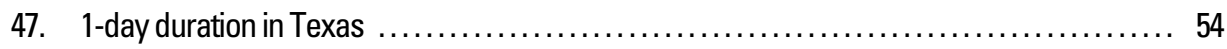

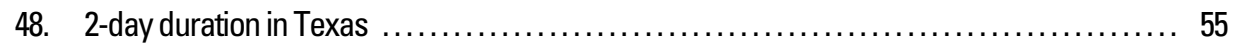

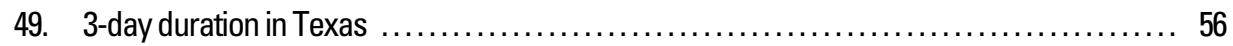

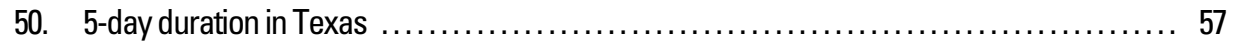

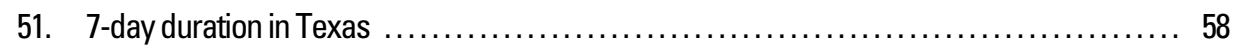

52-63. Maps showing depth of precipitation for 50-year storm for:

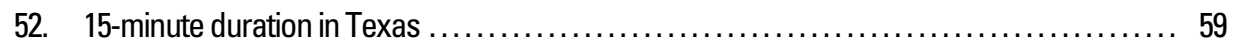

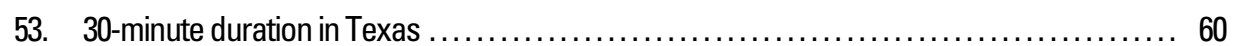

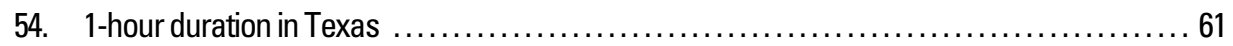

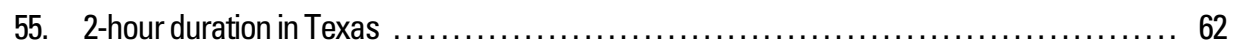

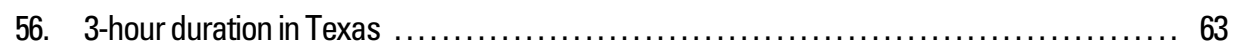

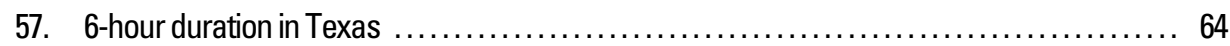

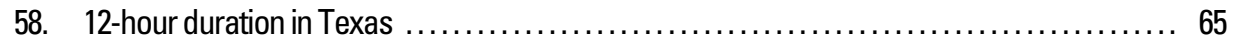

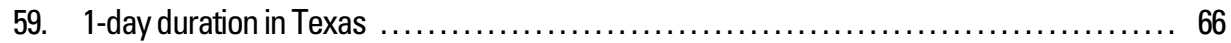

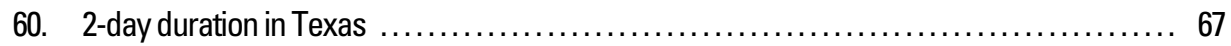

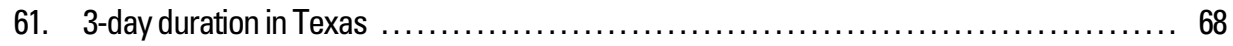

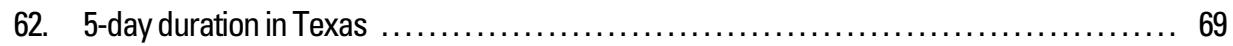

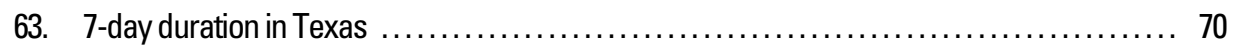

64-75. Maps showing depth of precipitation for 100-year storm for:

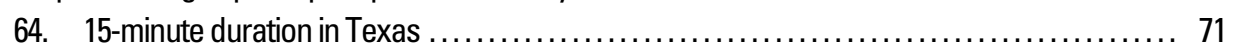

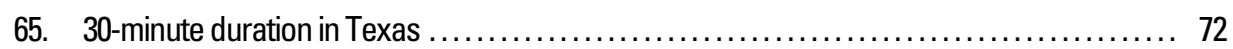

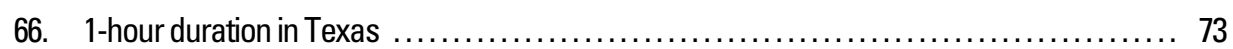

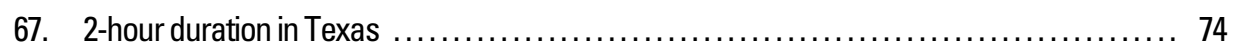

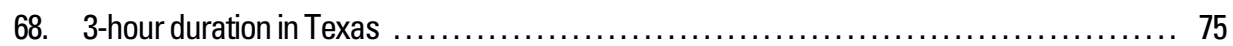

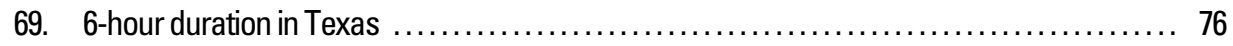

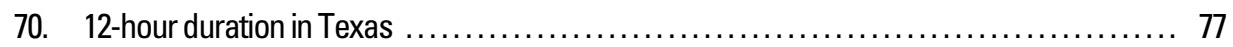

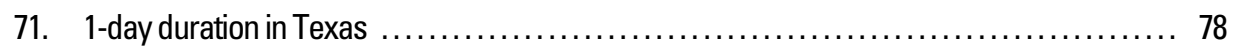

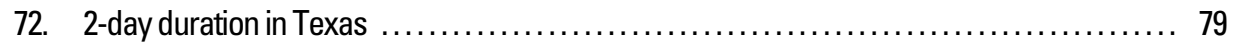




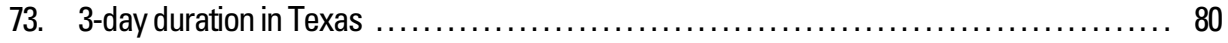

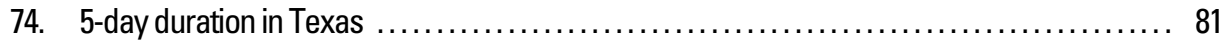

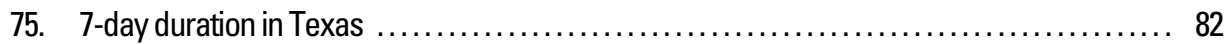

76-87. Maps showing depth of precipitation for 250-year storm for:

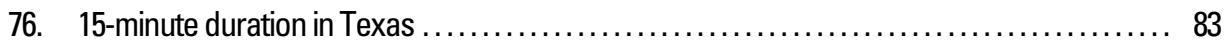

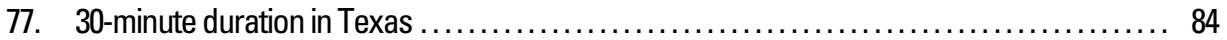

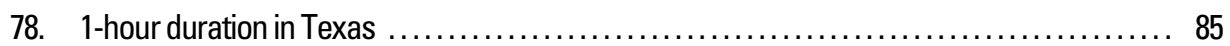

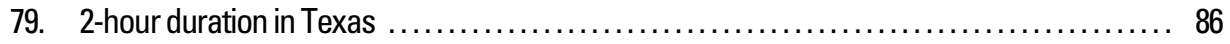

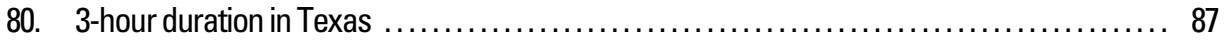

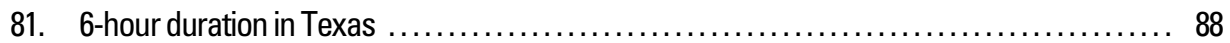

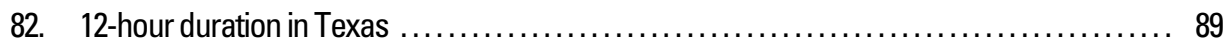

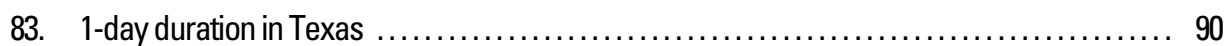

84. 2-day duration in Texas .................................................. 91

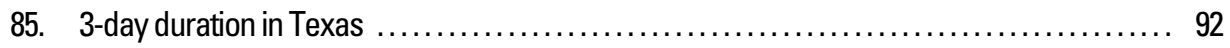

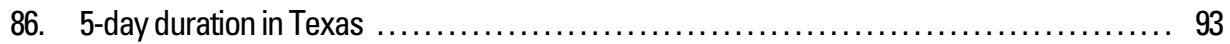

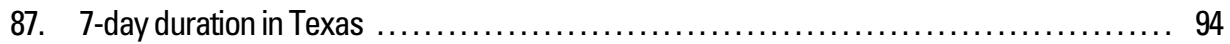

88-99. Maps showing depth of precipitation for 500 -year storm for:

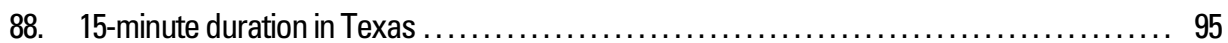

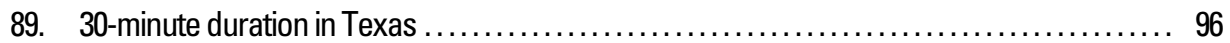

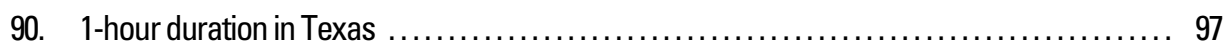

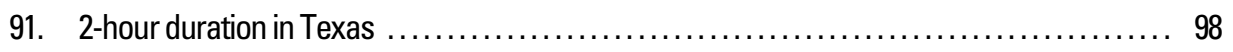

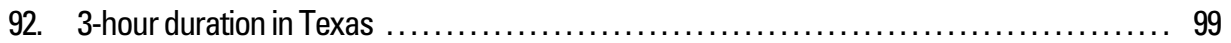

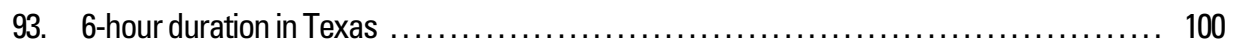

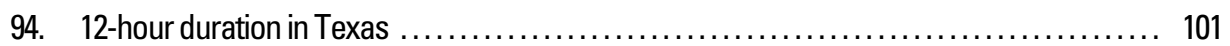

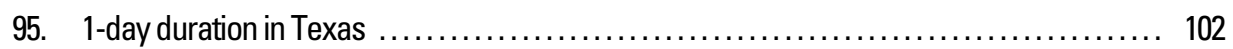

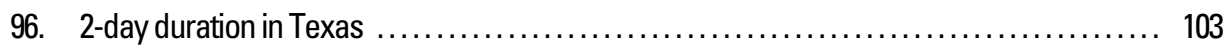

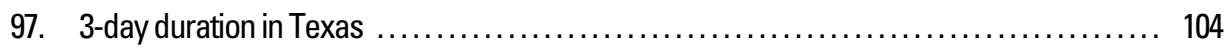

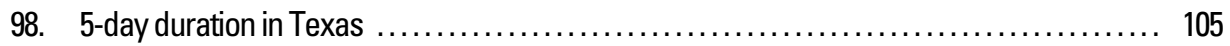

99. 7-day duration in Texas ................................................. 106

\section{TABLES}

1. National Weather Service hourly precipitation stations for South Texas region ................ 4

2. National Weather Service hourly precipitation stations for western North Texas region ..........6 6

3. National Weather Service hourly precipitation stations for southwestern Oklahoma region .......6 6

4. Regional values for L-moments of 6-, 12-, and 24-hour precipitation annual maxima and corresponding parameters for selected distributions in South Texas region ................. 7

5. Regional values for L-moments of 6- and 12-hour precipitation annual maxima and corresponding parameters for selected distributions in western North Texas region ........... 7

6. Regional values for L-moments of 12-hour precipitation annual maxima and corresponding parameters for the GEV distribution in southwestern Oklahoma region ..................... 8

7. Depth-duration frequency of precipitation annual maxima for South Texas region derived from Asquith (1998) and alternative regional frequency analysis ........................ 8

8. Depth-duration frequency of precipitation annual maxima for western North Texas region derived from Asquith (1998) and alternative regional frequency analysis ................... 9

9. Depth-duration frequency of precipitation for the 12-hour duration in southwestern Oklahoma region 


\title{
Atlas of Depth-Duration Frequency of Precipitation Annual Maxima for Texas
}

\author{
By William H. Asquith and Meghan C. Roussel
}

\section{Abstract}

Ninety-six maps depicting the spatial variation of the depth-duration frequency of precipitation annual maxima for Texas are presented. The recurrence intervals represented are 2 , $5,10,25,50,100,250$, and 500 years. The storm durations represented are 15 and 30 minutes; 1, 2, 3, 6, and 12 hours; and 1, $2,3,5$, and 7 days. The maps were derived using geographically referenced parameter maps of probability distributions used in previously published research by the U.S. Geological Survey to model the magnitude and frequency of precipitation annual maxima for Texas. The maps in this report apply that research and update depth-duration frequency of precipitation maps available in earlier studies done by the National Weather Service.

\section{Introduction}

Precipitation depths for various durations and frequencies, referred to as depth-duration frequency (DDF), have many uses in surface-water hydrology and engineering. A common use of DDF is for the design of structures that control and route localized runoff, such as from parking lots, storm drains, and culverts. Another use of DDF is to drive streamflow models that incorporate precipitation characteristics. Accurate DDF estimates are important for cost-effective, risk-mitigated structural designs at stream crossings and for developing reliable floodprediction models. In 1995, the U.S. Geological Survey (USGS), in cooperation with the Texas Department of Transportation, began a 3-year study of precipitation characteristics for Texas. The major results of the study are a definition of the DDF of precipitation for Texas (Asquith, 1998), determination of appropriate areal-reduction factors of the 1-day design storm for selected localities in Texas (Asquith, 1999; Asquith and Famiglietti, 2000), and an investigation of the extreme precipitation potential for Texas (Lanning-Rush and others, 1998).

Asquith (1998) provides procedures to develop DDF values for any location in Texas for 12 distinct storm durations from 15 minutes to 7 days and recurrence intervals from 2 to 500 years. The procedures, though well documented, are cumbersome to apply. Therefore, in 2003, the USGS, again in cooperation with the Texas Department of Transportation, began a 2-year project to construct an atlas of DDF of precipitation for Texas. The maps of the atlas are analogous to the DDF maps prepared by the National Weather Service (NWS) in earlier studies.

\section{Purpose and Scope}

The purpose of this report is to present maps that depict the DDF of precipitation annual maxima for any location in Texas. This report is an extension of Asquith (1998) and updates earlier NWS DDF studies applicable for Texas such as Hershfield (1961), Miller (1964), and Frederick and others (1977). Precipitation durations of 15 and 30 minutes; 1, 2, 3, 6, and 12 hours; and 1, 2, 3, 5, and 7 days are presented. The frequencies (expressed as recurrence intervals) are 2, 5, 10, 25, 50, 100,250 , and 500 years. The term precipitation in this report is restricted to rainfall.

\section{Background}

From a foundation of analysis based on L-moment statistics (Hosking, 1990) of precipitation annual maxima in Texas, Asquith (1998) provides 37 maps and one table depicting the statewide variation of the parameters for two probability distributions. The distributions model the magnitude and frequency of precipitation for each of the selected durations. The generalized logistic (GLO) distribution is used for storm durations from 15 minutes to 24 hours; whereas the generalized extreme value (GEV) distribution is used for storm durations from 1 to 


\section{Atlas of Depth-Duration Frequency of Precipitation Annual Maxima for Texas}
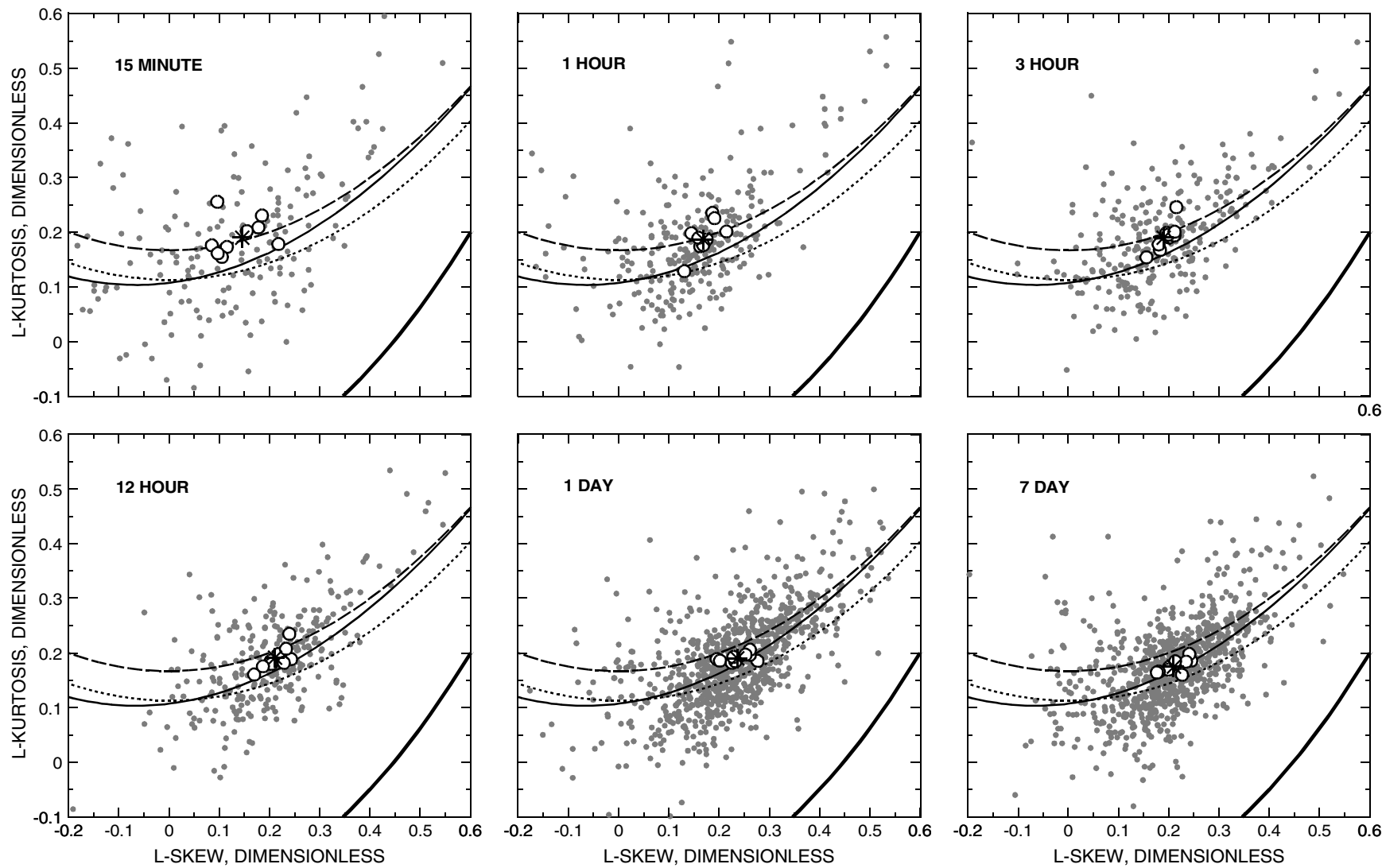

EXPLANATION

Theoretical L-moment ratio limits

- L-moment ratios for station and indicated duration

_- Generalized extreme value (GEV) distri

○ Regional weighted mean L-moment ratios (L-skew and L-kurtosis) for indicated duration

* Weighted mean statewide L-moment ratio (L-skew and L-kurtosis)

Figure 1. L-moment ratio diagrams for selected storm durations in Texas (modified from Asquith, 1998).

7 days. The quantile $(Q)$ function (depth of precipitation for a nonexceedance probability ${ }^{1}$ ) for the GLO distribution is

$$
Q(F)=\xi+\frac{\alpha}{\kappa}\left\{1-\left[\frac{(1-F)}{F}\right]^{\kappa}\right\} \text {, and }
$$

the quantile function of the GEV distribution is

$$
Q(F)=\xi+\frac{\alpha}{\kappa}\left\{1-[-\ln (F)]^{\kappa}\right\},
$$

where, for each distribution, $\xi, \alpha$, and $\kappa$ are location, scale, and shape parameters, respectively, and for which $F$ is annual nonexceedance probability. The parameters can be estimated using L-moment statistics through the method of L-moments (Hosking, 1990).
The decision by Asquith (1998) to use the GLO and GEV distributions and the selection of the applicable duration ranges for each was made through the use of L-moment (ratio) diagrams (Vogel and Fennessey, 1993) (fig. 1).

L-moment diagrams illustrate the intrinsic relation between the L-moments of L-skew and L-kurtosis for several distributions. From the diagrams, the GLO and GEV distributions were judged by Asquith (1998) to be applicable across the entire State for two ranges of storm duration because of the general location of the clustering of regional weighted-mean values for L-skew and L-kurtosis (the open-circle symbols on the diagrams) and the location of the statewide weighted-mean L-moment ratios (the asterisk symbol). On these diagrams a three-parameter distribution (like the GLO or GEV distribution) is characterized by a curvilinear line. In general, the threeparameter distribution judged most suitable to model a data set has its trajectory on the diagram closest to the cluster of L-skew

\footnotetext{
${ }^{1}$ Annual nonexceedance probability is unity minus the reciprocal of a recurrence interval. For example, a 100-year precipitation has an annual nonexceedance probability of 0.99 , which by definition means that there is a 99-percent chance in each and every year that the annual precipitation maximum for that year is less than or equal to the 100 -year precipitation value.
} 


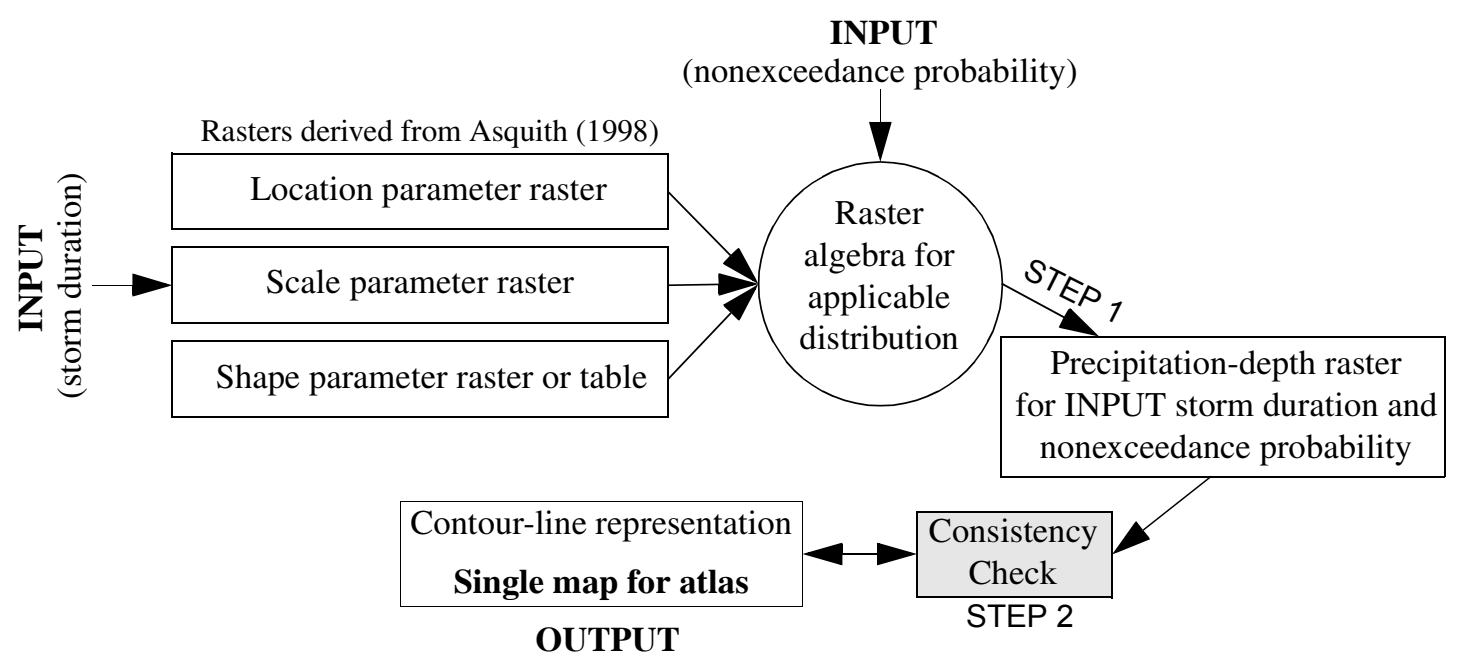

Figure 2. Components of the process to generate a depth-duration frequency of precipitation map for Texas.

and L-kurtosis values of the data. From comparative inspection between the durations on the diagrams, a change in distribution type from GLO to GEV with increasing duration is evident. At the 12-hour duration, neither the GLO or GEV distribution is preferable because the regional and statewide L-moment ratios plot between the trajectories of the distributions; this observation is important for later analysis in this report. Asquith (1998) chose to change distribution type from GLO to GEV at the transition from the 24-hour to 1-day duration.

Explanation of the difference between seemingly equivalent 60-minute and 1-hour, and 24-hour and 1-day durations is needed. Asquith (1998) considers two separate durations of "60 minutes" and " 1 hour" in which the 60 -minute duration is derived from aggregation of four 15-minute values of precipitation from 15-minute-based precipitation data and the 1-hour duration is associated with precipitation data from hourly recorded precipitation data, respectively. Furthermore, the duration of " 24 hours" is associated with the aggregation of twenty-four 1-hour values of precipitation from hourly based precipitation data; whereas the duration of " 1 day" is associated with precipitation data from daily recorded precipitation data. For this report, the DDF for 60-minute and 1-hour durations were combined by arithmetically averaging the two surface representations (defined in the "Depth-Duration Frequency of Precipitation Annual Maxima" section of this report) of depth for each frequency to yield a combined duration referred to as 1 hour. Similarly, the 24-hour and 1-day durations were combined by summing a weighted mean of the 24-hour surface representation and three times the 1-day surface representation, then dividing the resultant surface by four to yield a combined duration referred to as 1 day. A weighted average is preferable because the 1-day DDF values are based on more data and are considered more reliable than the 24-hour DDF values (Asquith, 1998).

\section{Depth-Duration Frequency of Precipitation Annual Maxima}

A DDF map depicts the spatial variation of DDF of precipitation annual maxima. Each DDF map in this report is a contour-line representation of a raster or "surface representation" (cell or grid based) data set of precipitation depth for each of the selected storm durations and frequencies (nonexceedance probability). Each "precipitation-depth raster" data set was generated through a geographical information system (GIS) compatible algebraic representation of the quantile function of each distribution (eqs. 1 and 2). Each distribution has three parameters (location, scale, and shape). The location parameter describes the central tendency of the distribution and locates the distribution along the real-number line. The scale parameter describes the spread or "steepness" of the distribution, and the shape parameter describes the skewness or "curvature" of the distribution. Raster representations of the contour maps of the parameters for each duration provided by Asquith (1998) were generated. These "parameter rasters" were used in conjunction with each nonexceedance probability to compute the precipitation-depth rasters from which the DDF maps in this report were derived. A diagrammatic summary of this process is depicted in figure 2 .

The process depicted in figure 2 was repeated for each of the 12 distinct storm durations and for each of the eight frequency values. However, an intermediate analysis of the 96 rasters was required. This analysis evaluated the consistency of the precipitation-depth rasters prior to final contour-map preparation.

DDF values are statistically based; as a result, errors and uncertainty are in the estimates of DDF of precipitation annual maxima. The uncertainty in DDF estimates increases with increasing recurrence interval. Also, by definition, DDF values for a given location and duration become larger with increasing 


\section{Atlas of Depth-Duration Frequency of Precipitation Annual Maxima for Texas}

recurrence interval (increasing nonexceedance probability), and DDF values for a given location and nonexceedance probability become larger with increasing duration. To clarify, two types of lines on a graph are associated with DDF values. The line of equal duration is defined by the DDF values for a constant duration, and the line monotonically increases with nonexceedance probability. The line of equal frequency is defined by the DDF values for a constant nonexceedance probability, and the line monotonically increases with duration. If the monotonic condition is not met by the estimates of DDF for a given location, then the DDF values are said to be "inconsistent"- - that is, error in the estimation of one or more DDF values for the location has occurred.

The procedures of Asquith (1998) specify lines of equal duration, or in other words, the entire distribution of DDF values for each duration. Therefore, for a given duration Asquith (1998) procedures cannot produce inconsistent DDF values. However, because the precipitation statistics were treated independently for each duration, Asquith (1998) procedures could yield inconsistent lines of equal frequency. Asquith (1998, p. 24-25) recognizes this possibility and suggests a "best-fit" line be hand-plotted on suitable graph paper to reconcile the inconsistencies by smoothing the relation between precipitation depth (expressed as intensity, depth per time) and duration for a given frequency.

It is fundamental that the contour-line maps in this report be consistent. Specifically, lines of equal duration and equal frequency of DDF values for a given location in Texas should monotonically increase. Numerous minor inconsistencies were discovered (results not presented here) in GIS processing of the precipitation-depth rasters for this report. Sources of inconsistency include random statistical errors related to distribution of original data-collection locations and unpredictability of sampling, minor errors in placement and limited resolution of contour lines shown in Asquith (1998), and errors related to the various automated interpolation methods and contourline-to-raster-to-contour-line conversions as part of the GIS processing of the data. Adjustment of DDF values through minor and localized realignment of contour lines eliminated the majority of observed inconsistencies. However, as explained in the next section, an alternative regional frequency analysis was required because substantially inconsistent precipitation depths were discovered in a region in South Texas, and substantial differences in DDF values were encountered when comparing DDF values in a region along a short length of the OklahomaTexas border. These differences resulted in the authors questioning results of Asquith (1998) and an Oklahoma DDF atlas (Tortorelli and others, 1999) and prompted an "alternative" regional analysis for the two regions.

\section{Alternative Regional Frequency Analysis}

The precipitation-depth rasters showing inconsistencies or questionable DDF values required further analysis. One region had substantial inconsistency - that is, inconsistency too large to correct through minor and localized realignment of contour
Table 1. National Weather Service hourly precipitation stations for South Texas region.

[WB, Weather Bureau]

\begin{tabular}{clrrr}
\hline $\begin{array}{c}\text { Station } \\
\text { number } \\
\text { (fig. 3) }\end{array}$ & Station name & \multicolumn{2}{c}{$\begin{array}{c}\text { Latitude and } \\
\text { longitude }\end{array}$} & $\begin{array}{c}\text { Period of } \\
\text { record } \\
\text { analyzed }\end{array}$ \\
\hline 0380 & Asherton & $28^{\circ} 26^{\prime}$ & $99^{\circ} 45^{\prime}$ & $1941-59$ \\
0580 & Baylor Ranch & $28^{\circ} 18^{\prime}$ & $98^{\circ} 59^{\prime}$ & $1941-52$ \\
1528 & Caterina & $28^{\circ} 21^{\prime}$ & $99^{\circ} 37^{\prime}$ & $1960-98$ \\
2048 & Cotulla & $28^{\circ} 26^{\prime}$ & $99^{\circ} 15^{\prime}$ & $1957-98$ \\
2679 & Eagle Pass & $28^{\circ} 42^{\prime}$ & $100^{\circ} 29^{\prime}$ & $1942-98$ \\
4920 & La Pryor & $28^{\circ} 57^{\prime}$ & $99^{\circ} 50^{\prime}$ & $1941-98$ \\
5057 & Laredo WB Airport & $27^{\circ} 32^{\prime}$ & $99^{\circ} 28^{\prime}$ & $1945-64$ \\
\hline
\end{tabular}

lines. The other region had questionable DDF values. The analysis is referred to as "alternative regional frequency analysis" and is described in this section.

The first region is in South Texas (fig. 3). Alternative analysis was required for this region because of a large area in which the depths for the 12-hour duration and large recurrence intervals (50 to 500 years) were larger than the depths for the 1-day duration. The second region is in western North Texas (fig. 3). This region required alternative analysis because DDF values for many durations, particularly the 12-hour duration, at large recurrence intervals near the western North Texas border with Oklahoma did not closely match values for the southwestern Oklahoma region (fig. 3) reported by Tortorelli and others (1999). To augment the alternative regional frequency analysis, the DDF values for a region in southwestern Oklahoma also were investigated for the 12-hour duration. The NWS hourly precipitation stations in each region also are shown in figure 3 and are labeled with the NWS station number associated with each.

The NWS hourly precipitation stations for the South Texas region are listed in table 1 . The NWS hourly precipitation stations for the western North Texas region are listed in table 2. The NWS hourly precipitation stations for the southwestern Oklahoma region are listed in table 3. The latitude, longitude, and period of record analyzed also are listed in tables 1-3.

For the 6-, 12-, and 24-hour durations; the 6- and 12-hour durations; and the 12-hour duration for South Texas, western North Texas, and southwestern Oklahoma, respectively, the annual maxima of precipitation for each complete year of record for each station was determined. The 12-hour duration was of principal concern in the South Texas region as DDF values for this duration were inconsistent with those of the 24-hour duration. The 6- and 24-hour durations additionally were considered because both durations showed inconsistencies with the alternative 12-hour values. The 6- and 12-hour durations were analyzed in western North Texas to determine if regional DDF of precipitation would adequately match Oklahoma values. These durations were selected to test if the regional frequency 


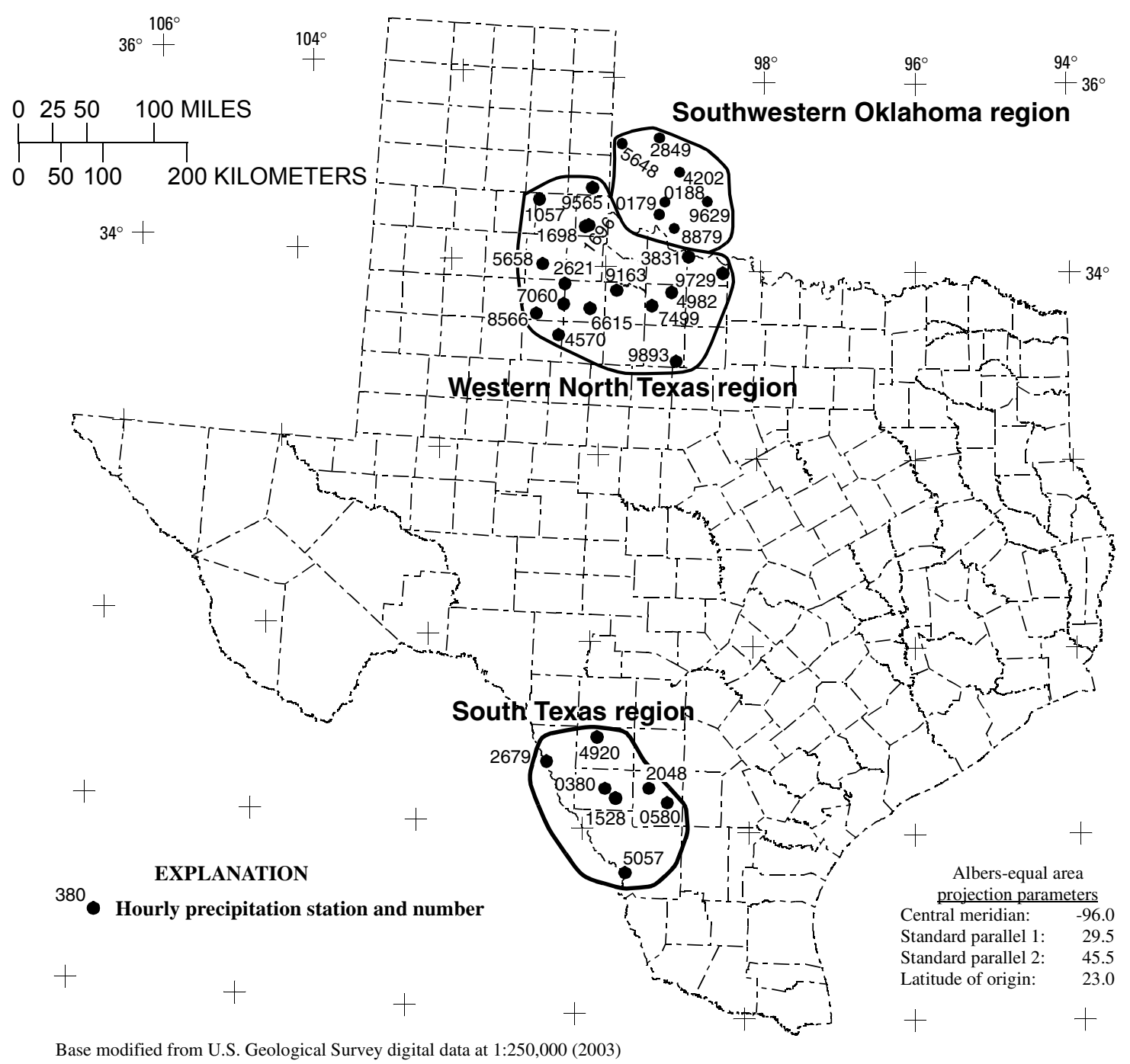

Figure 3. National Weather Service hourly precipitation stations in the South Texas, western North Texas, and southwestern Oklahoma regions.

analysis was beneficial for DDF estimation in the western North Texas region. Finally, to further explore the border dissimilarity of DDF values for the 12-hour duration in southwestern Oklahoma, the depths of a precipitation frequency curve were computed using the alternative frequency analysis and compared with the depths presented by Tortorelli and others (1999).

The L-moments (mean, L-coefficient of variation [L-CV], L-skew, L-kurtosis, and Tau5) of the annual maxima for each station in each region were computed. Weighted-mean values for each L-moment in each of the three regions using each station were computed. The weight factors used were the years of record available for each station. Stations with long records hence are given more weight than stations with short records. The weighted-mean values are referred to as "regional values." The regional values for the L-moments are shown in tables 4-6. The appropriate Weiss (1964) correction factor has been applied to the mean depth listed in the tables. For further explanation, readers are directed to Weiss (1964) and Asquith (1998).
Using the method of L-moments, which equates the theoretical L-moments of a distribution to the L-moments of the data (tables 4-6) by adjusting the values for the parameters, a distribution is fit to the data. The number of L-moments required to fit a distribution is equal to the number of distribution parameters. For example, the three-parameter GLO distribution requires the mean, $\mathrm{L}-\mathrm{CV}$, and L-skew of the data.

For the regional analysis in the South Texas region, four distributions were fit to the L-moments of each of the three durations analyzed. The distributions are the GEV, GLO, Kappa, and Wakeby. The GEV and GLO already have been described. The quantile function for the Kappa distribution (Hosking, 1994; Hosking and Wallis, 1997) is

$$
Q(F)=\xi+\frac{\alpha}{\kappa}\left\{1-\left(\frac{1-F^{h}}{h}\right)^{\kappa}\right\}
$$




\section{Atlas of Depth-Duration Frequency of Precipitation Annual Maxima for Texas}

where $\xi, \alpha, \kappa$, and $h$ are location, scale, shape 1 , and shape 2 parameters, respectively. The quantile function for the Wakeby distribution (Houghton, 1978; Hosking and Wallis, 1997) is

$$
Q(F)=\xi+\frac{\alpha}{\beta}\left\{1-(1-F)^{\beta}\right\}-\frac{\gamma}{\delta}\left\{1-(1-F)^{-\delta}\right\},
$$

where $\xi, \alpha, \beta, \gamma$, and $\delta$ are location, scale1, shape1, scale2, and shape 2 parameters, respectively. The parameters for each of the four distributions for each of the three durations are listed in table 4.

For the regional analysis in the western North Texas region, the same four distributions were fit to the L-moments of each of the two durations considered. However, the Kappa distribution does not have a solution space compatible with the regional L-moments for a parameter solution to be obtained. The parameters for the GEV, GLO, and Wakeby distributions for each of the two durations are listed in table 5 .

Finally, for the regional analysis in the southwestern Oklahoma region, only the GEV distribution was fit to the regional L-moments for only the 12-hour duration. Only the GEV distribution was used because this distribution was used by Tortorelli and others (1999) for the Oklahoma DDF atlas. The parameters of the GEV distribution fitted to the L-moments are listed in table 6 .

Table 2. National Weather Service hourly precipitation stations for western North Texas region.

[S, south; W, west; FAA, Federal Aviation Administration; ESE, eastsoutheast; WSO, Weather Service Office; NNE, north-northeast]

\begin{tabular}{clrrr}
\hline $\begin{array}{c}\text { Station } \\
\text { number } \\
\text { (fig. 3) }\end{array}$ & \multicolumn{1}{c}{ Station name } & $\begin{array}{c}\text { Latitude and } \\
\text { longitude }\end{array}$ & $\begin{array}{c}\text { Period of } \\
\text { record } \\
\text { analyzed }\end{array}$ \\
\hline 1057 & Brice 2 S & $34^{\circ} 31^{\prime}$ & $100^{\circ} 54^{\prime}$ & $1942-81$ \\
1696 & Childress 3 W & $34^{\circ} 26^{\prime}$ & $100^{\circ} 15^{\prime}$ & $1941-74$ \\
1698 & Childress FAA Airport & $34^{\circ} 26^{\prime}$ & $100^{\circ} 17^{\prime}$ & $1948-52$, \\
& & & & $1975-98$ \\
2621 & Dumont & $33^{\circ} 48^{\prime}$ & $100^{\circ} 31^{\prime}$ & $1972-98$ \\
3831 & Guyer & $34^{\circ} 08^{\prime}$ & $98^{\circ} 56^{\prime}$ & $1940-51$ \\
4570 & Jayton & $33^{\circ} 15^{\prime}$ & $100^{\circ} 34^{\prime}$ & $1941-98$ \\
4982 & Lake Kemp & $33^{\circ} 45^{\prime}$ & $99^{\circ} 09^{\prime}$ & $1975-98$ \\
5658 & Matador & $34^{\circ} 01^{\prime}$ & $100^{\circ} 50^{\prime}$ & $1942-65$ \\
6615 & Old '8” Camp (6666) & $33^{\circ} 34^{\prime}$ & $100^{\circ} 11^{\prime}$ & $1974-98$ \\
7060 & Pitchfork Ranch & $33^{\circ} 36^{\prime}$ & $100^{\circ} 32^{\prime}$ & $1972-98$ \\
7499 & Red Springs 2 ESE & $33^{\circ} 36^{\prime}$ & $99^{\circ} 23^{\prime}$ & $1944-98$ \\
8566 & Spur & $33^{\circ} 29^{\prime}$ & $100^{\circ} 51^{\prime}$ & $1948-63$ \\
9163 & Truscott 5 W & $33^{\circ} 45^{\prime}$ & $99^{\circ} 55^{\prime}$ & $1941-98$ \\
9565 & Wellington & $34^{\circ} 50^{\prime}$ & $100^{\circ} 13^{\prime}$ & $1950-71$, \\
9729 & Wichita Falls WSO Airport & $33^{\circ} 58^{\prime}$ & $98^{\circ} 29^{\prime}$ & $1941-98$ \\
9893 & Woodson 5 NNE & $33^{\circ} 06^{\prime}$ & $99^{\circ} 02^{\prime}$ & $1942-98$ \\
\hline & & & & $1985-98$
\end{tabular}

\section{Results for South Texas}

The results of the alternative regional frequency analysis for the South Texas region are discussed in this section. Representative DDF values for the region from Asquith (1998) are listed in table 7. Also listed in the table are the DDF values for the Kappa distribution determined for this report.

The four-parameter Kappa distribution is favored for the alternative frequency analysis because it more accurately fits the 6- and 12-hour durations than the GLO distribution. Using the Kappa distribution with a fourth parameter allows a greater range in shape of L-skew and L-kurtosis combinations than would be possible using a three-parameter distribution. However, the greater range in shape adds uncertainty with the estimation of the fourth parameter.

The GLO distribution has a larger L-kurtosis than the data, whereas the GEV distribution has a smaller L-kurtosis than the data. The Kappa distribution lies between the GLO and the GEV distributions because the Kappa distribution is specifically fit to the L-kurtosis of the data. This discussion of L-kurtosis is clarified by an L-moment ratio diagram (fig. 1) where, for the 12-hour distribution, the regional mean values plot between the curves for the GLO and the GEV distributions. Because of the L-kurtosis matching, the Kappa distribution is expected to be more accurate in the South Texas region for the 12-hour duration (and possibly for the 6-hour duration) than the GLO distribution considered by Asquith (1998). The 24-hour duration values for mean DDF were not revised because of the heavier weight (3 to 1 times) given to 1-day values when the weighted DDF values for the 1-day duration were computed (column 7 of table 7). The authors conclude that the GLO distribution overestimates the depth of precipitation in South Texas for recurrence intervals of 50 years and more for the 6-, 12-, and 24-hour durations.

Table 3. National Weather Service hourly precipitation stations for southwestern Oklahoma region.

[NE, northeast; S, south.

Note that several more years of data for stations 2849 and 5648 were readily available at time of analysis]

\begin{tabular}{cllll}
\hline $\begin{array}{c}\text { Station } \\
\text { number } \\
\text { (fig. 3) }\end{array}$ & Station name & $\begin{array}{c}\text { Latitude and } \\
\text { longitude }\end{array}$ & $\begin{array}{c}\text { Period of } \\
\text { record } \\
\text { analyzed }\end{array}$ \\
\hline 0179 & $\begin{array}{c}\text { Altus Irrigation } \\
\text { Research Station }\end{array}$ & $34^{\circ} 35^{\prime}$ & $99^{\circ} 20^{\prime}$ & $1948-98$ \\
& Altus 7 NE & $34^{\circ} 43^{\prime}$ & $99^{\circ} 16^{\prime}$ & $1948-69$ \\
0188 & Elk City & $35^{\circ} 23^{\prime}$ & $99^{\circ} 24^{\prime}$ & $1948-2001$ \\
2849 & $35^{\circ} 01^{\prime}$ & $99^{\circ} 05^{\prime}$ & $1953-98$ \\
4202 & Hobart & $35^{\circ} 20^{\prime}$ & $99^{\circ} 52^{\prime}$ & $1948-2002$ \\
5648 & Mayfield & $34^{\circ} 26^{\prime}$ & $99^{\circ} 08^{\prime}$ & $1948-53$ \\
8879 & Tipton 4 S & $34^{\circ} 44^{\prime}$ & $98^{\circ} 43^{\prime}$ & $1948-98$ \\
9629 & Wichita Mountain & & & \\
\hline & Wildlife Refuge & & & \\
\hline
\end{tabular}


Table 4. Regional values for L-moments of 6-, 12-, and 24-hour precipitation annual maxima and corresponding parameters for selected distributions in South Texas region.

[in., inches; L-CV, L-coefficient of variation; --, dimensionless; L-kurt, L-kurtosis; GEV, generalized extreme value; GLO, generalized logistic; na, not applicable.

Parameter definitions: GEV and GLO-1 $(\xi), 2(\alpha)$, and $3(\kappa)$ are location, scale, and shape parameters, respectively; Kappa-1 $(\xi), 2(\alpha), 3(\kappa)$, and $4(h)$ are location, scale, shape1, and shape2 parameters, respectively; Wakeby-1 $(\xi), 2(\alpha), 3(\beta), 4(\gamma)$, and $5(\delta)$ are location, scale1, shape1, scale2, and shape 2 parameters, respectively]

\begin{tabular}{|c|c|c|c|c|c|c|c|c|c|c|c|}
\hline \multirow{2}{*}{$\begin{array}{l}\text { Dura- } \\
\text { tion }\end{array}$} & \multirow{2}{*}{$\begin{array}{l}\text { Distri- } \\
\text { bution } \\
\text { type }\end{array}$} & \multicolumn{5}{|c|}{$\begin{array}{l}\text { Regional L-moments for } \\
\text { corresponding duration }\end{array}$} & \multicolumn{5}{|c|}{$\begin{array}{l}\text { Parameters for corresponding } \\
\text { distribution and duration }\end{array}$} \\
\hline & & $\begin{array}{l}\text { Mean }^{1} \\
\text { (in.) }\end{array}$ & $\begin{array}{l}\mathrm{L}-\mathrm{CV} \\
(--)\end{array}$ & $\begin{array}{l}\text { L-skew } \\
(--)\end{array}$ & $\begin{array}{c}\text { L-kurt } \\
(--)\end{array}$ & $\begin{array}{l}\text { Tau5 } \\
(--)\end{array}$ & $\begin{array}{c}1 \\
\text { (in.) }\end{array}$ & $\begin{array}{c}2 \\
\text { (in.) }\end{array}$ & $\begin{array}{c}3 \\
(--)\end{array}$ & $\begin{array}{c}4 \\
(--)\end{array}$ & $\begin{array}{c}5 \\
(--)\end{array}$ \\
\hline \multirow{3}{*}{6 hour } & GEV & \multirow{3}{*}{2.9141} & \multirow{3}{*}{0.2657} & \multirow{3}{*}{0.2089} & \multirow{3}{*}{0.1761} & \multirow{3}{*}{0.0660} & 2.2400 & 1.0538 & -0.0597 & na & na \\
\hline & GLO & & & & & & 2.6537 & .7199 & -.2089 & na & na \\
\hline & Wakeby & & & & & & .6032 & 8.6132 & 8.3996 & 1.4398 & -.03241 \\
\hline \multirow{3}{*}{12 hour } & GEV & \multirow{3}{*}{3.1180} & \multirow{3}{*}{.2670} & \multirow{3}{*}{.2227} & \multirow{3}{*}{.1907} & \multirow{3}{*}{.0582} & 2.3827 & 1.1085 & -.0805 & na & na \\
\hline & GLO & & & & & & 2.8203 & .7661 & -.2227 & na & na \\
\hline & Kappa & & & & & & 2.5446 & .9605 & -.1401 & -.2880 & na \\
\hline \multirow{2}{*}{24 hour } & Kappa & \multirow{2}{*}{3.3464} & \multirow{2}{*}{.2645} & \multirow{2}{*}{.2136} & \multirow{2}{*}{.1752} & \multirow{2}{*}{.0518} & 2.6314 & 1.1383 & -.0879 & -.0898 & na \\
\hline & Wakeby & & & & & & .4812 & 17.6907 & 13.8588 & 1.7873 & -.06728 \\
\hline
\end{tabular}

\footnotetext{
${ }^{1}$ Weiss (1964) correction factors have been applied to mean statistics; cumulative record length is 243 years.
}

Table 5. Regional values for L-moments of 6- and 12-hour precipitation annual maxima and corresponding parameters for selected distributions in western North Texas region.

[in., inches; L-CV, L-coefficient of variation; --, dimensionless; L-kurt, L-kurtosis; GEV, generalized extreme value; GLO, generalized logistic; na, not applicable.

Parameter definitions: GEV and GLO-1 $(\xi), 2(\alpha)$, and $3(\kappa)$ are location, scale, and shape parameters, respectively; Kappa-1 $(\xi), 2(\alpha), 3(\kappa)$, and $4(h)$ are location, scale, shape1, and shape2 parameters, respectively; Wakeby-1 $(\xi), 2(\alpha), 3(\beta), 4(\gamma)$, and $5(\delta)$ are location, scale1, shape1, scale2, and shape2 parameters, respectively]

\begin{tabular}{|c|c|c|c|c|c|c|c|c|c|c|c|}
\hline \multirow{2}{*}{$\begin{array}{l}\text { Dura- } \\
\text { tion }\end{array}$} & \multirow{2}{*}{$\begin{array}{l}\text { Distri- } \\
\text { bution } \\
\text { type }\end{array}$} & \multicolumn{5}{|c|}{$\begin{array}{l}\text { Regional L-moments for } \\
\text { corresponding duration }\end{array}$} & \multicolumn{5}{|c|}{$\begin{array}{l}\text { Parameters for corresponding } \\
\text { distribution and duration }\end{array}$} \\
\hline & & $\begin{array}{l}\text { Mean }^{1} \\
\text { (in.) }\end{array}$ & $\begin{array}{l}\mathrm{L}-\mathrm{CV} \\
(--)\end{array}$ & $\begin{array}{l}\text { L-skew } \\
(--)\end{array}$ & $\begin{array}{c}\text { L-kurt } \\
(--)\end{array}$ & $\begin{array}{l}\text { Tau5 } \\
(--)\end{array}$ & $\begin{array}{c}1 \\
\text { (in.) }\end{array}$ & $\begin{array}{c}2 \\
\text { (in.) }\end{array}$ & $\begin{array}{c}3 \\
(--)\end{array}$ & $\begin{array}{c}4 \\
\text { (in.) }\end{array}$ & $\begin{array}{c}5 \\
(--)\end{array}$ \\
\hline \multirow{3}{*}{6 hour } & GEV & \multirow{3}{*}{2.3754} & \multirow{3}{*}{0.2441} & \multirow{3}{*}{0.2536} & \multirow{3}{*}{0.2459} & \multirow{3}{*}{0.1052} & 1.8479 & 0.7340 & -0.1261 & na & na \\
\hline & GLO & & & & & & 2.1411 & .5204 & -.2536 & na & na \\
\hline & Wakeby & & & & & & .5532 & 9.027 & 8.987 & 0.7765 & 0.1544 \\
\hline \multirow{3}{*}{12 hour } & GEV & \multirow{3}{*}{2.6801} & \multirow{3}{*}{.2437} & \multirow{3}{*}{.2570} & \multirow{3}{*}{.2395} & \multirow{3}{*}{.08756} & 2.0842 & .8219 & -.1311 & na & na \\
\hline & GLO & & & & & & 2.4129 & .5844 & -.2570 & na & na \\
\hline & Kappa & & & & & & \multicolumn{5}{|c|}{ no solution obtainable } \\
\hline
\end{tabular}

\footnotetext{
${ }^{1}$ Weiss (1964) correction factors have been applied to mean statistics; cumulative record length is 570 years.
} 


\section{Atlas of Depth-Duration Frequency of Precipitation Annual Maxima for Texas}

Table 6. Regional values for L-moments of 12-hour precipitation annual maxima and corresponding parameters for the GEV distribution in southwestern Oklahoma region.

[GEV, generalized extreme value; in., inches; L-CV, L-coefficient of variation; --, dimensionless; L-kurt, L-kurtosis; na, not applicable]

\begin{tabular}{lclc}
\hline $\begin{array}{c}\text { L-moment } \\
\text { type } \\
\text { (units) }\end{array}$ & $\begin{array}{c}\text { Weighted } \\
\text { mean } \\
\text { L-moment } \\
\text { value }\end{array}$ & $\begin{array}{c}\text { GEV } \\
\text { parameters } \\
\text { (units) }\end{array}$ & $\begin{array}{c}\text { Parameter } \\
\text { value }\end{array}$ \\
\hline Mean $^{1}$ (in.) & 2.9575 & $\xi$ (in.) & 2.4160 \\
L-CV (--) & .2134 & $\alpha$ (in.) & .8769 \\
L-skew (--) & .1955 & $\kappa(--)$ & -.03941 \\
L-kurt (--) & .1881 & na & na \\
Tau5 (--) & .0222 & na & na \\
\hline
\end{tabular}

\footnotetext{
${ }^{1}$ Weiss (1964) correction factor has been applied to mean value listed; cumulative record length is 261 years.
}

In conclusion, for the South Texas region the adoption of the Kappa distribution eliminated inconsistencies and resulted in a modest reduction of the depths of precipitation relative to those derived using the GLO distribution (Asquith, 1998). The contour lines in and adjacent to the South Texas region of the DDF maps for the 50-, 100-, 250-, and 500-year recurrence intervals required localized realignment to reflect the revised magnitude of precipitation estimated by the Kappa distribution.

\section{Results for Western North Texas and Southwestern Oklahoma}

The results of the alternative regional frequency analysis for the western North Texas and southwestern Oklahoma regions are discussed in this section. Representative DDF values for the western North Texas region from Asquith (1998) are listed in table 8. Also listed in the table are the DDF values for GLO and Wakeby distributions determined for this report.

For the western North Texas region, the DDF values (table 8 ) from the alternative regional frequency analysis are not sensitive to choice of distribution. The GLO and Wakeby distributions are both shown in the table. A Kappa distribution consistent with the L-moments of the data is not possible because L-moments of the data are outside those obtainable by the Kappa; the Wakeby distribution is favored by the authors instead. Although the Wakeby distribution is a more flexible distribution (more parameters) than the GLO distribution and even the Kappa distribution, the values of precipitation depths for the Wakeby distribution matched the GLO distribution and therefore are consistent with results in Asquith (1998).

No realignment of contours was necessary in western North Texas because DDF values from Asquith (1998) matched DDF values from the alternative analysis in this part of Texas. The three sets of DDF values for each of the two durations in table 8 are larger than the DDF values for the two durations for the relatively nearby southwestern Oklahoma region provided by Tortorelli and others (1999).

Table 7. Depth-duration frequency of precipitation annual maxima for South Texas region derived from Asquith (1998) and alternative regional frequency analysis.

[DDF, depth-duration frequency; in., inches.

Location used for computation (latitude $28^{\circ} 21^{\prime}$, longitude $9^{\circ} 37^{\prime}$ ) is coincident with station number 1528 and is approximate center of South Texas region. Weighted-mean value for 1-day duration is computed by summing 24-hour value and three times the 1-day value, then dividing the result by four]

\begin{tabular}{|c|c|c|c|c|c|c|c|c|c|}
\hline \multirow{2}{*}{$\begin{array}{c}\text { Annual } \\
\text { non- } \\
\text { exceedance } \\
\text { probability }\end{array}$} & \multirow{2}{*}{$\begin{array}{l}\text { Annual } \\
\text { recurrence } \\
\text { interval } \\
\text { (years) }\end{array}$} & \multicolumn{5}{|c|}{$\begin{array}{l}\text { DDF of precipitation annual maxima } \\
\text { derived from Asquith (1998) } \\
\text { (in.) }\end{array}$} & \multicolumn{3}{|c|}{$\begin{array}{l}\text { DDF derived from alternative regional frequency } \\
\text { analysis and Kappa distribution } \\
\text { (in.) }\end{array}$} \\
\hline & & $6 \mathrm{hr}$ & $12 \mathrm{hr}$ & $24 \mathrm{hr}$ & 1 day & $\begin{array}{l}\text { Weighted- } \\
\text { mean } \\
1 \text { day }\end{array}$ & $6 \mathrm{hr}$ & $12 \mathrm{hr}$ & $24 \mathrm{hr}$ \\
\hline 0.500 & 2 & 2.51 & 2.74 & 3.01 & 3.15 & 3.12 & 2.63 & 2.80 & 3.02 \\
\hline .800 & 5 & 3.69 & 4.10 & 4.34 & 4.48 & 4.45 & 3.87 & 4.11 & 4.44 \\
\hline .900 & 10 & 4.59 & 5.15 & 5.36 & 5.45 & 5.42 & 4.75 & 5.07 & 5.46 \\
\hline .960 & 25 & 5.96 & 6.74 & 6.92 & 6.78 & 6.82 & 5.95 & 6.41 & 6.83 \\
\hline .980 & 50 & 7.20 & 8.18 & 8.33 & 7.85 & 7.97 & 6.90 & 7.53 & 7.93 \\
\hline .990 & 100 & 8.66 & 9.88 & 9.99 & 8.98 & 9.23 & 7.91 & 8.75 & 9.08 \\
\hline .996 & 250 & 11.02 & 12.61 & 12.67 & 10.54 & 11.07 & 9.34 & 10.54 & 10.72 \\
\hline .998 & 500 & 13.20 & 15.15 & 15.14 & 11.91 & 12.72 & 10.51 & 12.06 & 12.04 \\
\hline
\end{tabular}


Table 8. Depth-duration frequency of precipitation annual maxima for western North Texas region derived from Asquith (1998) and alternative regional frequency analysis.

[DDF, depth-duration frequency; in., inches; GLO, generalized logistic.

Location used for computation (latitude $33^{\circ} 45^{\prime}$, longitude $99^{\circ} 55^{\prime}$ ) is coincident with station number 9163 and is approximate center of western North Texas region]

\begin{tabular}{|c|c|c|c|c|c|c|c|}
\hline \multirow[t]{2}{*}{$\begin{array}{l}\text { Annual } \\
\text { non- } \\
\text { exceedance } \\
\text { probability }\end{array}$} & \multirow[t]{2}{*}{$\begin{array}{l}\text { Annual } \\
\text { recurrence } \\
\text { interval } \\
\text { (years) }\end{array}$} & \multicolumn{2}{|c|}{$\begin{array}{l}\text { DDF of precipitation annual } \\
\text { maxima derived from } \\
\text { Asquith (1998) } \\
\text { (in.) }\end{array}$} & \multicolumn{2}{|c|}{$\begin{array}{l}\text { DDF derived from alternative } \\
\text { regional frequency analysis } \\
\text { and GLO distribution } \\
\text { (in.) }\end{array}$} & \multicolumn{2}{|c|}{$\begin{array}{l}\text { DDF derived from alternative } \\
\text { regional frequency analysis } \\
\text { and Wakeby distribution } \\
\text { (in.) }\end{array}$} \\
\hline & & $6 \mathrm{hr}$ & $12 \mathrm{hr}$ & $6 \mathrm{hr}$ & $12 \mathrm{hr}$ & $6 \mathrm{hr}$ & $12 \mathrm{hr}$ \\
\hline 0.500 & 2 & 2.00 & 2.27 & 2.14 & 2.41 & 2.12 & 2.37 \\
\hline .800 & 5 & 2.82 & 3.20 & 3.00 & 3.39 & 2.98 & 3.39 \\
\hline .960 & 25 & 4.42 & 5.00 & 4.68 & 5.29 & 4.80 & 5.44 \\
\hline .980 & 50 & 5.29 & 5.98 & 5.59 & 6.32 & 5.73 & 6.44 \\
\hline .990 & 100 & 6.31 & 7.13 & 6.67 & 7.55 & 6.77 & 7.52 \\
\hline .996 & 250 & 7.96 & 8.98 & 8.40 & 9.53 & 8.33 & 9.08 \\
\hline .998 & 500 & 9.49 & 10.68 & 10.00 & 11.36 & 9.66 & 10.37 \\
\hline
\end{tabular}

To evaluate the DDF values in western North Texas, the 12-hour duration was selected for analysis in southwestern Oklahoma. The 12-hour DDF values of the alternative regional analysis using the GEV distribution (column 2 of table 9) are slightly smaller than the DDF values obtained for the western North Texas region (columns 4, 6, and 8 of table 8). (The GEV distribution was selected as Tortorelli and others [1999] used the GEV for all storm durations- thus meaningful comparison is possible.) The southwestern Oklahoma DDF values from the alternative regional analysis are larger than those reported in Tortorelli and others (1999), particularly for large recurrence intervals-compare columns 2 and 3 of table 9 .

Table 9. Depth-duration frequency of precipitation for the 12hour duration in southwestern Oklahoma region.

[GEV, generalized extreme value; in., inches; na, not available. Oklahoma atlas refers to Tortorelli and others (1999); the approximate center of Harmon County, Okla., was used as the location to extract precipitation depths from the Oklahoma atlas]

\begin{tabular}{ccc}
\hline $\begin{array}{c}\text { Annual } \\
\text { recurrence } \\
\text { interval } \\
\text { (years) }\end{array}$ & $\begin{array}{c}\text { GEV-estimated depth for } \\
\text { recurrence interval from } \\
\text { parameters in table } 6 \\
\text { (in.) }\end{array}$ & $\begin{array}{c}\text { Oklahoma atlas } \\
\text { depth for recurrence } \\
\text { interval } \\
\text { (in.) }\end{array}$ \\
\hline 2 & 2.74 & 2.3 \\
5 & 3.77 & 3.2 \\
10 & 4.48 & 3.8 \\
25 & 5.40 & 4.6 \\
50 & 6.11 & 5.2 \\
100 & 6.84 & 5.8 \\
250 & 7.82 & na \\
500 & 8.59 & 7.2 \\
\hline
\end{tabular}

For the 12-hour duration, in general the DDF values from the western North Texas Wakeby distribution are largest, the southwestern Oklahoma GEV distribution are in-between, and the DDF values from the Oklahoma atlas are smallest. This ranking is reasonable for two reasons: First, the largest values in Texas are expected because of the L-moment values and use of the Wakeby distribution. The GEV-derived values are smaller in part because of the smaller L-skew of the data and L-kurtosis of the distribution. Second, the southwestern Oklahoma DDF values from the alternative analysis indicate slightly larger precipitation depths than those of Tortorelli and others (1999). However, the 12-hour precipitation depths from the alternative analysis adequately match those depicted in the Oklahoma atlas, and the principal cause for differences in DDF along the border of Texas and southwestern Oklahoma are attributed to choice of distribution (GLO or GEV). Secondary causes for the border differences are inherently different mapping techniques of Asquith (1998) and Tortorelli and others (1999).

\section{Contour Maps of Depth-Duration Frequency of Precipitation Annual Maxima in Texas}

Finally, after adjustment for inconsistencies and consideration of the results of the alternative regional frequency analysis, the DDF maps presented in figures 4-99 (at end of report) are consistent and provide reliable estimates of DDF of precipitation annual maxima in Texas. For a given location in Texas, however, ambiguity could exist in DDF values extracted from the 96 maps because of the limited resolution or general shape of the contour lines on the maps. When ambiguity exists, the authors suggest creating a log-log graph showing the relation between precipitation depth or intensity (inches per hour) and duration. 


\section{Summary}

Precipitation depths for various durations and frequencies, referred to as depth-duration frequency (DDF) in this report, have many uses in surface-water hydrology and engineering. A DDF map depicts the spatial variation of DDF of precipitation annual maxima. A previously published report by the U.S. Geological Survey (USGS) provides procedures to develop DDF values for any location in Texas for 12 distinct storm durations between 15 minutes and 7 days and recurrence intervals between 2 and 500 years. The procedures, though well documented, are cumbersome to apply. The maps presented in this report, prepared in cooperation with the Texas Department of Transportation, were developed using those procedures and an alternative regional frequency analysis for selected regions, thus precluding the need for such application by users. The maps update DDF of precipitation maps available in earlier studies of the National Weather Service.

Ninety-six maps depicting the spatial variation of the DDF of precipitation annual maxima for Texas are presented. The recurrence intervals represented are 2, 5, 10, 25, 50, 100, 250, and 500 years. The storm durations represented are 15 and 30 minutes; 1, 2, 3, 6, and 12 hours; and 1, 2, 3, 5, and 7 days.

The DDF maps are consistent, which means that both lines of equal duration and equal frequency for a given location are each monotonically increasing with frequency and duration, respectively. To ensure consistency, an alternative (to the previously published USGS report) regional frequency analysis was needed for a region in South Texas. The analysis for South Texas eliminated inconsistencies and resulted in a modest reduction in the depths of precipitation relative to those derived in the previously published report.

An alternative regional frequency analysis also was done for a region in western North Texas and (for the 12-hour duration only) a region in southwestern Oklahoma. No realignment of DDF contours was necessary in western North Texas. Differences in DDF values for the 12-hour duration and for large recurrence intervals between the results of the previously published USGS report for Texas and a USGS report for Oklahoma were found. However, the 12-hour DDF values from the alternative analysis adequately match those of the Oklahoma report.

The DDF maps are consistent and provide reliable estimates of DDF of precipitation annual maxima in Texas.

\section{Selected References}

Asquith, W.H., 1998, Depth-duration frequency of precipitation for Texas: U.S. Geological Survey Water-Resources Investigations Report 98-4044, 107 p.

Asquith, W.H., 1999, Areal-reduction factors for the precipitation of the 1-day design storm in Texas: U.S. Geological Survey Water-Resources Investigations Report 99-4267, $81 \mathrm{p}$.
Asquith, W.H., and Famiglietti, J.S., 2000, Precipitation arealreduction factor estimation using an annual-maxima centered approach: Journal of Hydrology, no. 230, p. 55-69.

Asquith, W.H., and Roussel, M.C., 2004, Atlas of interoccurrence intervals for selected thresholds of daily precipitation in Texas: U.S. Geological Survey Water-Resources Investigations Report 03-4281, 204 p.

Frederick, R.H., Meyers, V.A., and Auciello, E.P., 1977, Fiveto 60-minute precipitation frequency for the eastern and central United States: Silver Springs, Md., U.S. Department of Commerce, National Oceanic and Atmospheric Administration, National Weather Service, NOAA Technical Memorandum NWS HYDRO-35, 36 p.

Hershfield, D.M., 1961, Rainfall frequency atlas of the United States for durations from 30 minutes to 24 hours and return periods from 1 to 100 years: Washington, D.C., U.S. Weather Bureau Technical Paper 40, 61 p.

Hosking, J.R.M., 1990, L-moments-Analysis and estimation of distributions using linear combinations of order statistics: Journal Royal Statistical Society B, v. 52, no. 1, p. 105-124.

Hosking, J.R.M., 1994, The four-parameter Kappa distribution: IBM Journal of Research and Development, v. 38, no. 3, p. 251-258.

Hosking, J.R.M., and Wallis, J.R., 1997, Regional frequency analysis-An approach based on L-moments: Cambridge University Press, 224 p.

Houghton, J.C., 1978, Birth of a parent-The Wakeby distribution for modeling flood flows: Water Resources Research, v. 14, p. 1,105-1,109.

Lanning-Rush, Jennifer, Asquith, W.H., and Slade, R.M., Jr., 1998, Extreme precipitation depths for Texas, excluding the Trans-Pecos region: U.S. Geological Survey WaterResources Investigations Report 98-4099, 38 p.

Miller, J.F., 1964, Two- to ten-day precipitation for return periods of 2 to 100 years in the contiguous United States: Washington, D.C., U.S. Weather Bureau Technical Paper 49, 29 p.

Rea, Alan, and Tortorelli, R.L., 1999, Digital data sets for depth-duration frequency of precipitation for Oklahoma: U.S. Geological Survey Open-File Report 99-463, CD-ROM.

Tortorelli, R.L., Rea, Alan, and Asquith, W.H., 1999, Depthduration frequency of precipitation for Oklahoma: U.S. Geological Survey Water-Resources Investigations Report 99-4232, 113 p.

Vogel, R.M., and Fennessey, N.M., 1993, L-moment diagrams should replace product moment diagrams: Water Resources Research, v. 29, no. 6, p. 1,745-1,752.

Weiss, L.L., 1964, Ratio of true to fixed-interval maximum rainfall: American Society of Civil Engineers, Journal of the Hydraulics Division, v. 90, HY-1, p. 77-82. 


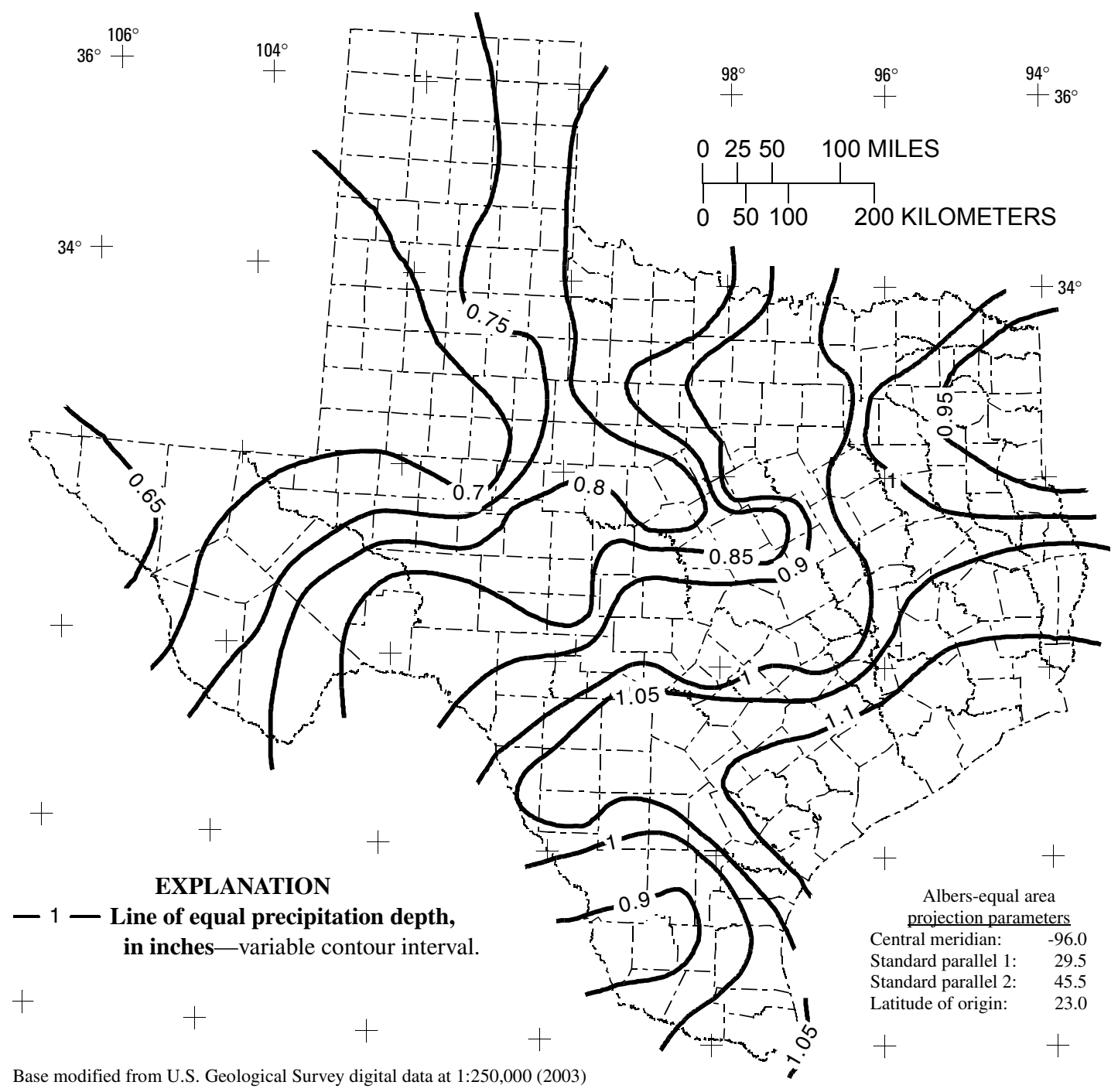

Figure 4. Depth of precipitation for 2-year storm for 15-minute duration in Texas. 


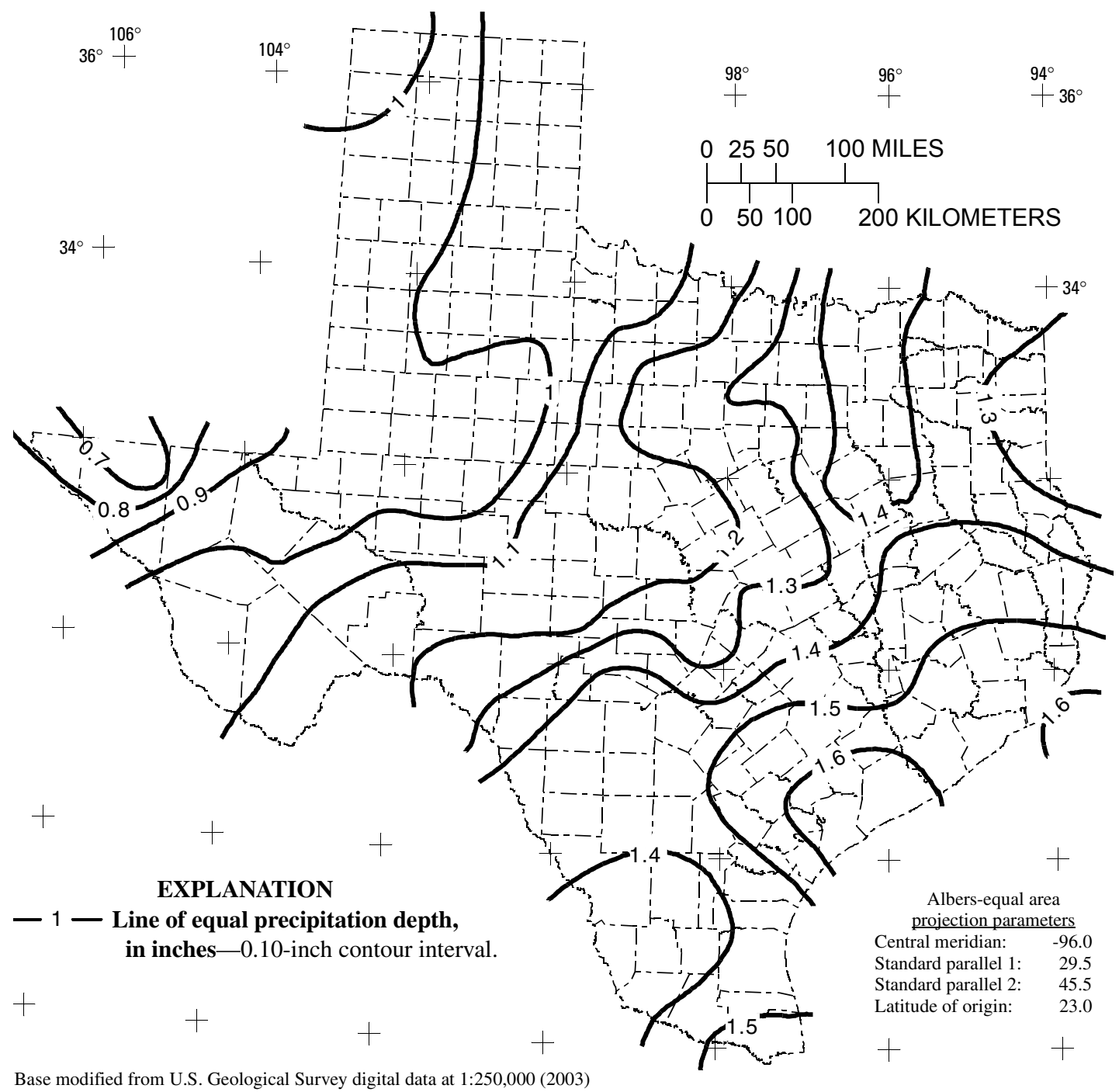

Figure 5. Depth of precipitation for 2-year storm for 30-minute duration in Texas. 


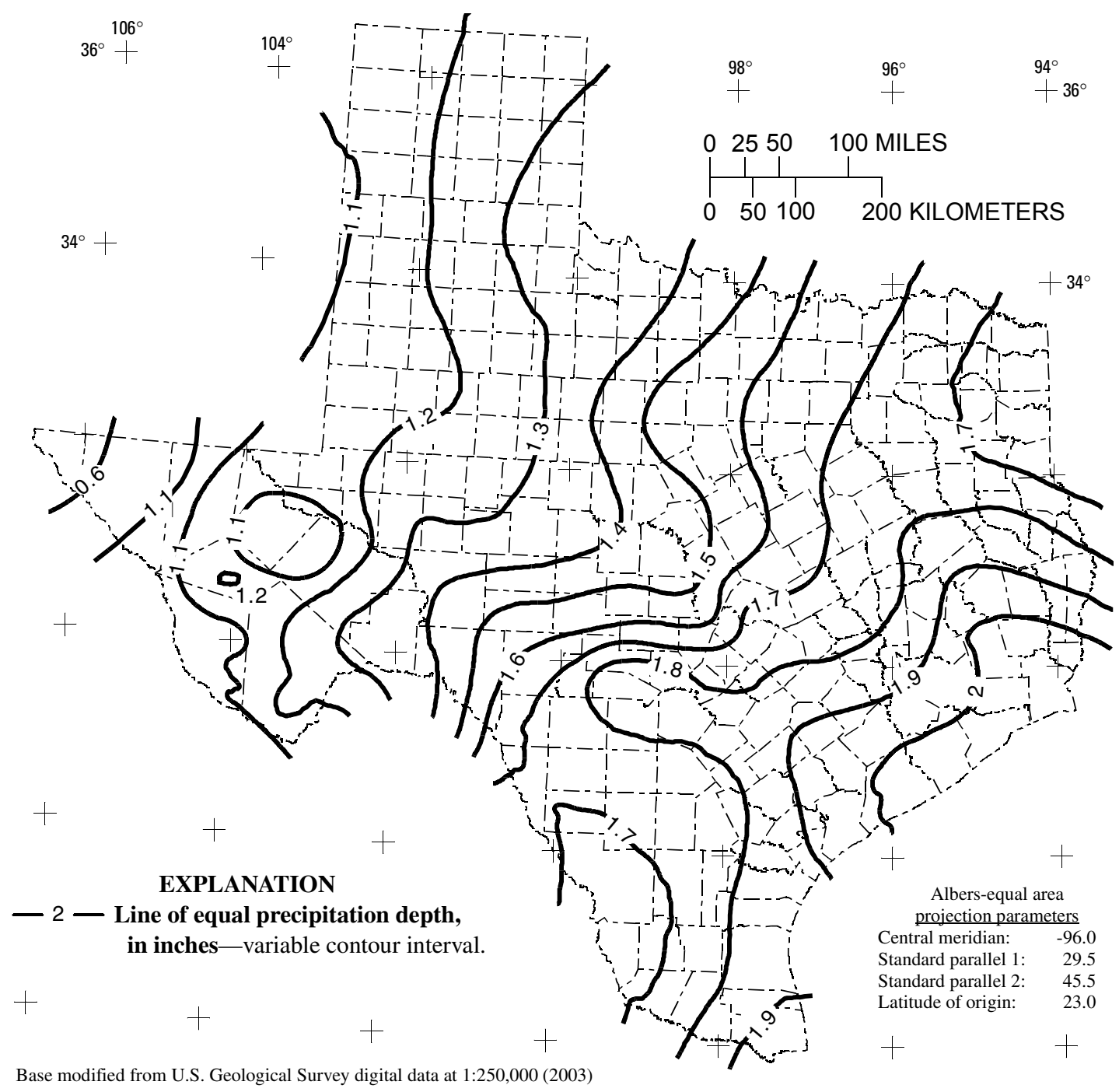

Figure 6. Depth of precipitation for 2-year storm for 1-hour duration in Texas. 


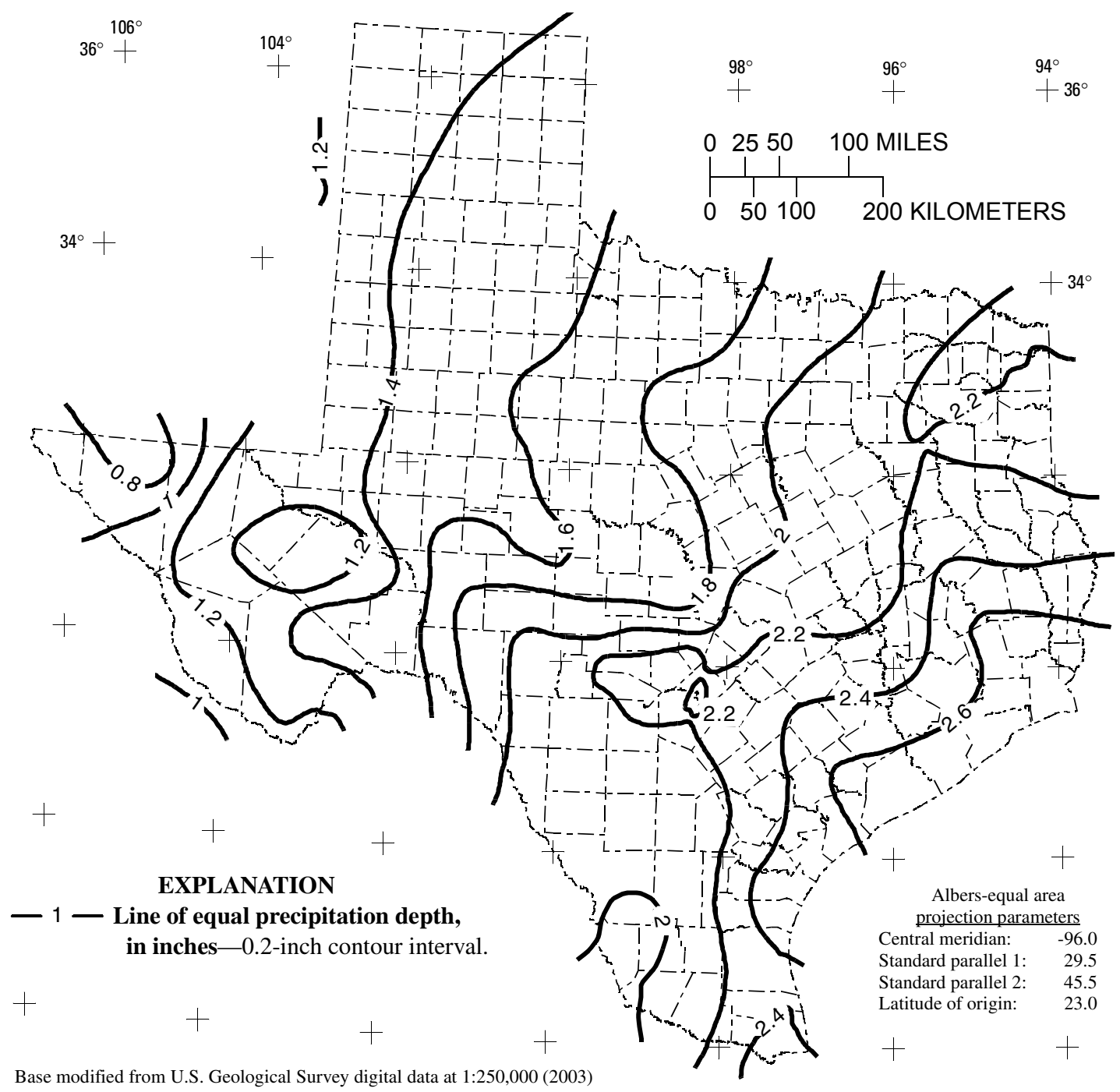

Figure 7. Depth of precipitation for 2-year storm for 2-hour duration in Texas. 


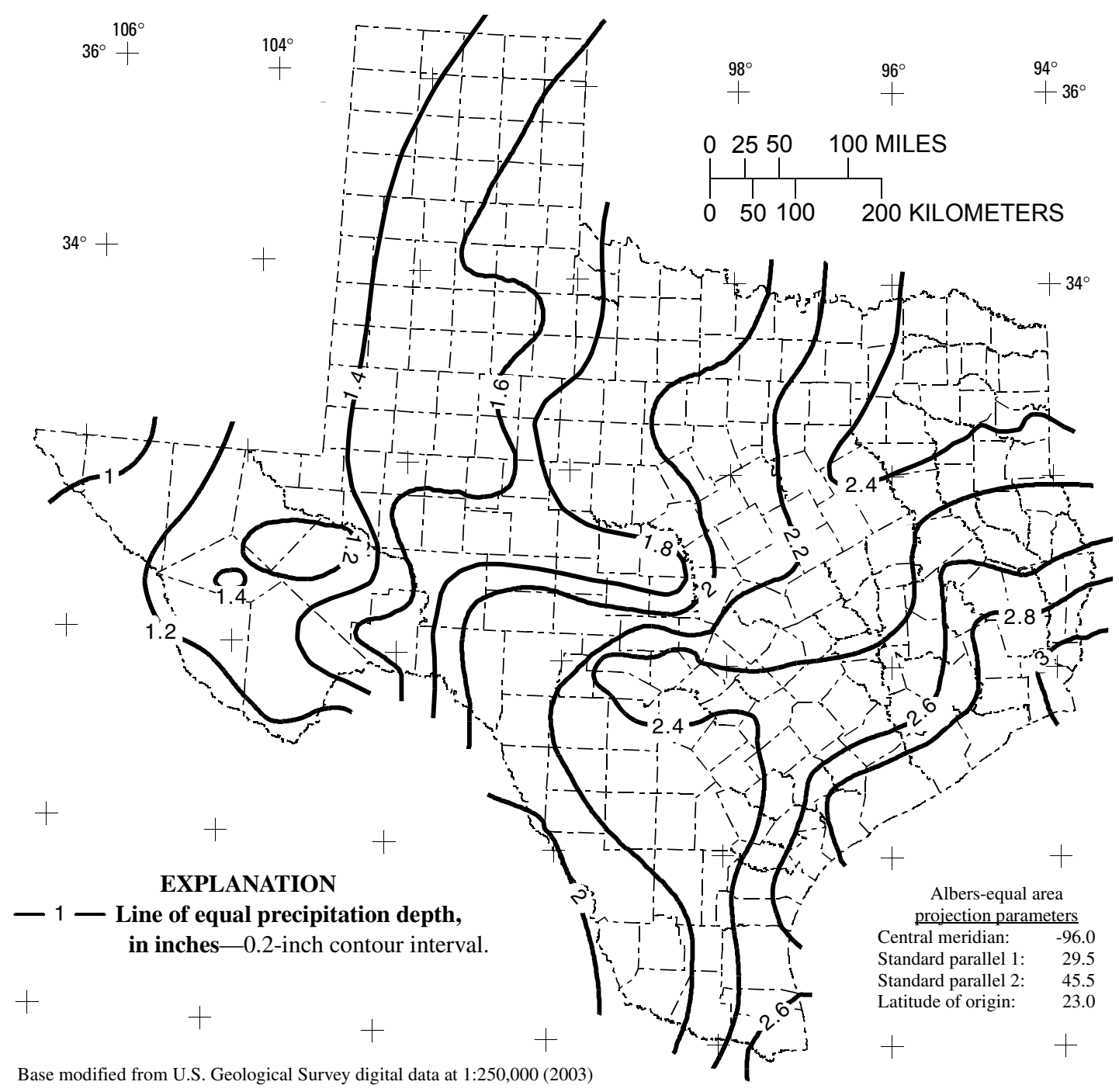

Figure 8. Depth of precipitation for 2-year storm for 3-hour duration in Texas. 


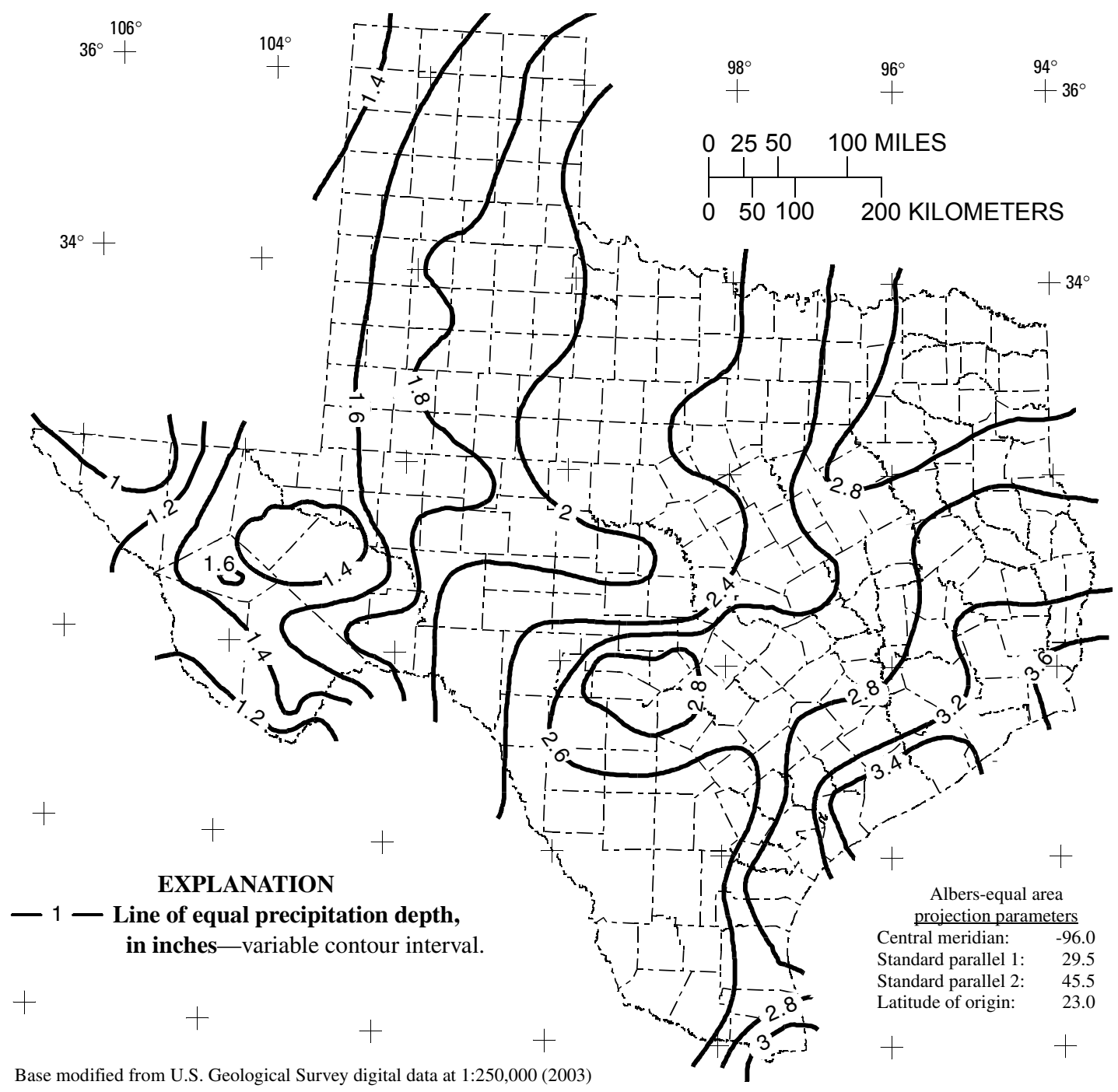

Figure 9. Depth of precipitation for 2-year storm for 6-hour duration in Texas. 


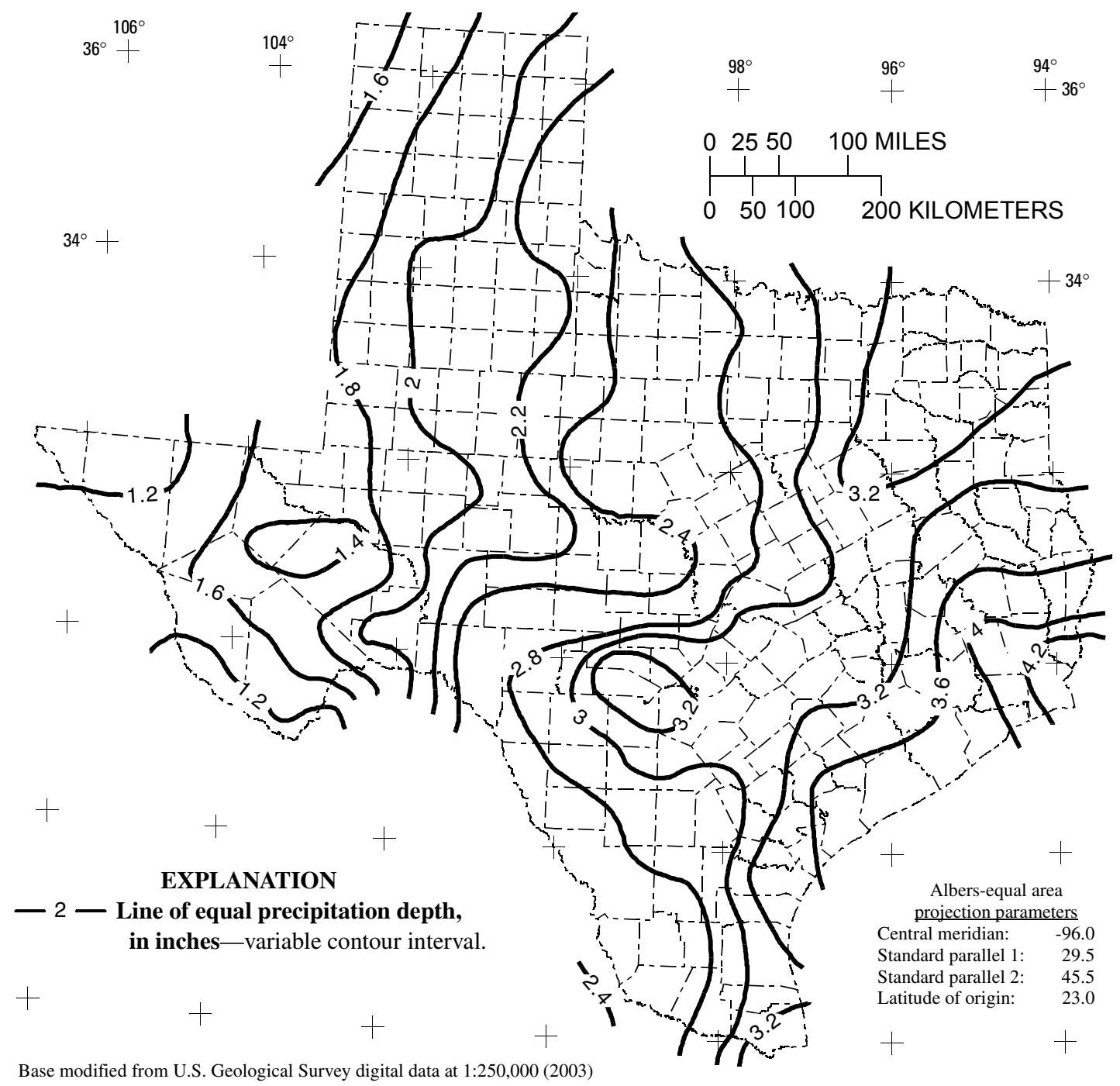

Figure 10. Depth of precipitation for 2-year storm for 12-hour duration in Texas. 


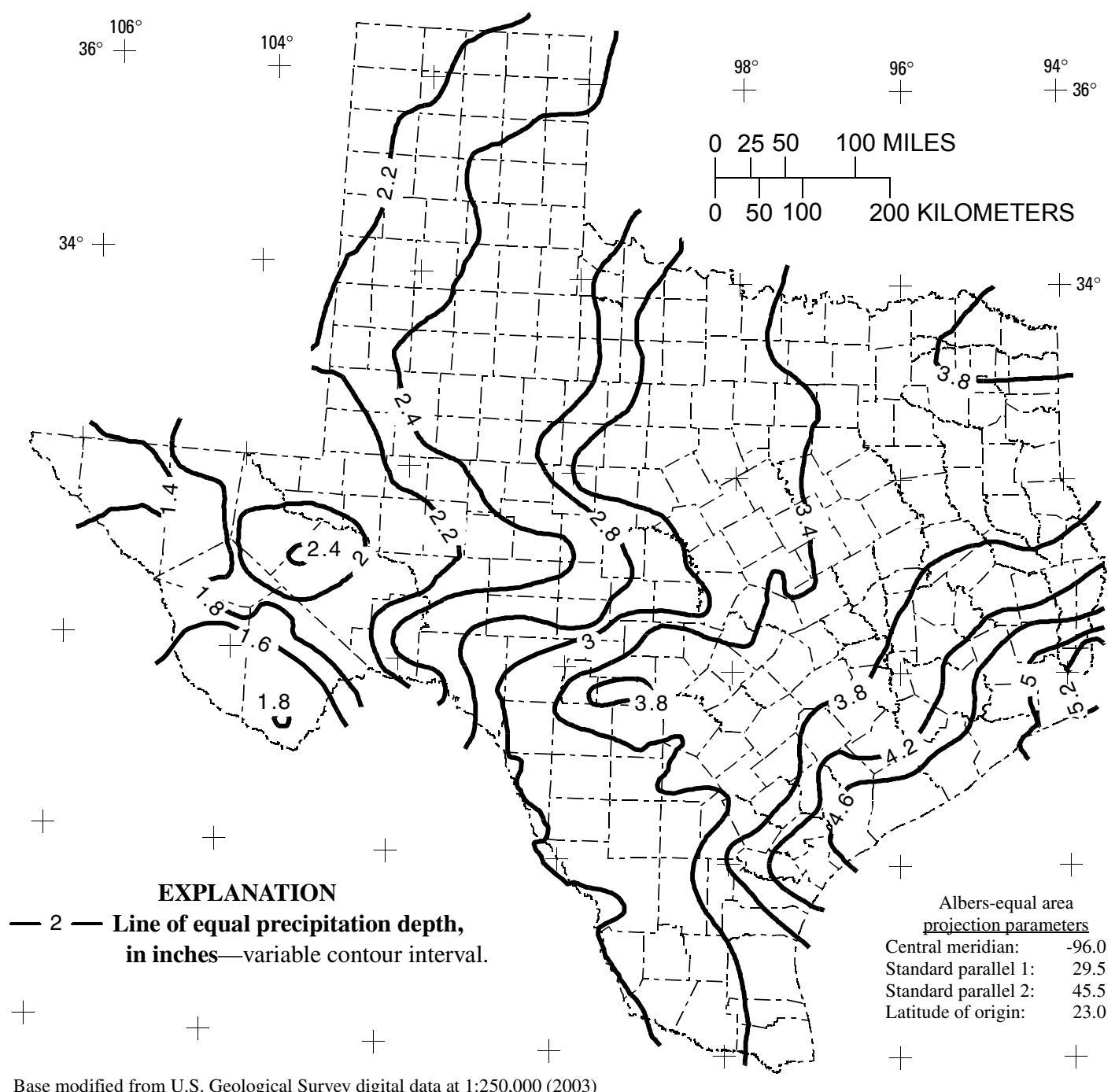

Figure 11. Depth of precipitation for 2-year storm for 1-day duration in Texas. 


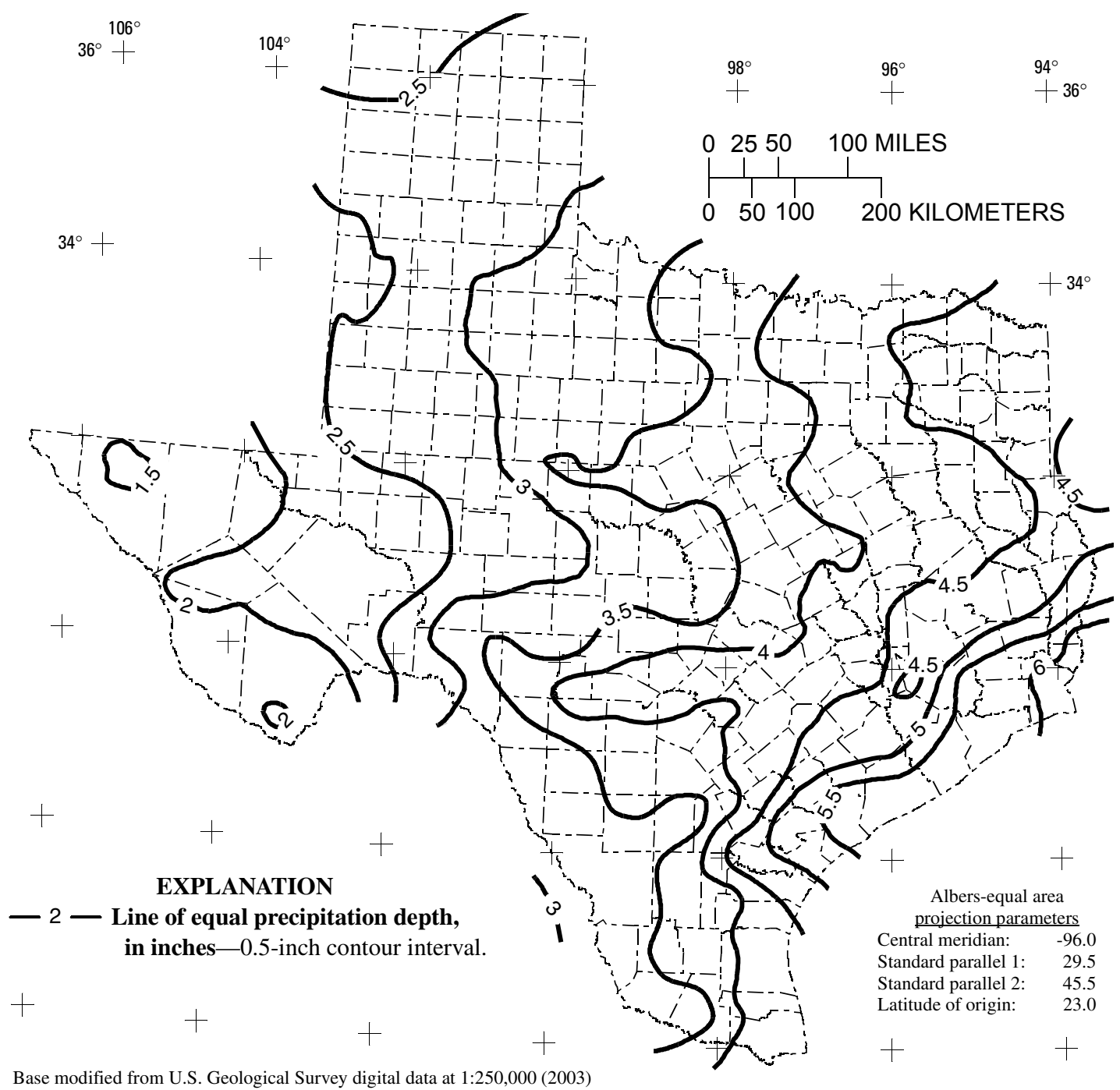

Figure 12. Depth of precipitation for 2-year storm for 2-day duration in Texas. 


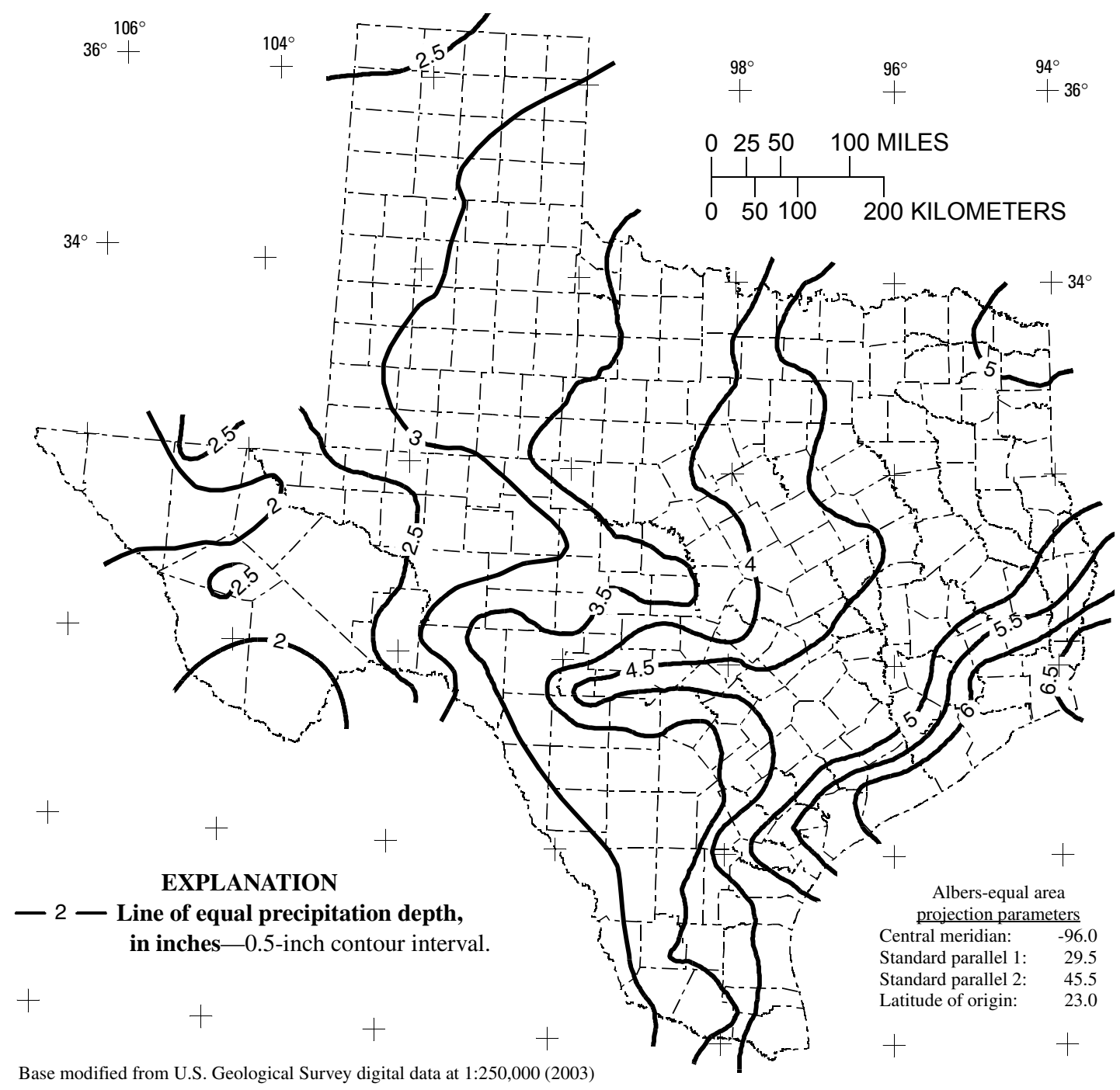

Figure 13. Depth of precipitation for 2-year storm for 3-day duration in Texas. 


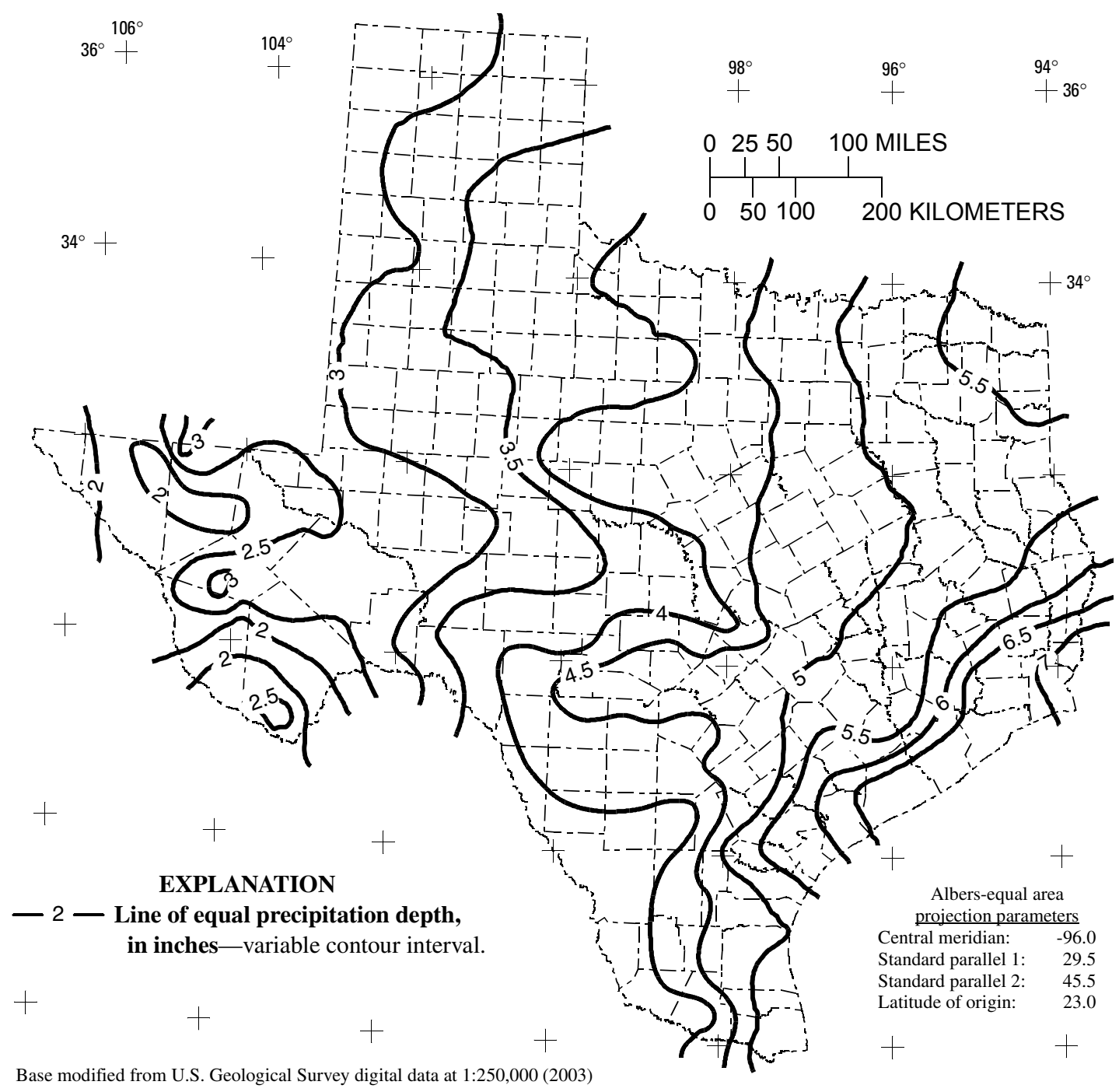

Figure 14. Depth of precipitation for 2-year storm for 5-day duration in Texas. 


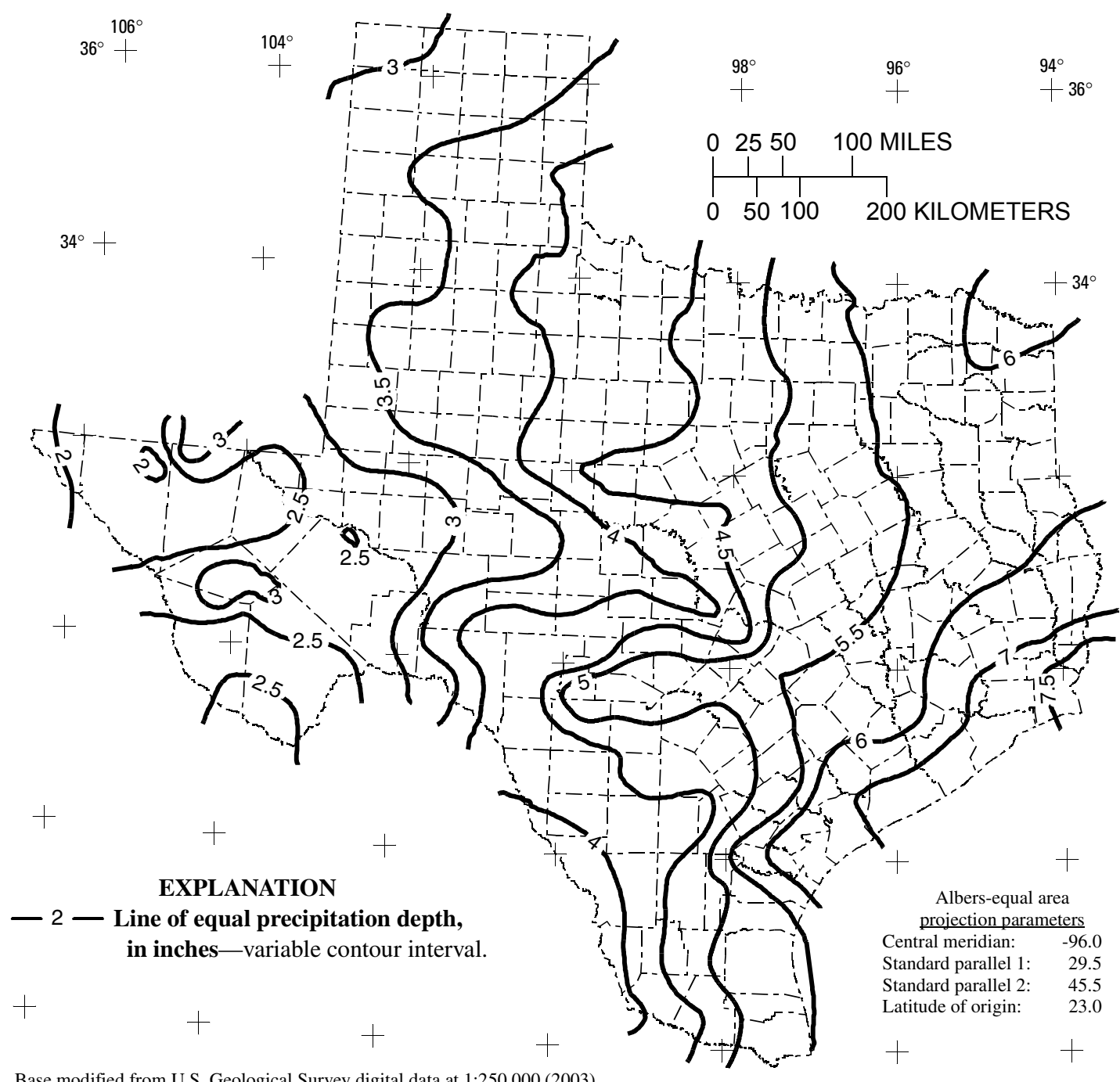

Figure 15. Depth of precipitation for 2-year storm for 7-day duration in Texas. 


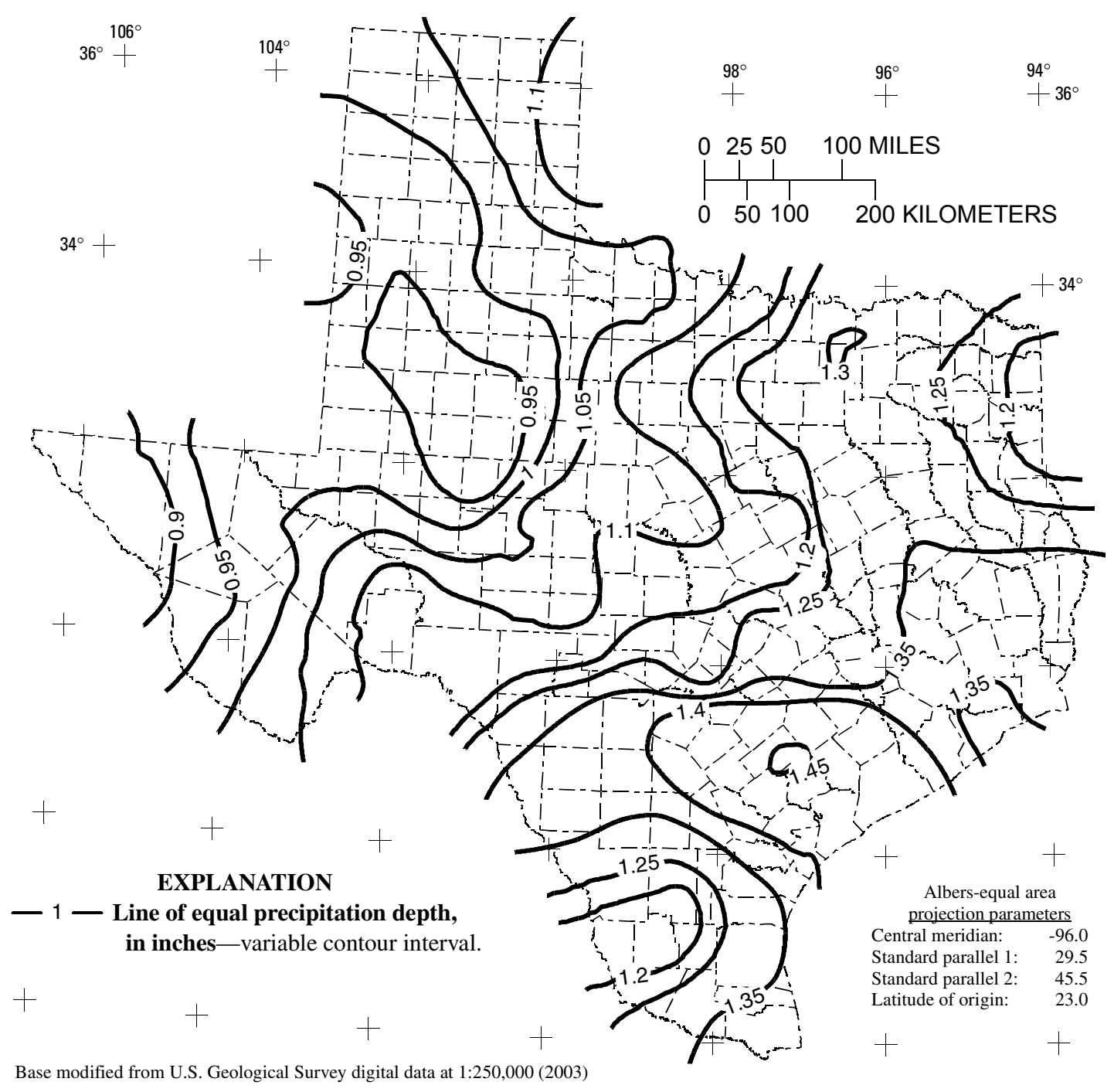

Figure 16. Depth of precipitation for 5-year storm for 15-minute duration in Texas. 


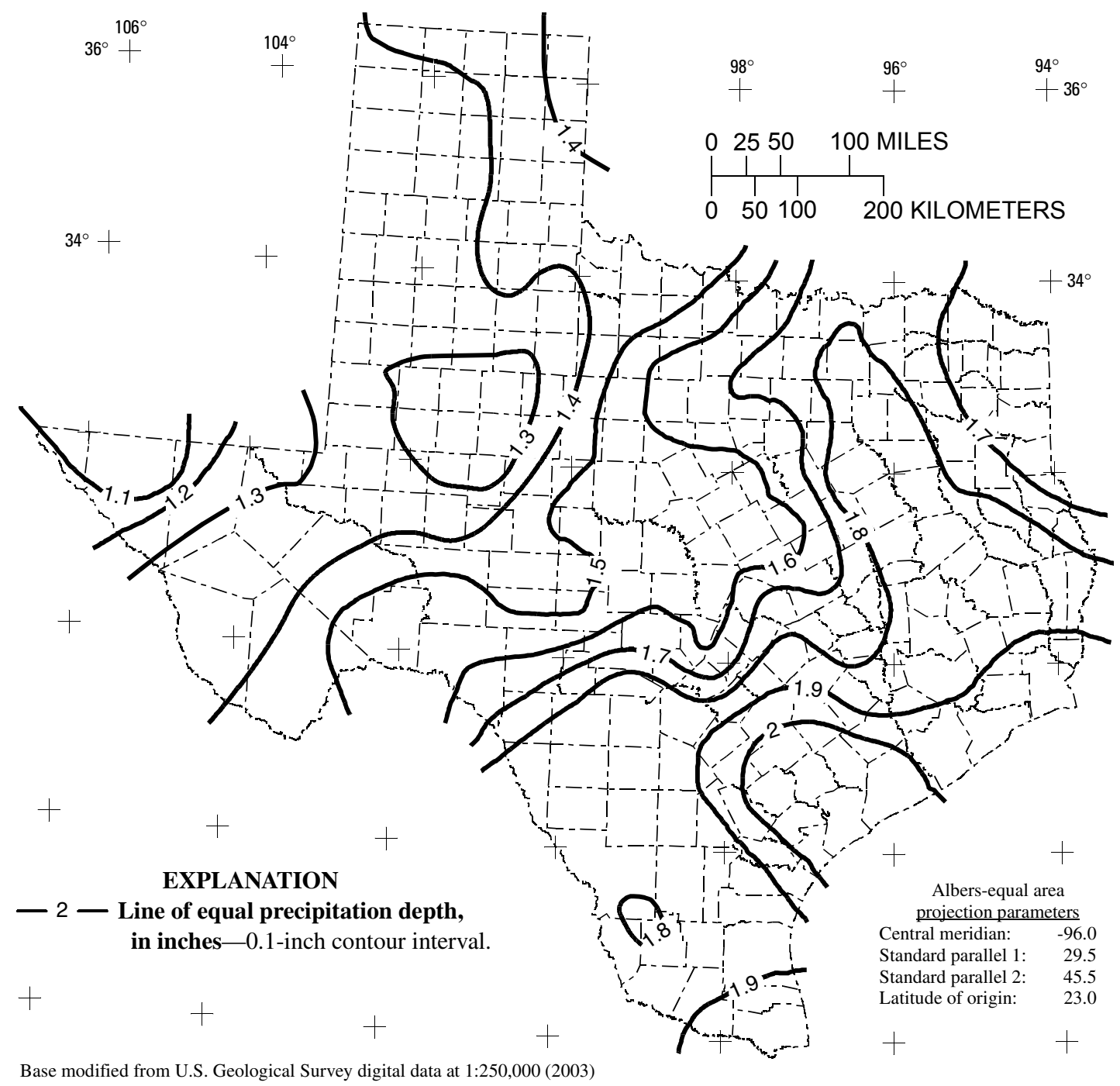

Figure 17. Depth of precipitation for 5-year storm for 30-minute duration in Texas. 


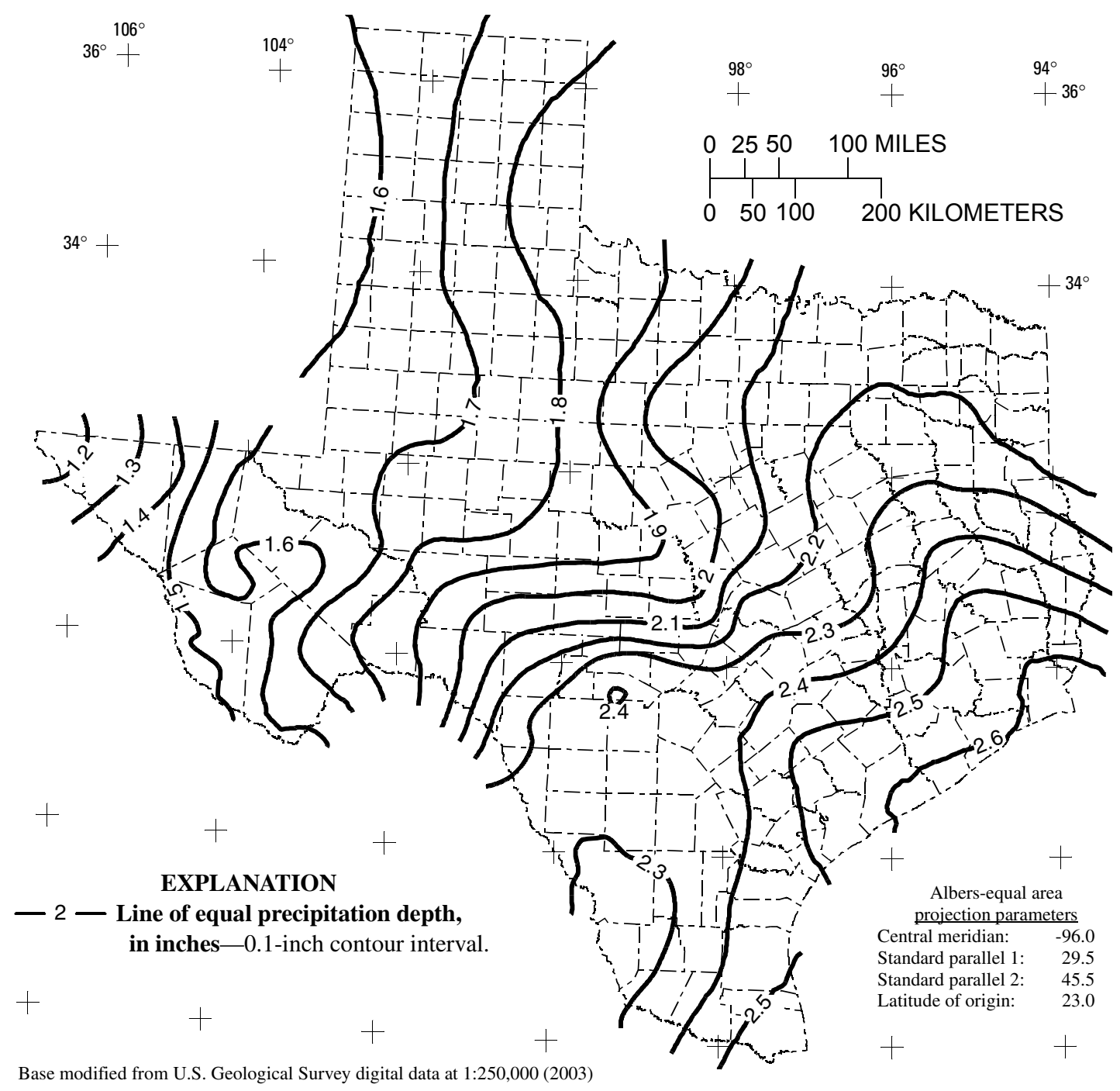

Figure 18. Depth of precipitation for 5-year storm for 1-hour duration in Texas. 


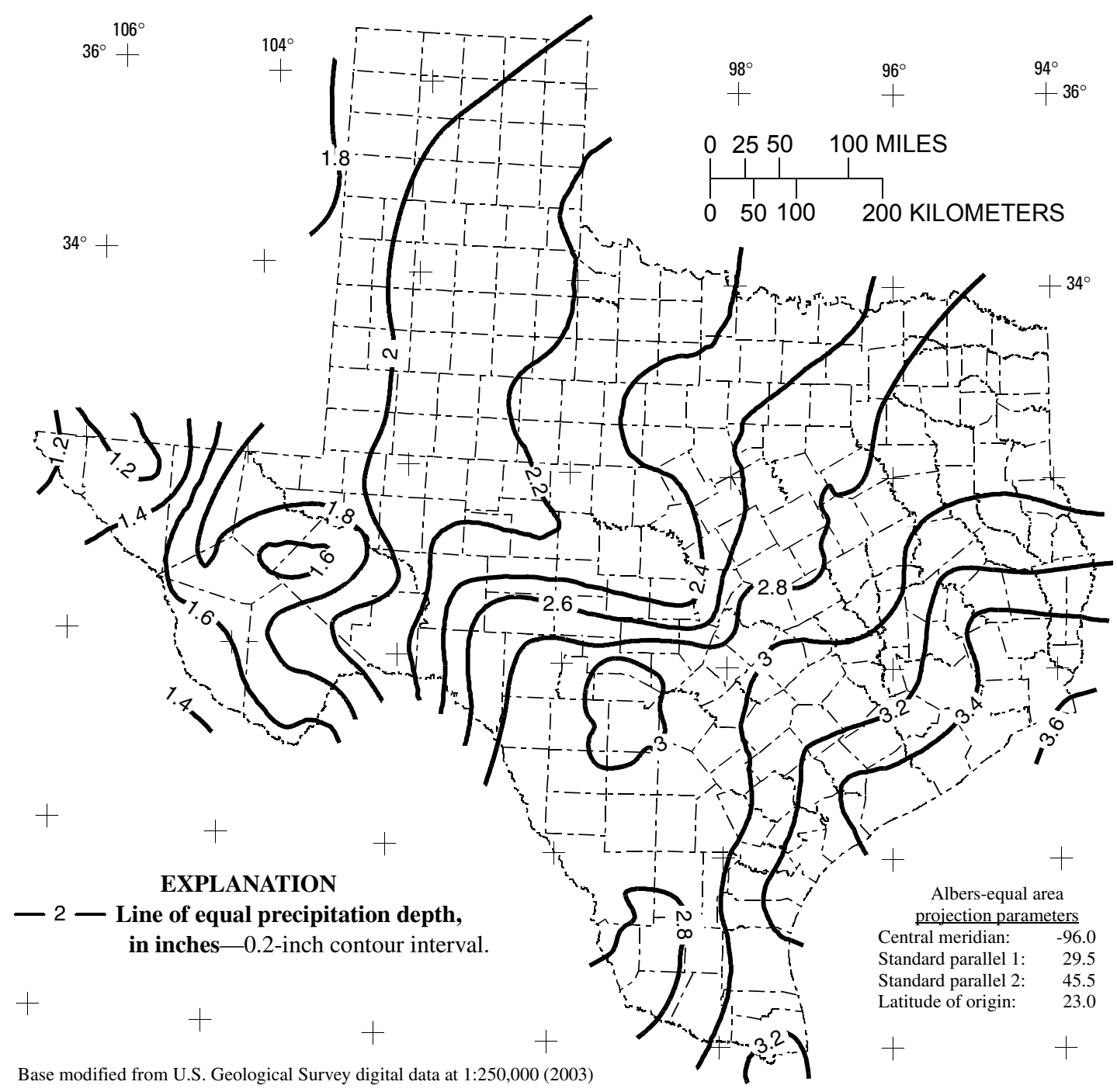

Figure 19. Depth of precipitation for 5-year storm for 2-hour duration in Texas. 


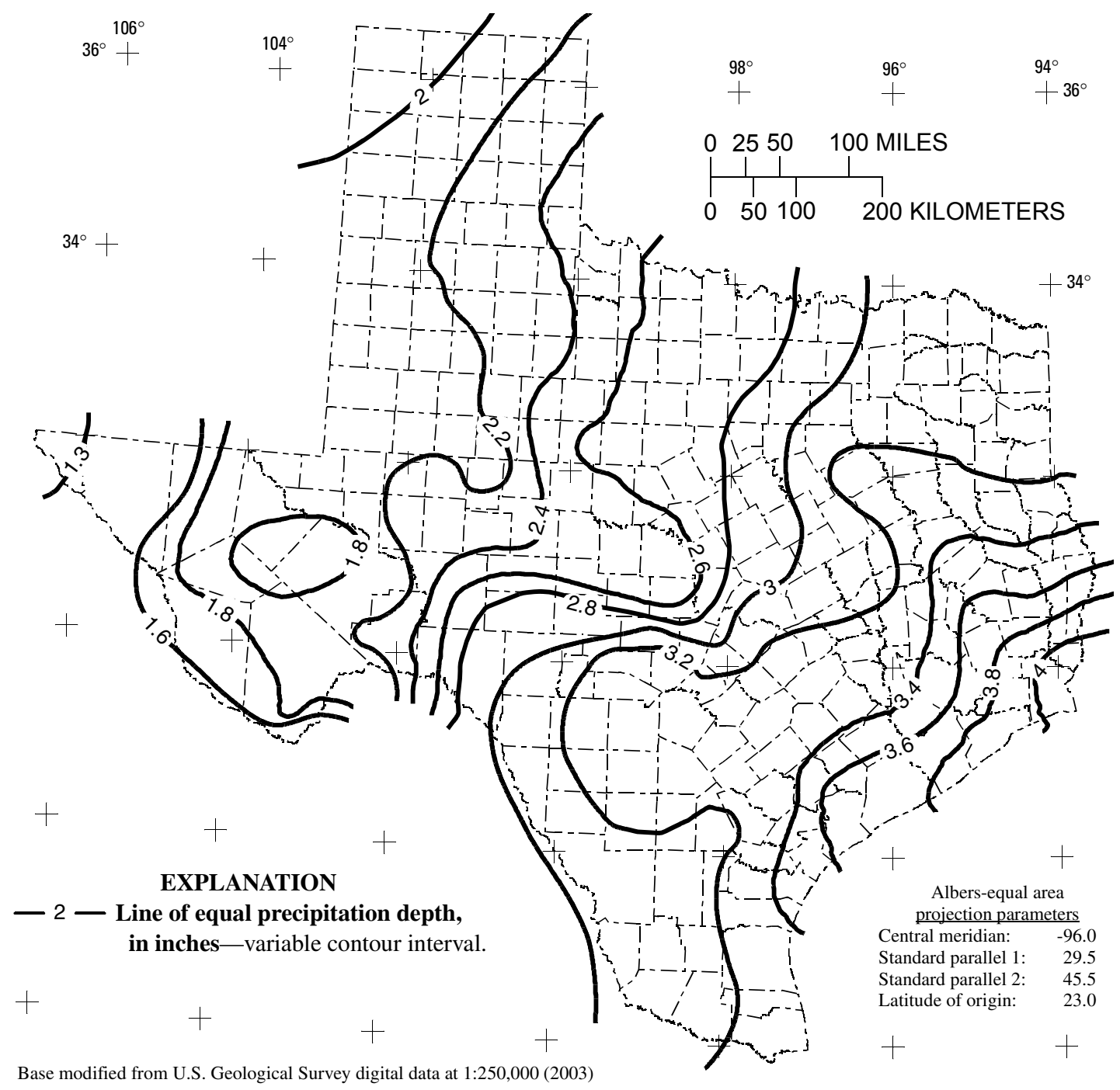

Figure 20. Depth of precipitation for 5-year storm for 3-hour duration in Texas. 


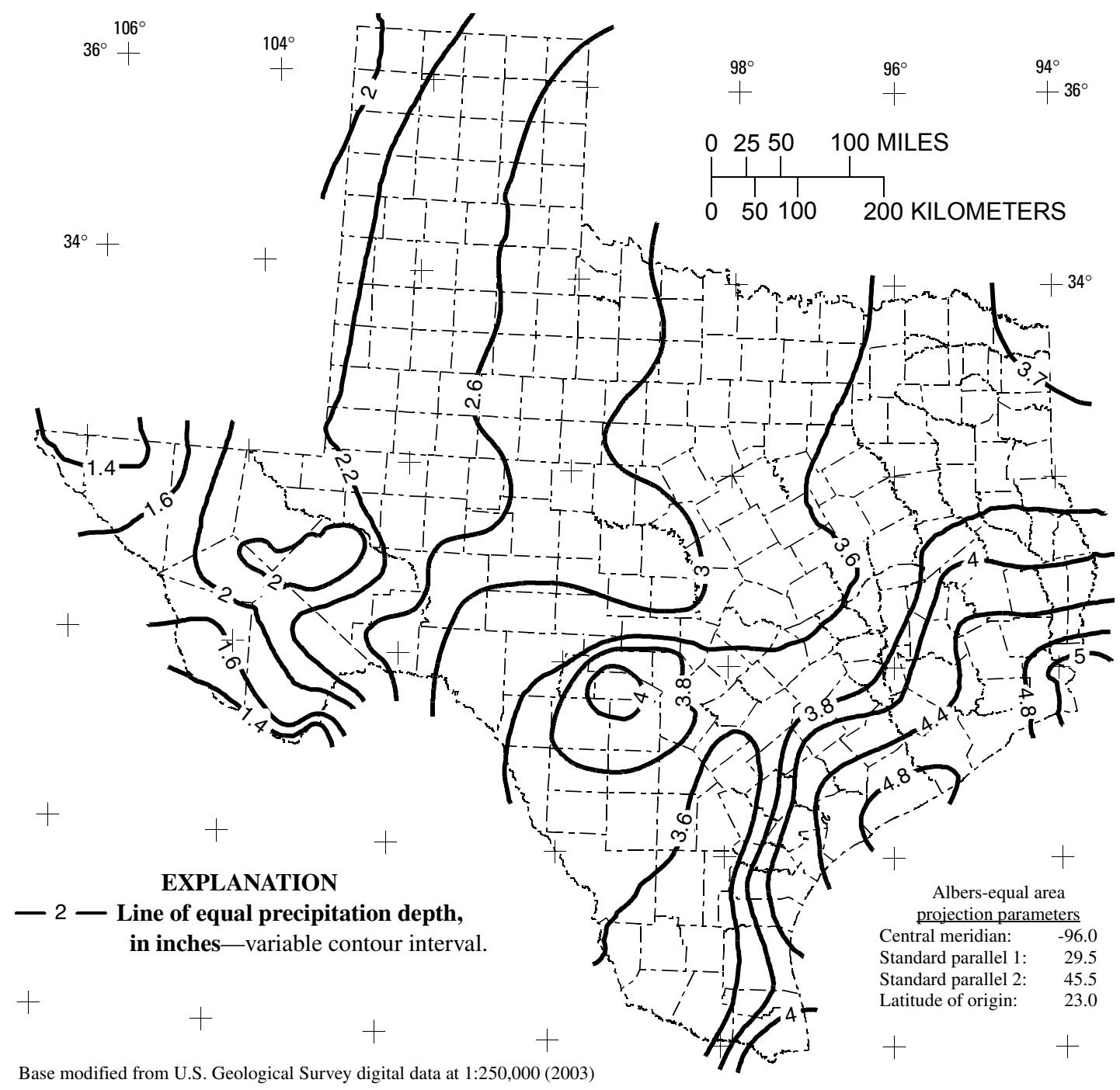

Figure 21. Depth of precipitation for 5-year storm for 6-hour duration in Texas. 


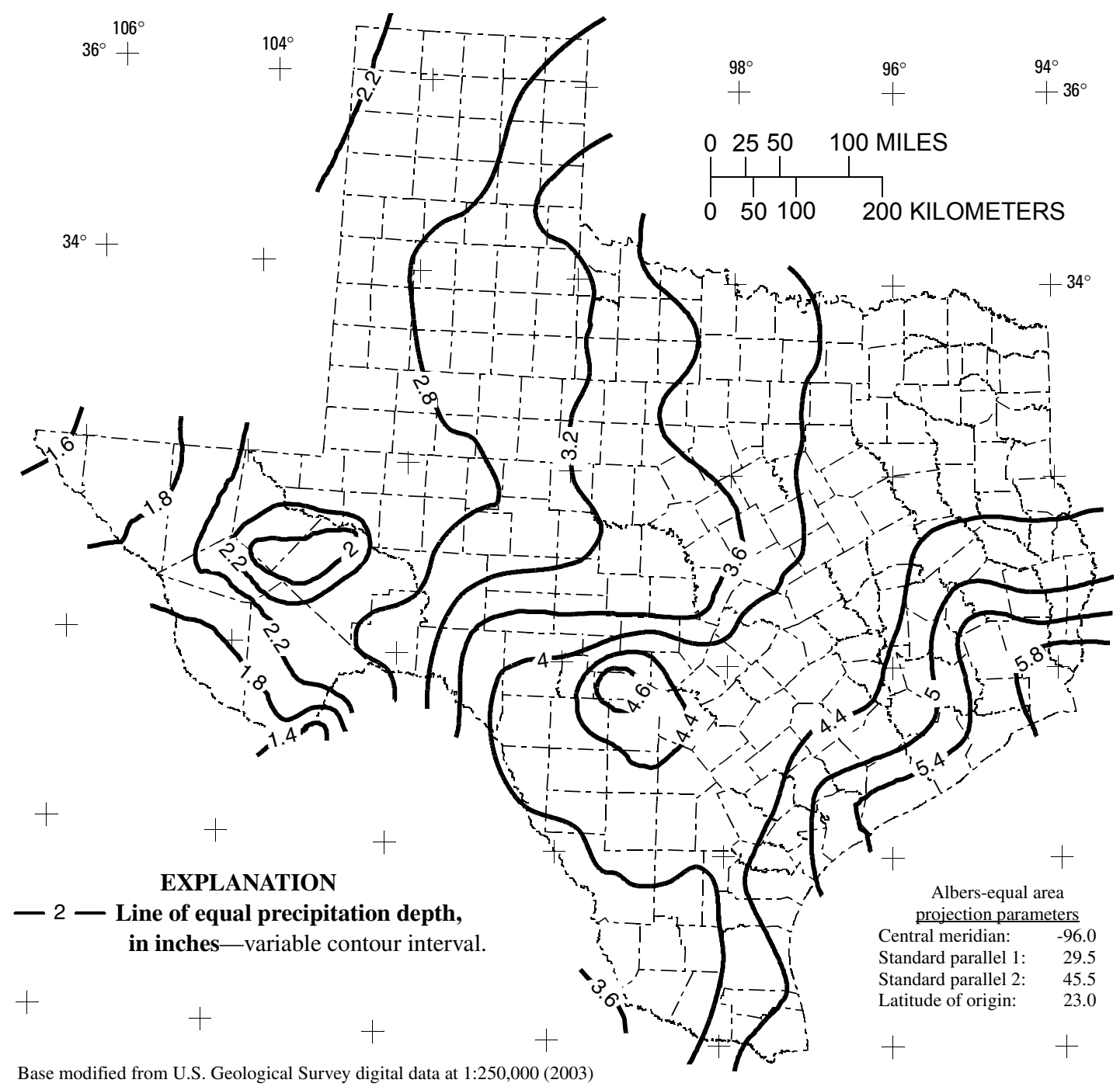

Figure 22. Depth of precipitation for 5-year storm for 12-hour duration in Texas. 


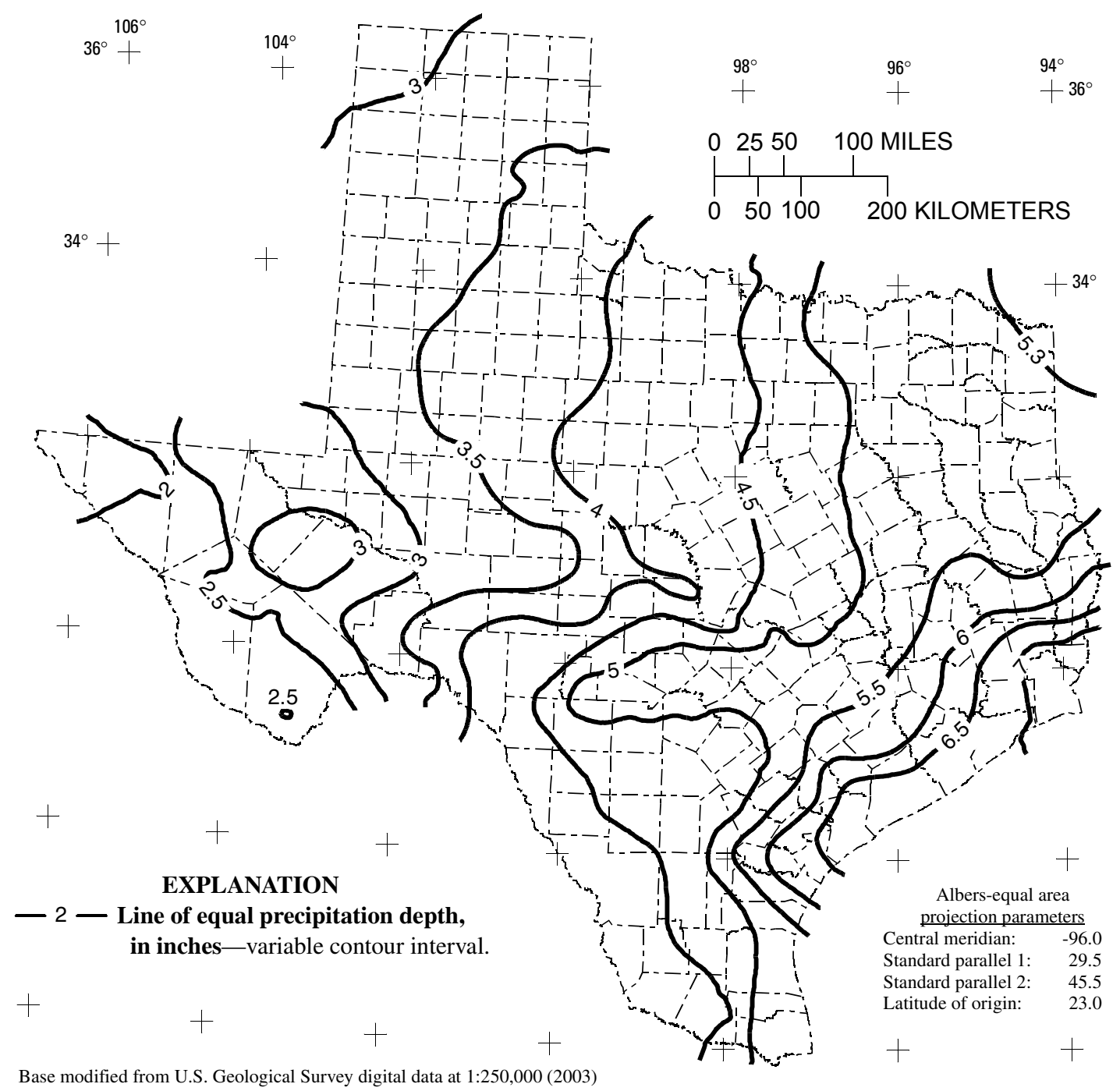

Figure 23. Depth of precipitation for 5-year storm for 1-day duration in Texas. 


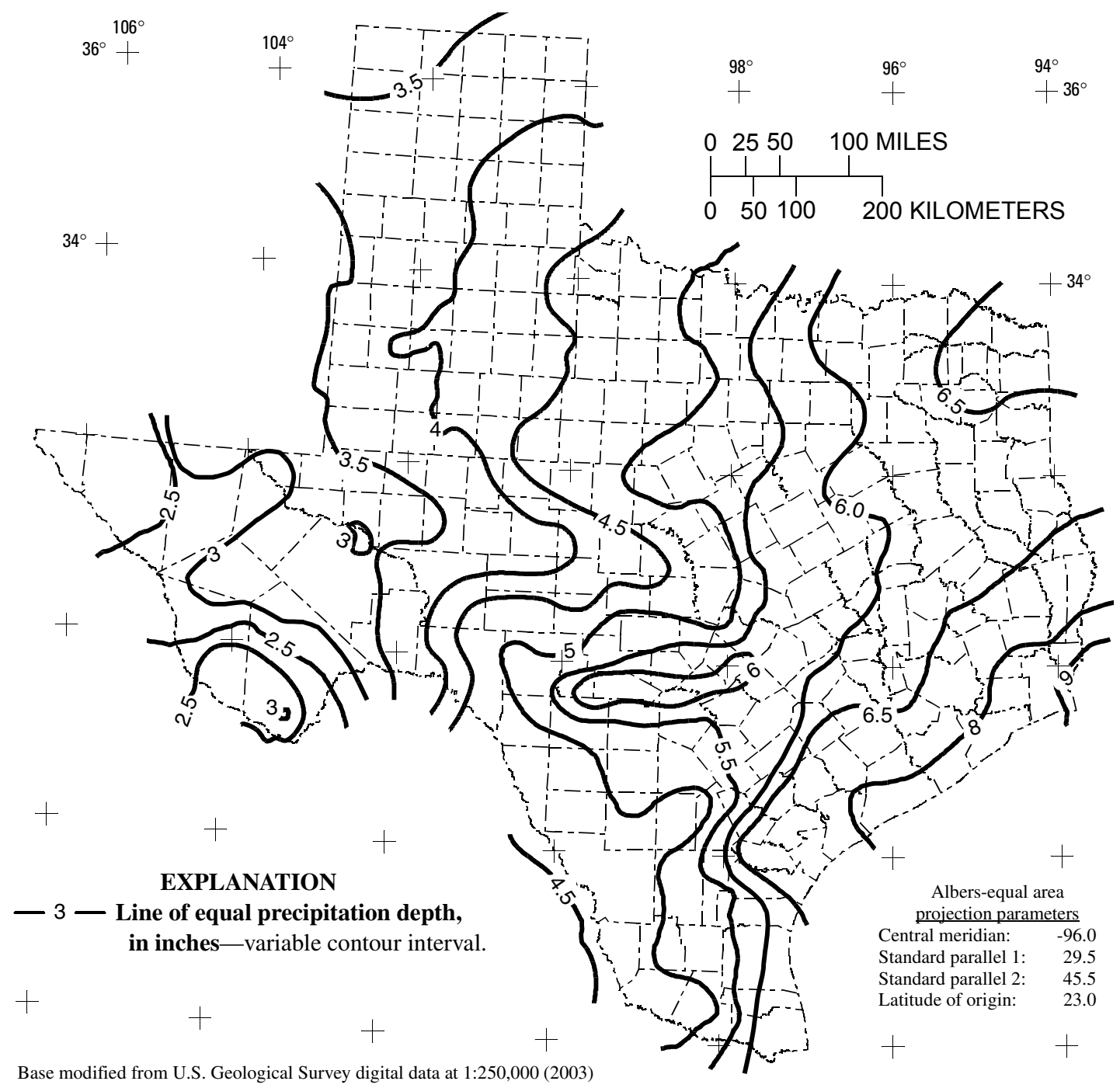

Figure 24. Depth of precipitation for 5-year storm for 2-day duration in Texas. 


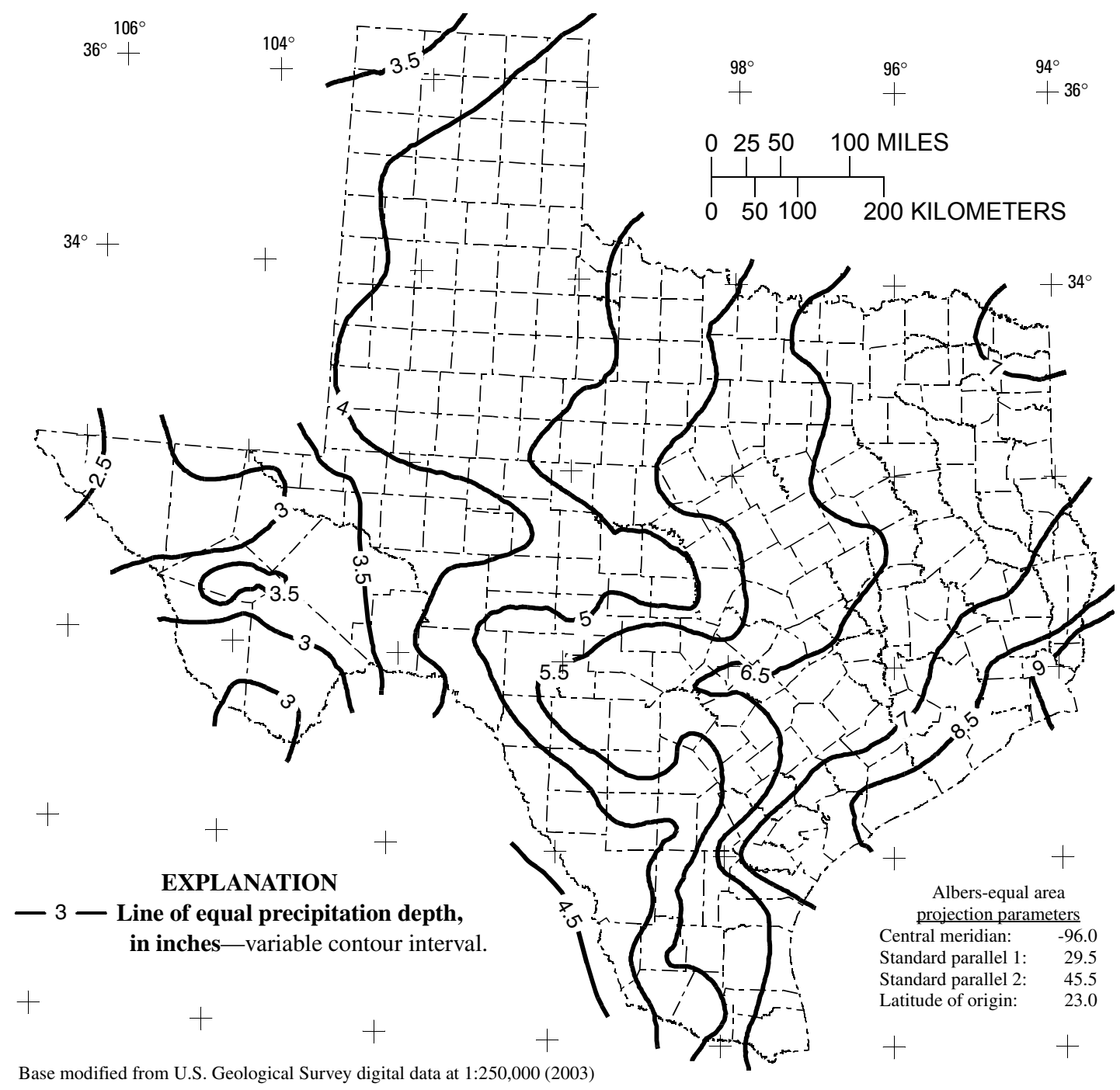

Figure 25. Depth of precipitation for 5-year storm for 3-day duration in Texas. 


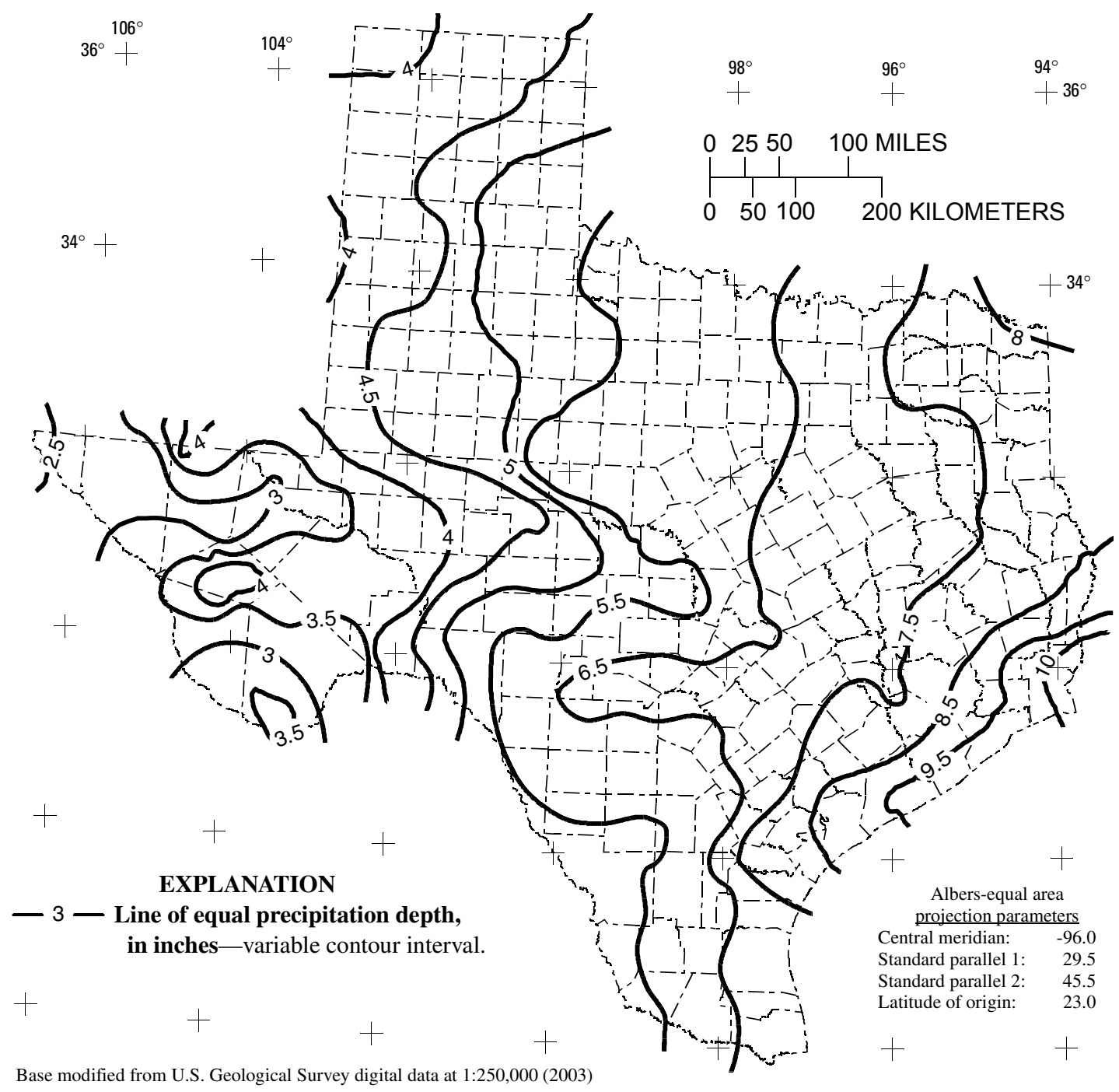

Figure 26. Depth of precipitation for 5-year storm for 5-day duration in Texas. 


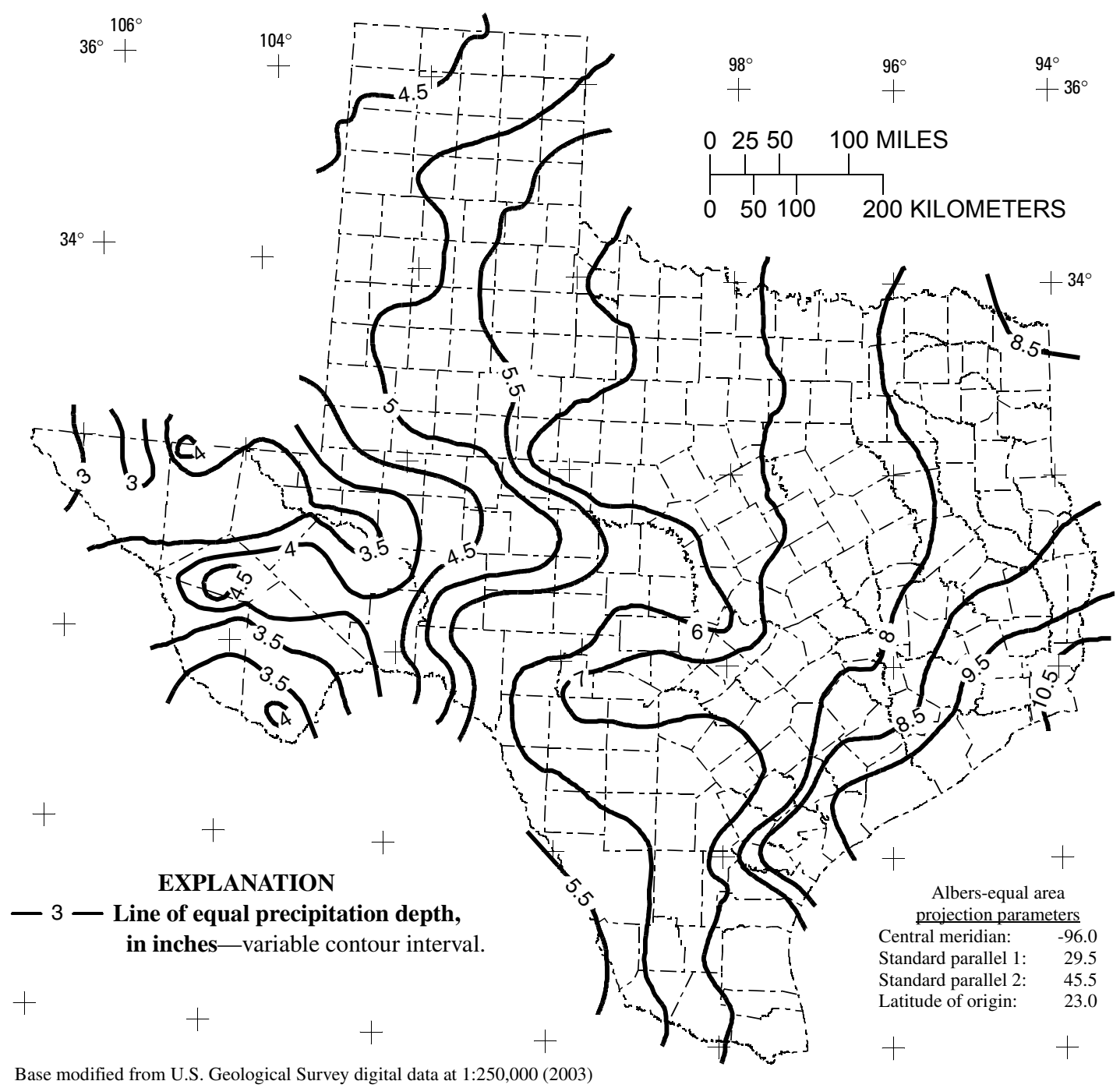

Figure 27. Depth of precipitation for 5-year storm for 7-day duration in Texas. 


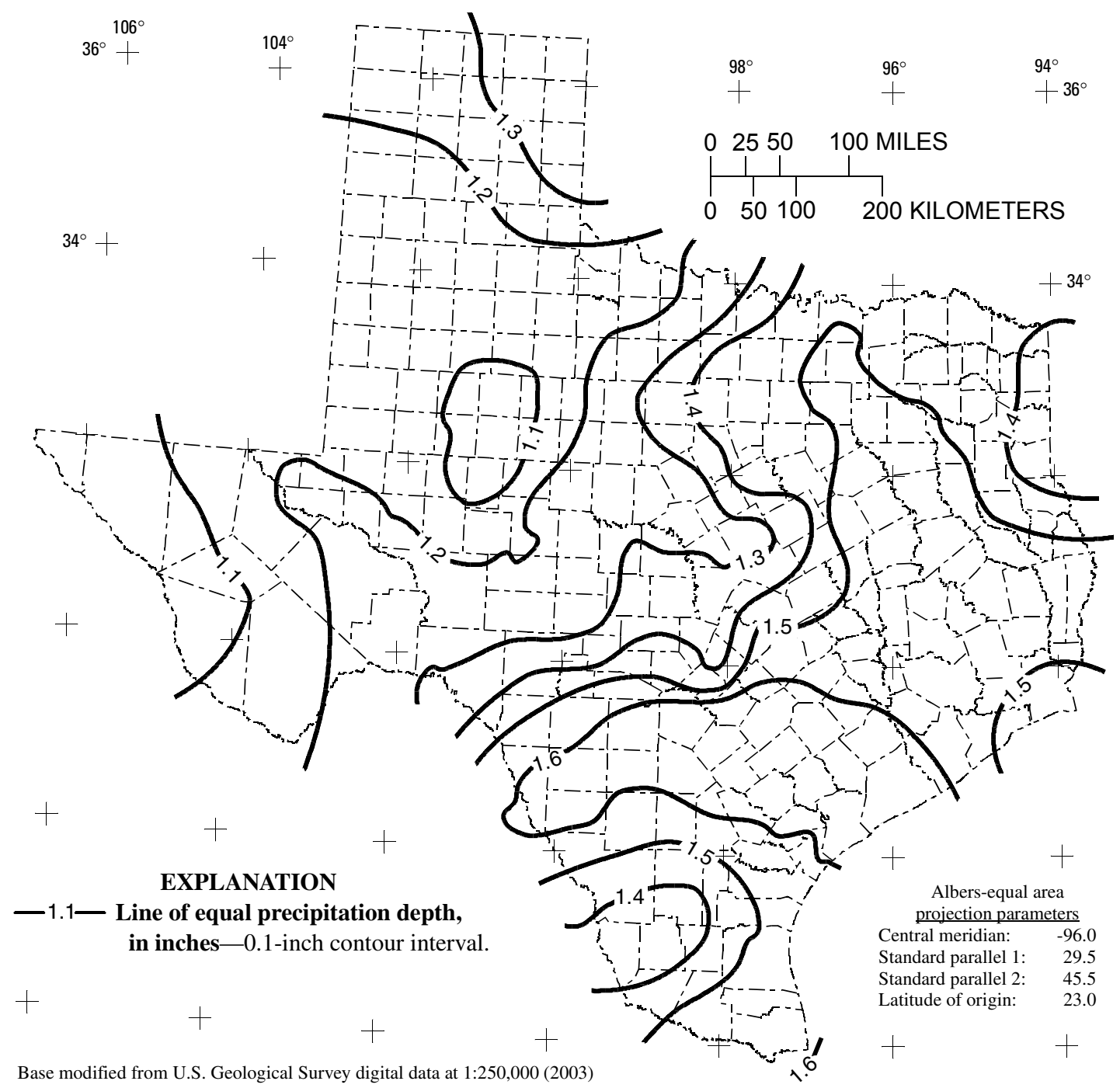

Figure 28. Depth of precipitation for 10-year storm for 15-minute duration in Texas. 


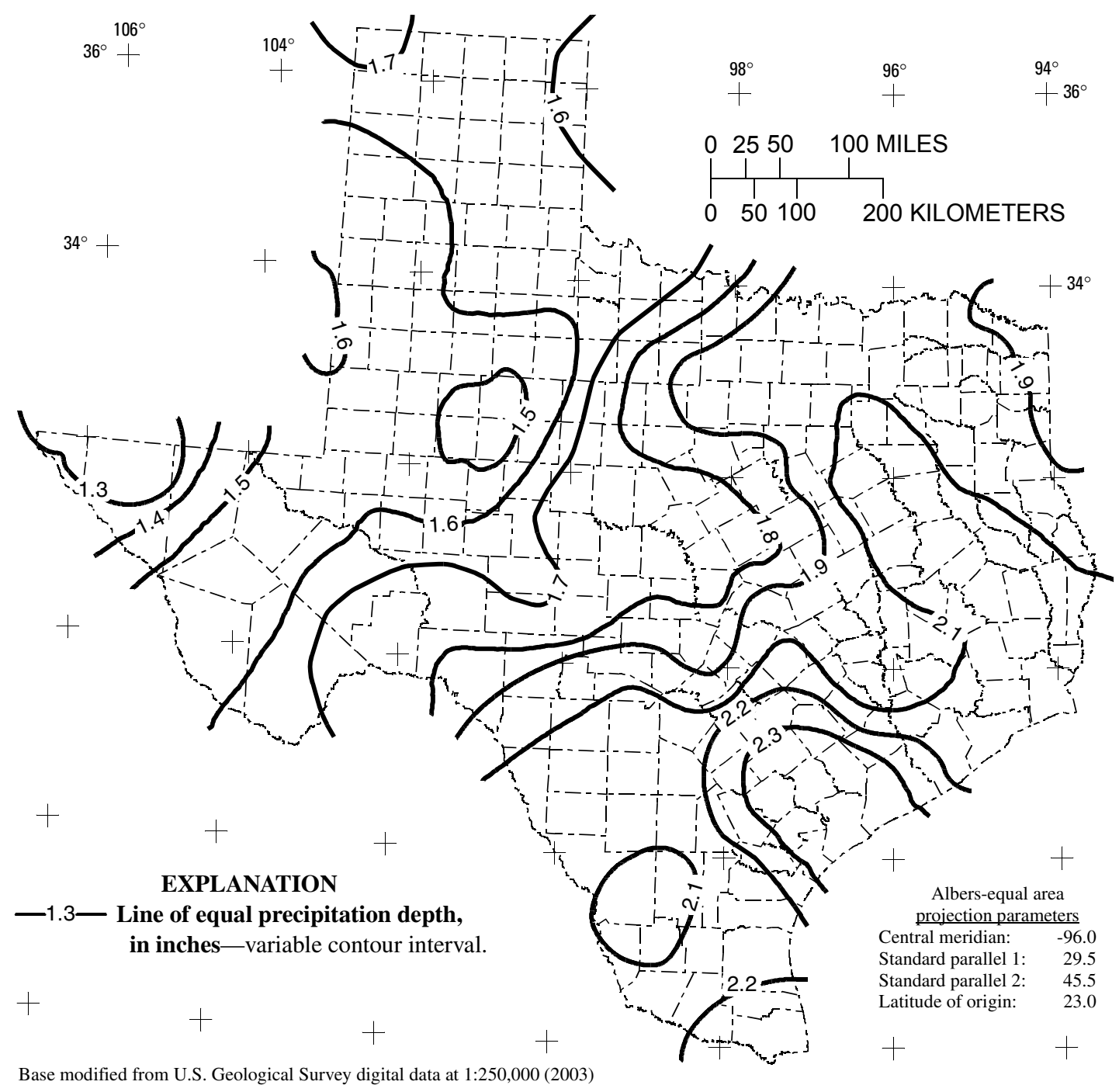

Figure 29. Depth of precipitation for 10-year storm for 30-minute duration in Texas. 


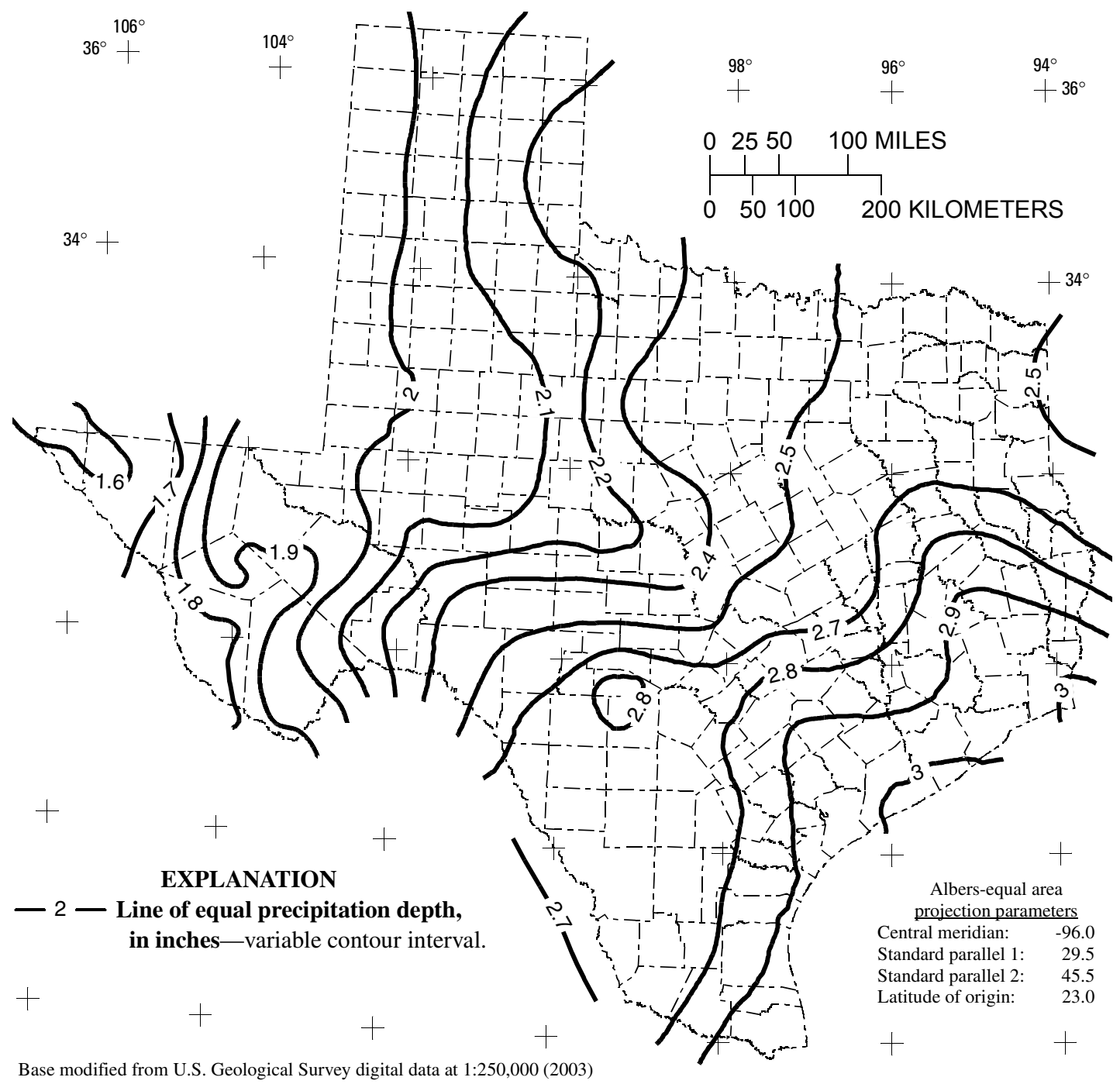

Figure 30. Depth of precipitation for 10-year storm for 1-hour duration in Texas. 


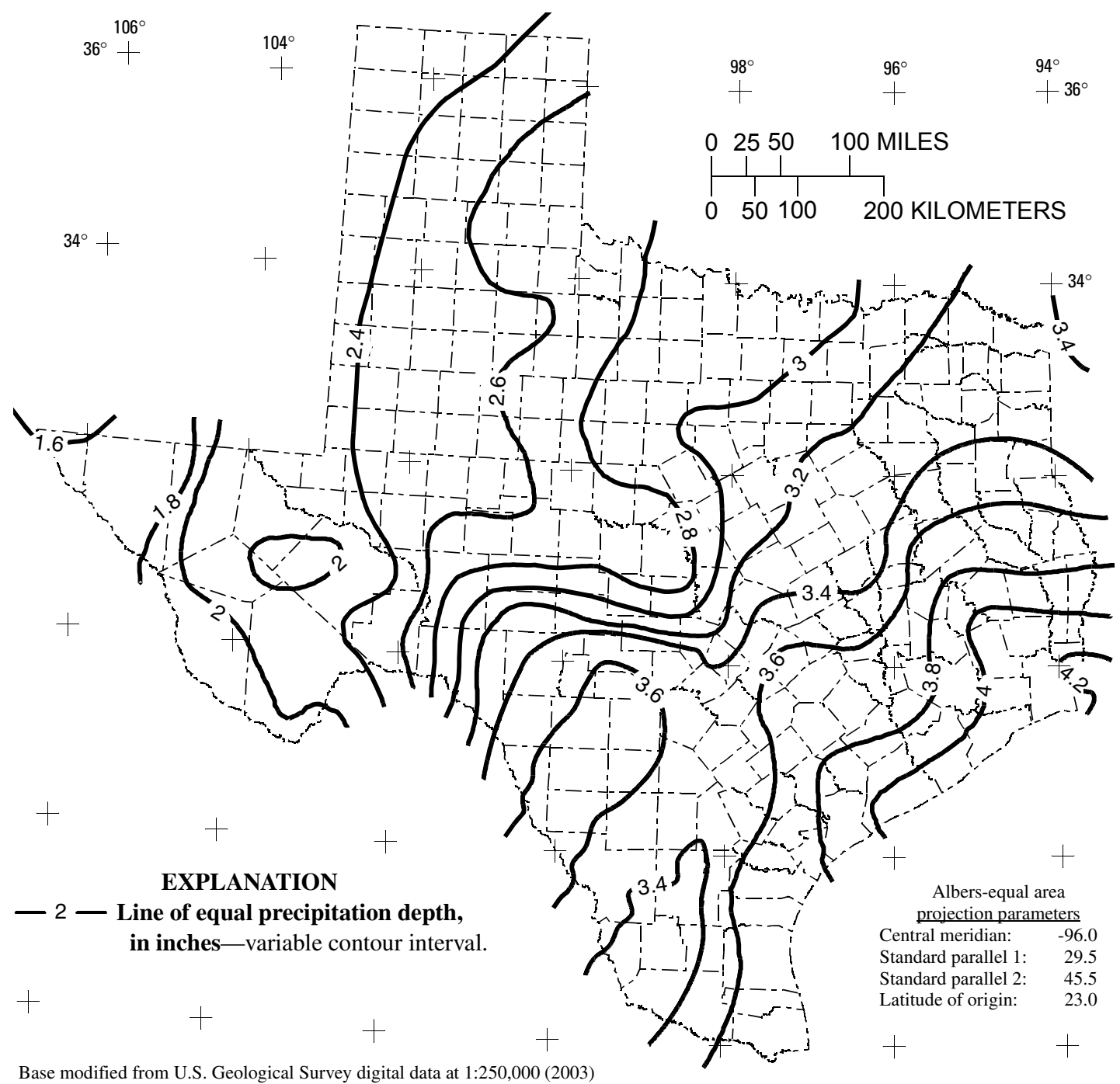

Figure 31. Depth of precipitation for 10-year storm for 2-hour duration in Texas. 


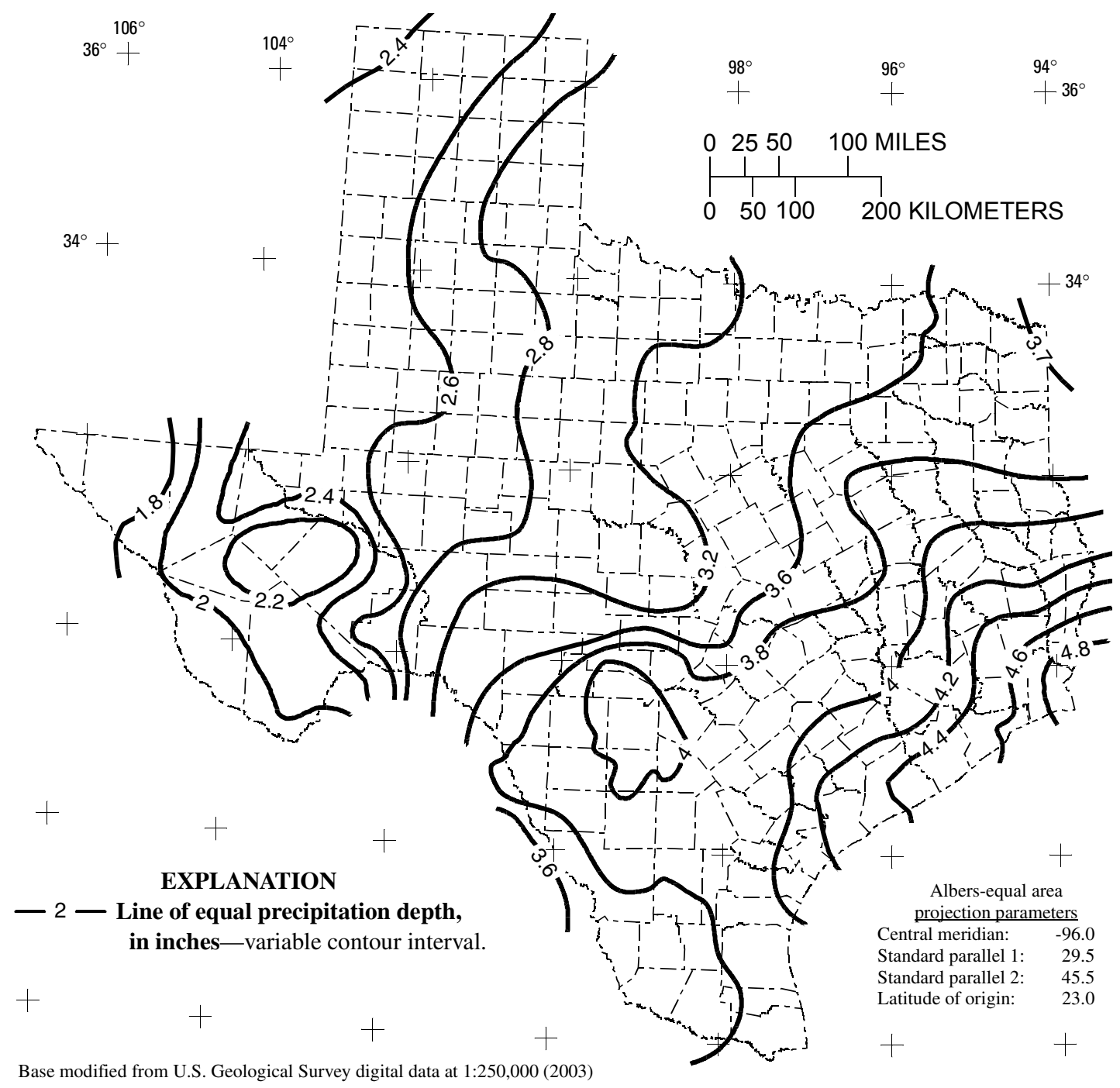

Figure 32. Depth of precipitation for 10-year storm for 3-hour duration in Texas. 


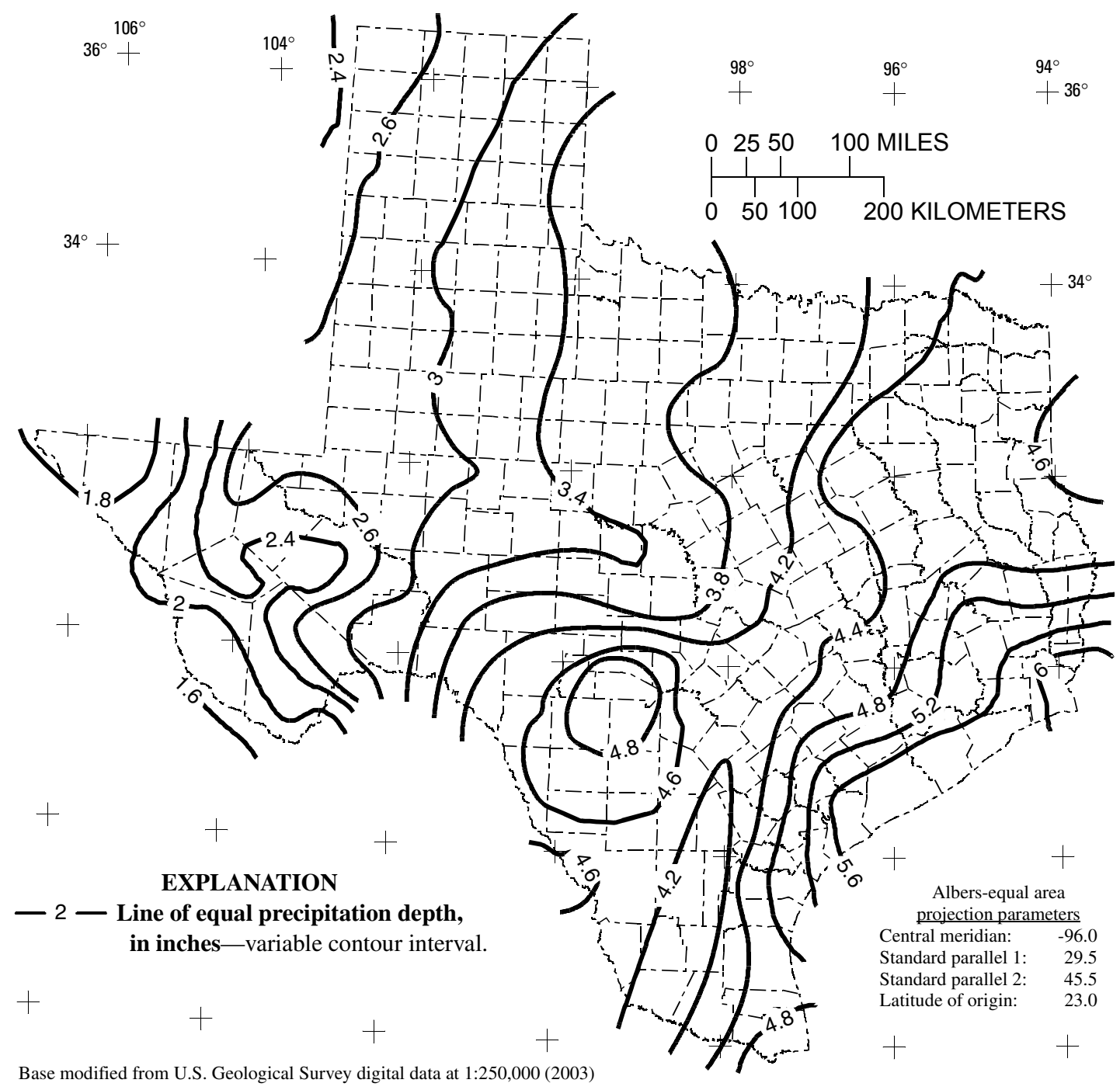

Figure 33. Depth of precipitation for 10-year storm for 6-hour duration in Texas. 


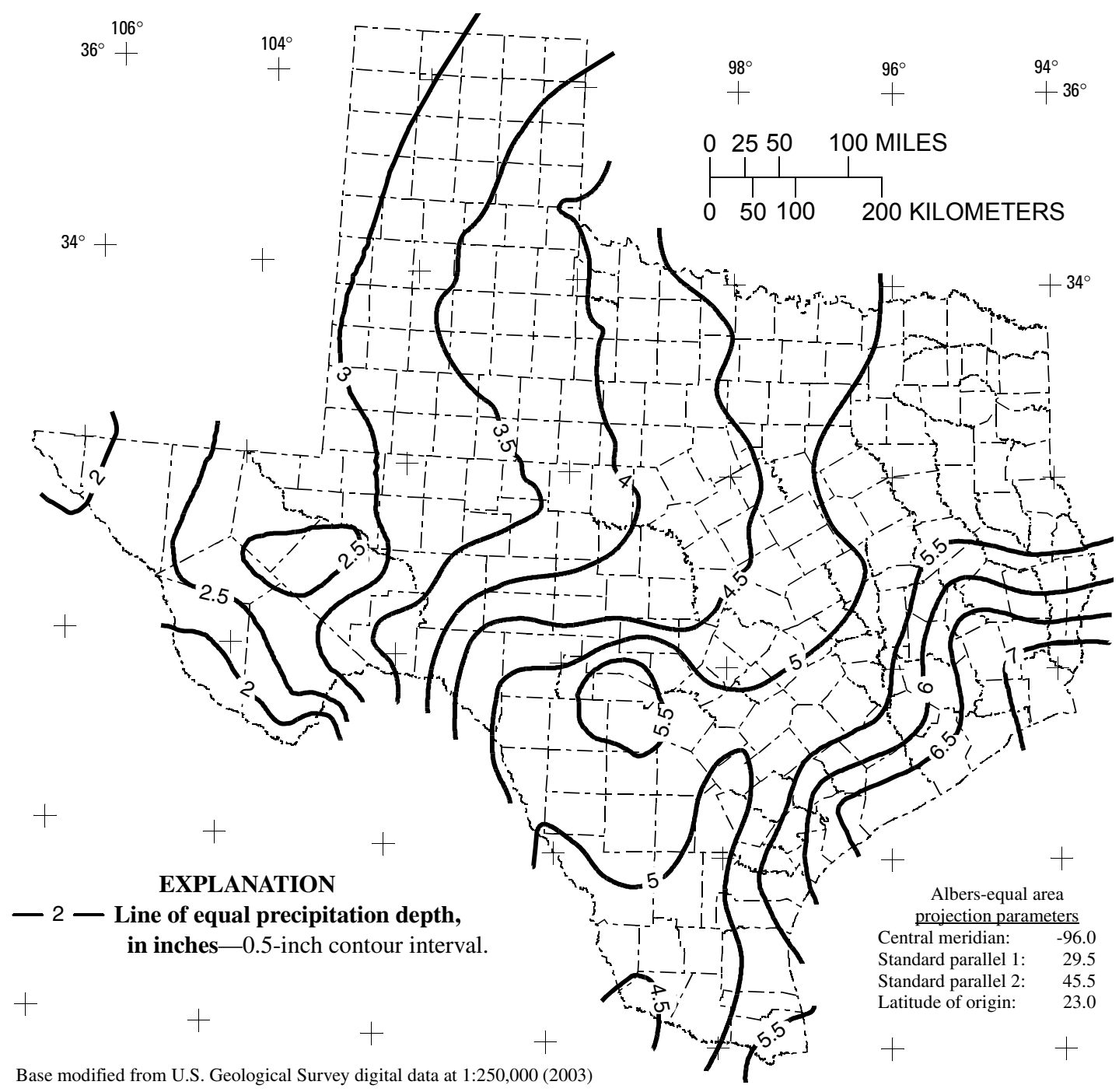

Figure 34. Depth of precipitation for 10-year storm for 12-hour duration in Texas. 


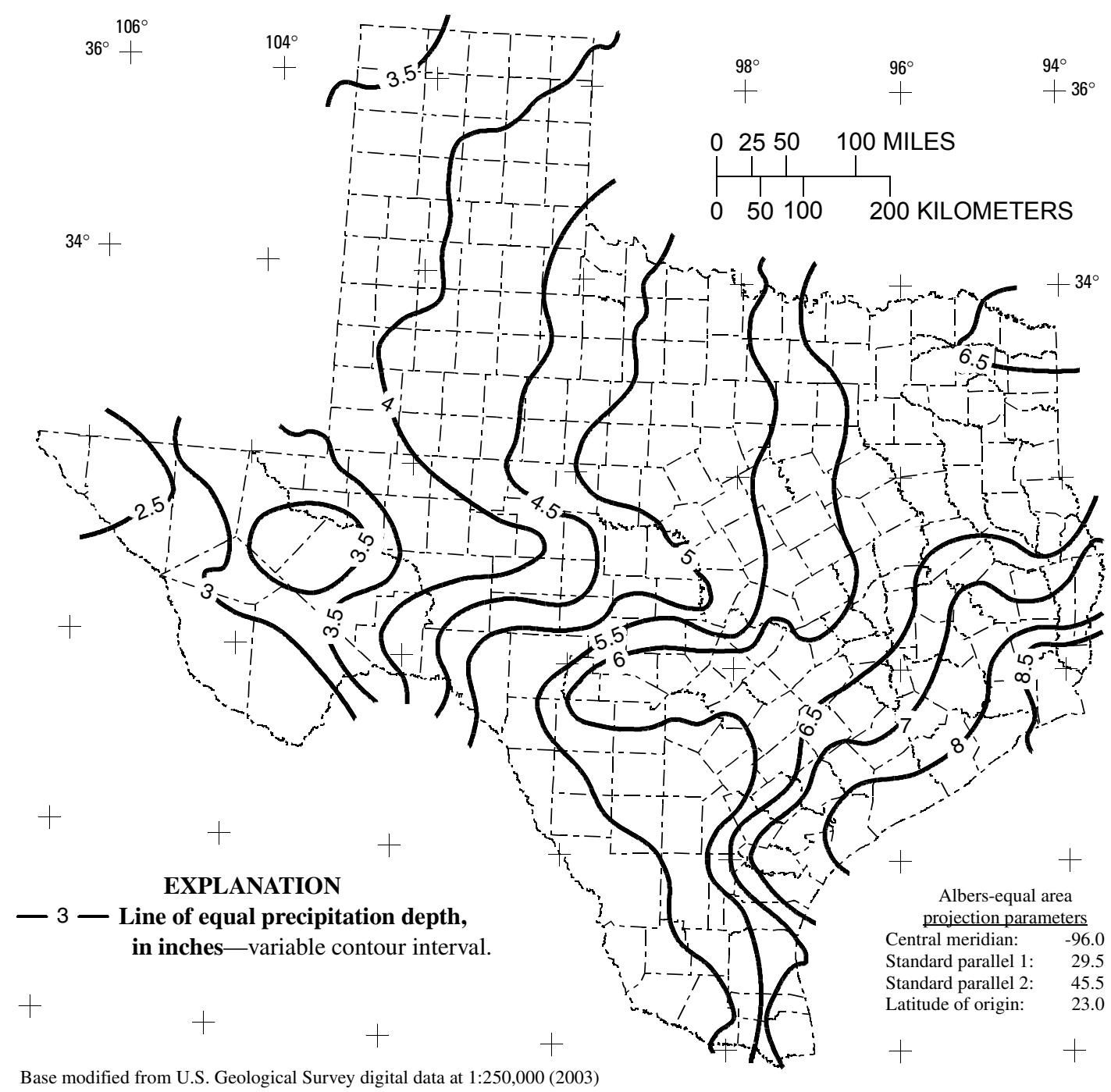

Figure 35. Depth of precipitation for 10-year storm for 1-day duration in Texas. 


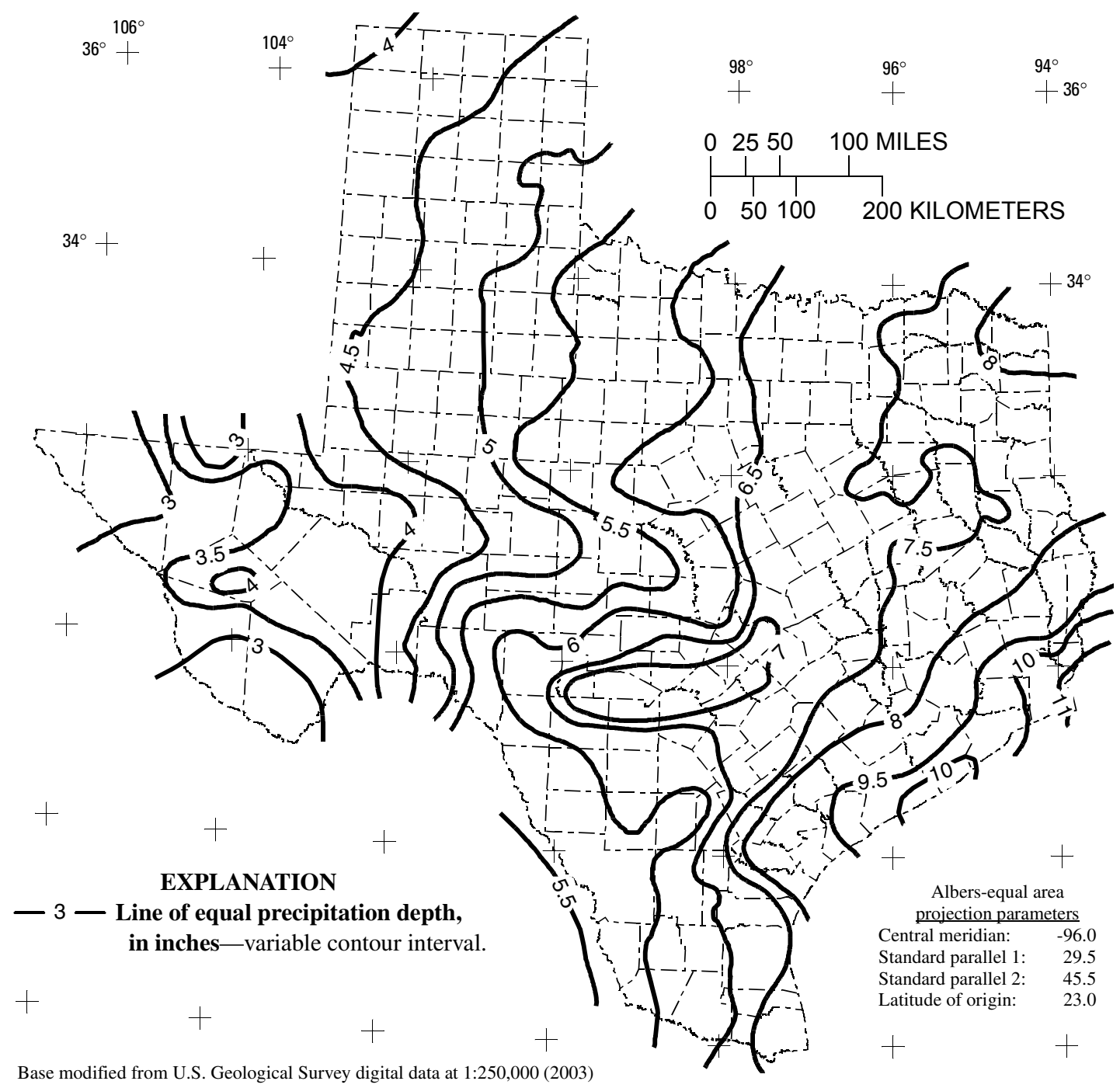

Figure 36. Depth of precipitation for 10-year storm for 2-day duration in Texas. 


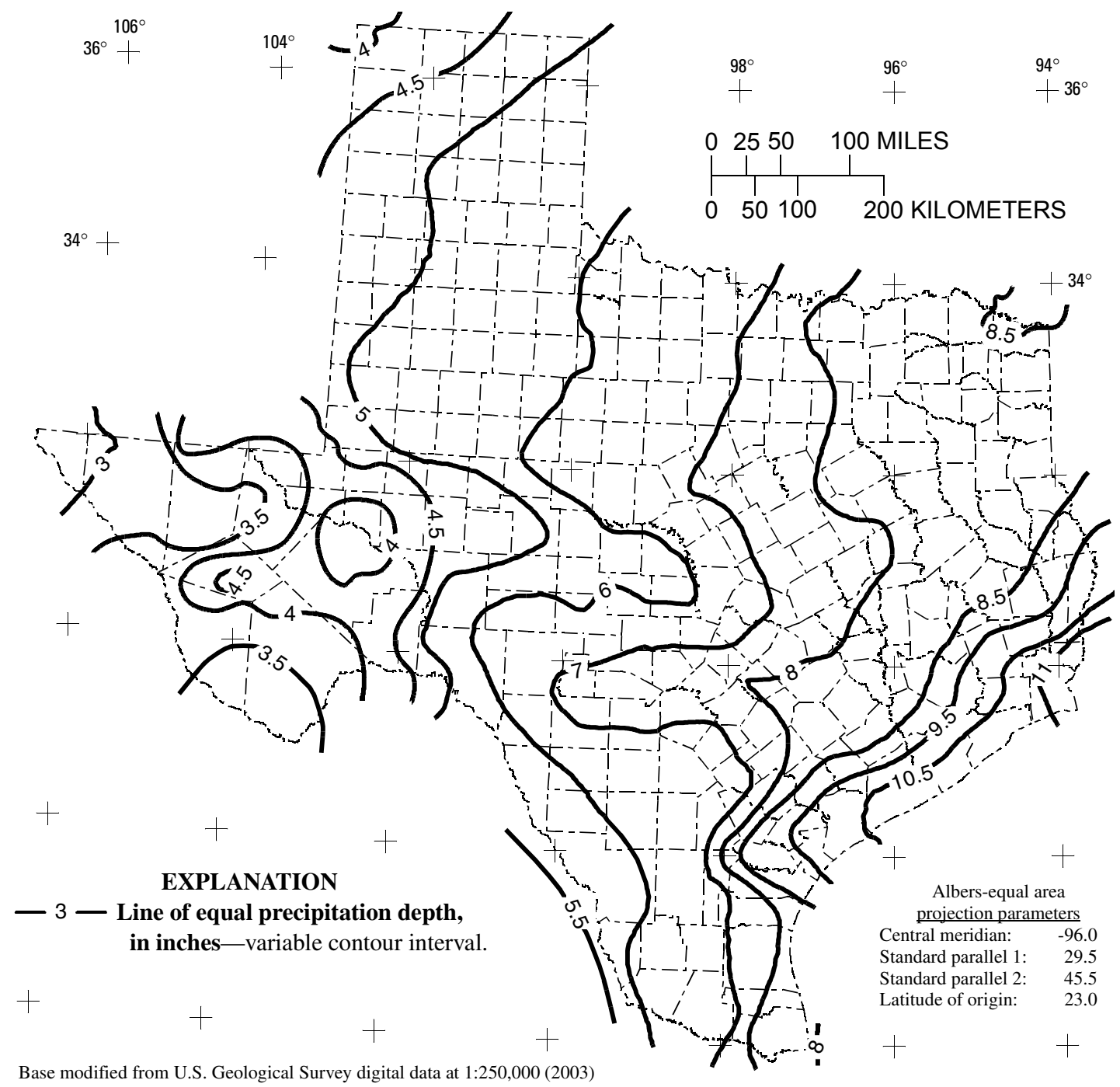

Figure 37. Depth of precipitation for 10-year storm for 3-day duration in Texas. 


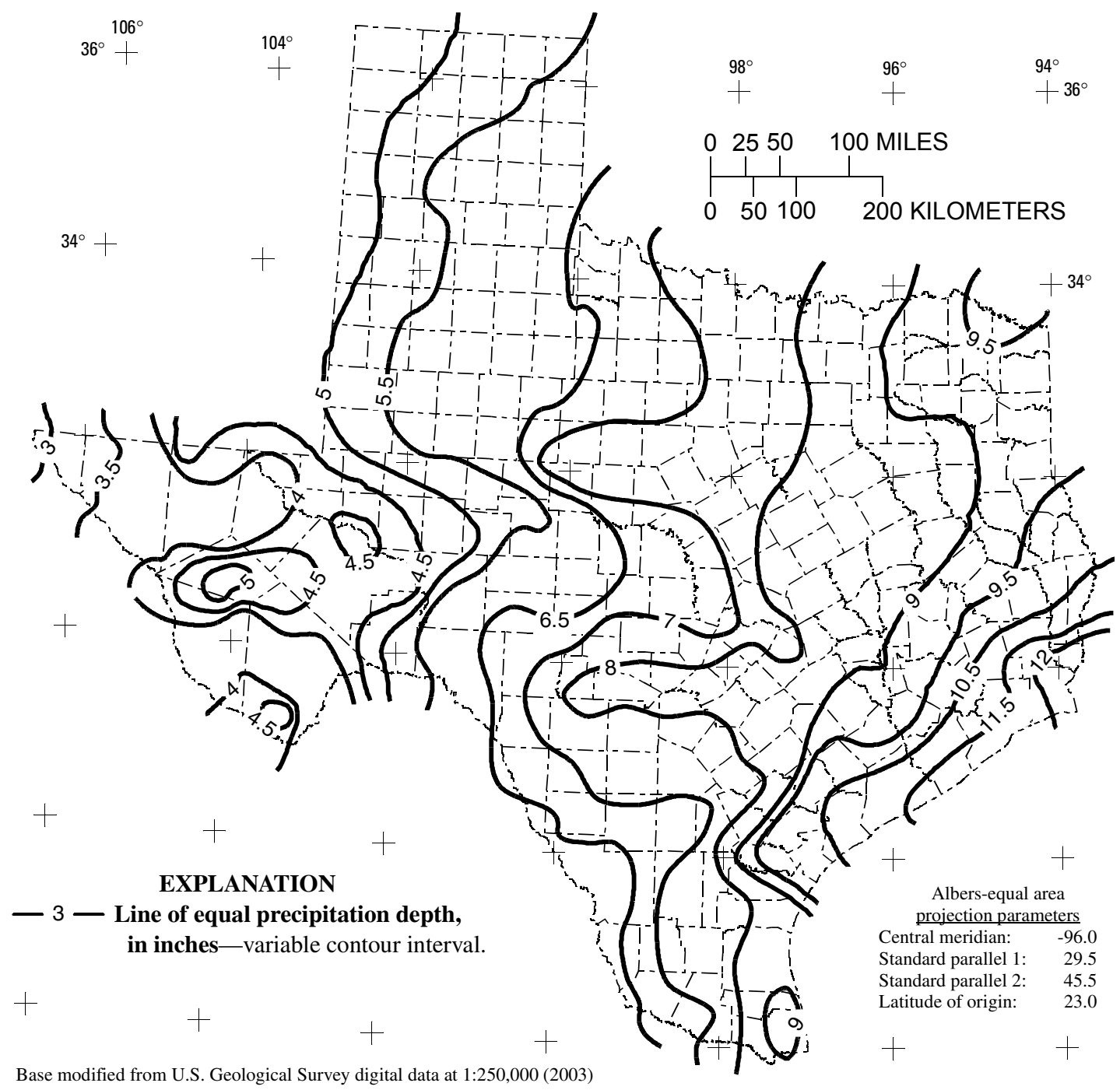

Figure 38. Depth of precipitation for 10-year storm for 5-day duration in Texas. 


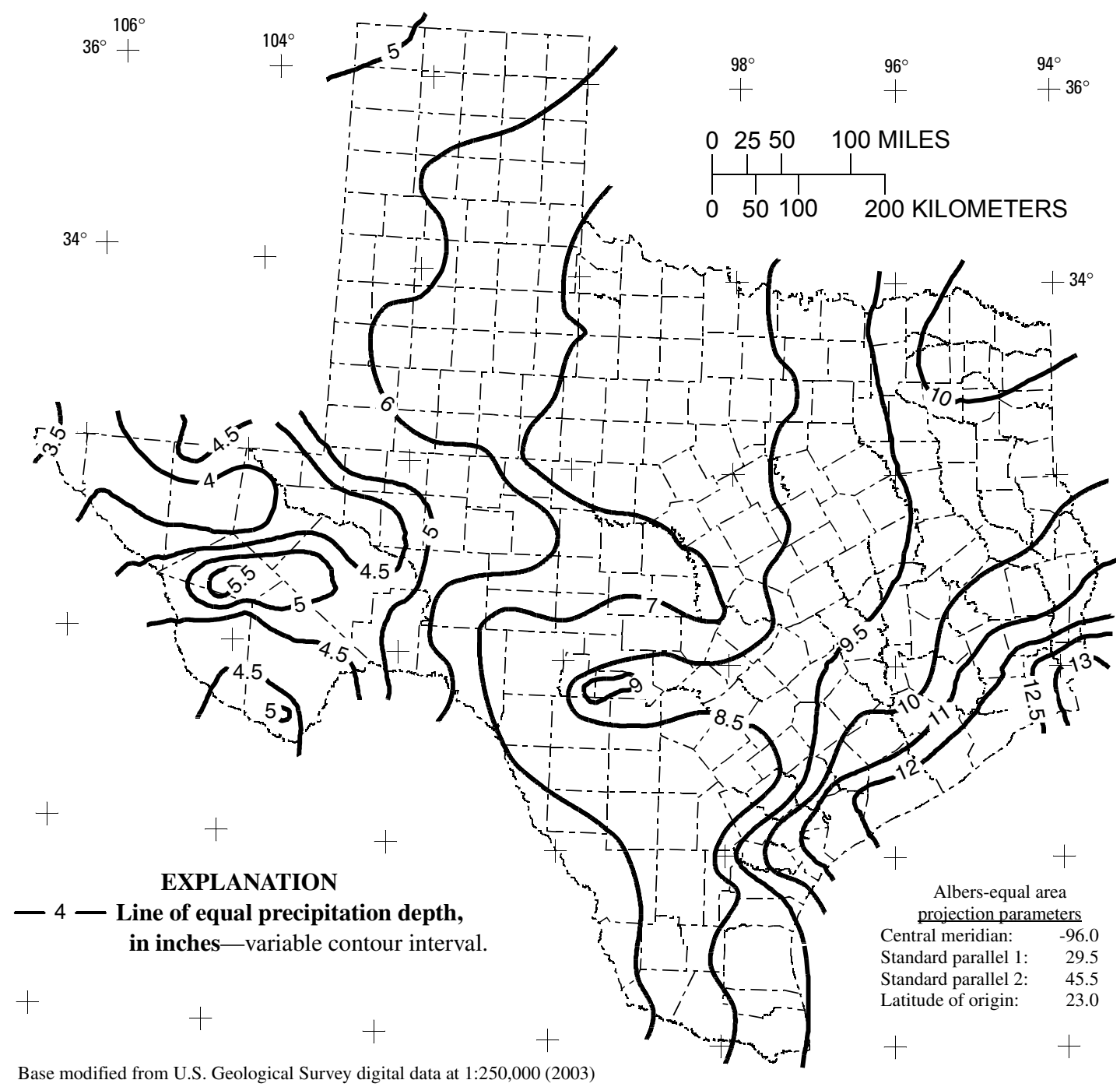

Figure 39. Depth of precipitation for 10-year storm for 7-day duration in Texas. 


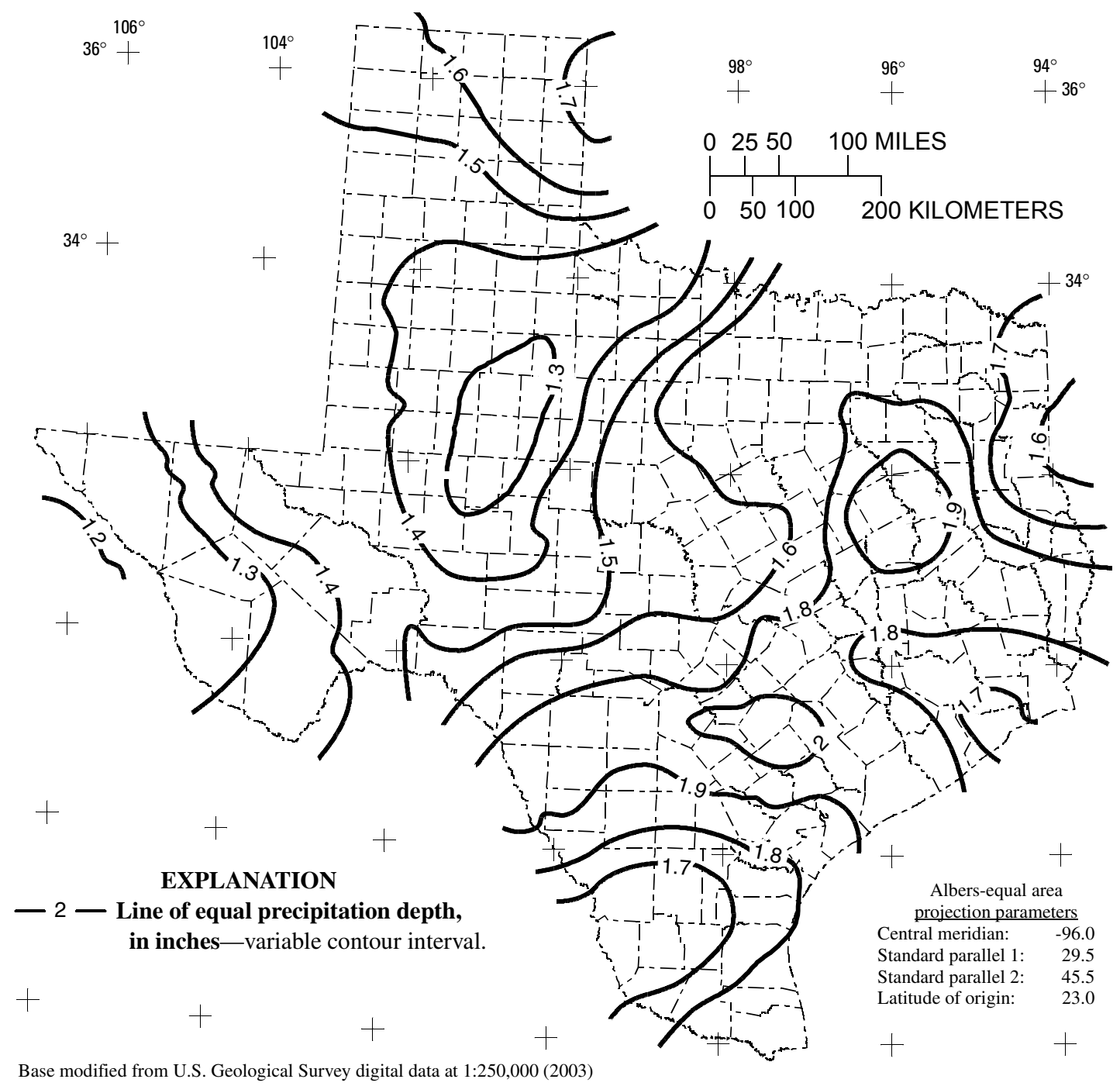

Figure 40. Depth of precipitation for 25-year storm for 15-minute duration in Texas. 


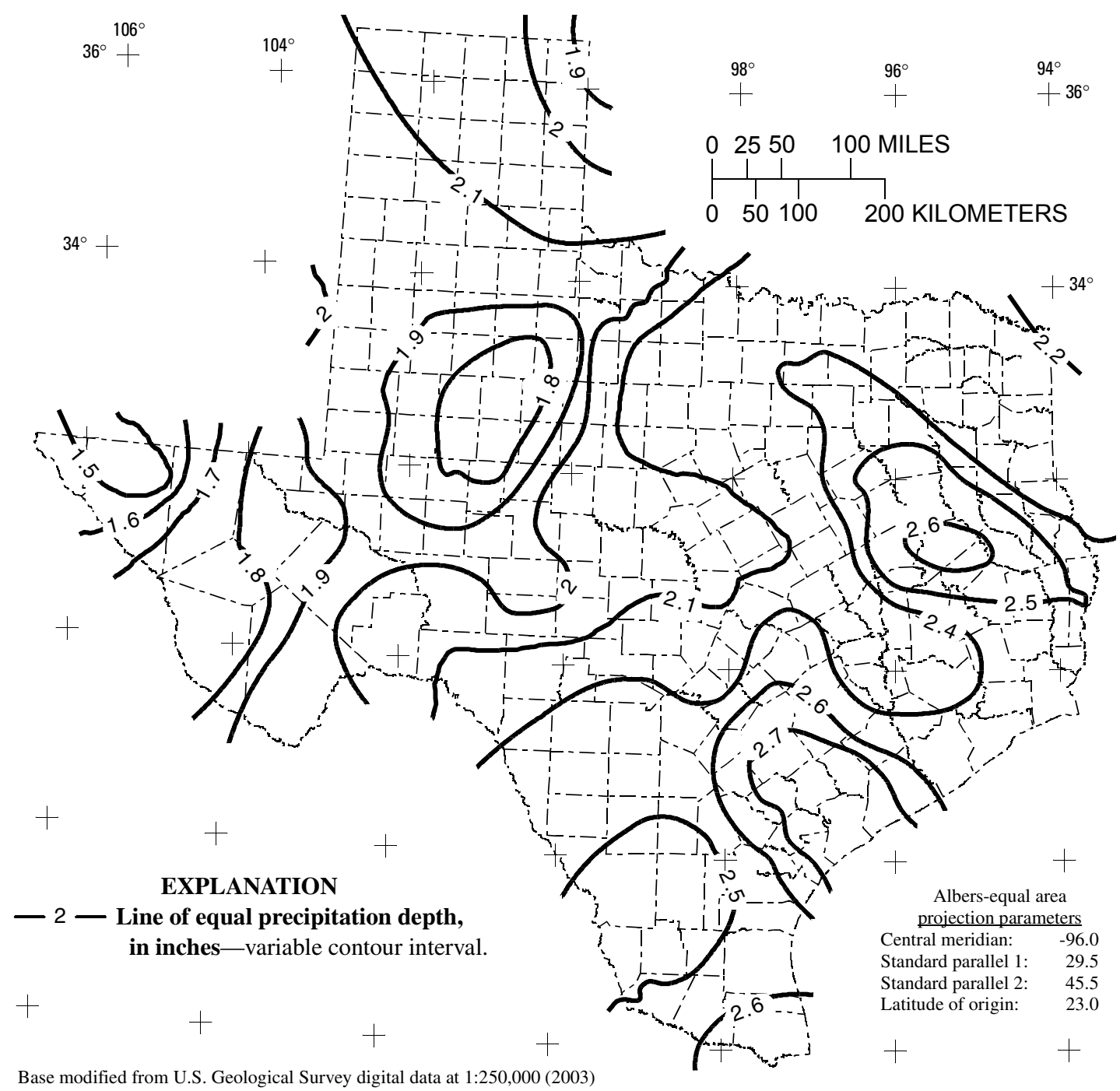

Figure 41. Depth of precipitation for 25-year storm for 30-minute duration in Texas. 


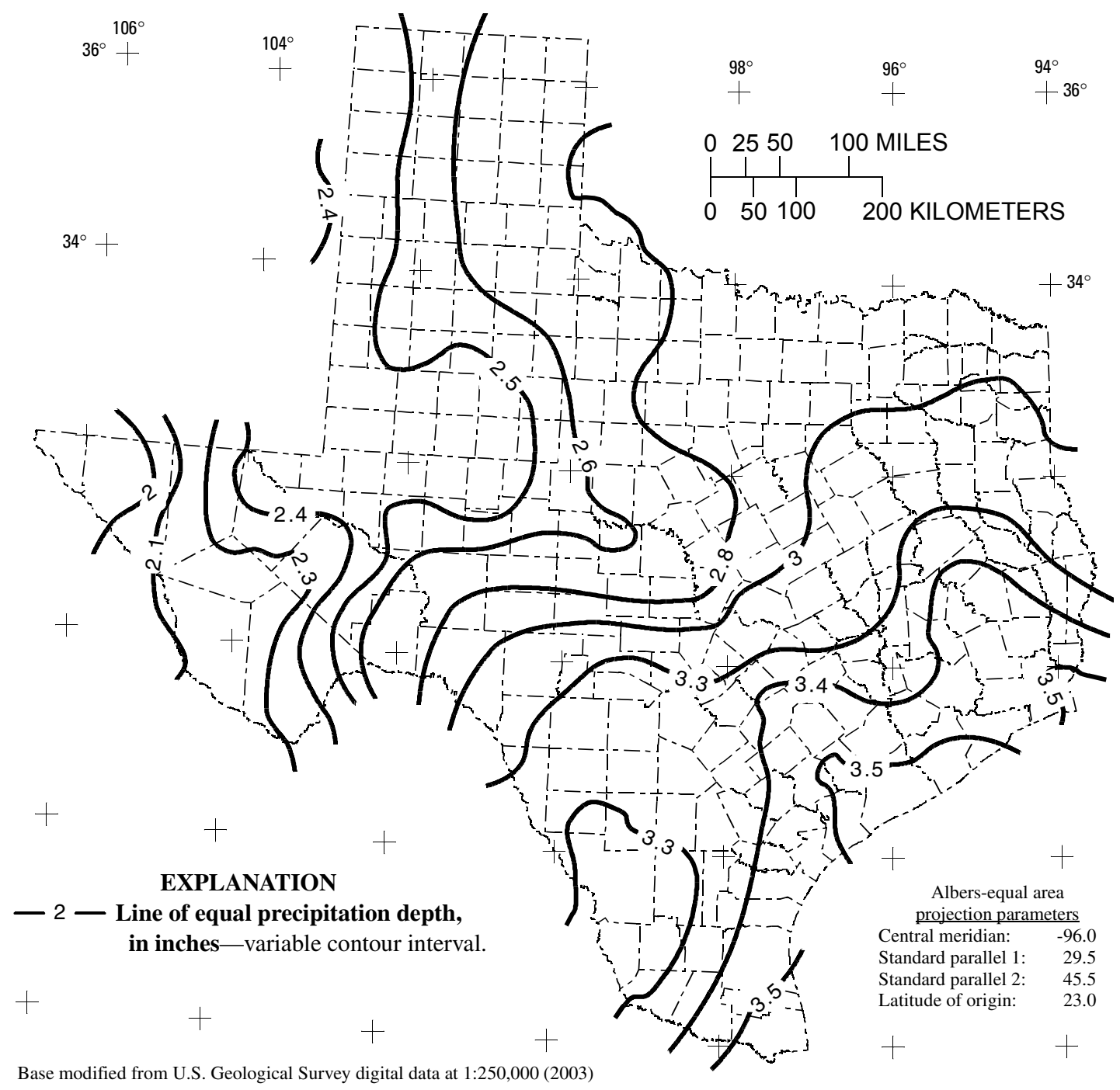

Figure 42. Depth of precipitation for 25-year storm for 1-hour duration in Texas. 


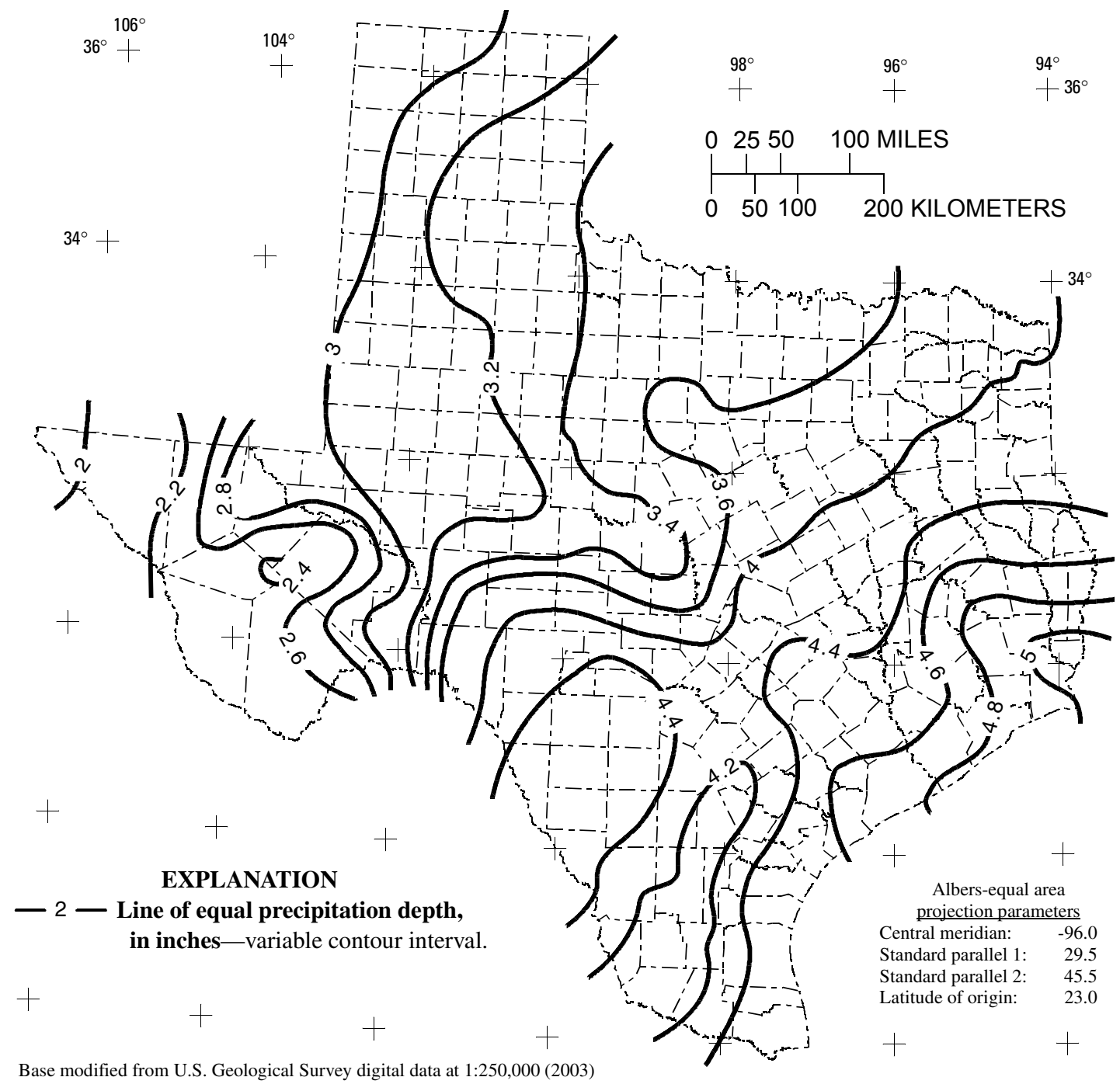

Figure 43. Depth of precipitation for 25-year storm for 2-hour duration in Texas. 


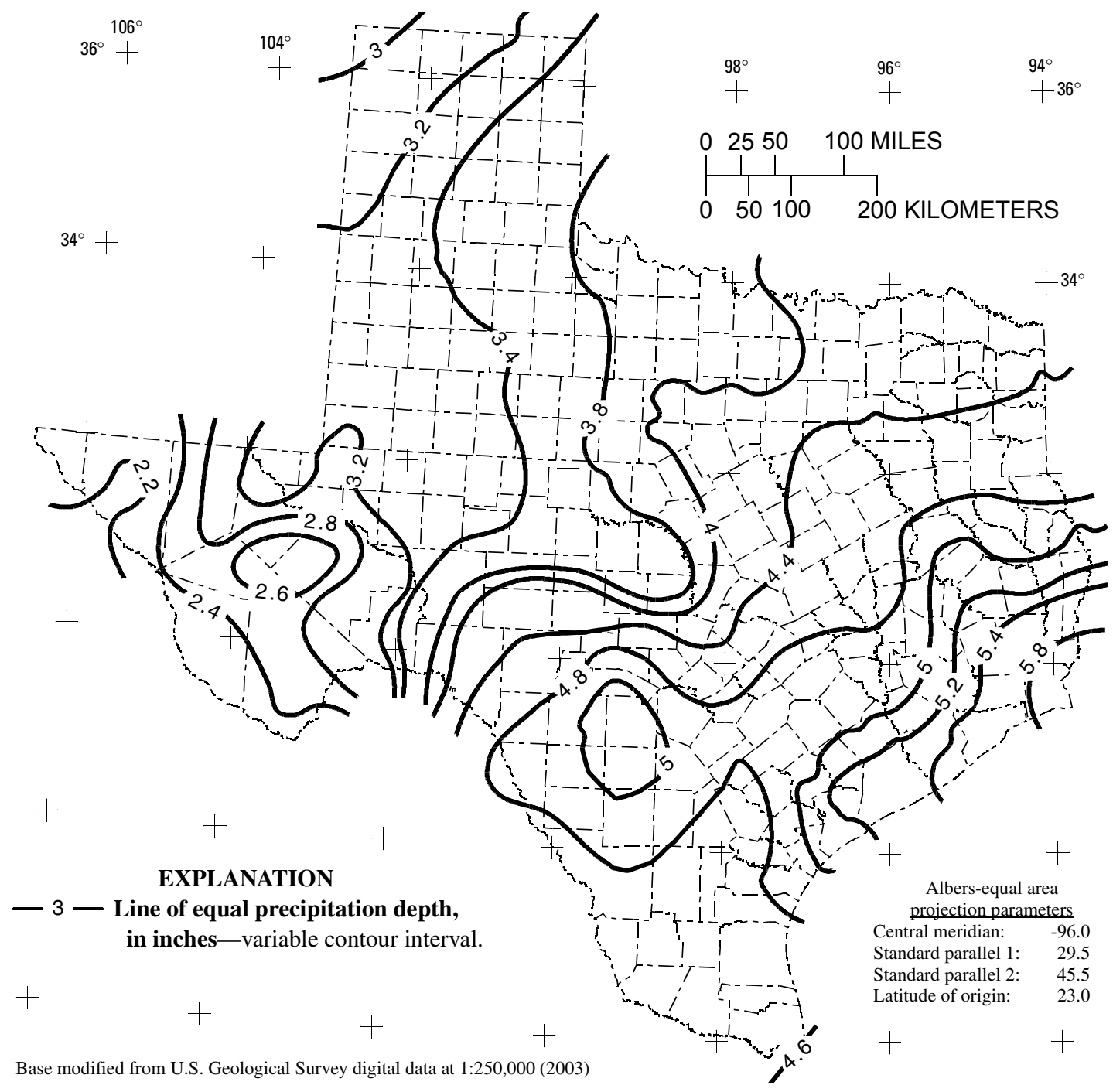

Figure 44. Depth of precipitation for 25-year storm for 3-hour duration in Texas. 


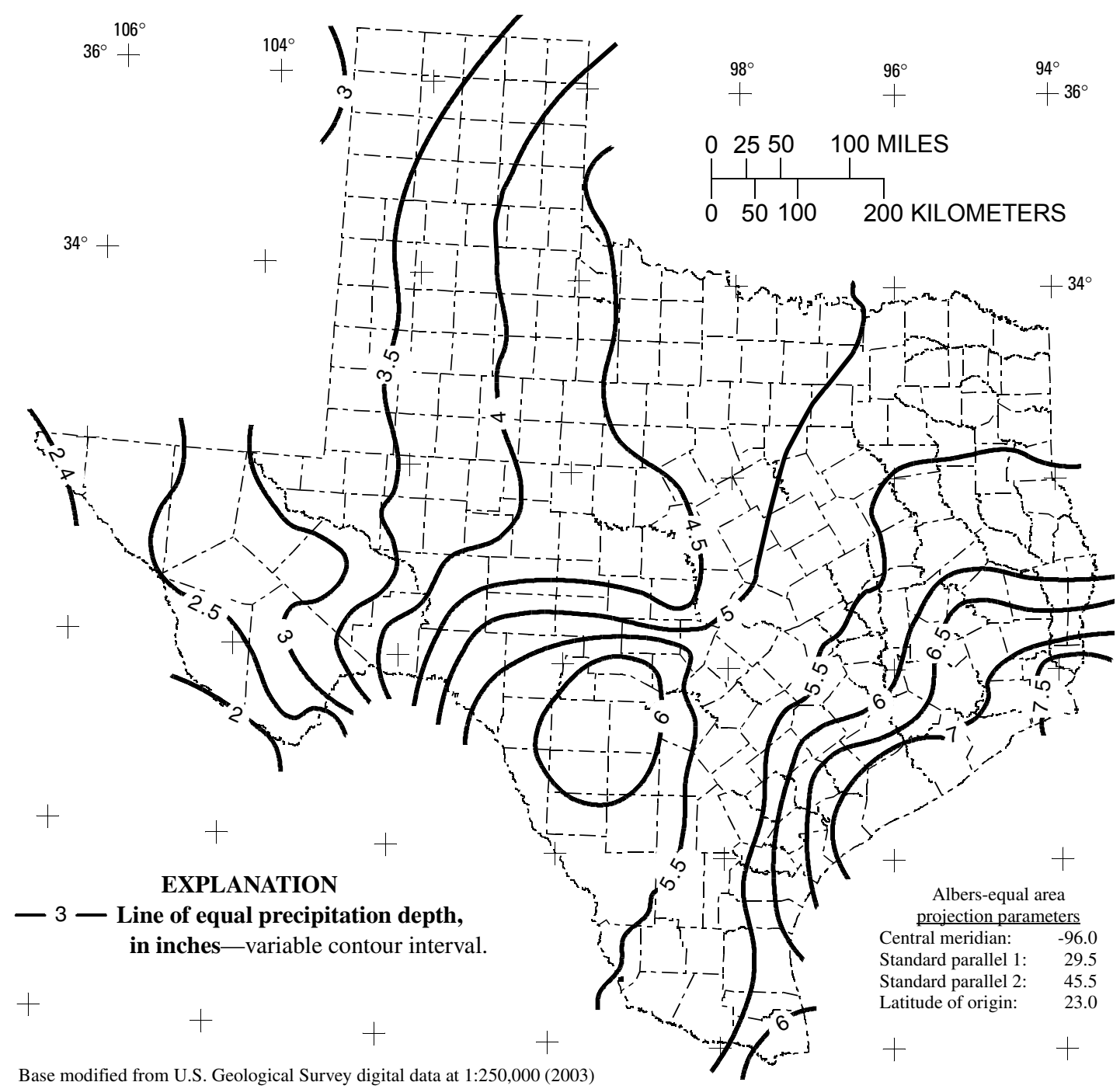

Figure 45. Depth of precipitation for 25-year storm for 6-hour duration in Texas. 


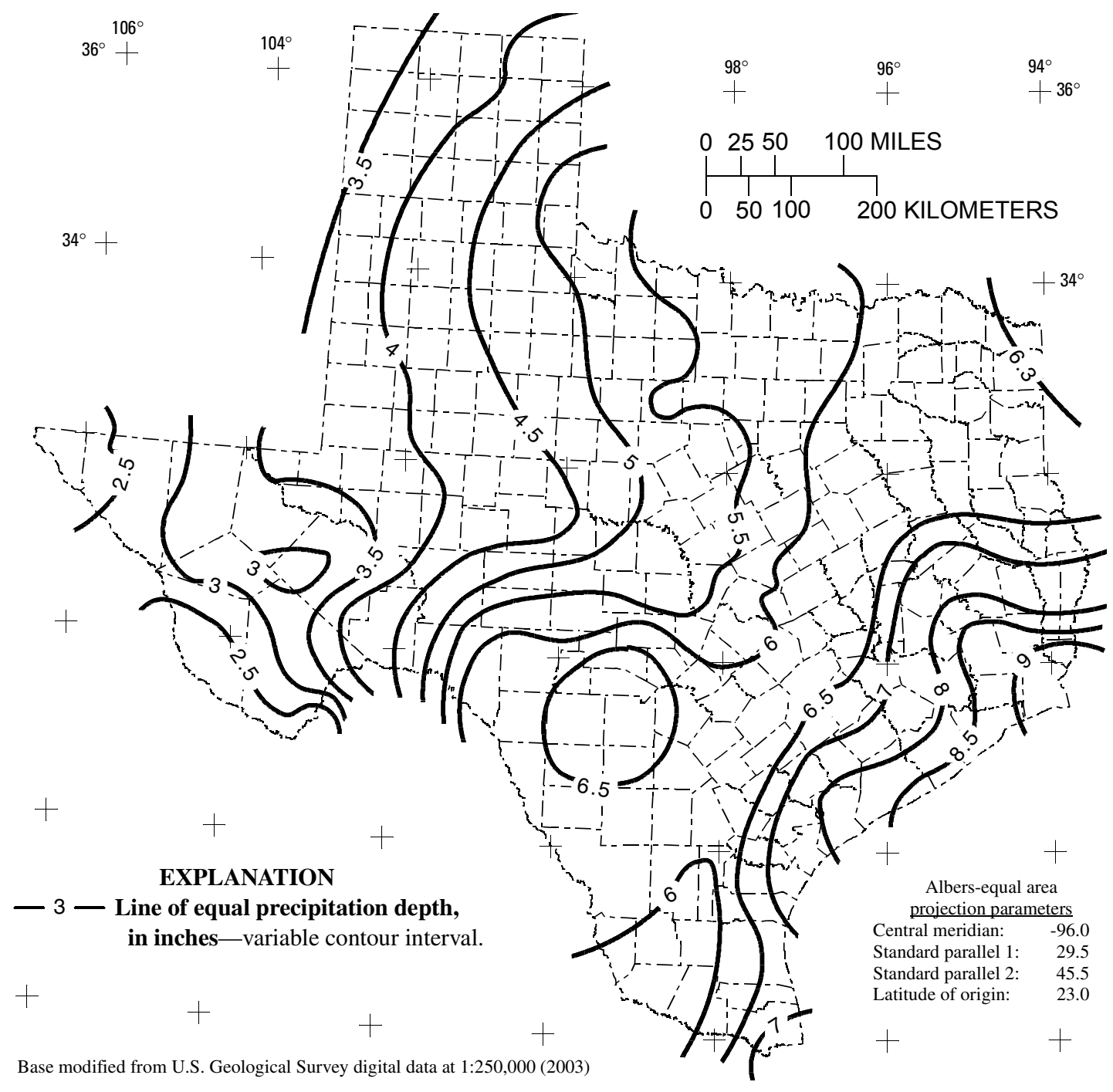

Figure 46. Depth of precipitation for 25-year storm for 12-hour duration in Texas. 


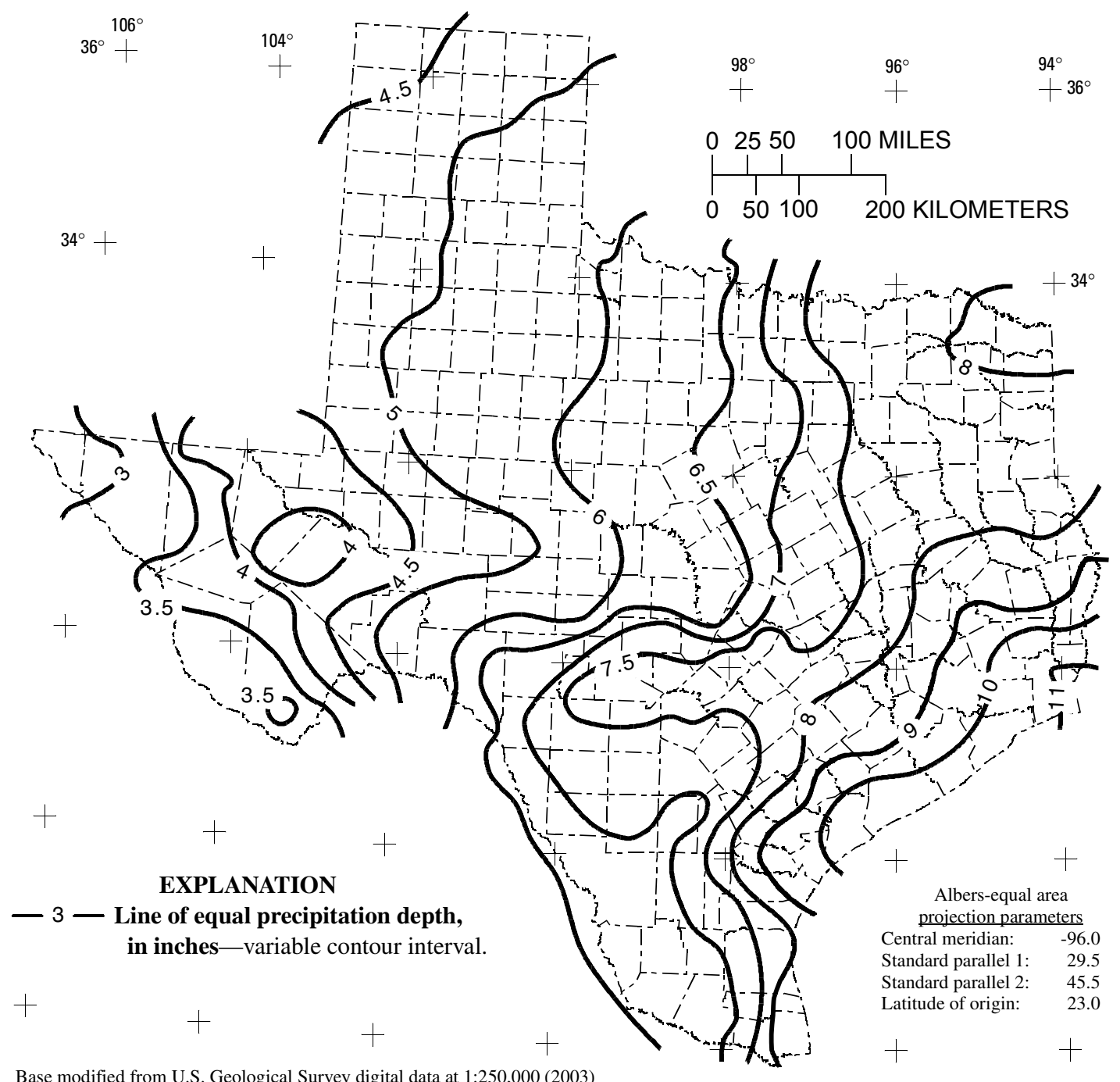

Figure 47. Depth of precipitation for 25-year storm for 1-day duration in Texas. 


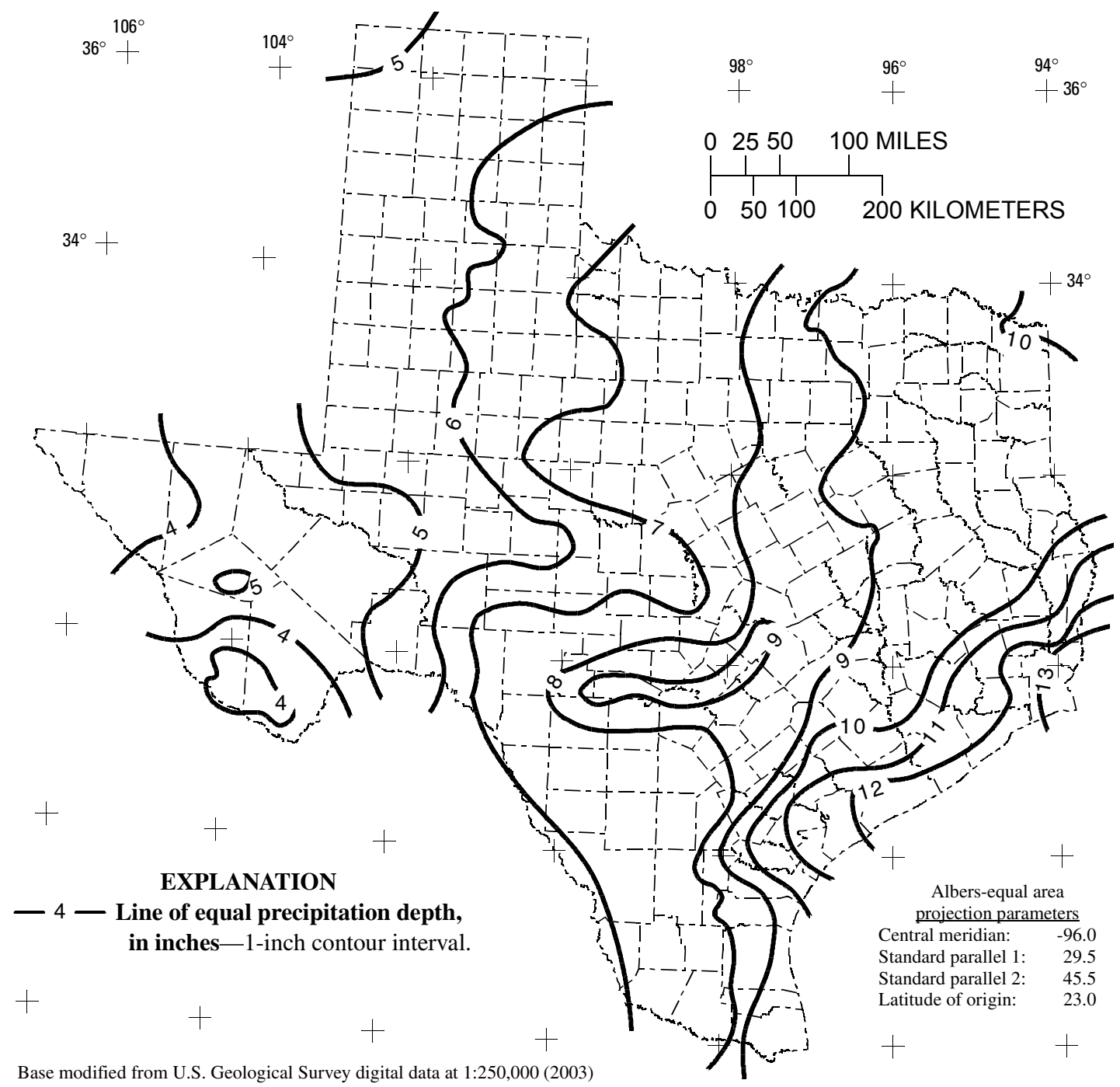

Figure 48. Depth of precipitation for 25-year storm for 2-day duration in Texas. 


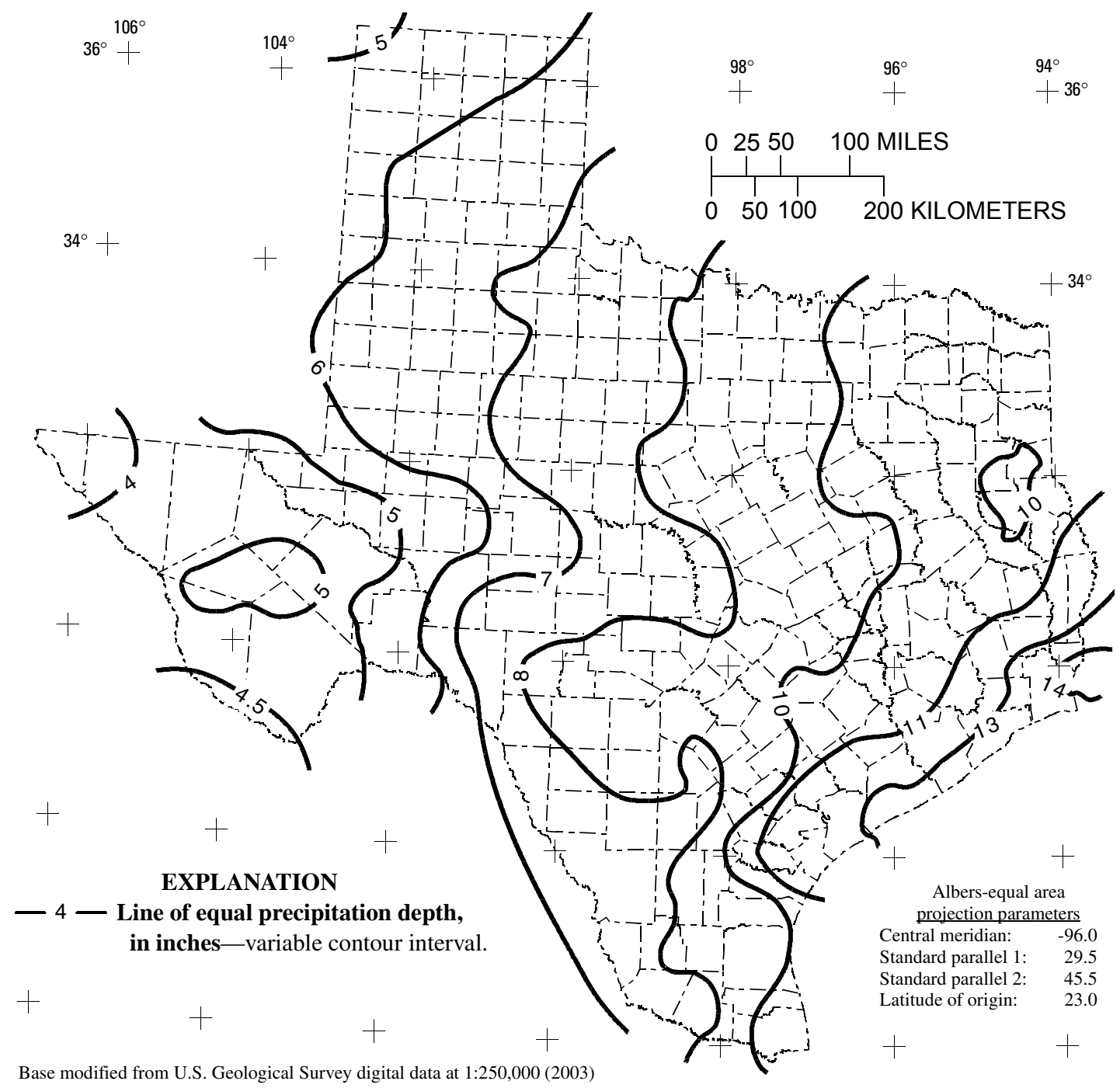

Figure 49. Depth of precipitation for 25-year storm for 3-day duration in Texas. 


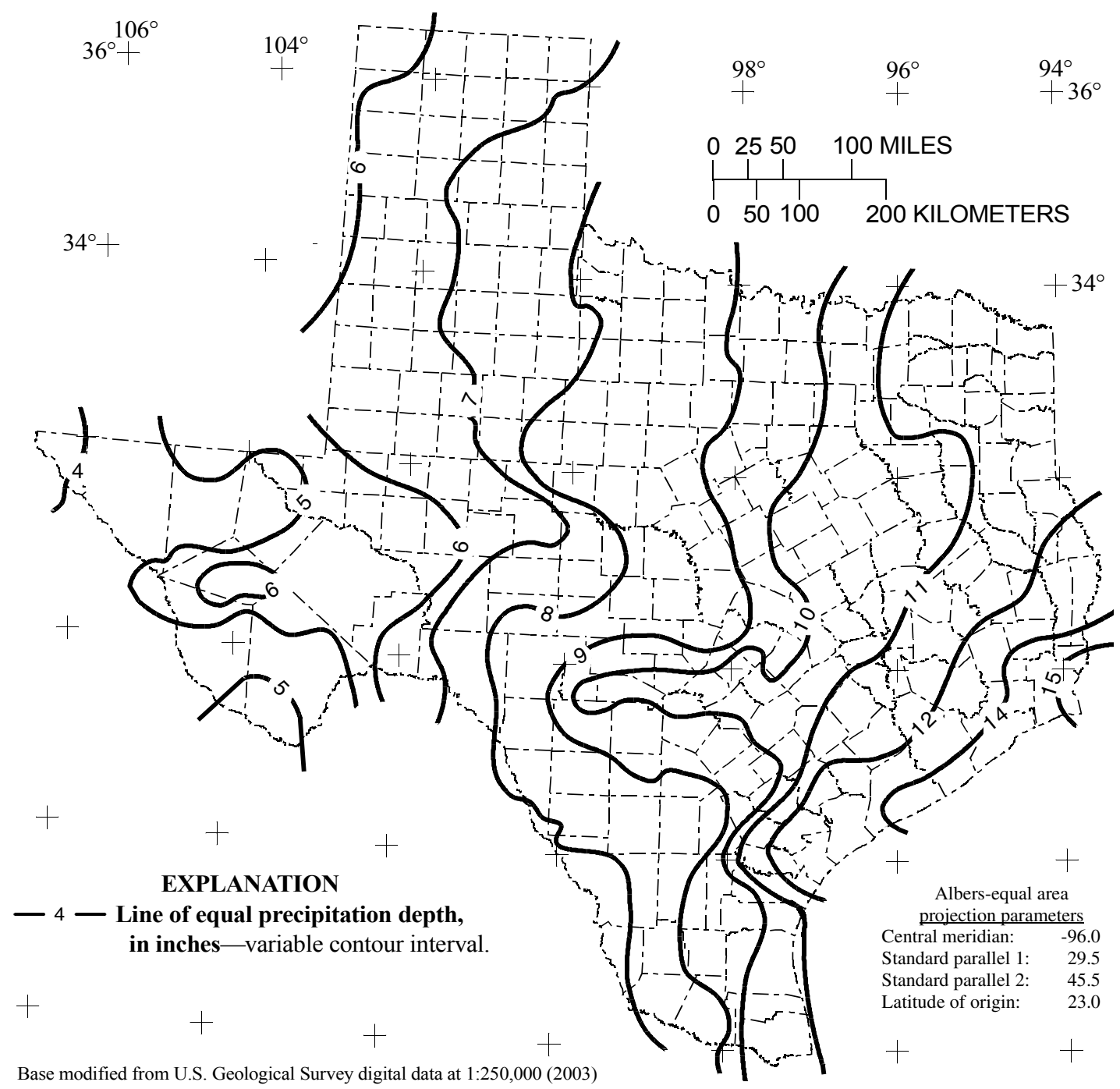

Figure 50. Depth of precipitation for 25-year storm for 5-day duration in Texas. 


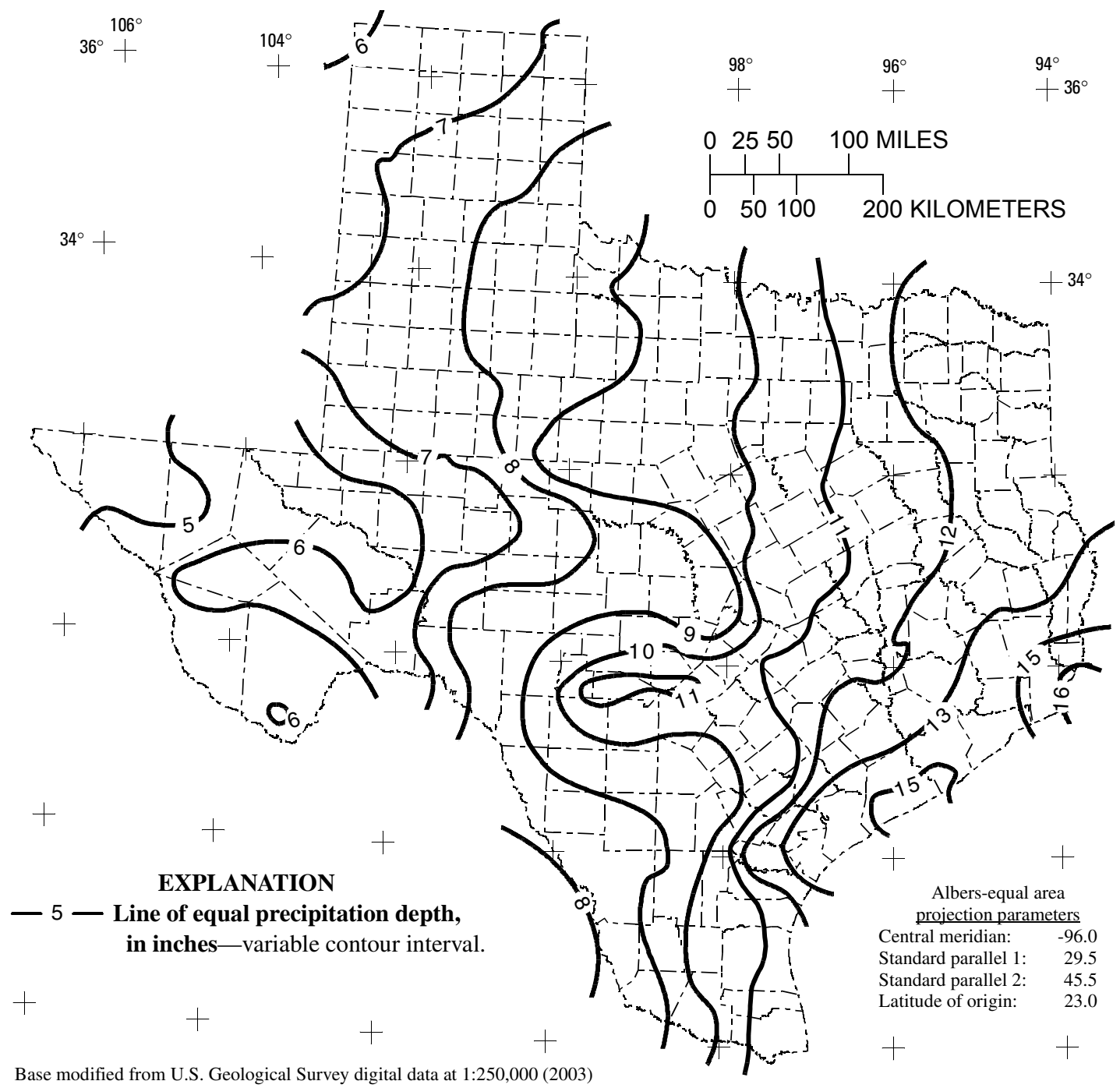

Figure 51. Depth of precipitation for 25-year storm for 7-day duration in Texas. 


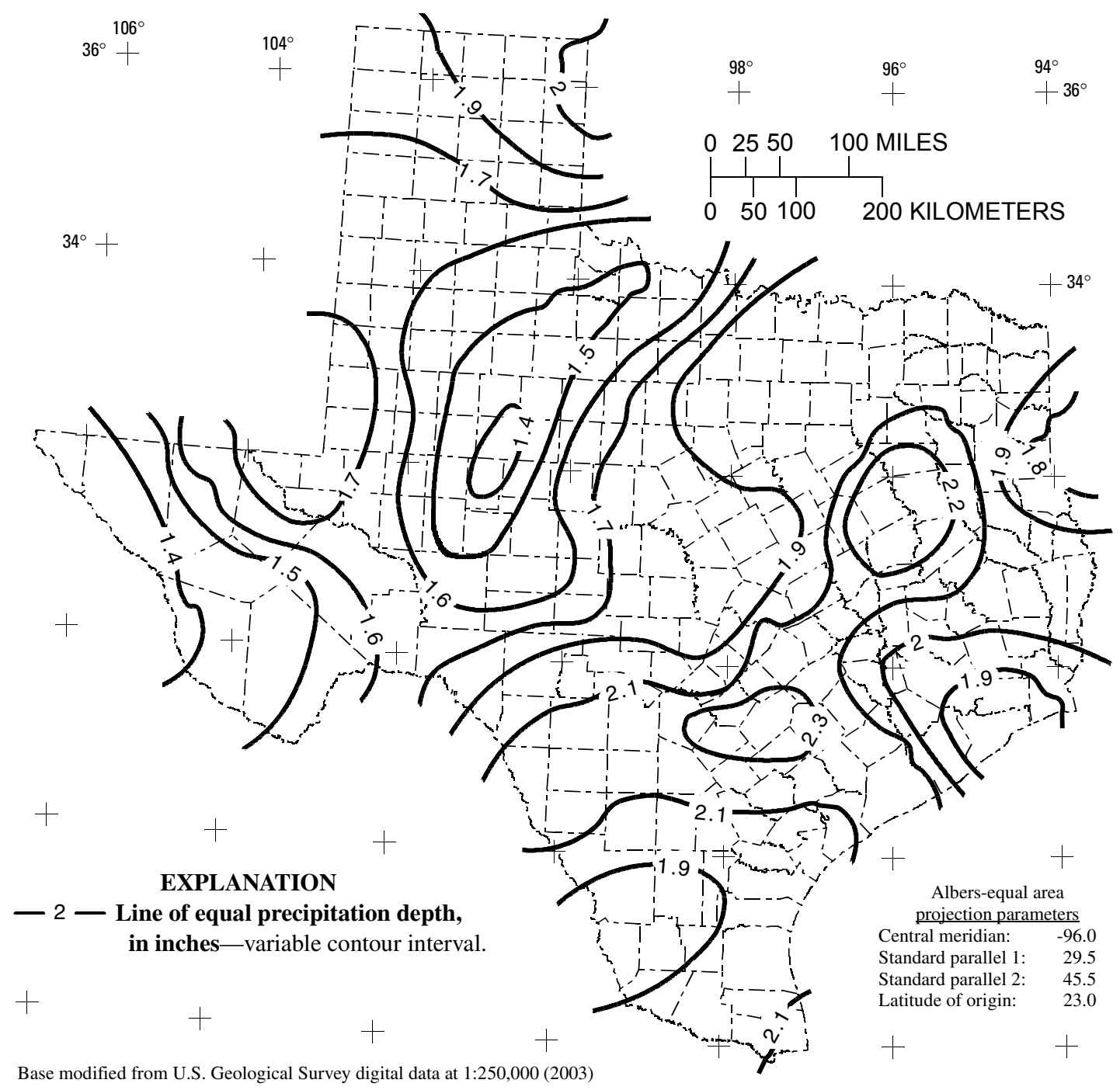

Figure 52. Depth of precipitation for 50-year storm for 15-minute duration in Texas. 


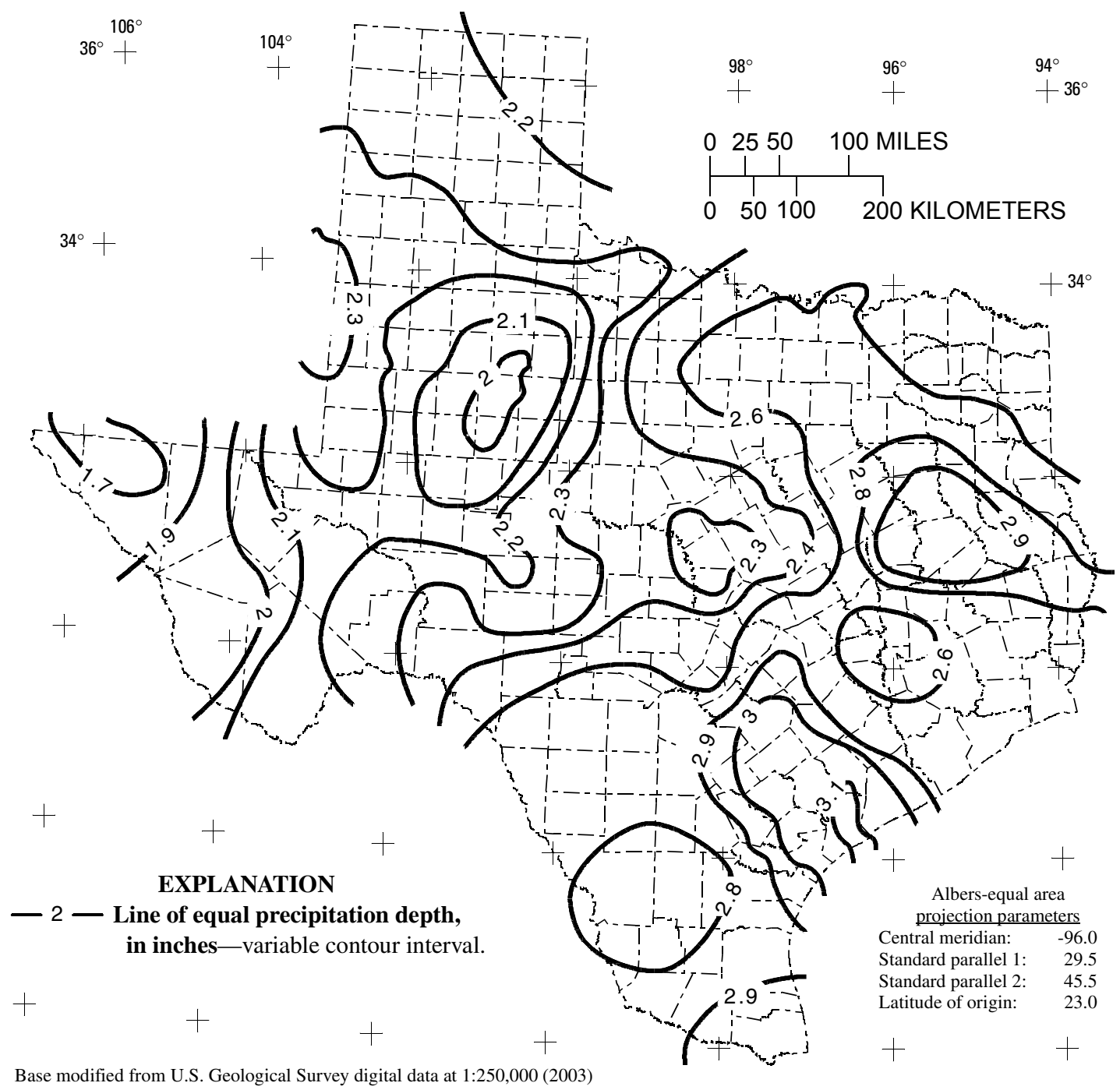

Figure 53. Depth of precipitation for 50-year storm for 30-minute duration in Texas. 


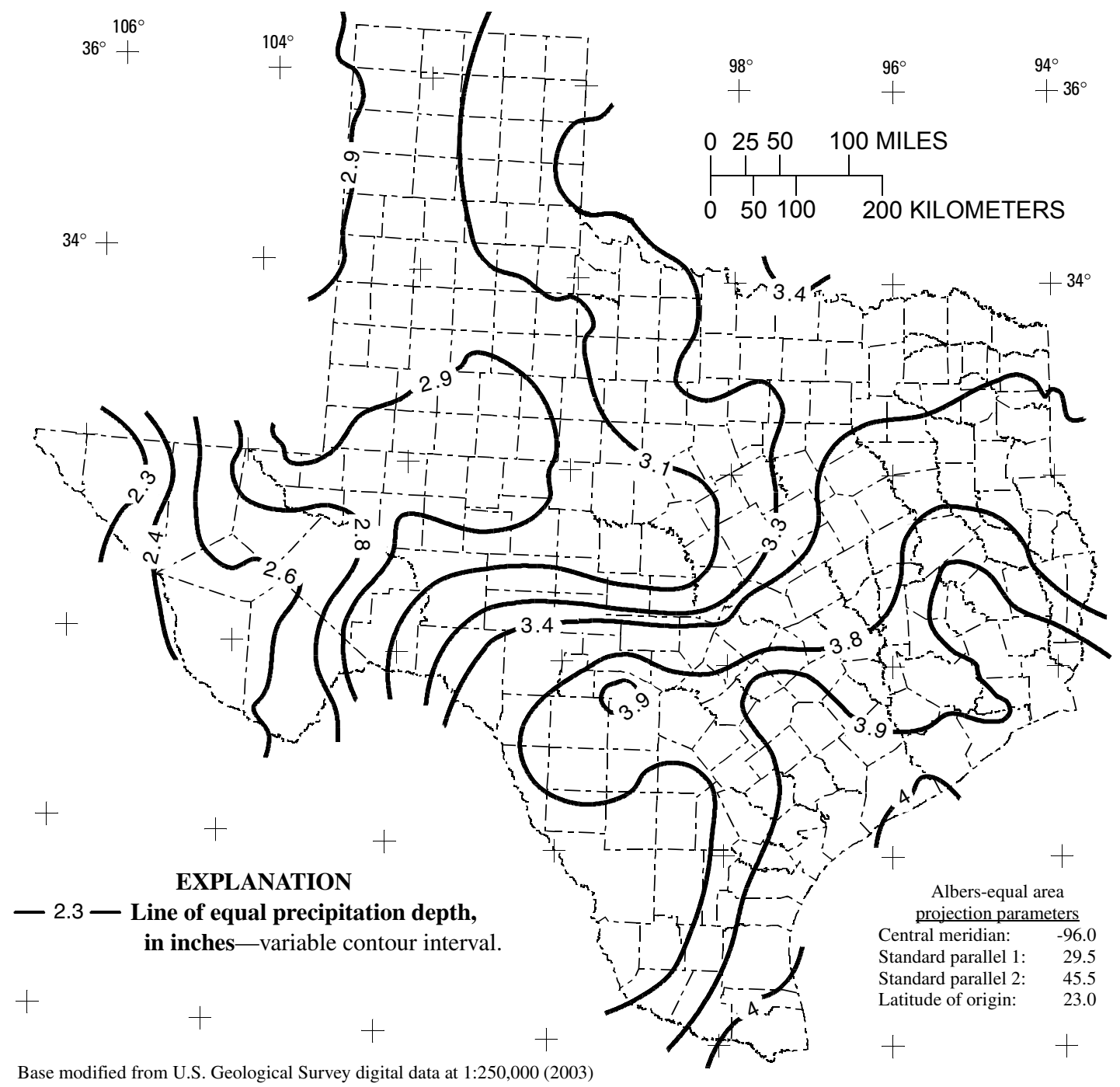

Figure 54. Depth of precipitation for 50-year storm for 1-hour duration in Texas. 


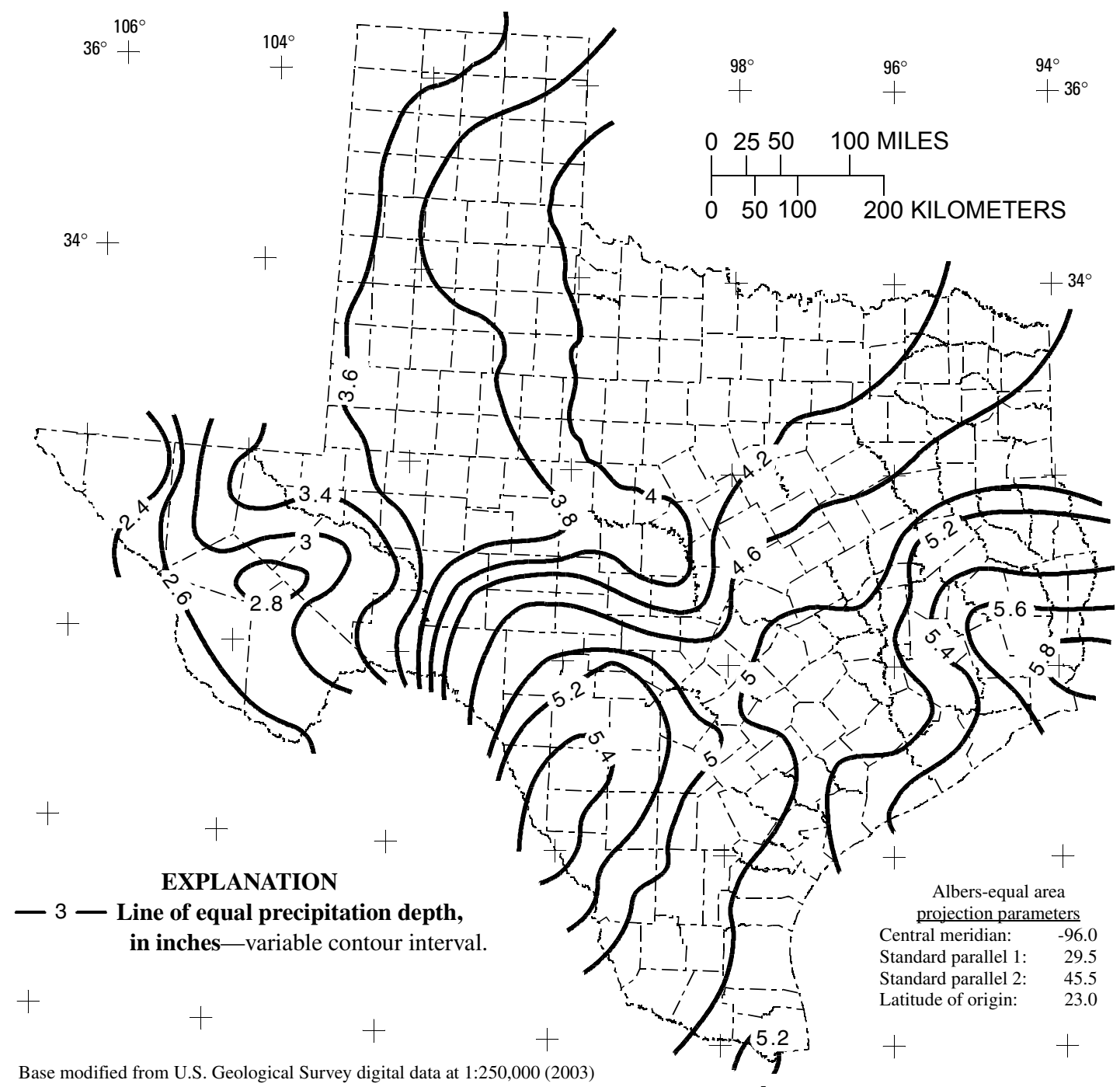

Figure 55. Depth of precipitation for 50-year storm for 2-hour duration in Texas. 


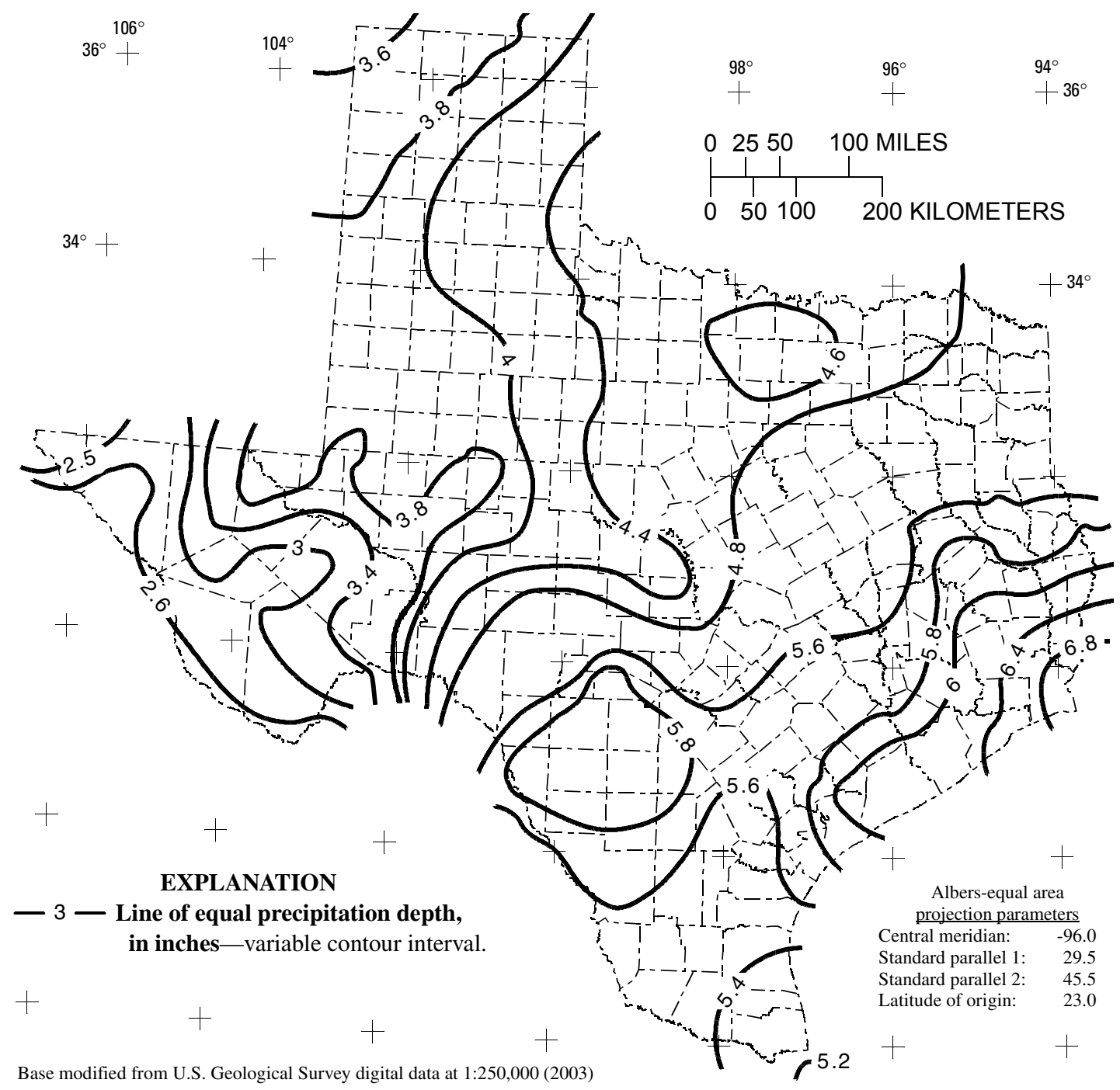

Figure 56. Depth of precipitation for 50-year storm for 3-hour duration in Texas. 


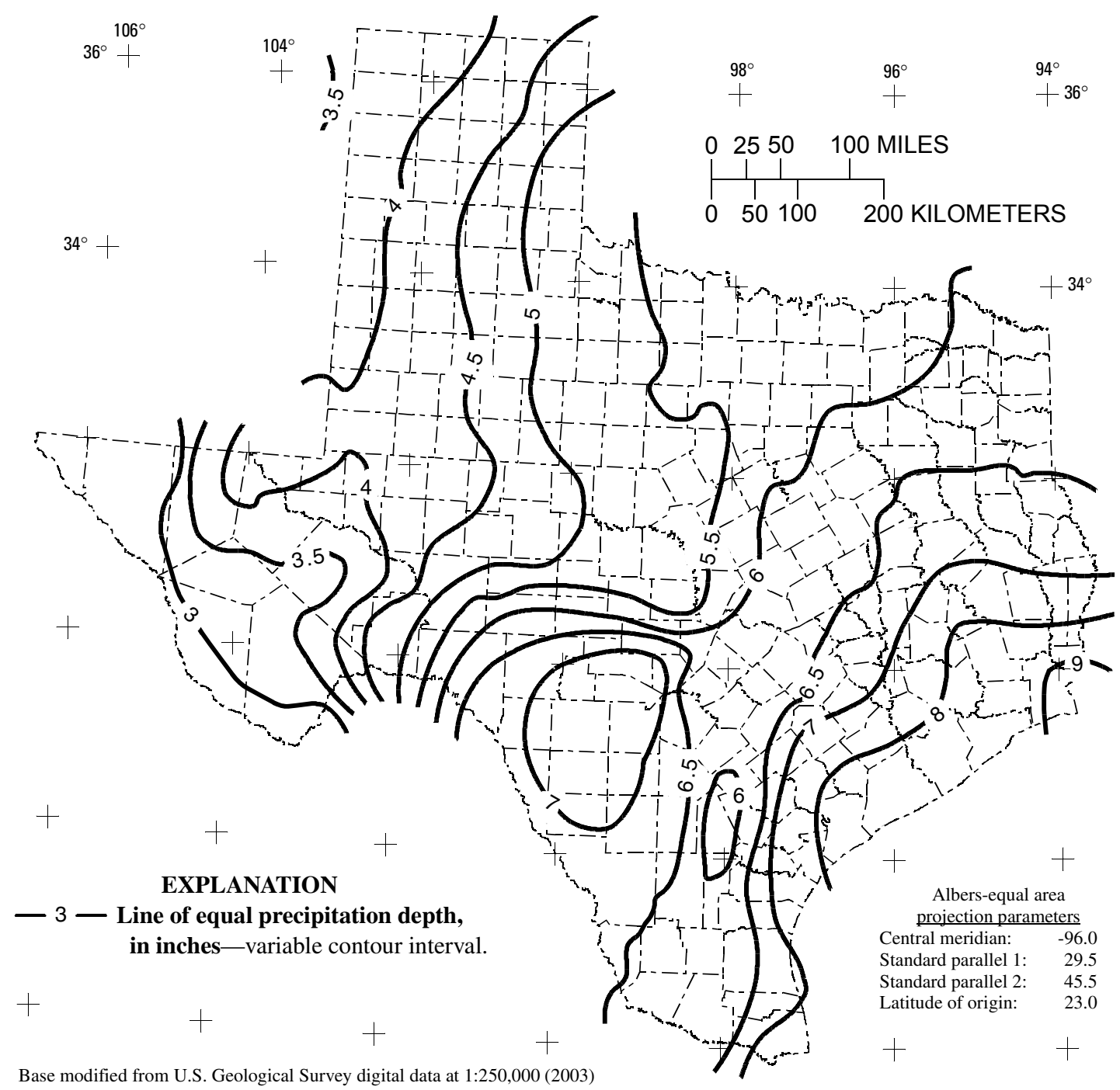

Figure 57. Depth of precipitation for 50-year storm for 6-hour duration in Texas. 


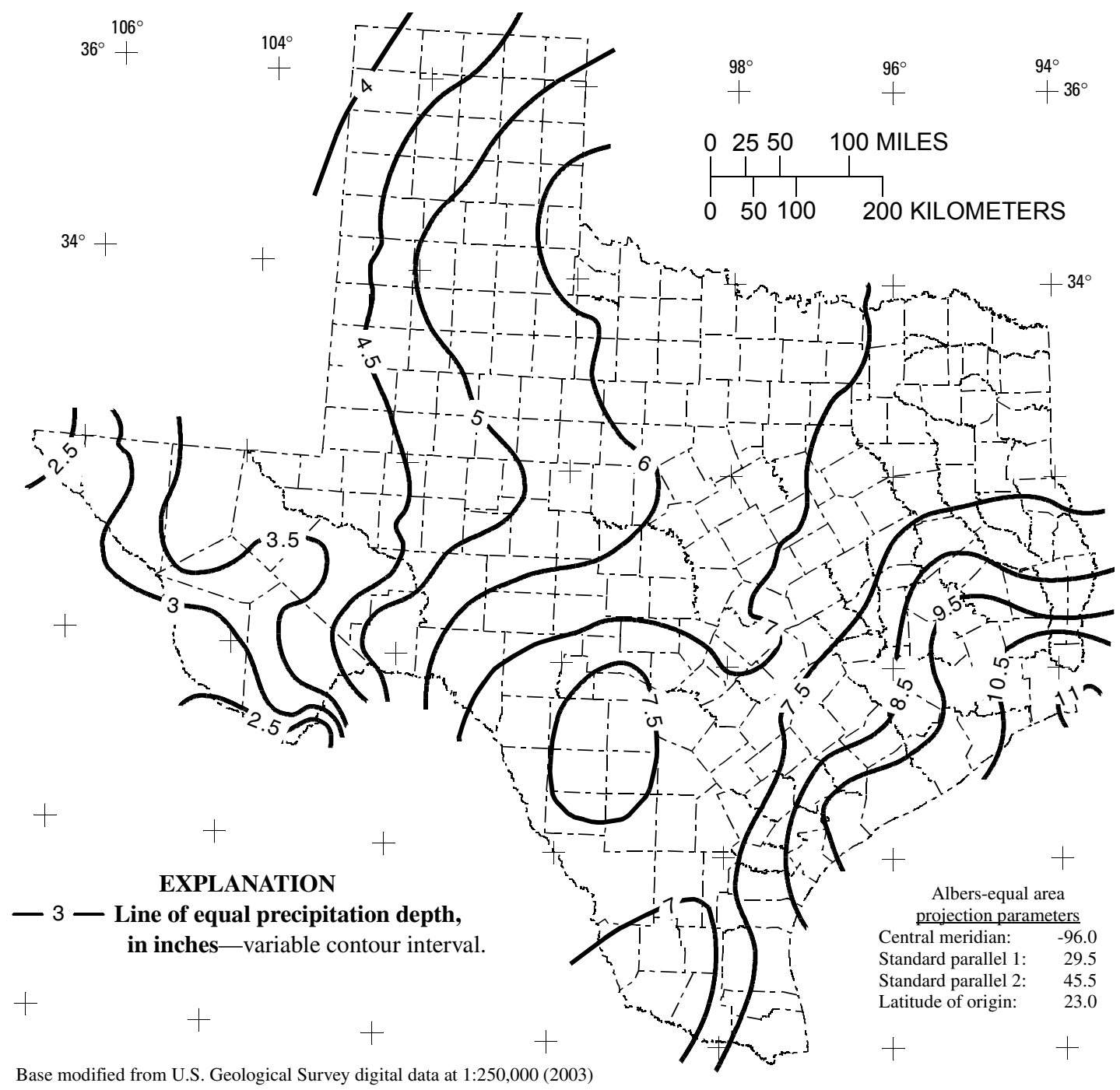

Figure 58. Depth of precipitation for 50-year storm for 12-hour duration in Texas. 


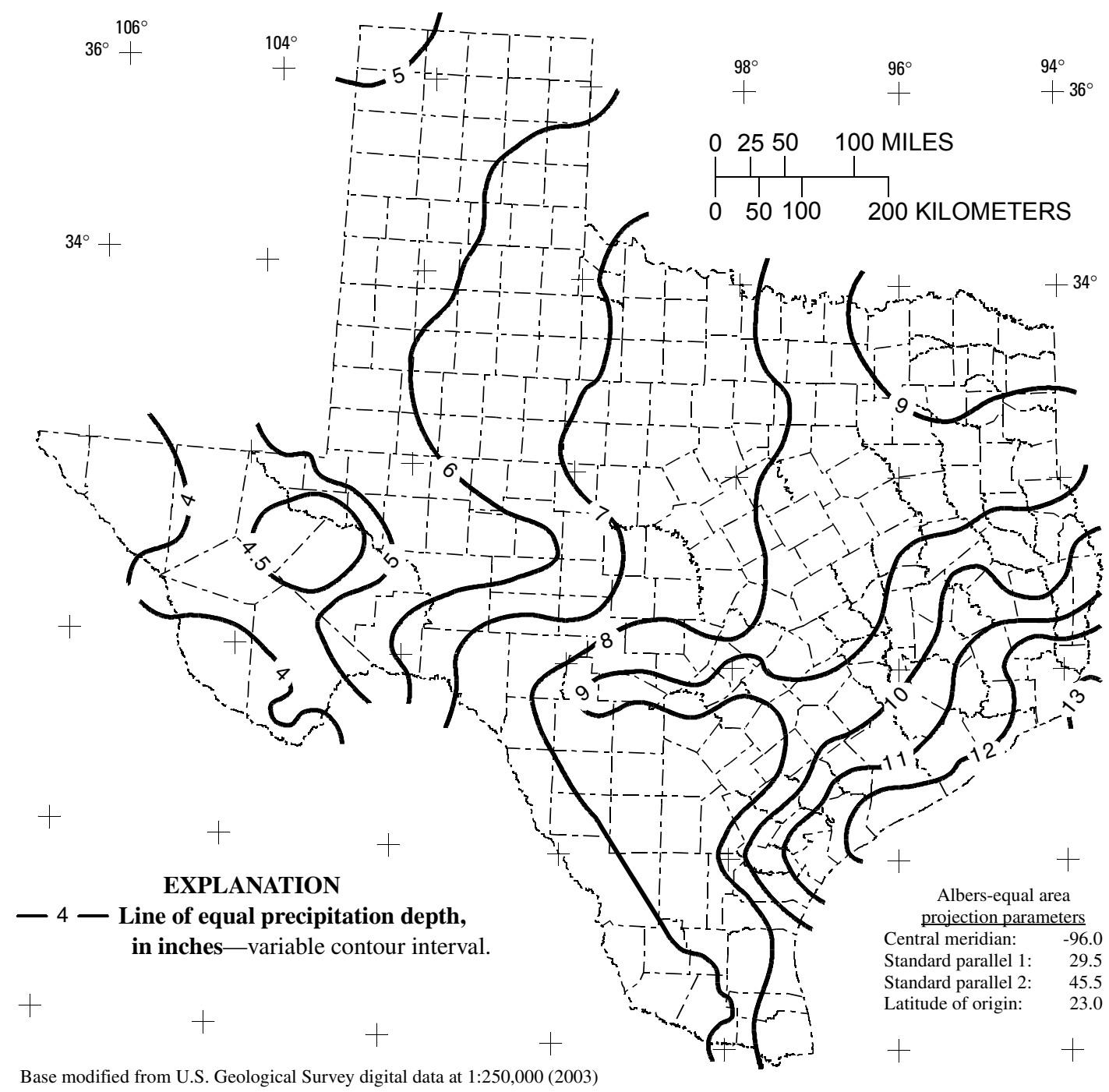

Figure 59. Depth of precipitation for 50-year storm for 1-day duration in Texas. 


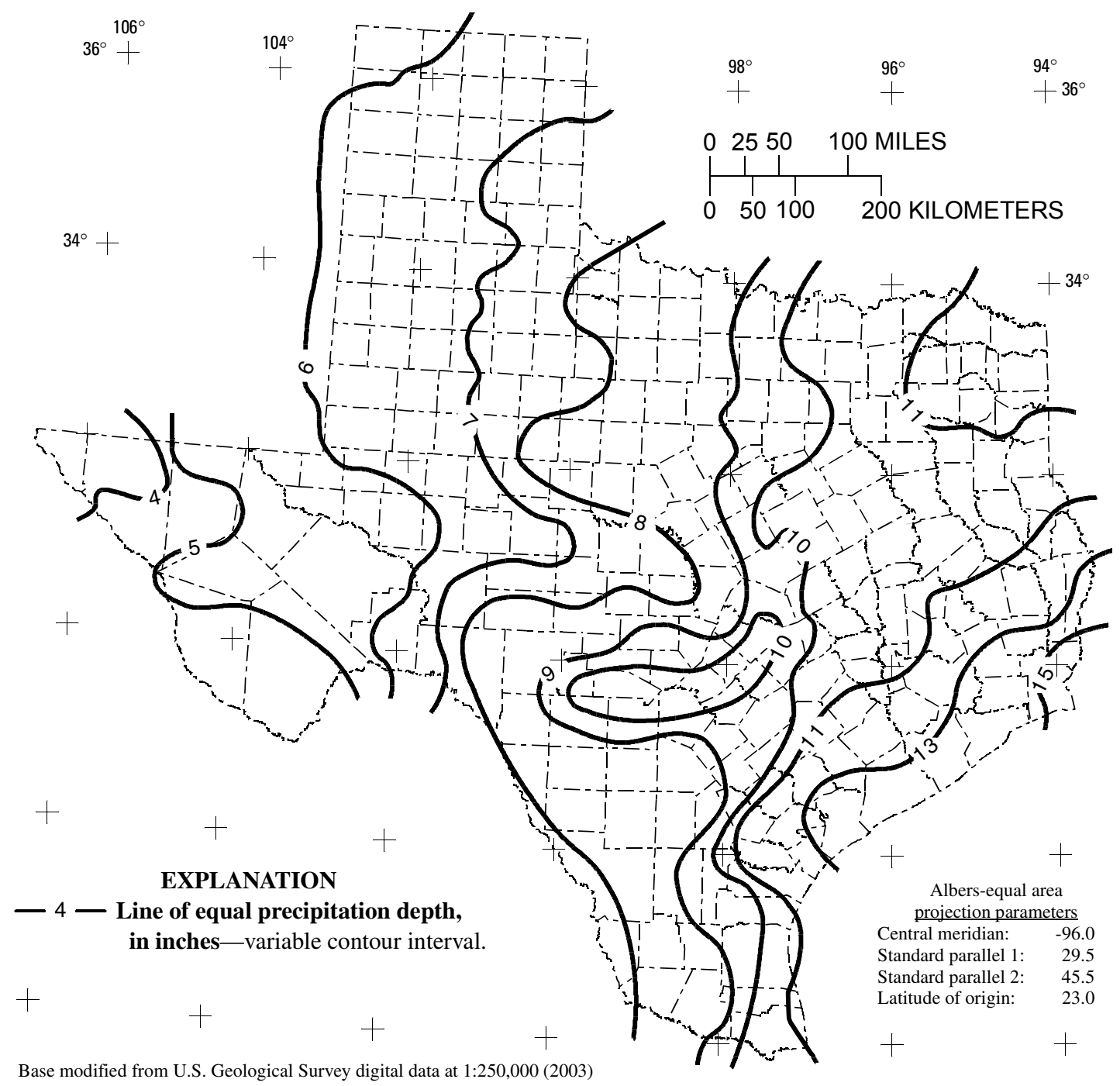

Figure 60. Depth of precipitation for 50-year storm for 2-day duration in Texas. 


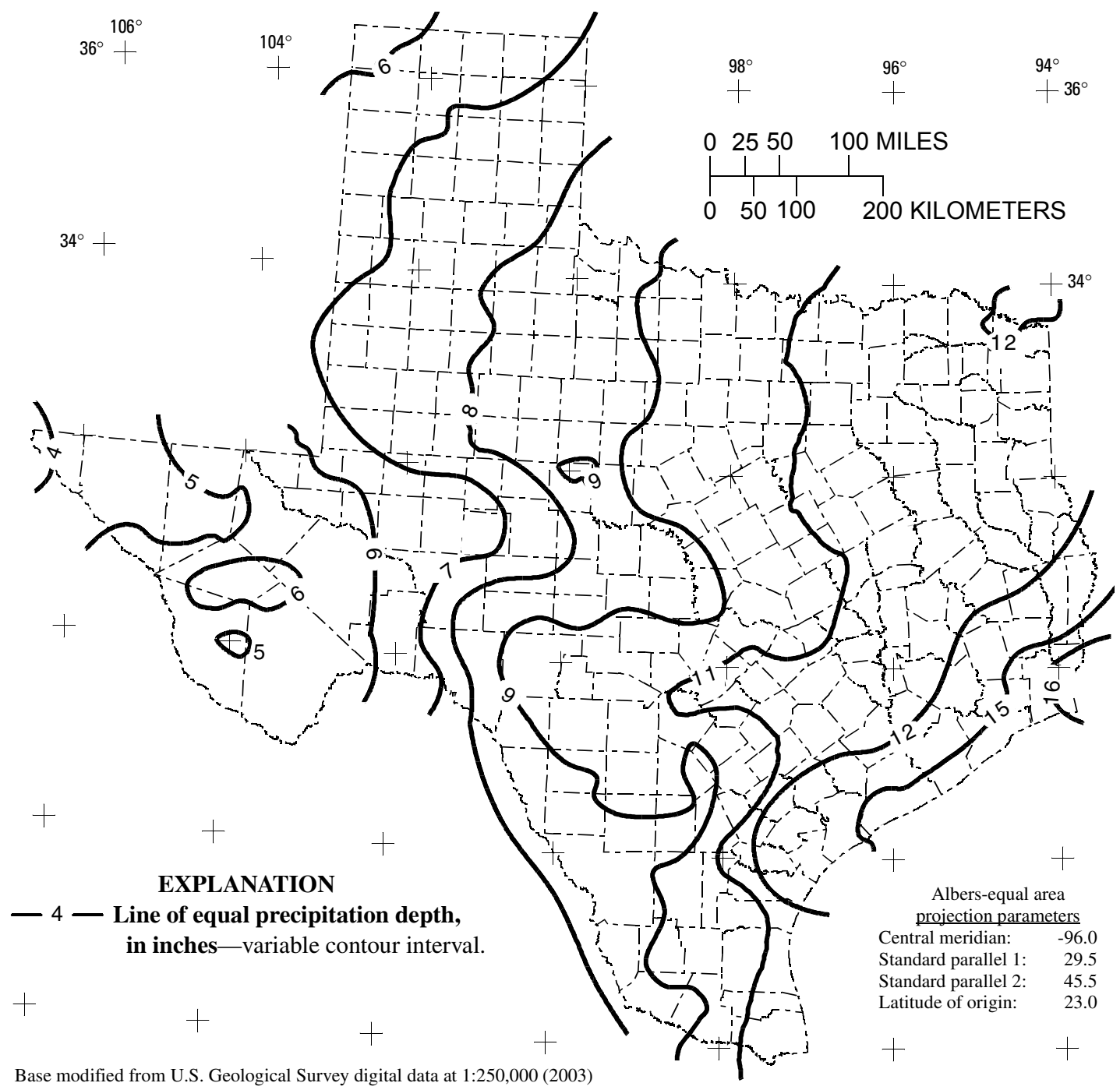

Figure 61. Depth of precipitation for 50-year storm for 3-day duration in Texas. 


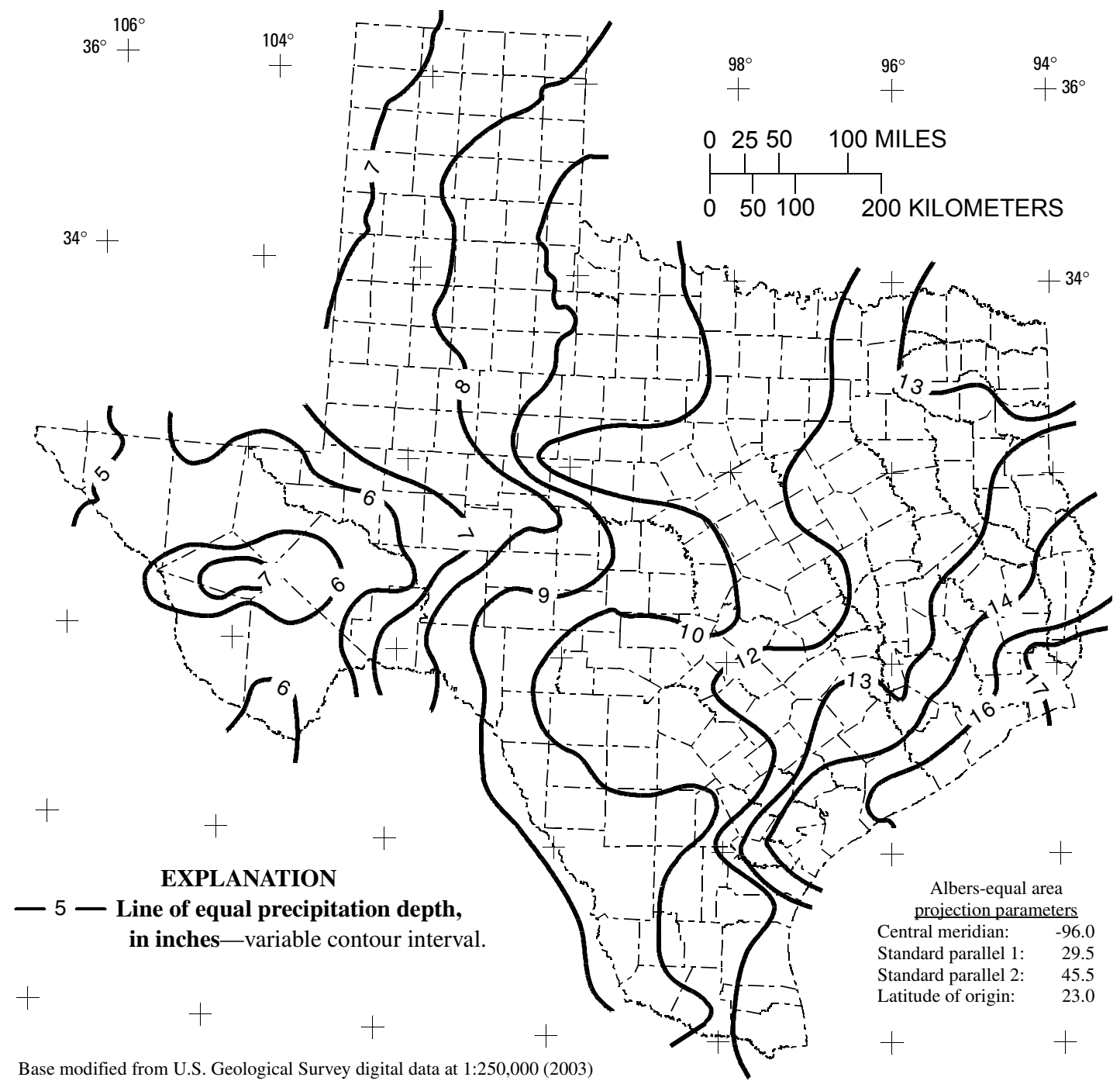

Figure 62. Depth of precipitation for 50-year storm for 5-day duration in Texas. 


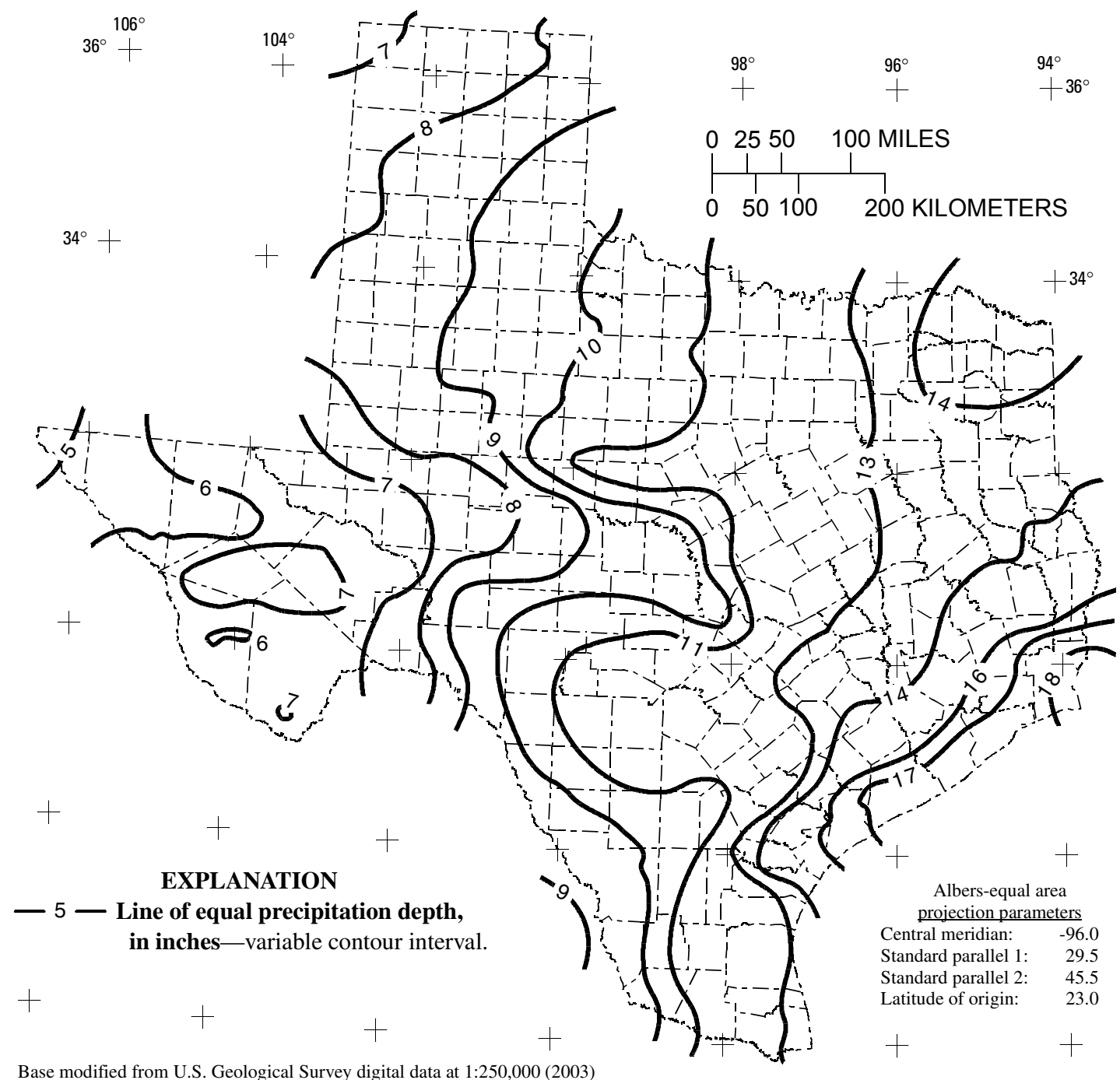

Figure 63. Depth of precipitation for 50-year storm for 7-day duration in Texas. 


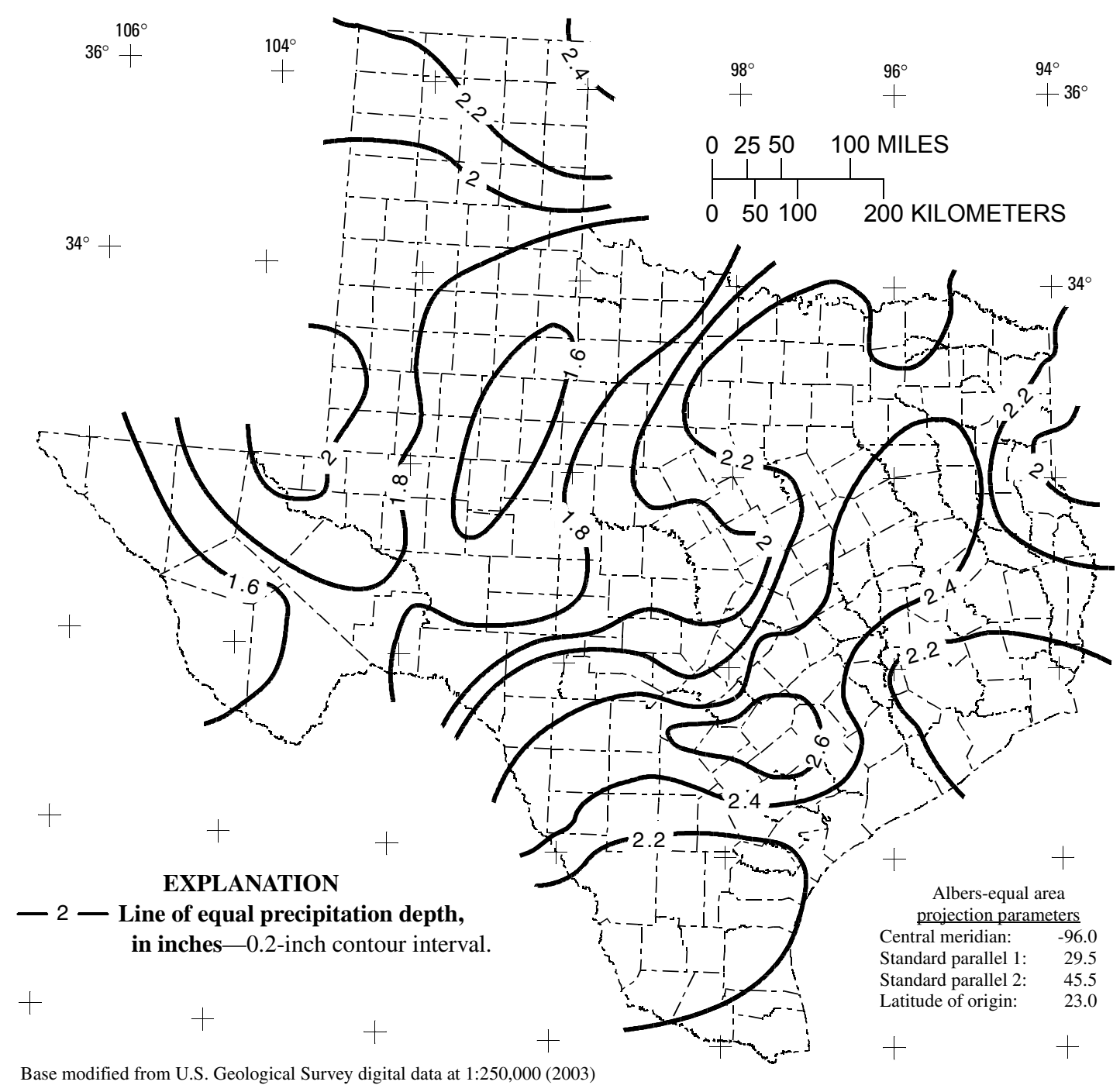

Figure 64. Depth of precipitation for 100-year storm for 15-minute duration in Texas. 


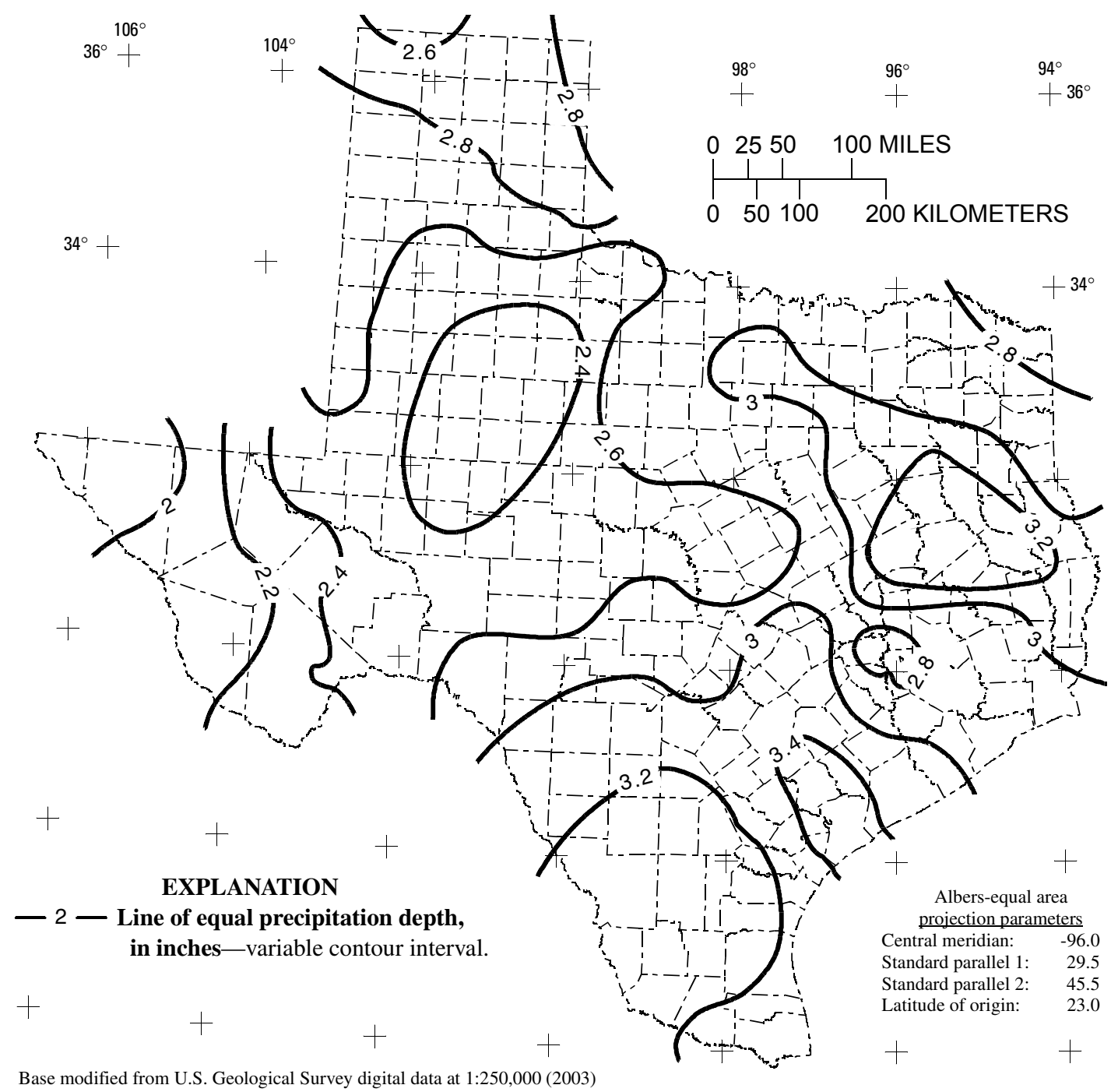

Figure 65. Depth of precipitation for 100-year storm for 30-minute duration in Texas. 


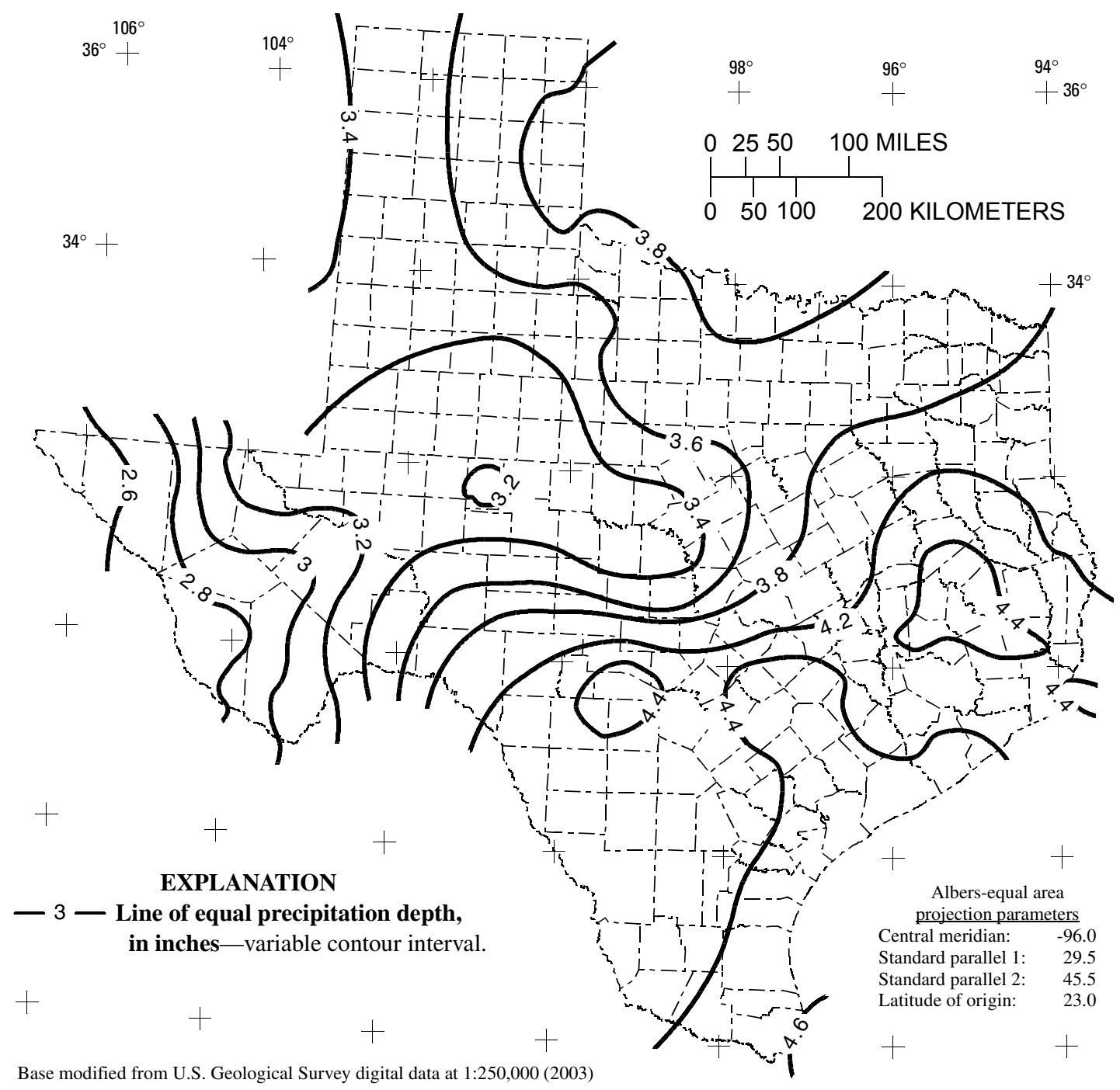

Figure 66. Depth of precipitation for 100-year storm for 1-hour duration in Texas. 


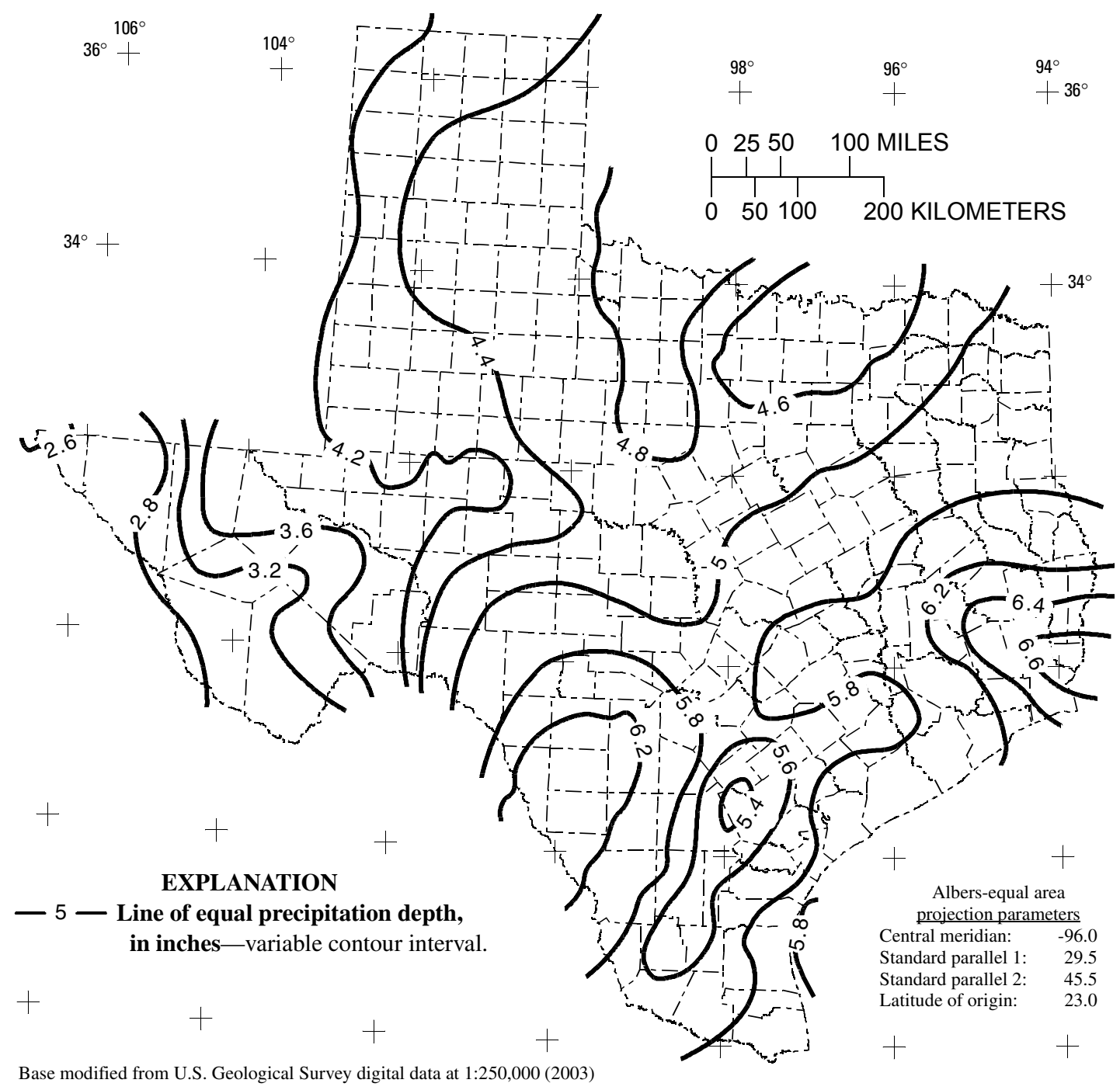

Figure 67. Depth of precipitation for 100-year storm for 2-hour duration in Texas. 


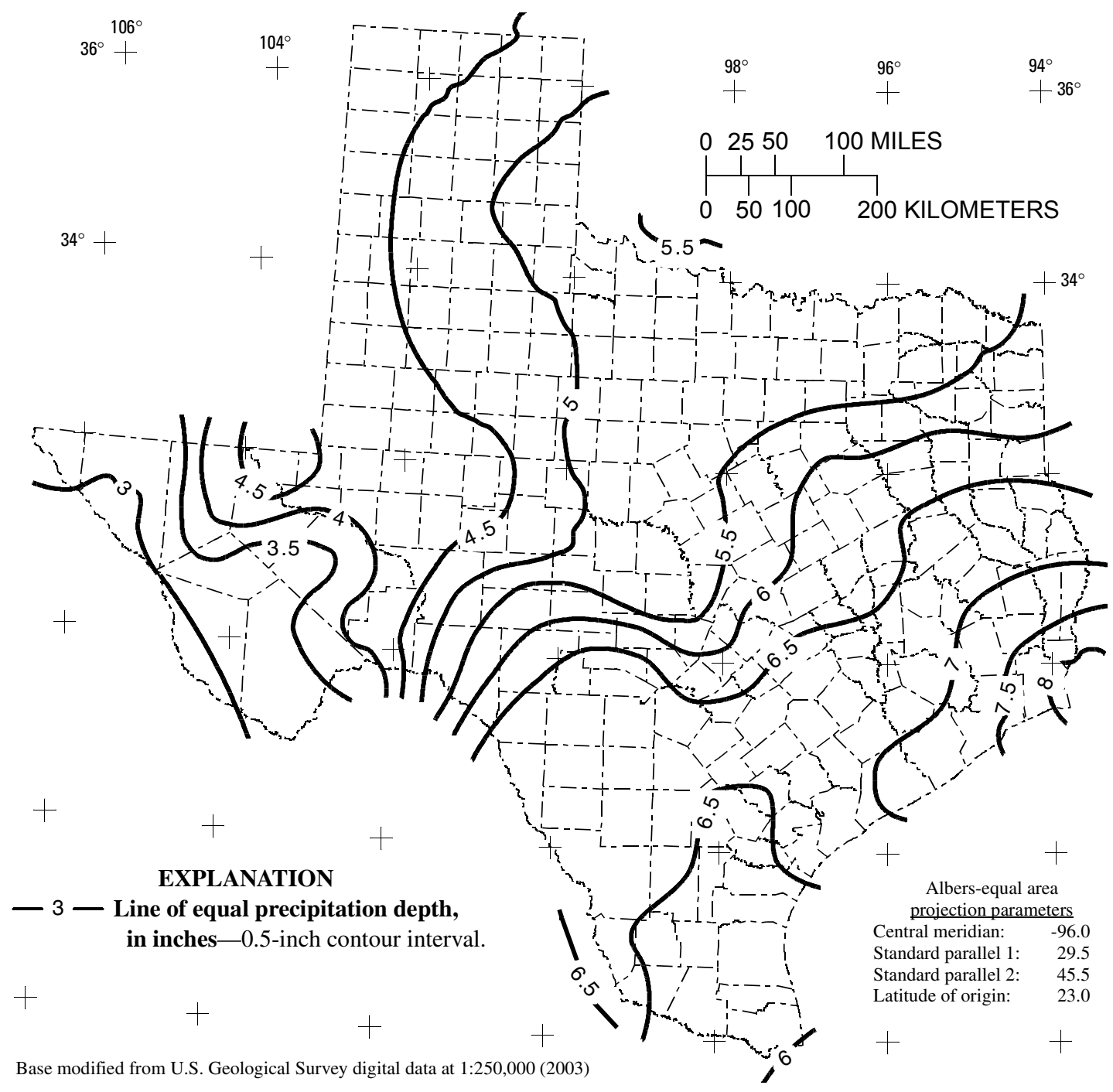

Figure 68. Depth of precipitation for 100-year storm for 3-hour duration in Texas. 


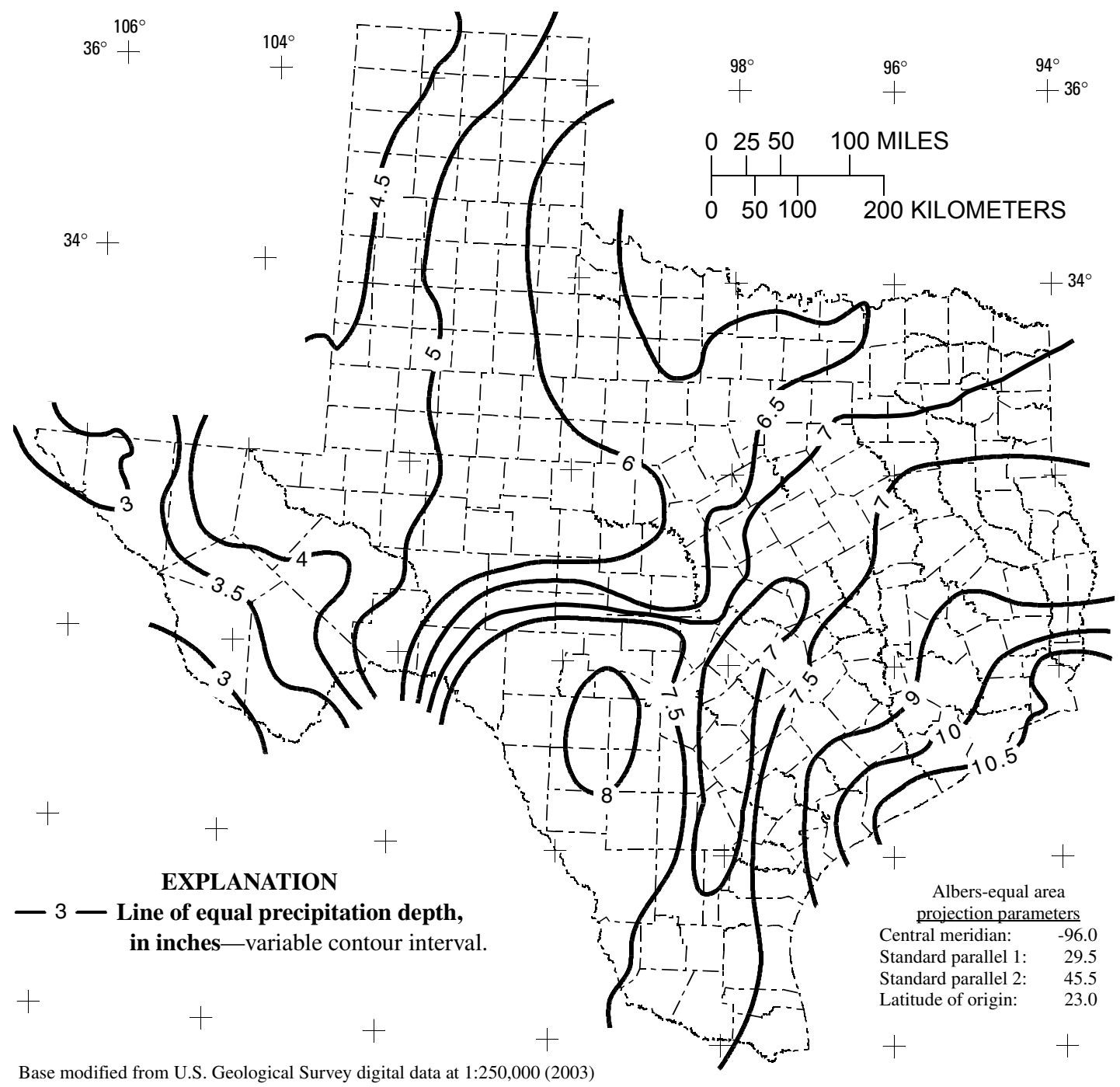

Figure 69. Depth of precipitation for 100-year storm for 6-hour duration in Texas. 


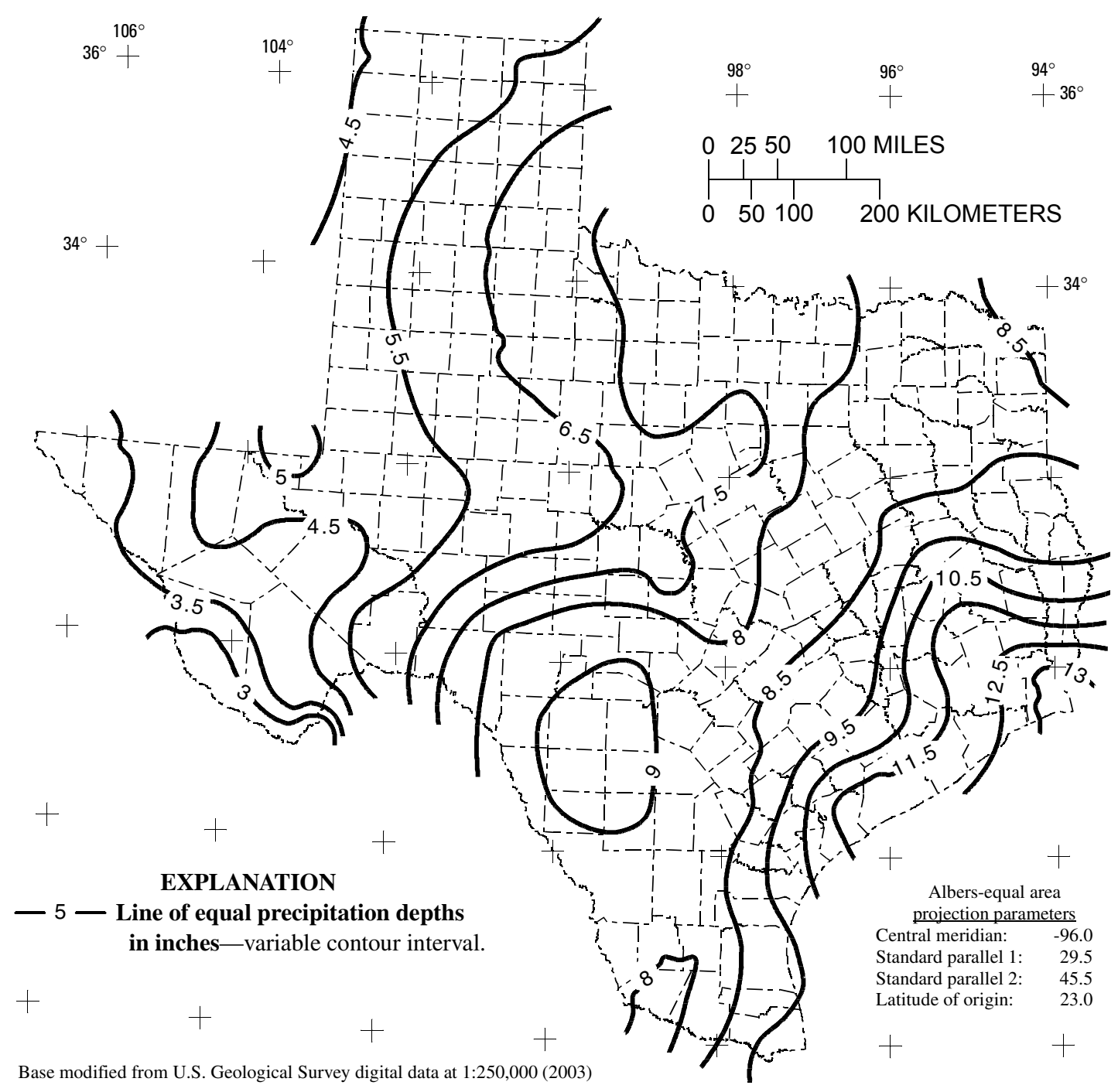

Figure 70. Depth of precipitation for 100-year storm for 12-hour duration in Texas. 


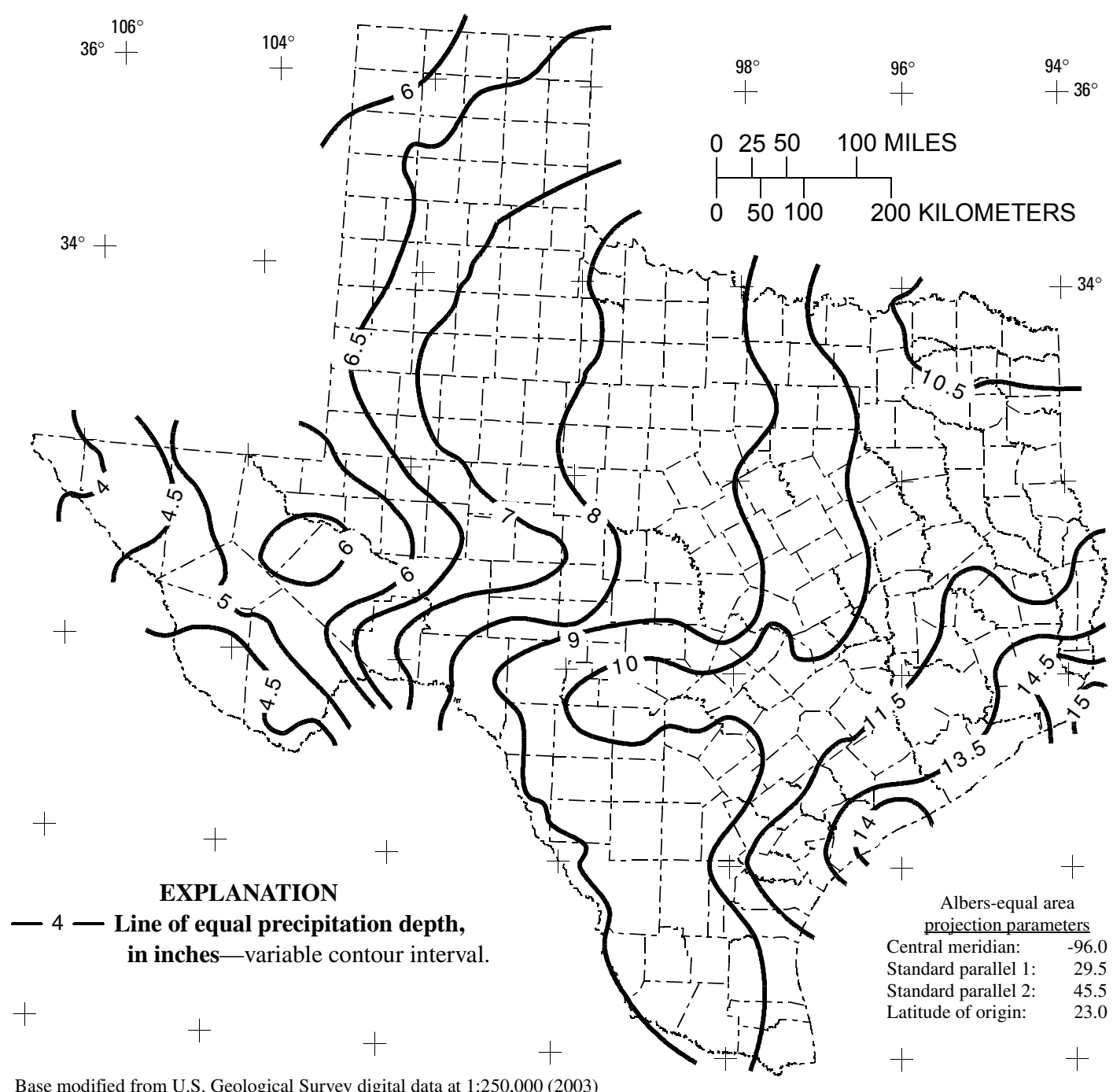

Figure 71. Depth of precipitation for 100-year storm for 1-day duration in Texas. 


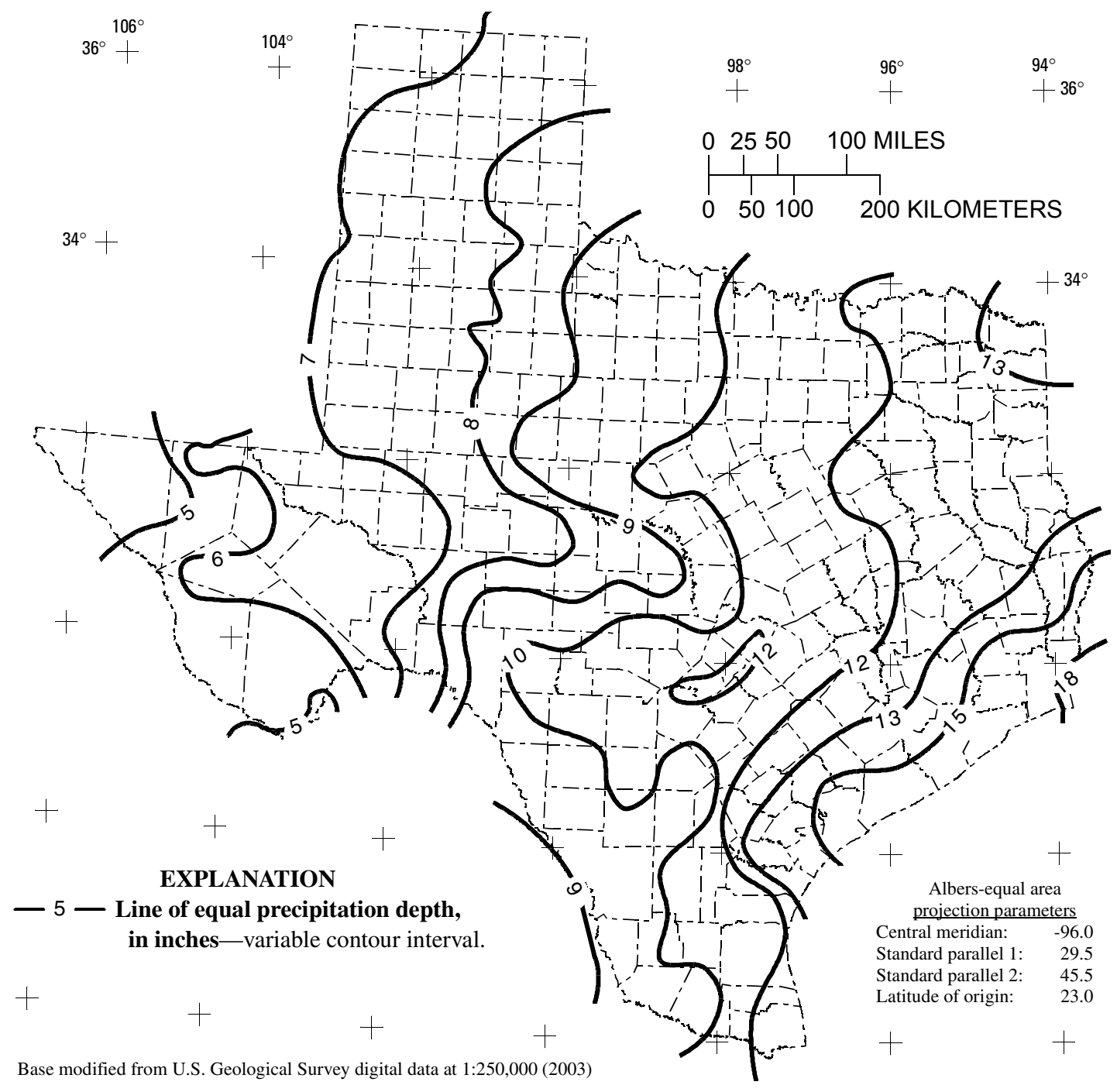

Figure 72. Depth of precipitation for 100-year storm for 2-day duration in Texas. 


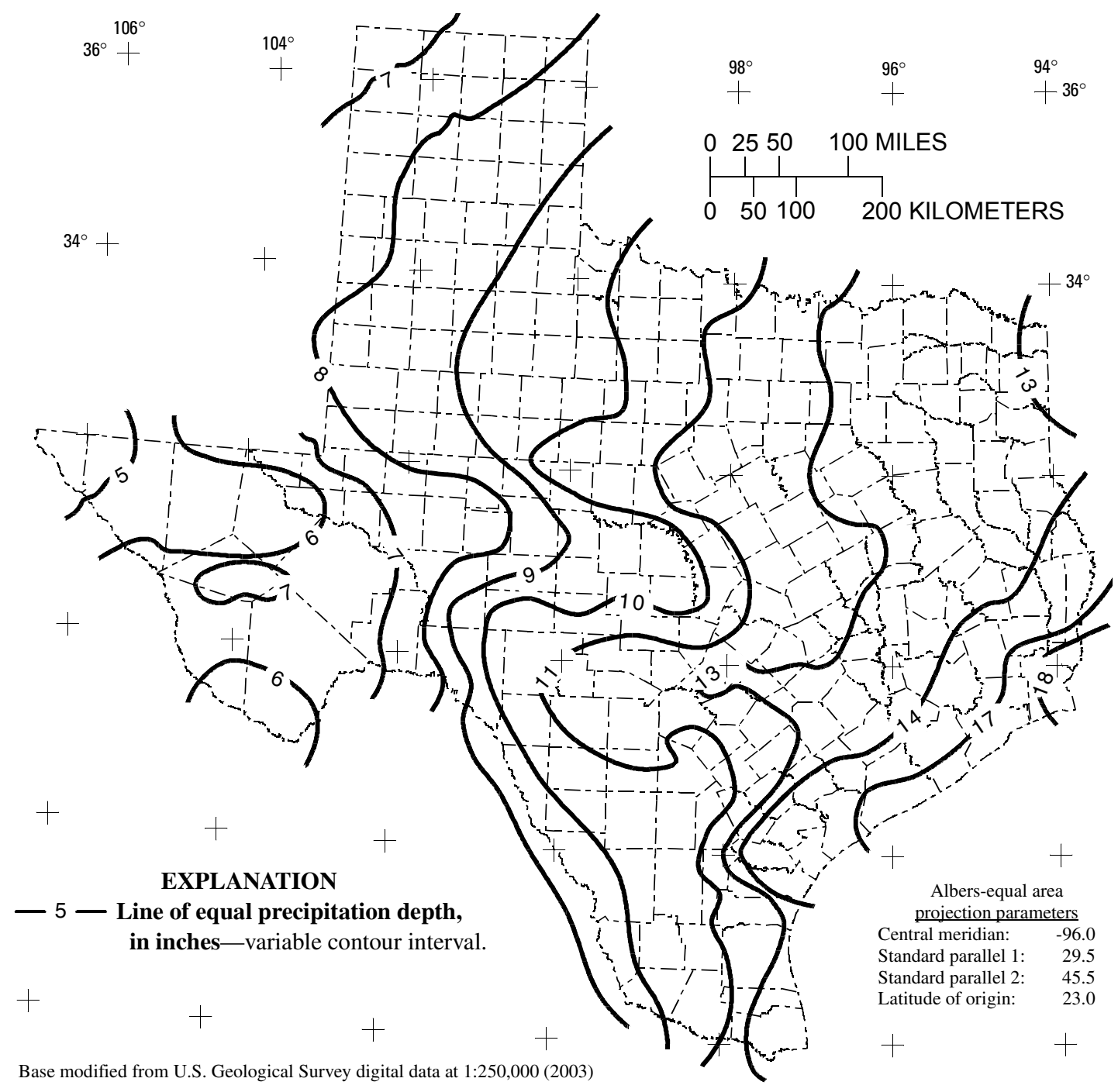

Figure 73. Depth of precipitation for 100-year storm for 3-day duration in Texas. 


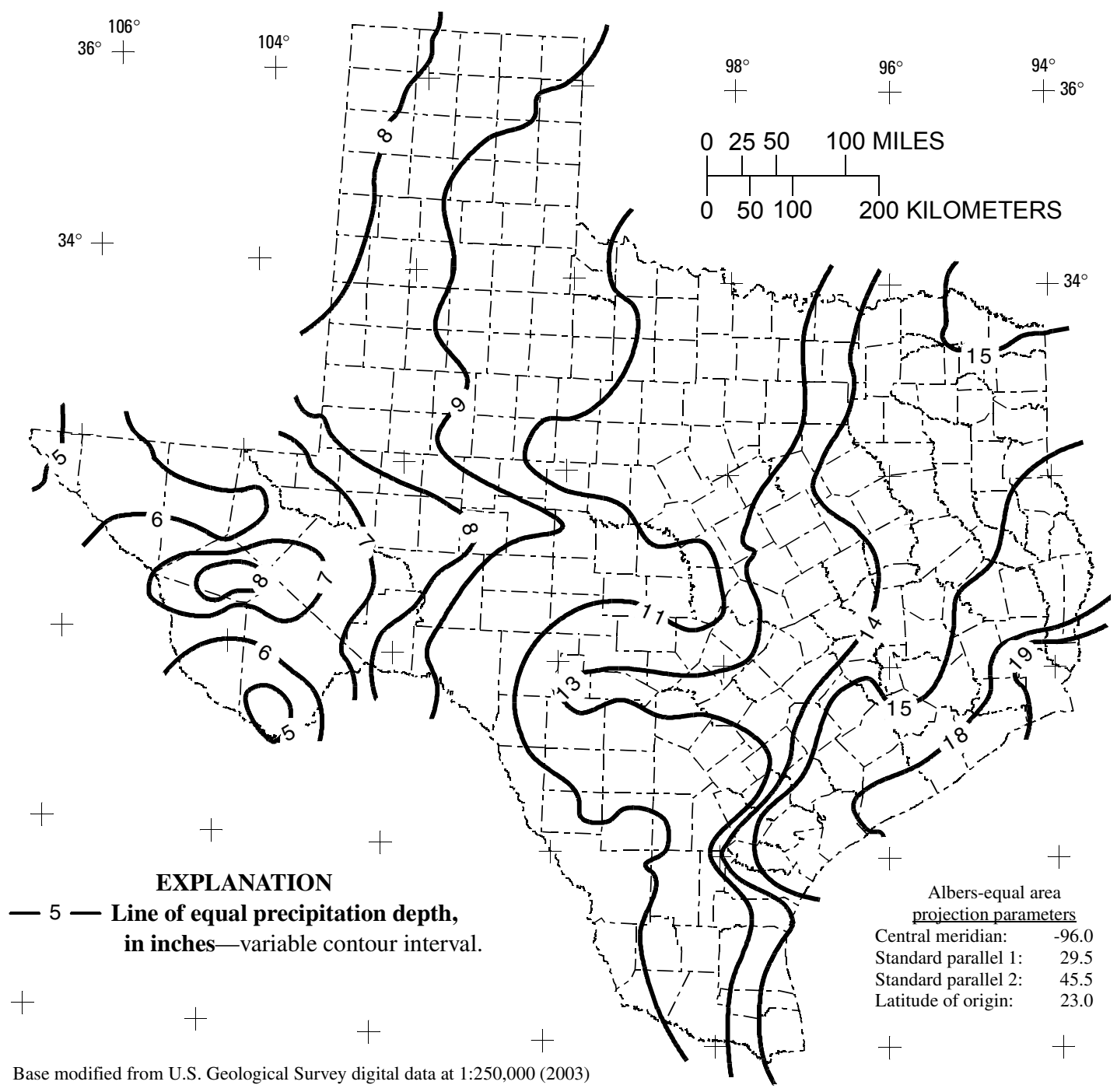

Figure 74. Depth of precipitation for 100-year storm for 5-day duration in Texas. 


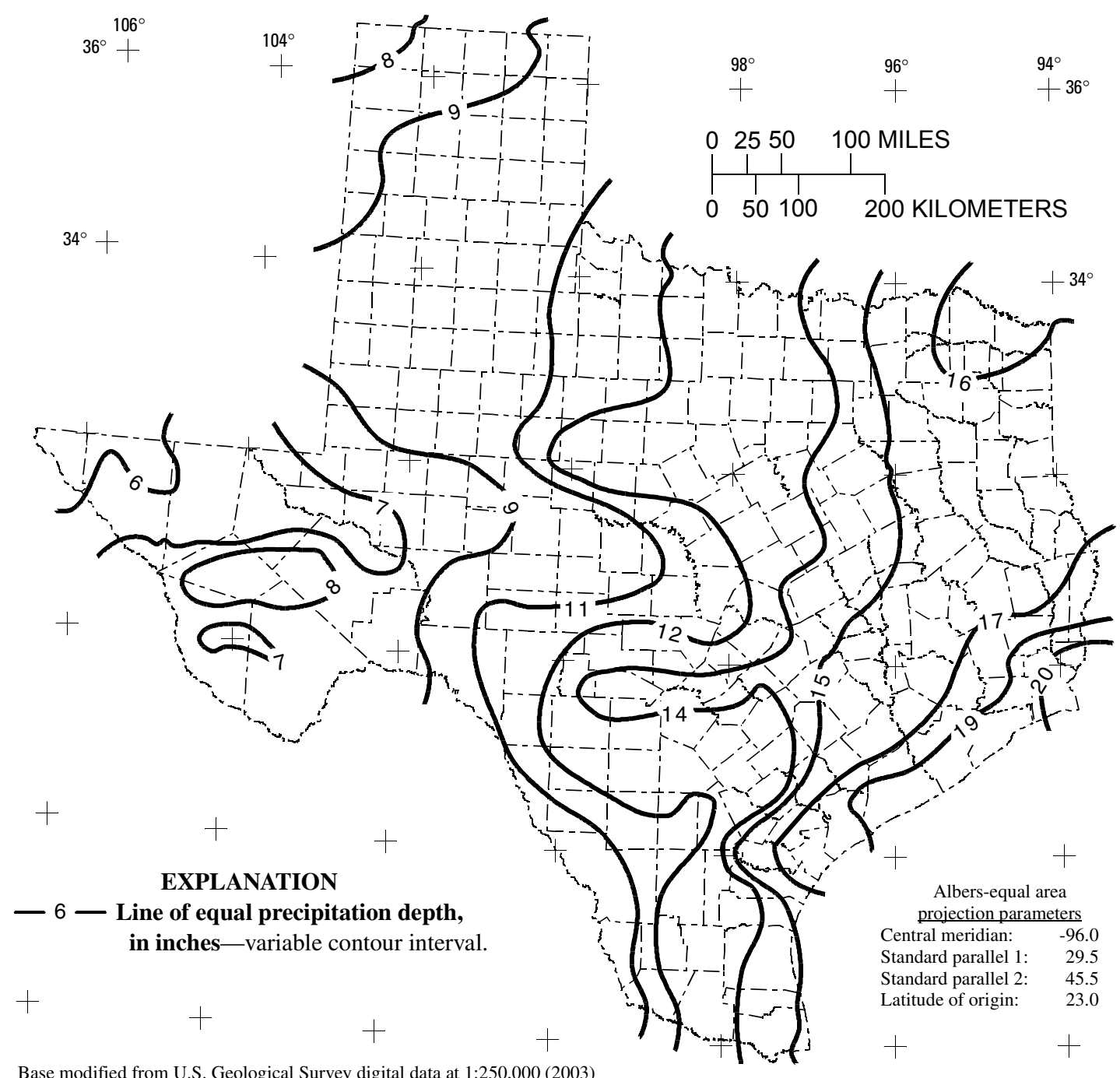

Figure 75. Depth of precipitation for 100-year storm for 7-day duration in Texas. 


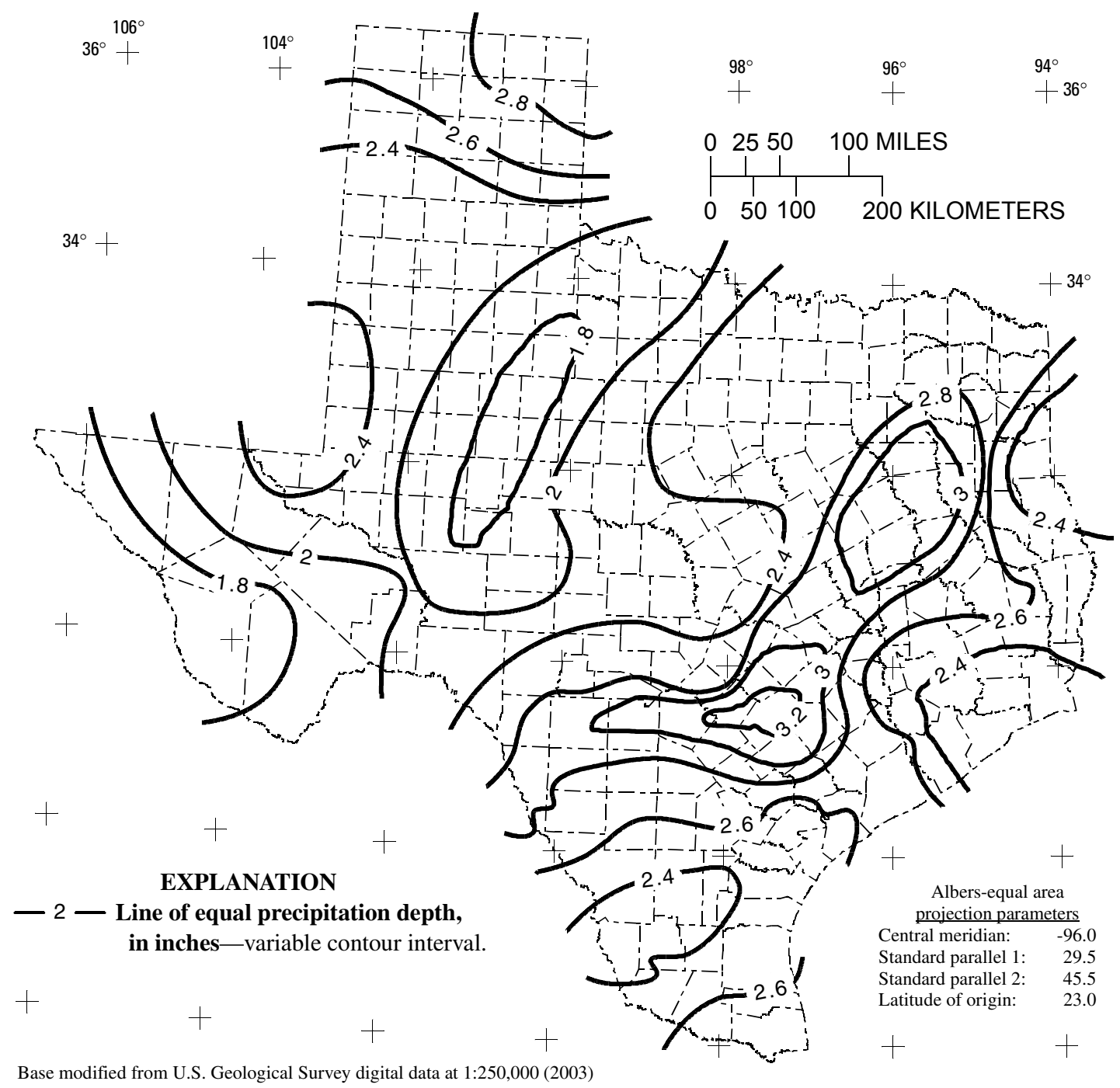

Figure 76. Depth of precipitation for 250-year storm for 15-minute duration in Texas. 


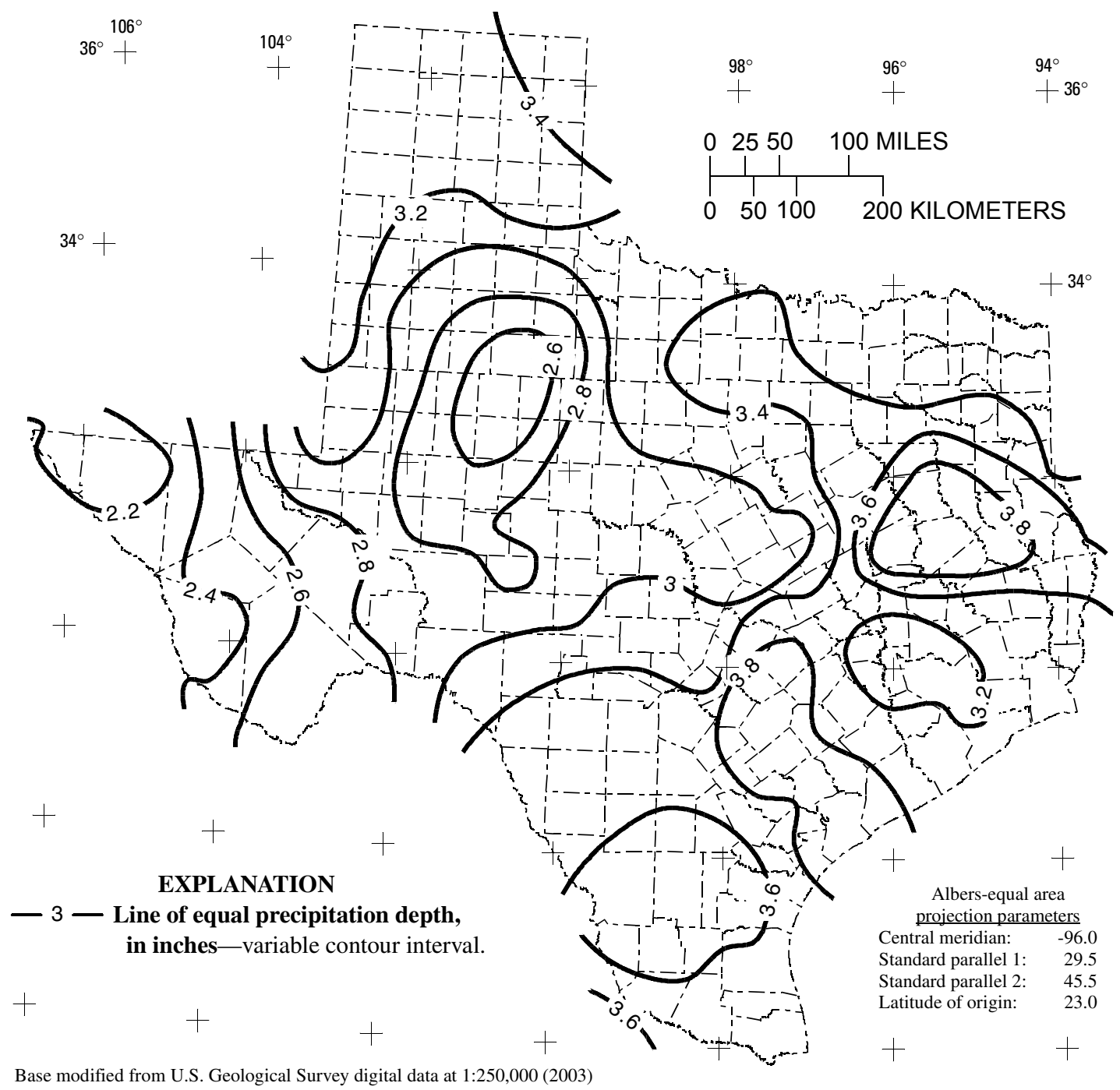

Figure 77. Depth of precipitation for 250-year storm for 30-minute duration in Texas. 


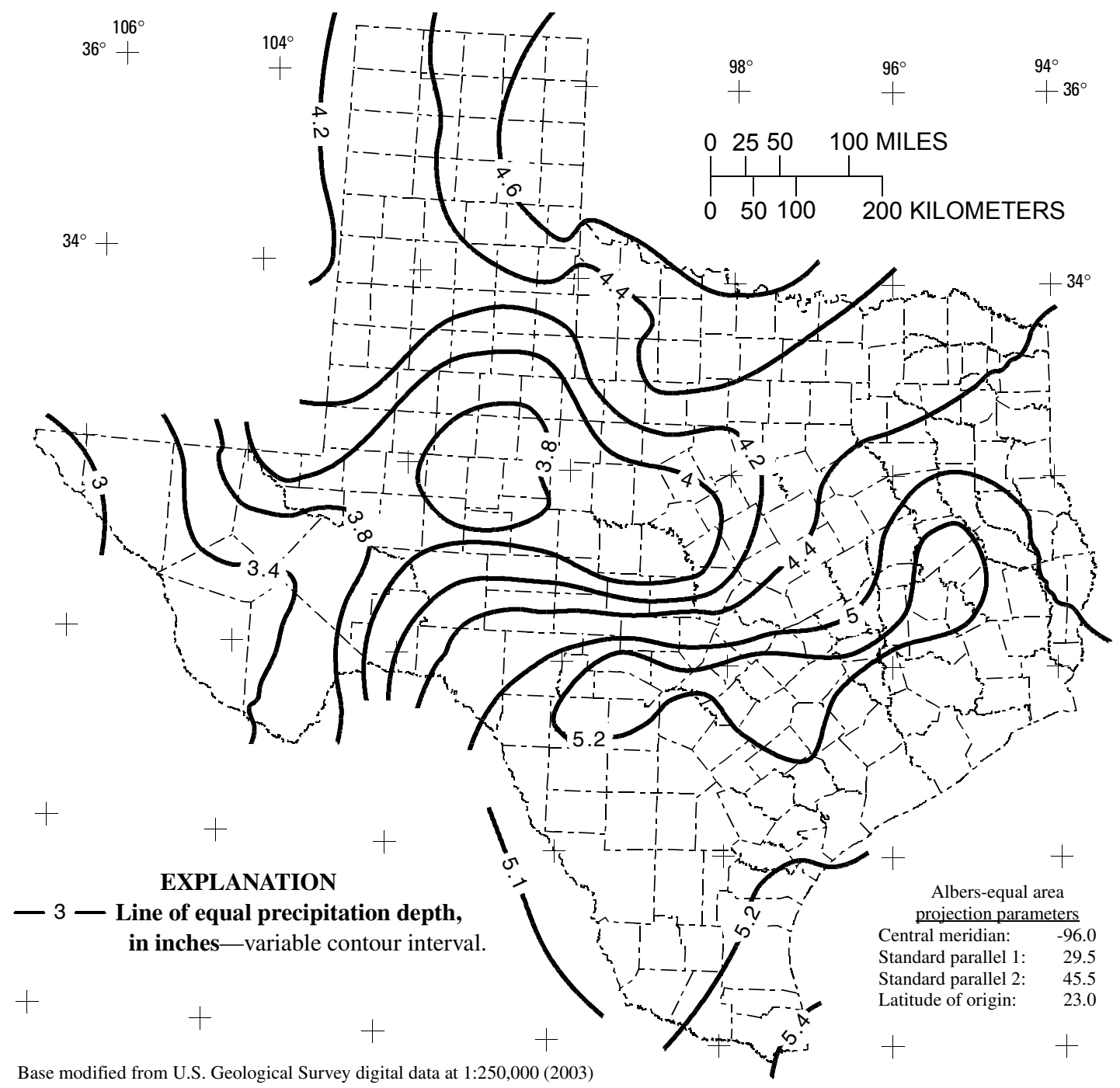

Figure 78. Depth of precipitation for 250-year storm for 1-hour duration in Texas. 


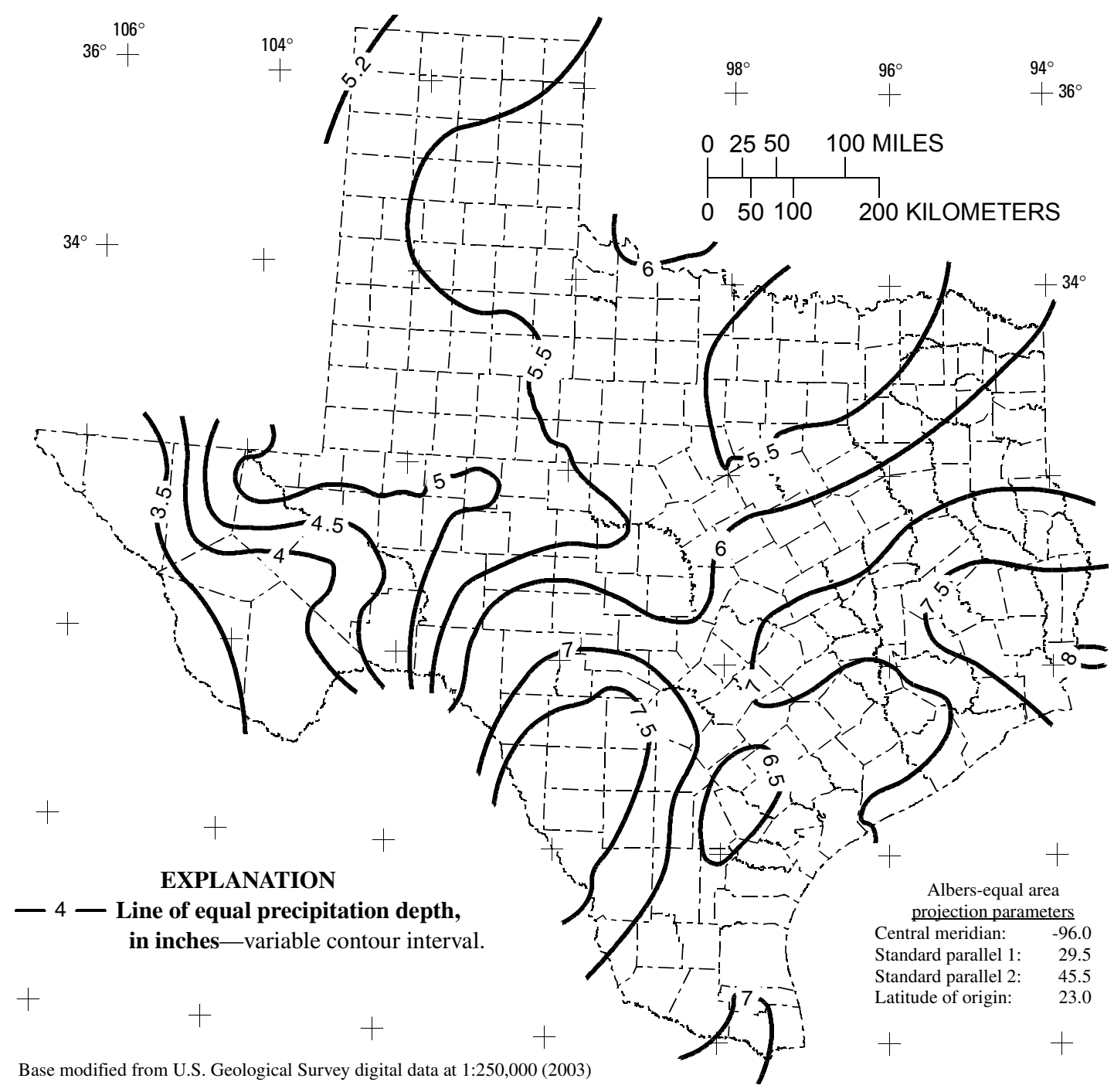

Figure 79. Depth of precipitation for 250-year storm for 2-hour duration in Texas. 


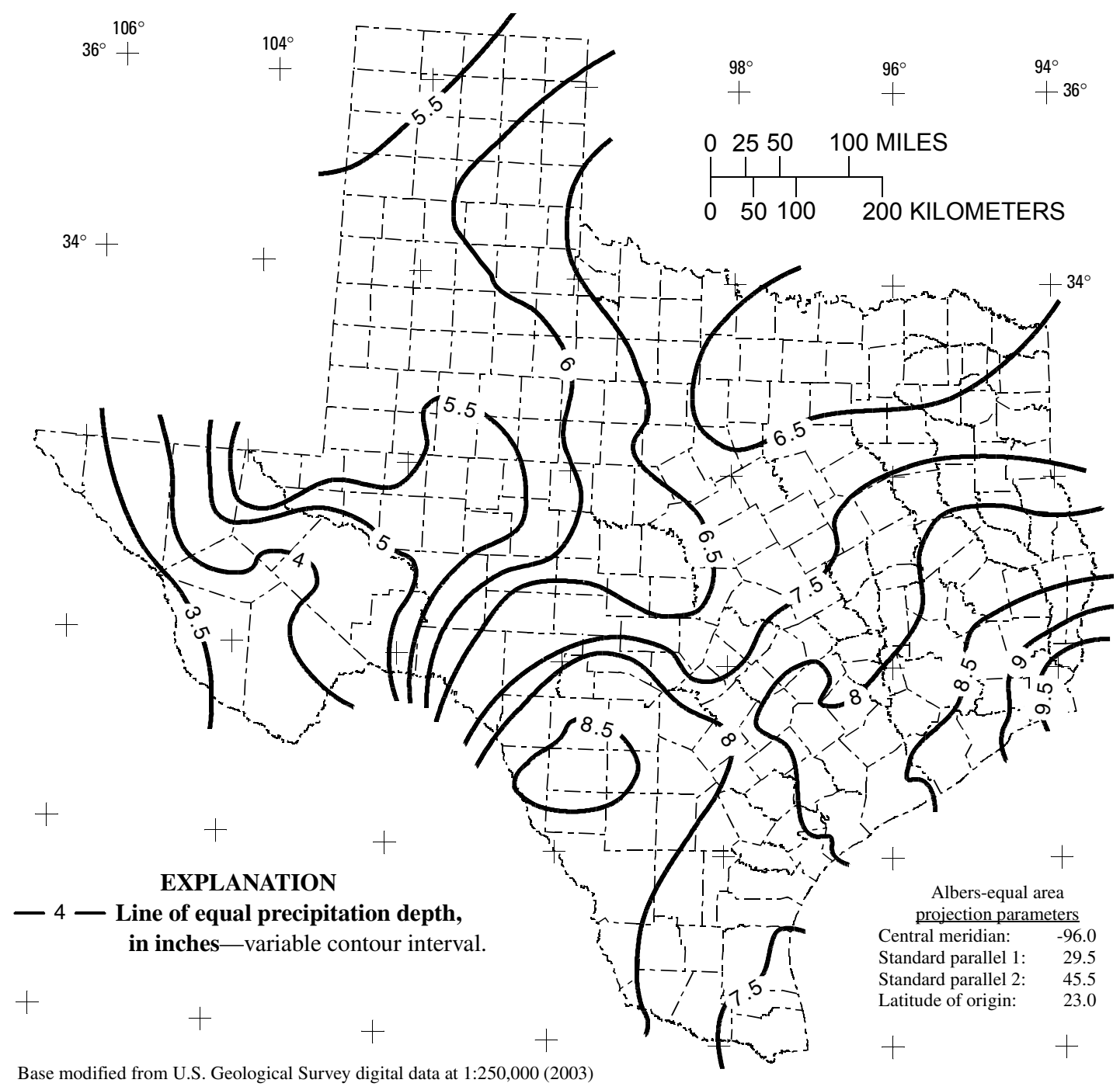

Figure 80. Depth of precipitation for 250-year storm for 3-hour duration in Texas. 


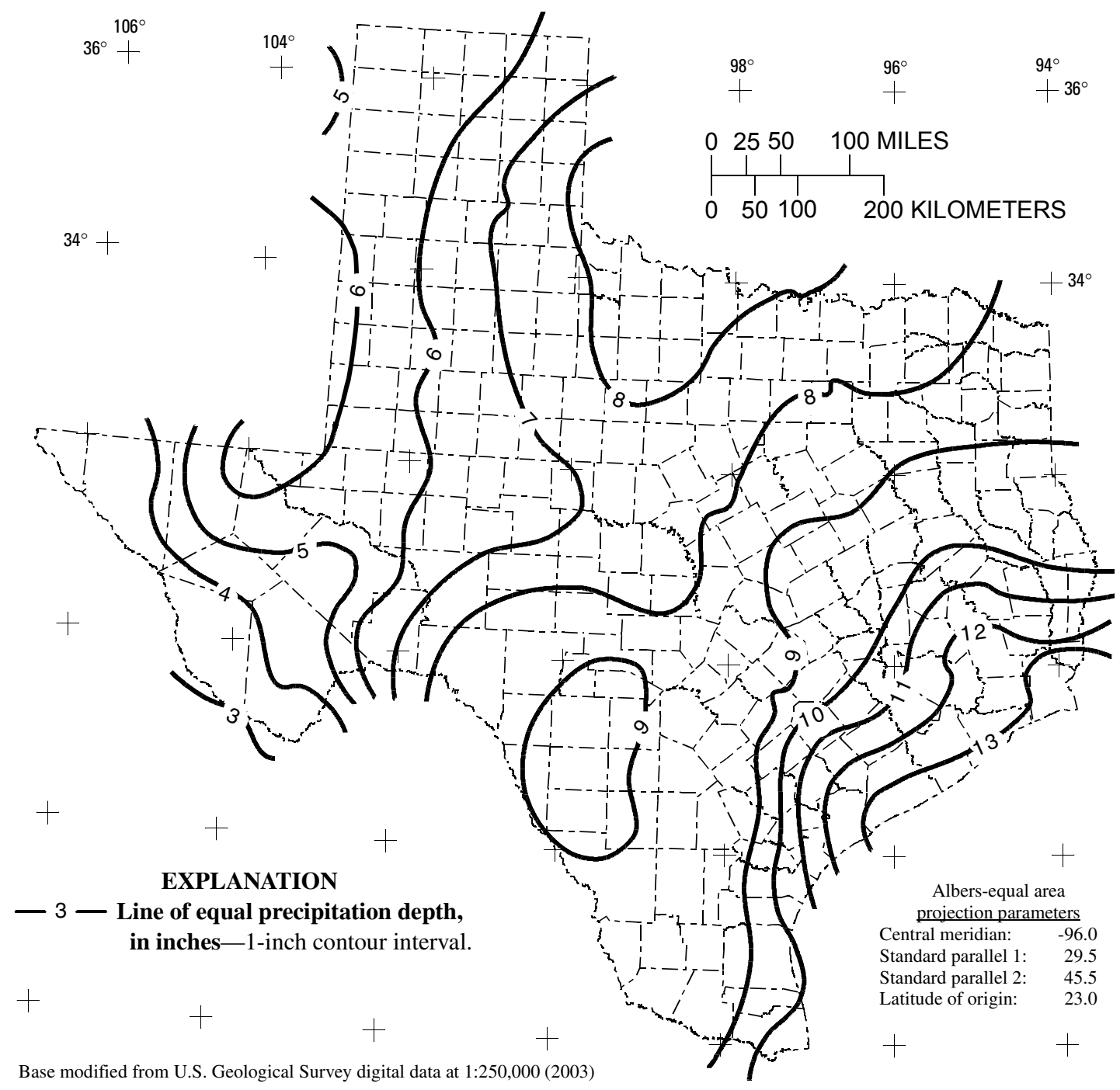

Figure 81. Depth of precipitation for 250-year storm for 6-hour duration in Texas. 


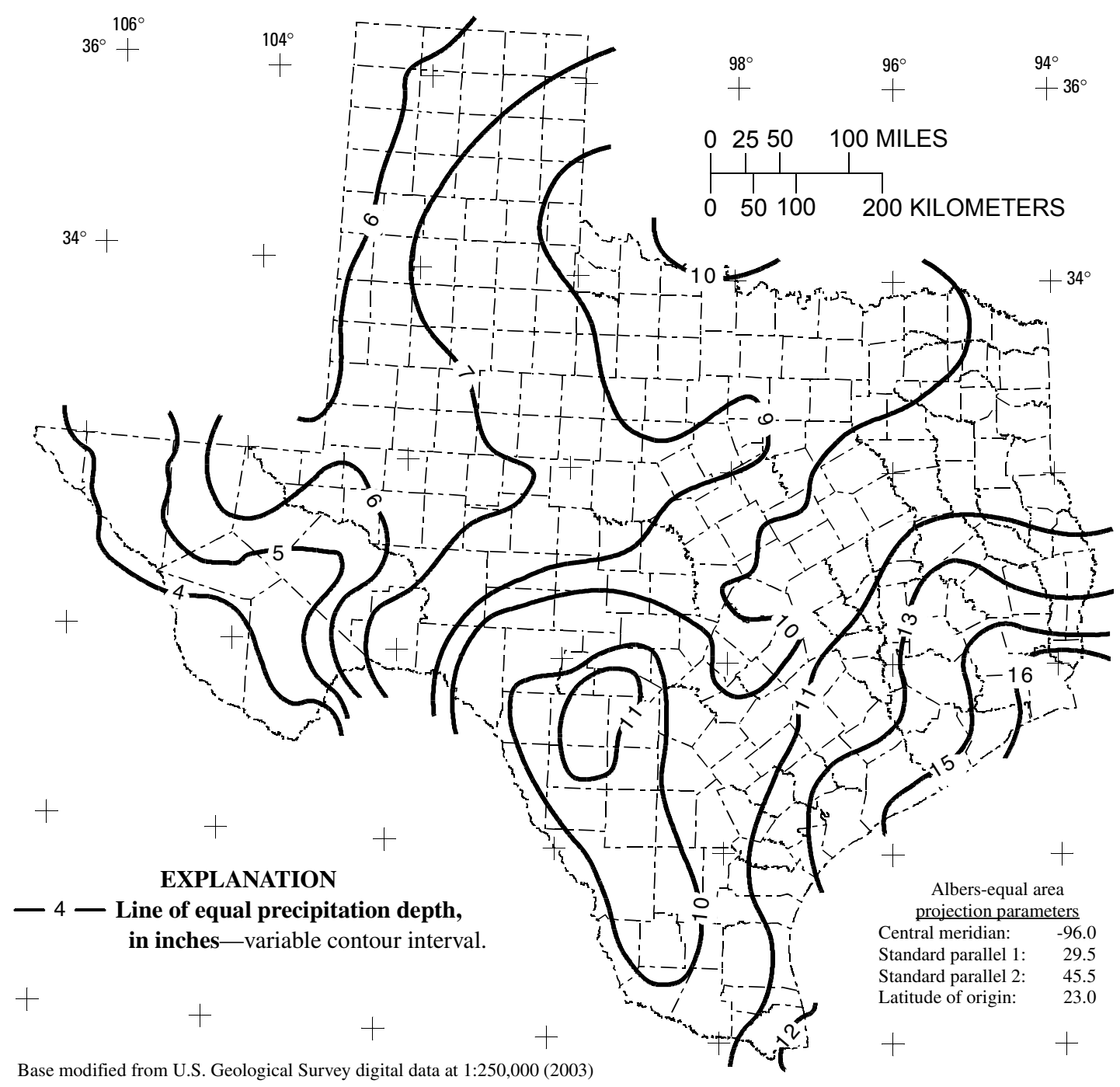

Figure 82. Depth of precipitation for 250-year storm for 12-hour duration in Texas. 


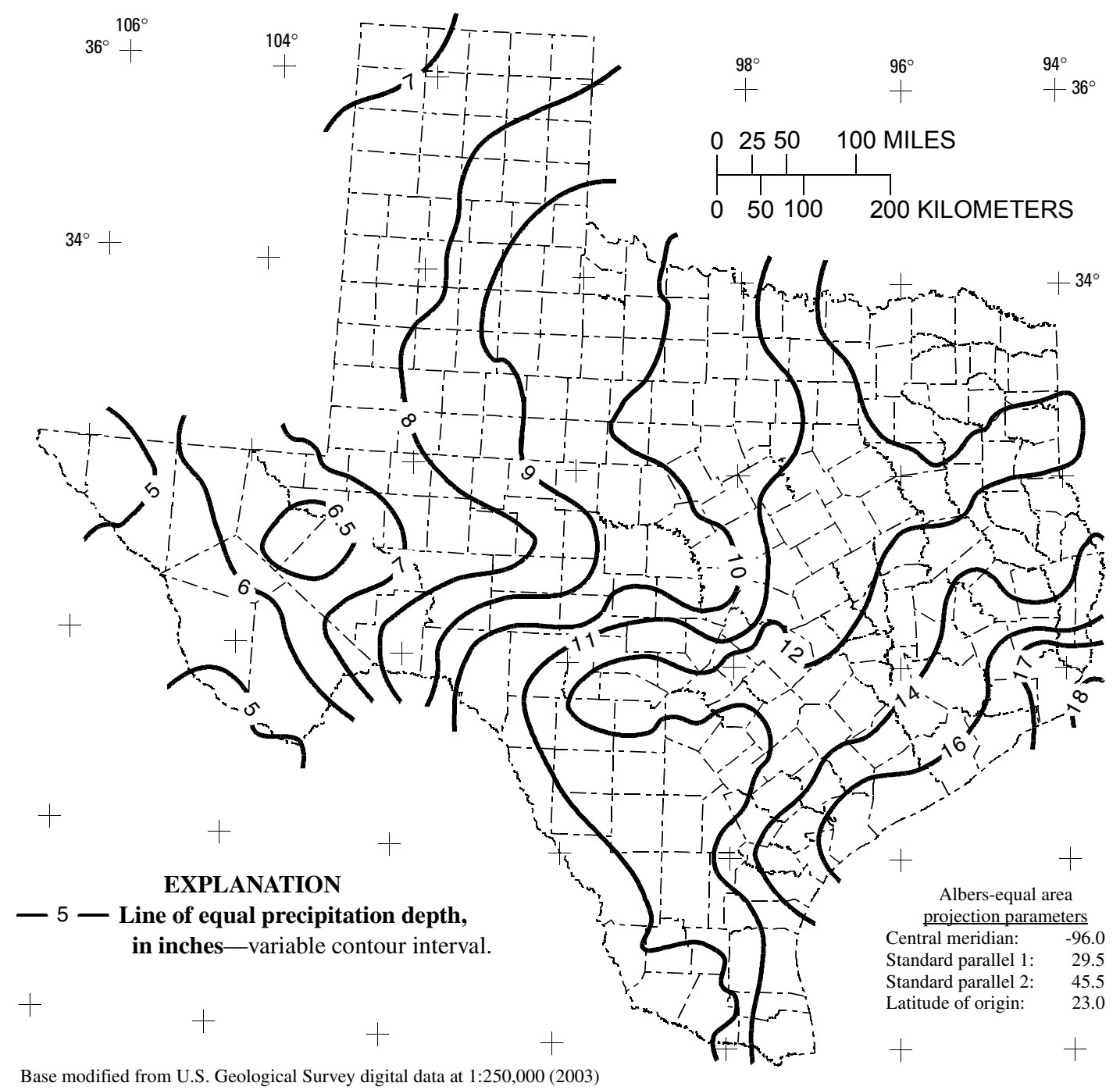

Figure 83. Depth of precipitation for 250-year storm for 1-day duration in Texas. 


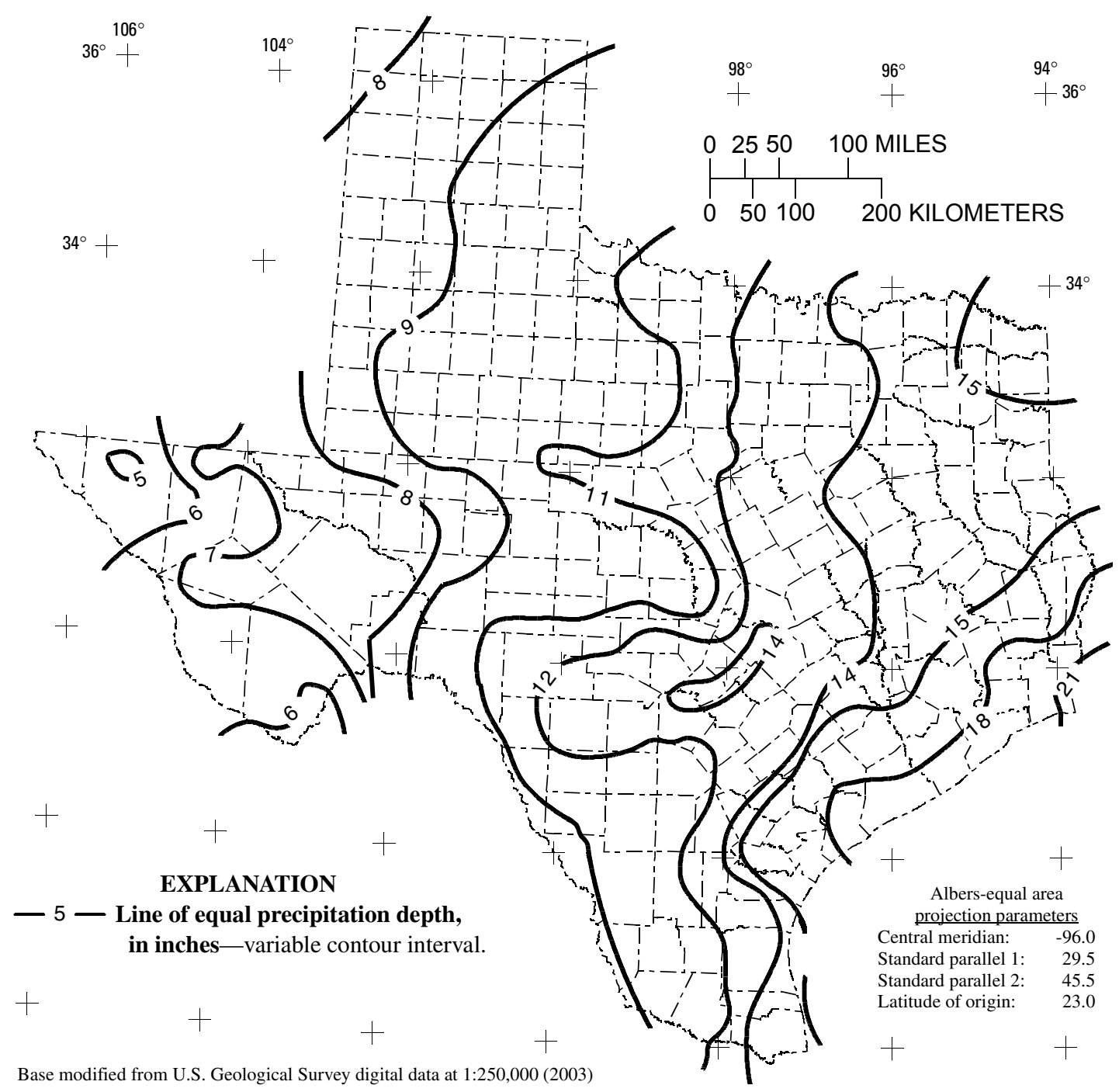

Figure 84. Depth of precipitation for 250-year storm for 2-day duration in Texas. 


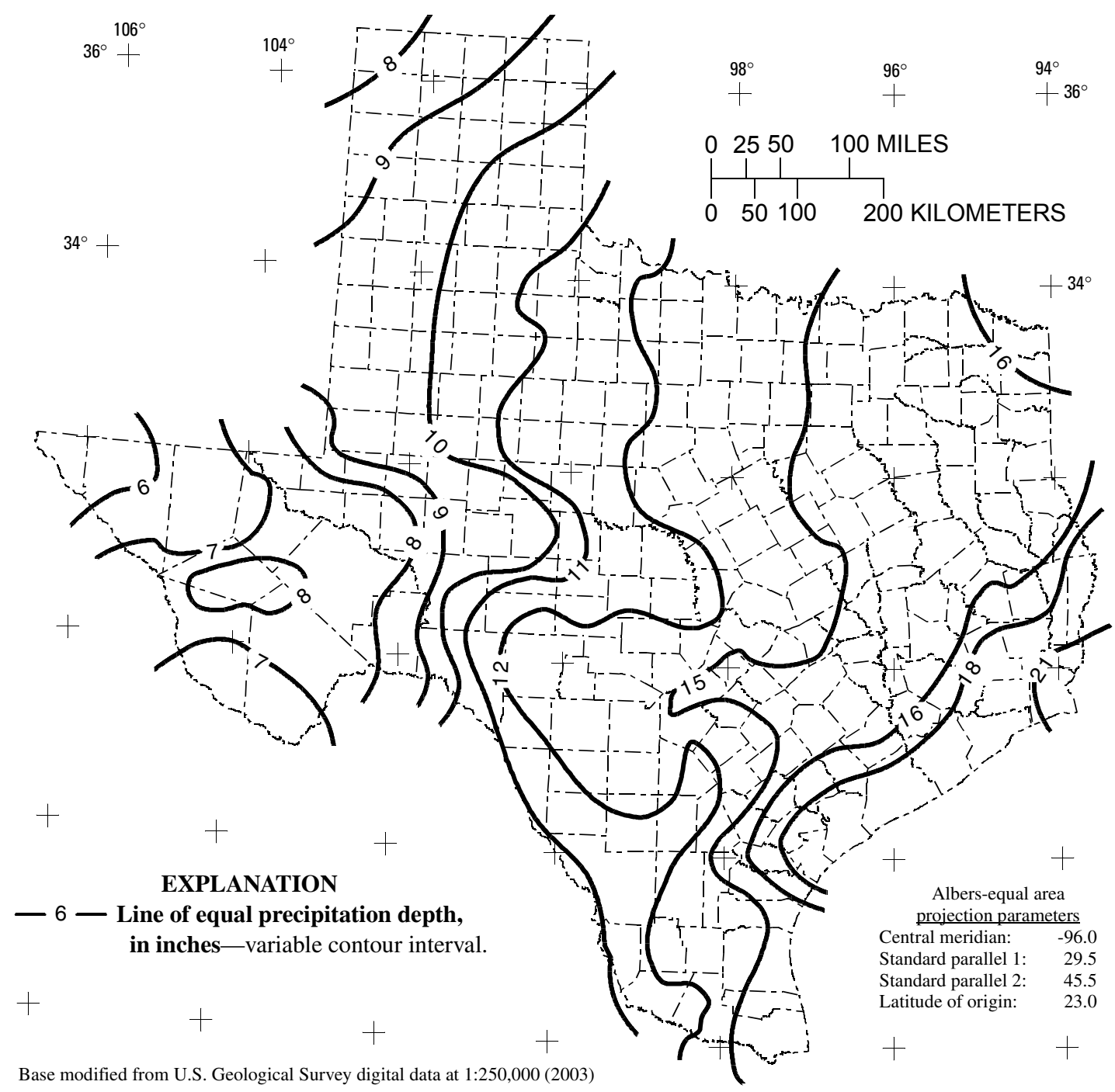

Figure 85. Depth of precipitation for 250-year storm for 3-day duration in Texas. 


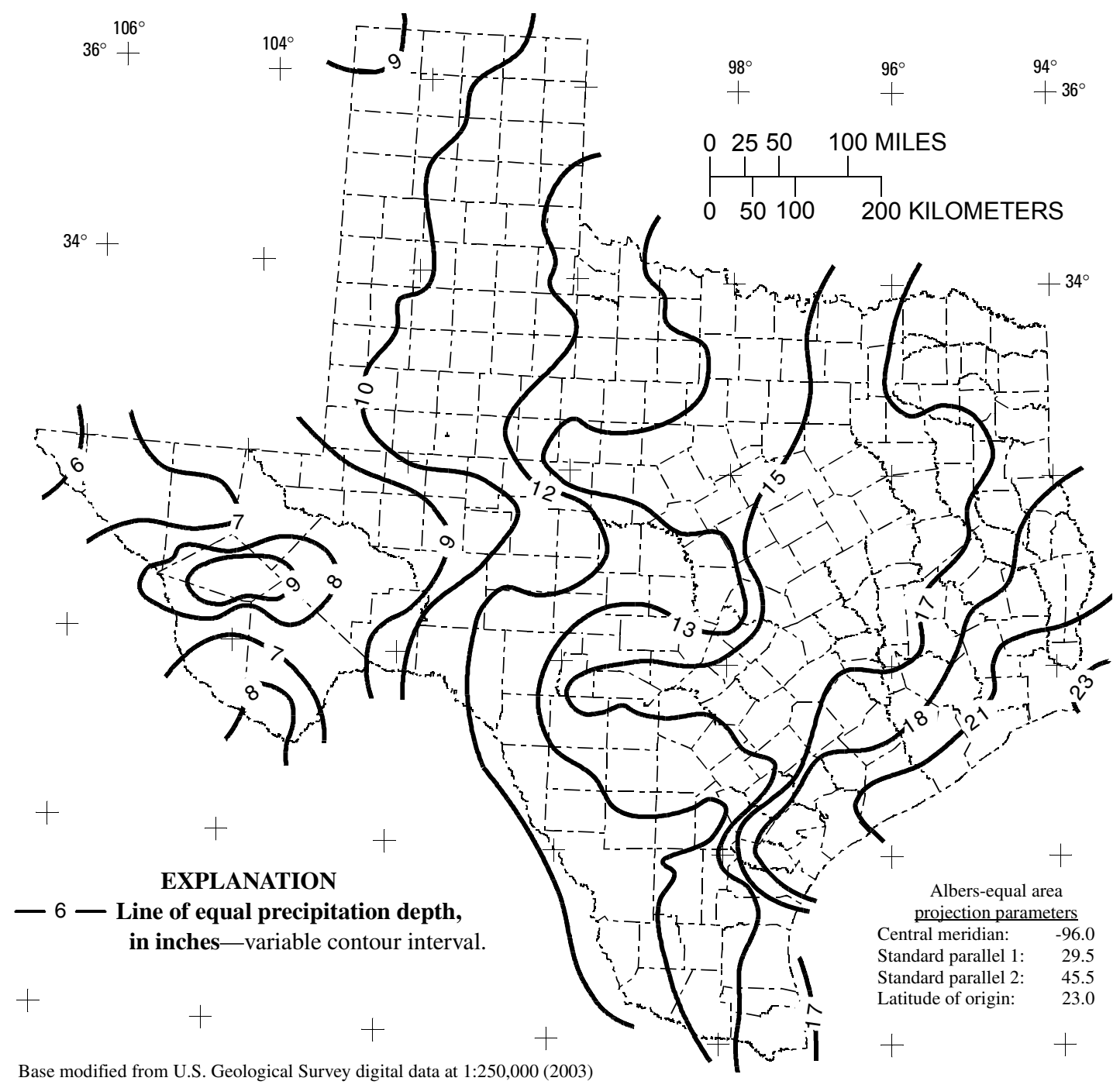

Figure 86. Depth of precipitation for 250-year storm for 5-day duration in Texas. 


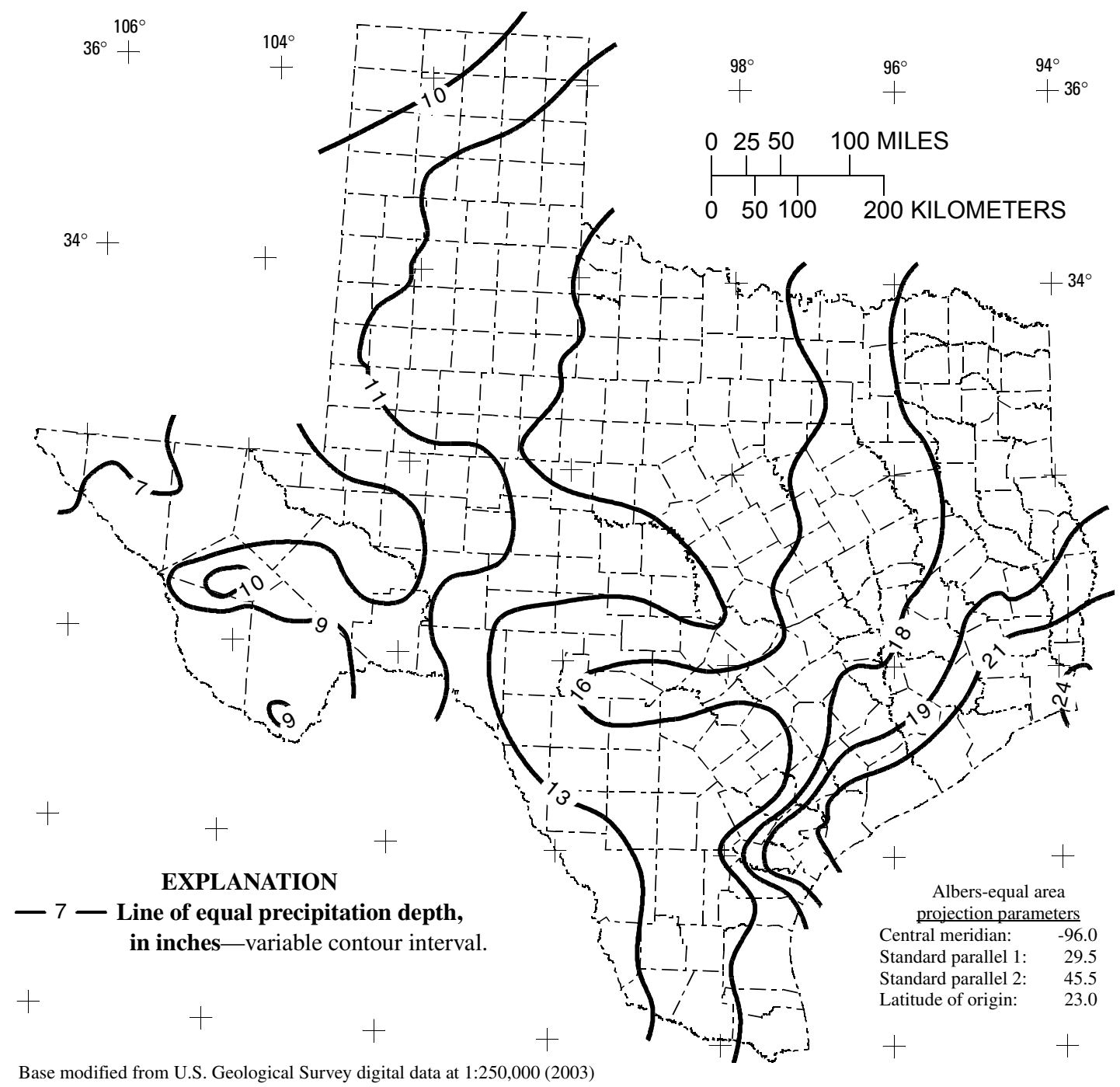

Figure 87. Depth of precipitation for 250-year storm for 7-day duration in Texas. 


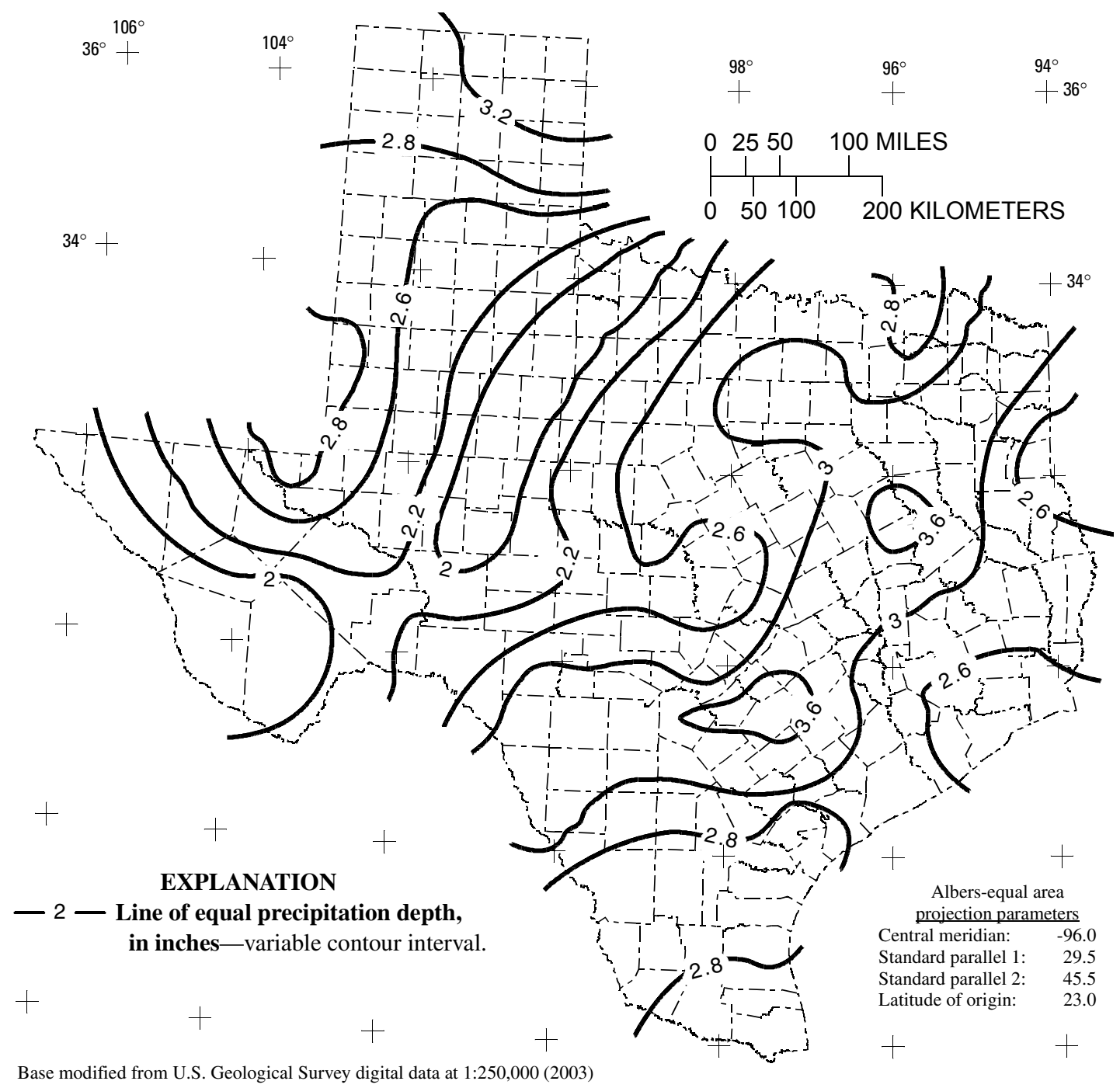

Figure 88. Depth of precipitation for 500-year storm for 15-minute duration in Texas. 


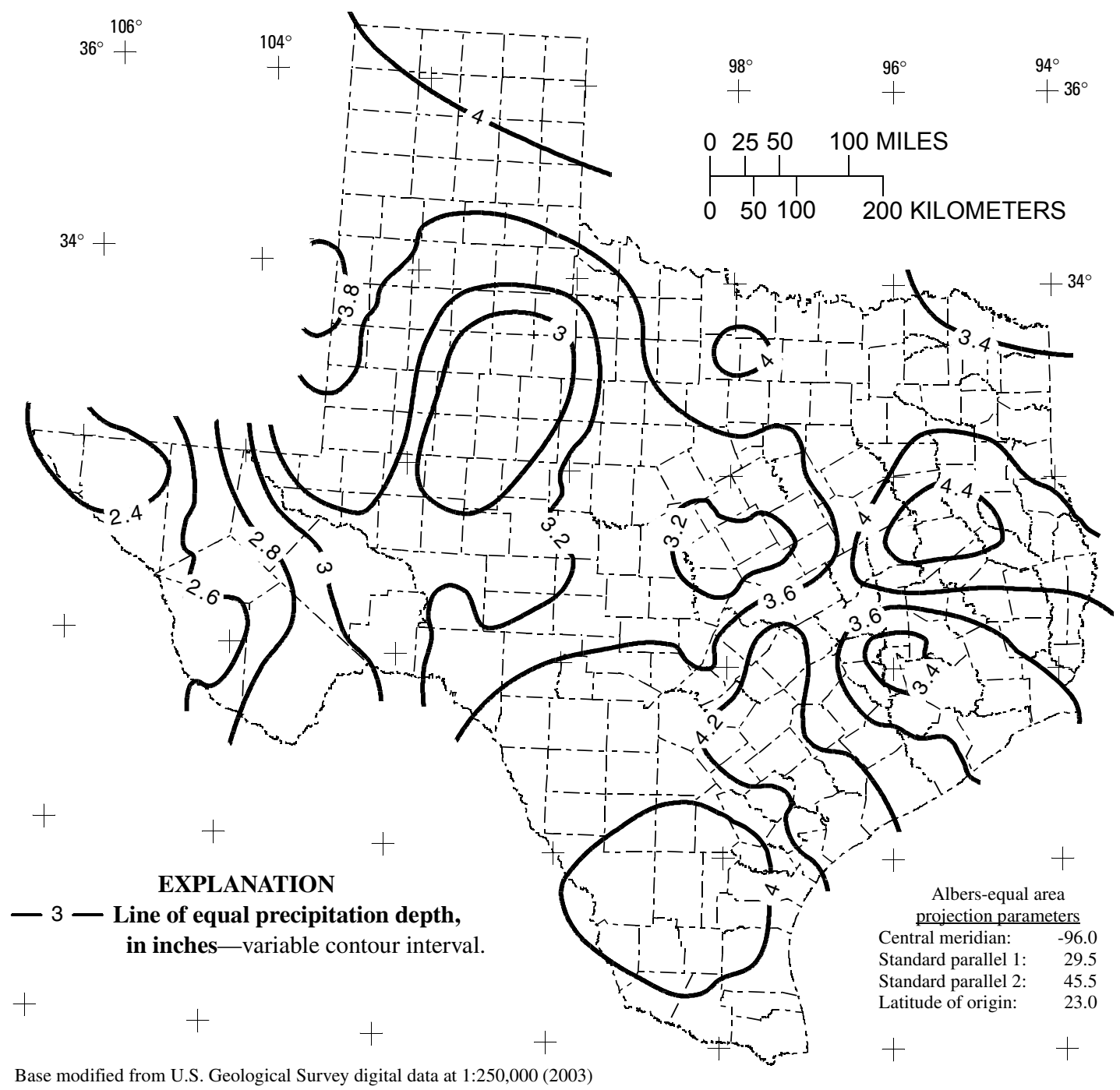

Figure 89. Depth of precipitation for 500-year storm for 30-minute duration in Texas. 


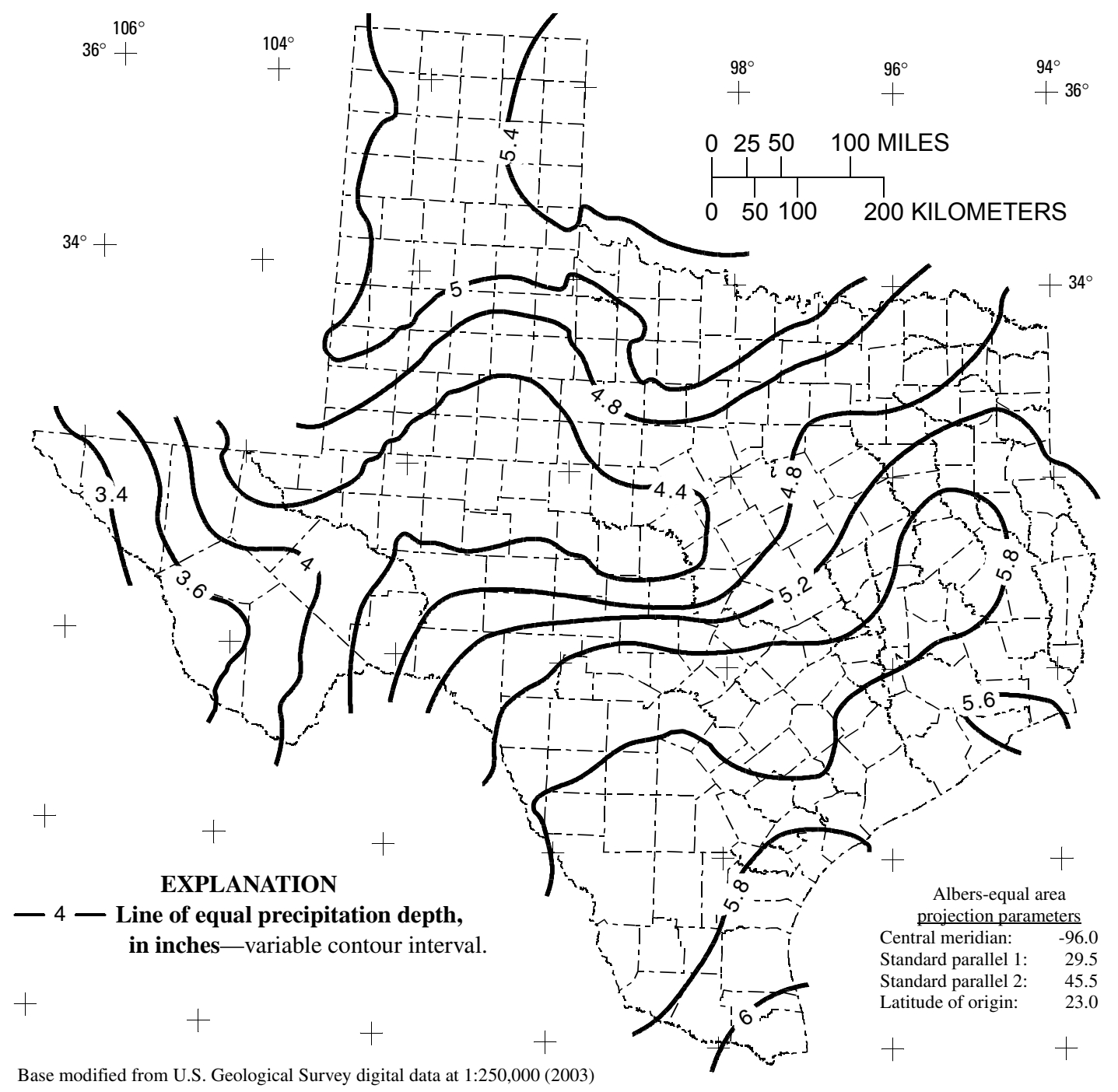

Figure 90. Depth of precipitation for 500-year storm for 1-hour duration in Texas. 


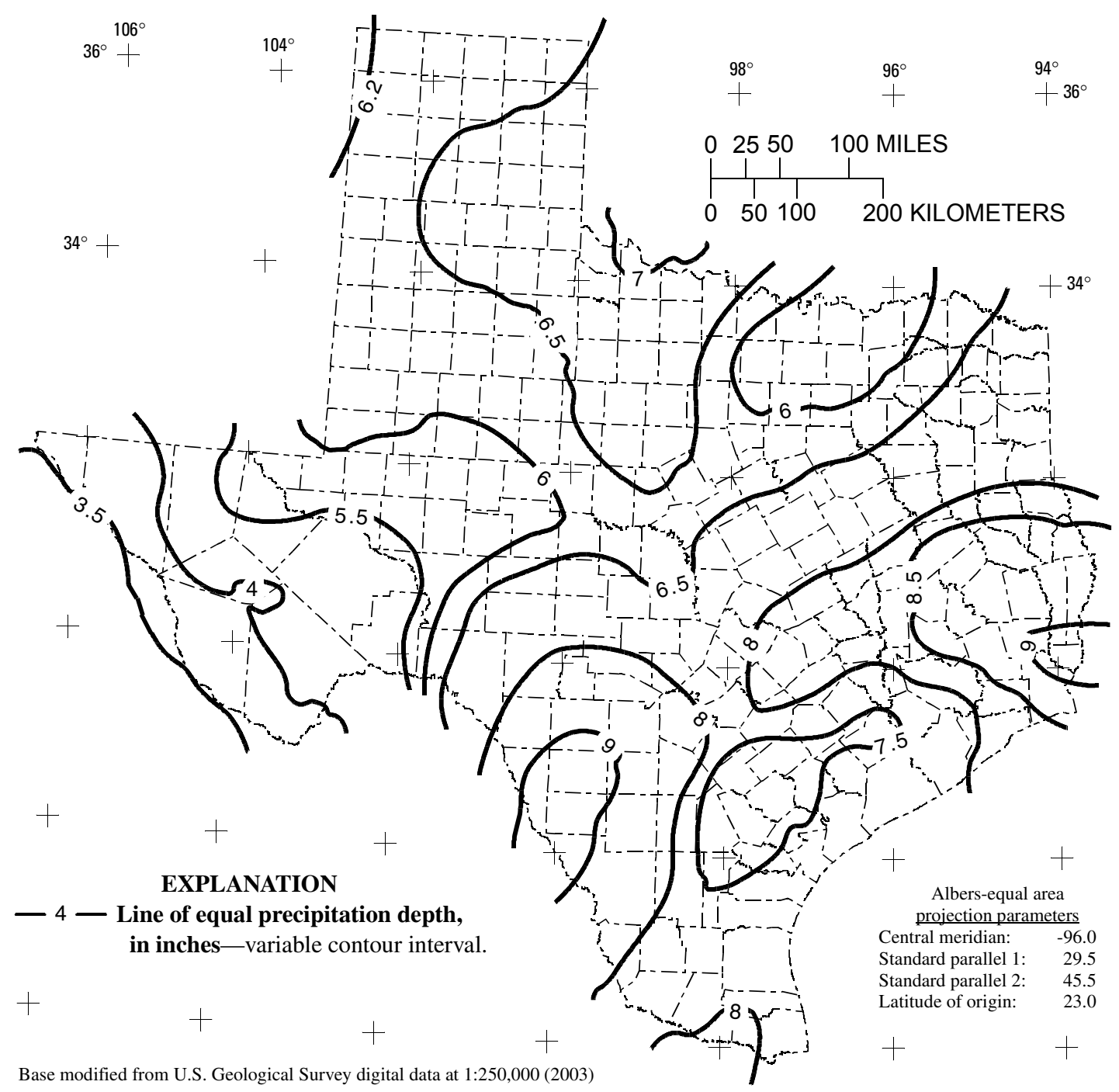

Figure 91. Depth of precipitation for 500-year storm for 2-hour duration in Texas. 


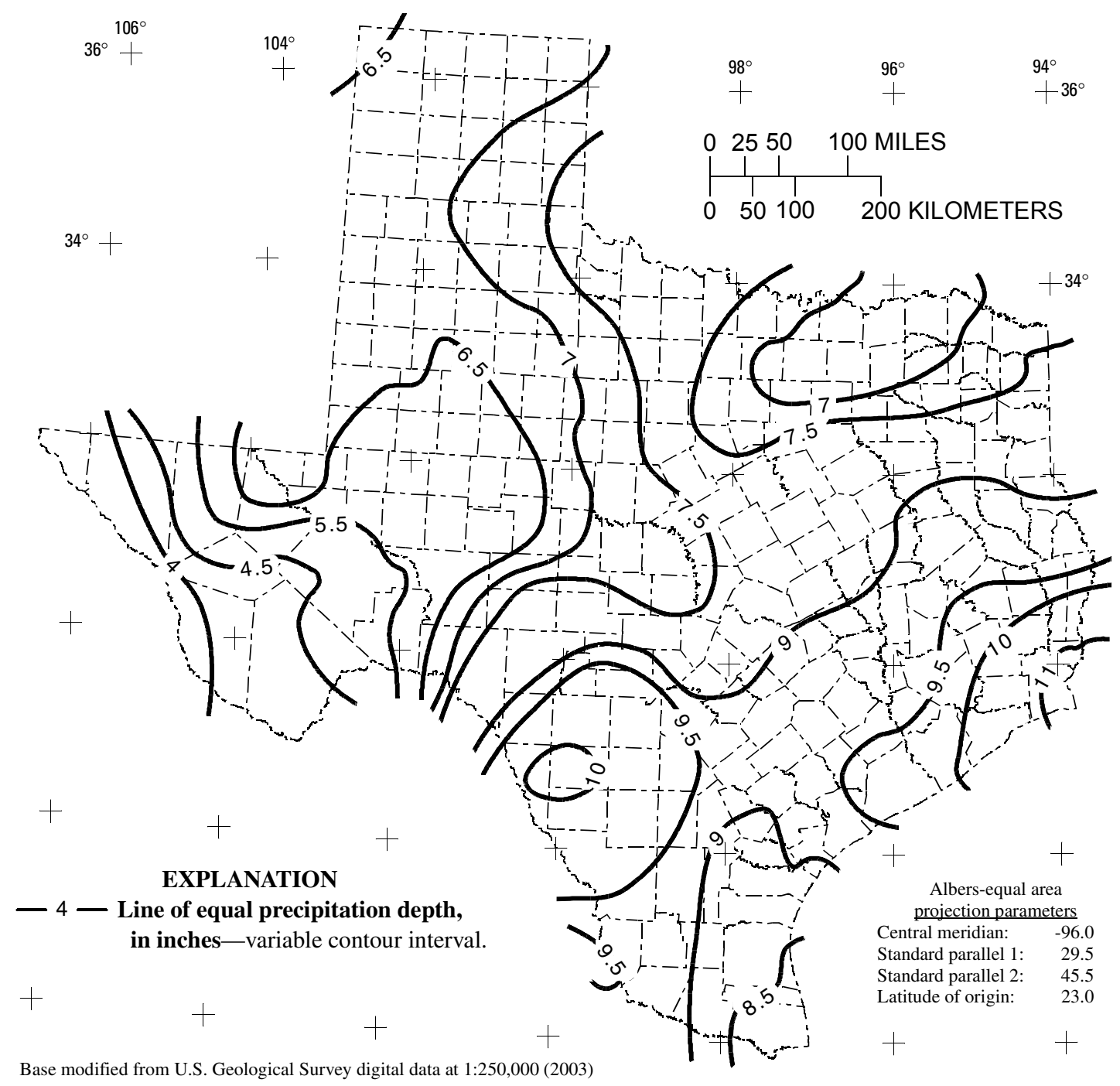

Figure 92. Depth of precipitation for 500-year storm for 3-hour duration in Texas. 


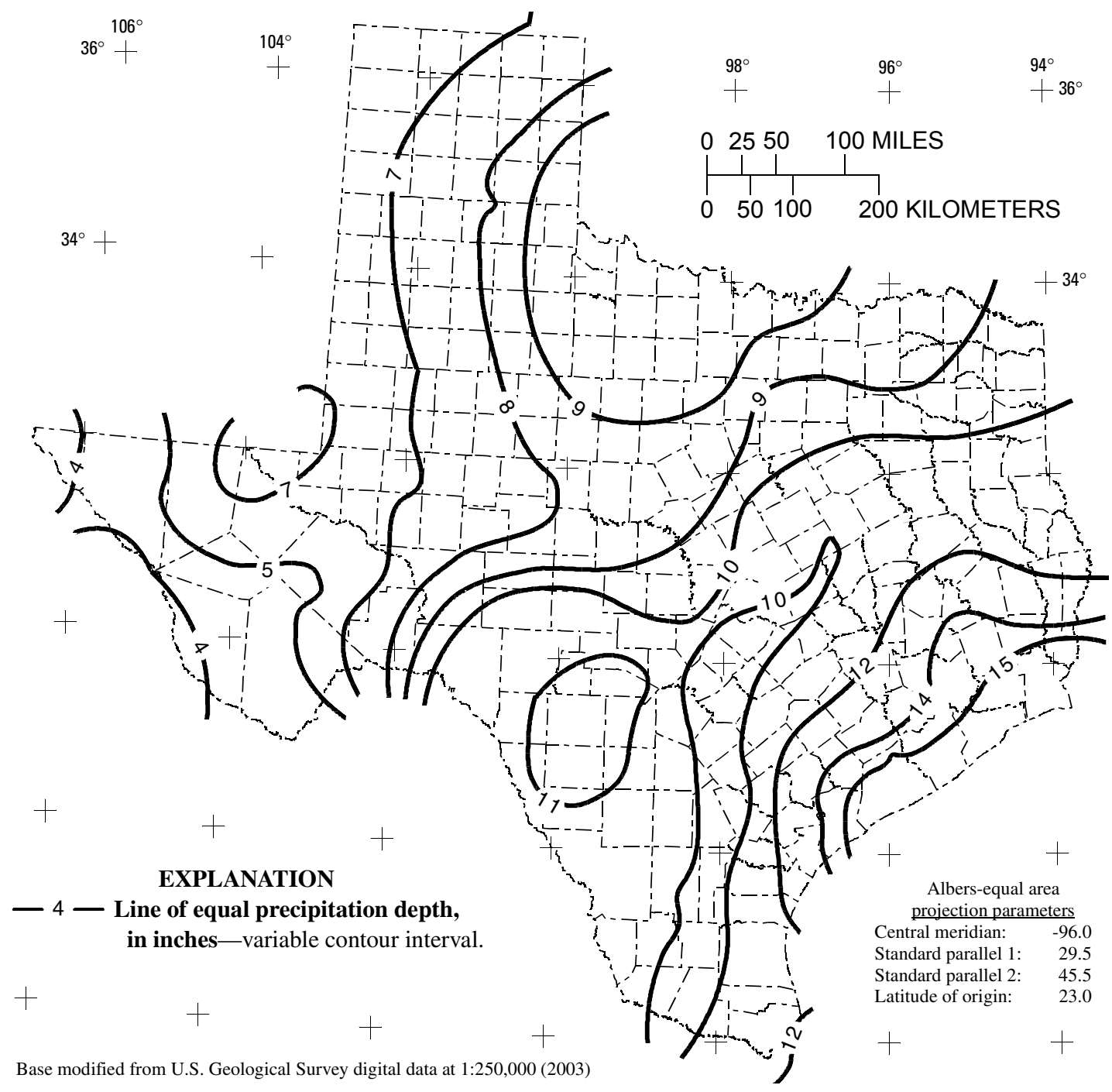

Figure 93. Depth of precipitation for 500-year storm for 6-hour duration in Texas. 


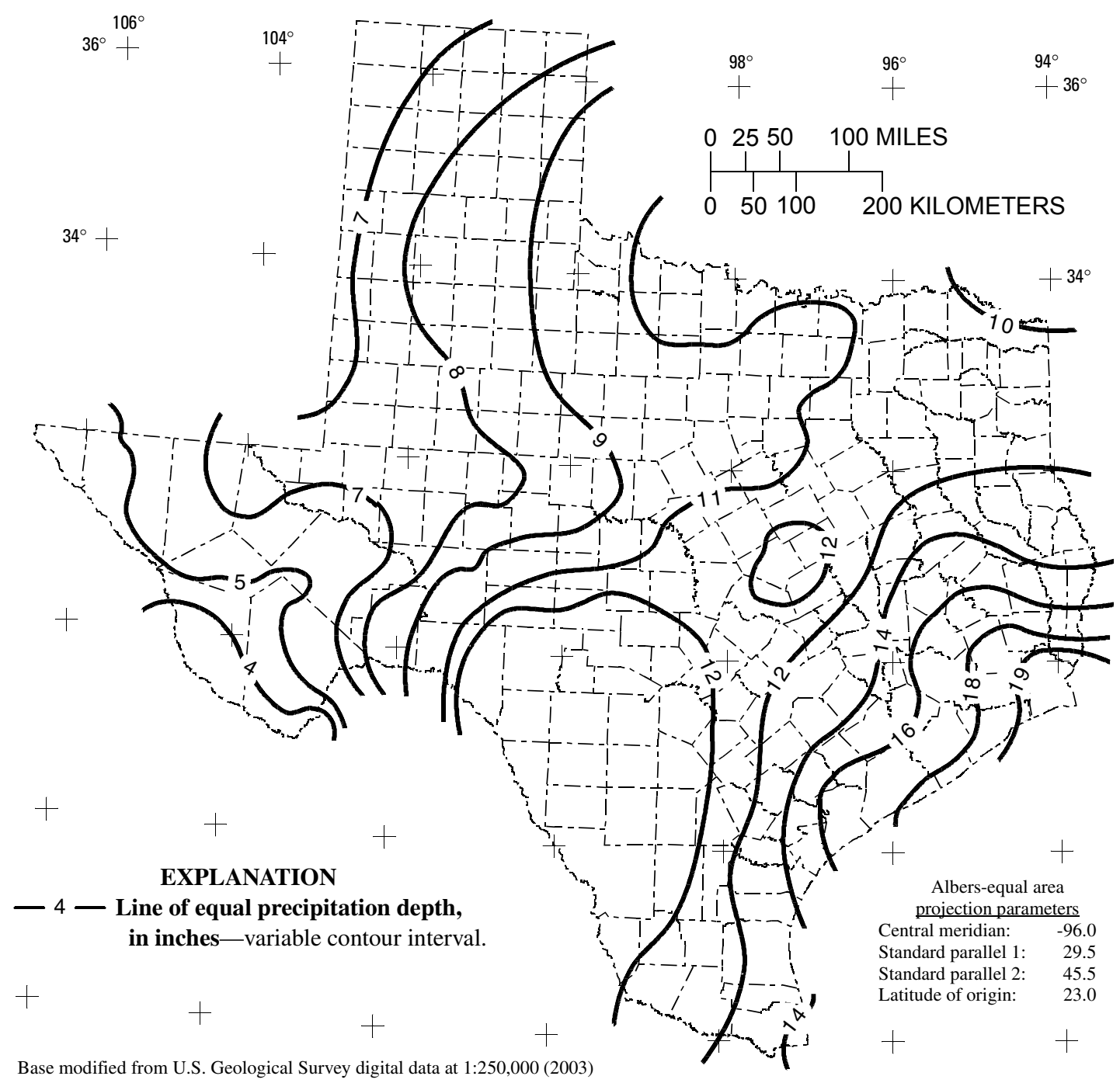

Figure 94. Depth of precipitation for 500-year storm for 12-hour duration in Texas. 


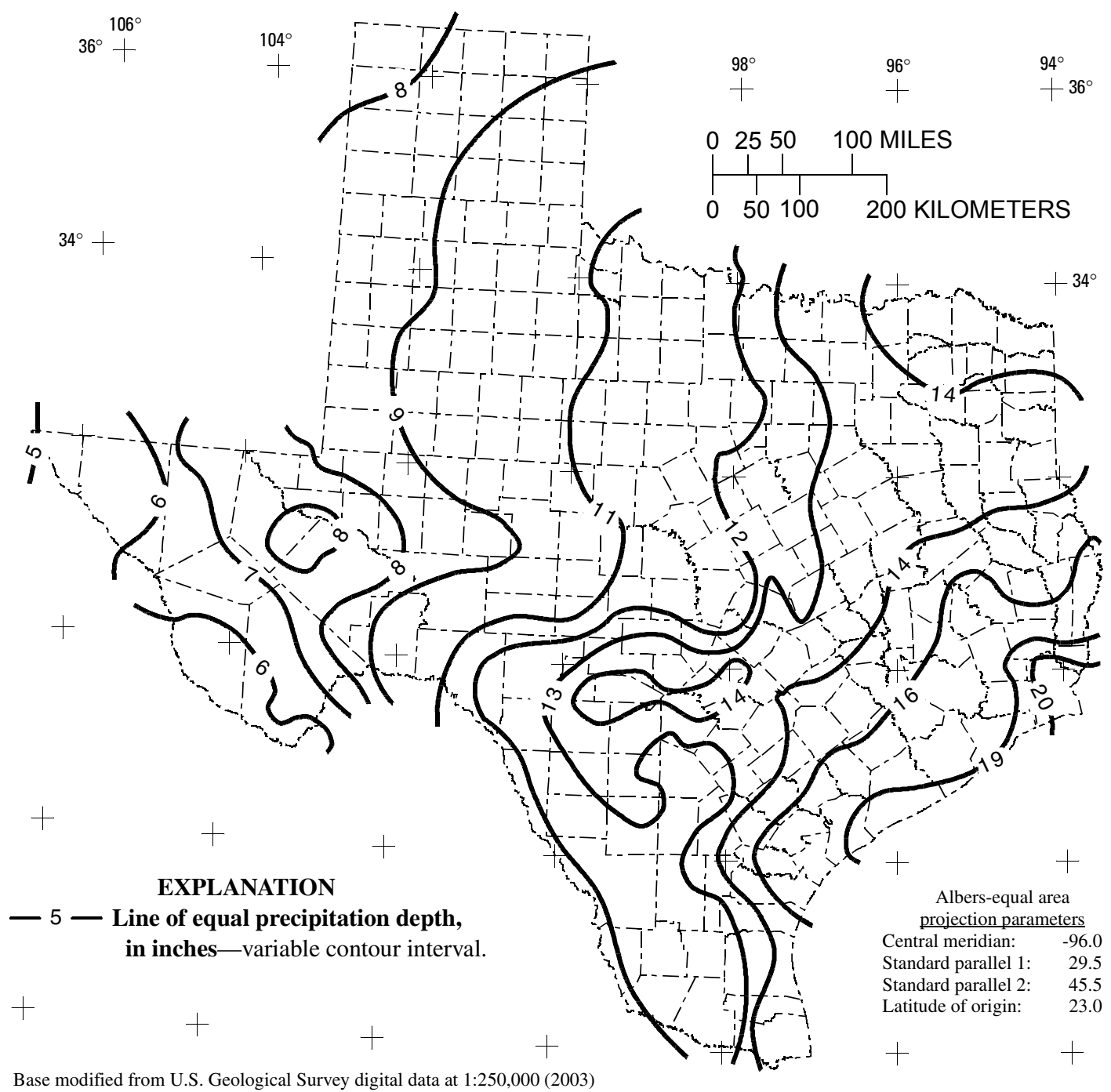

Figure 95. Depth of precipitation for 500-year storm for 1-day duration in Texas. 


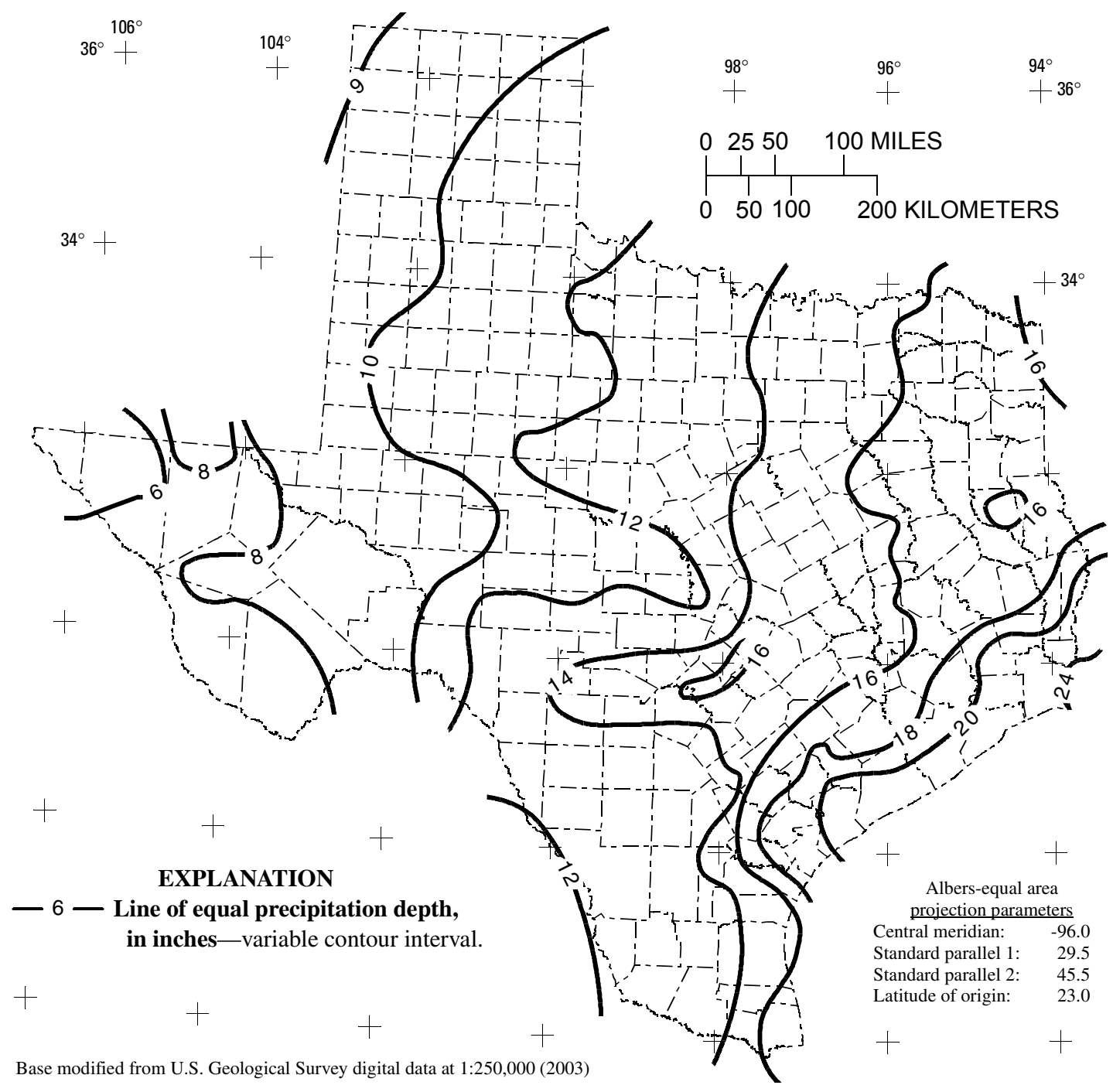

Figure 96. Depth of precipitation for 500-year storm for 2-day duration in Texas. 


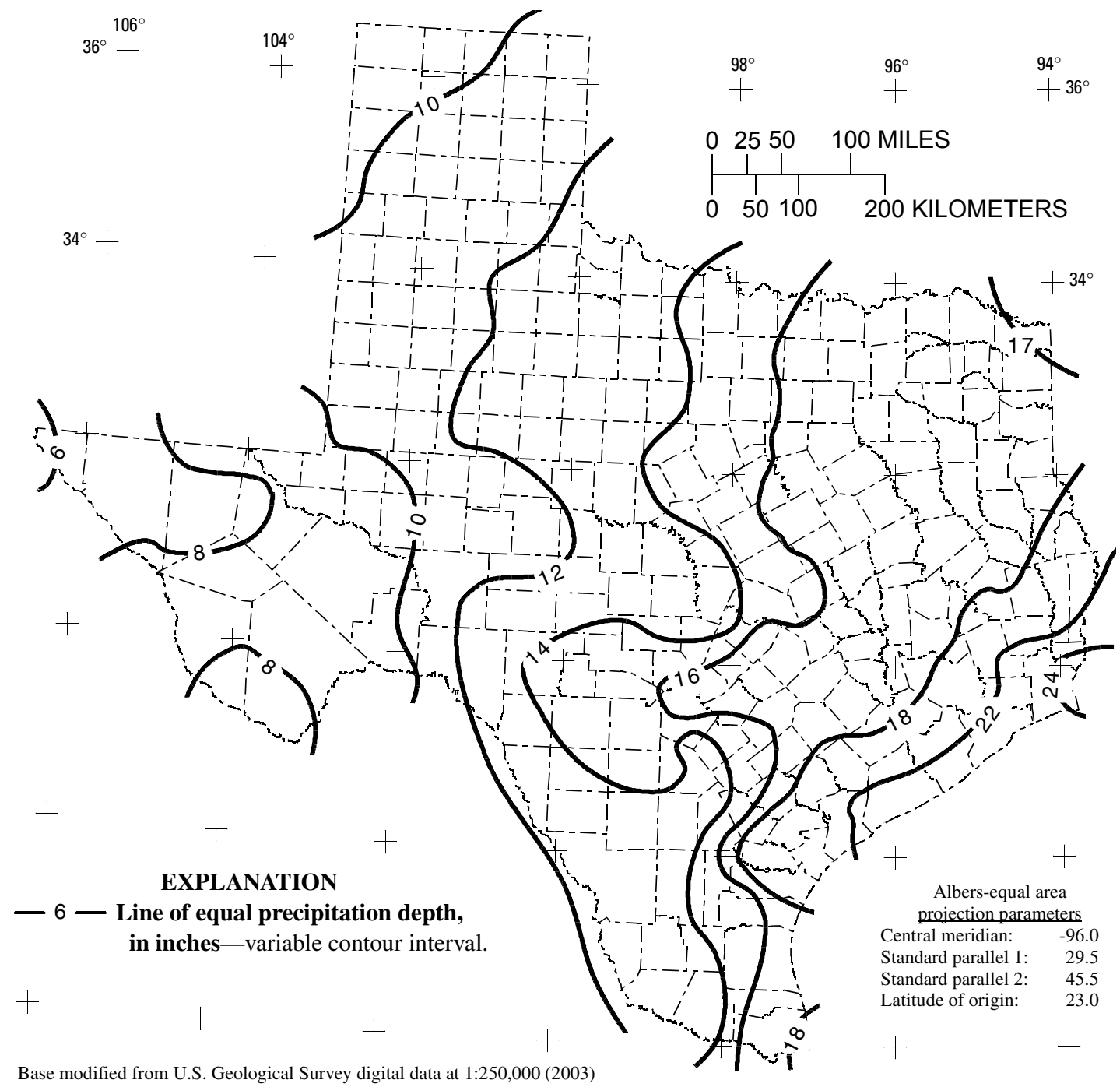

Figure 97. Depth of precipitation for 500-year storm for 3-day duration in Texas. 


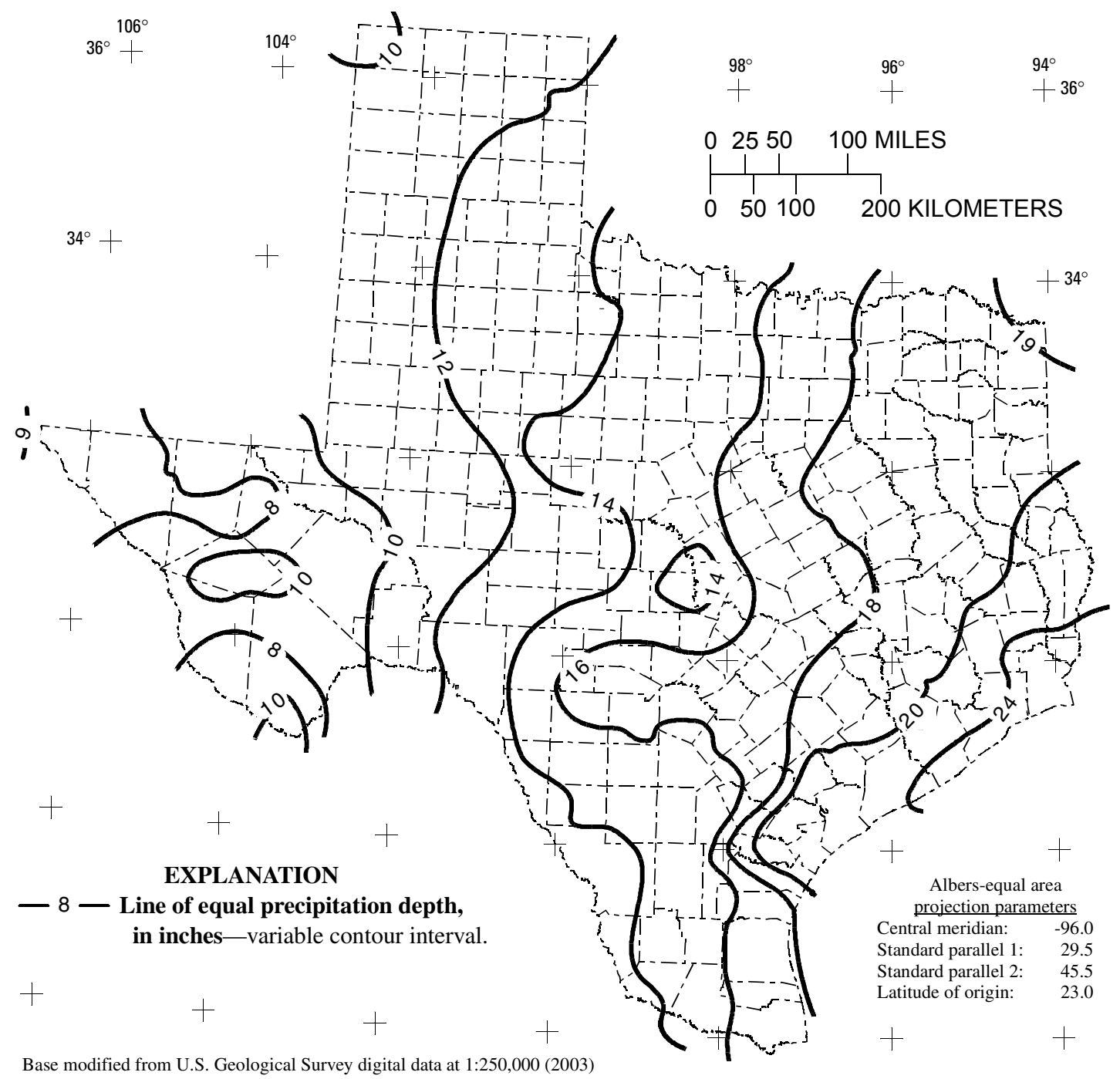

Figure 98. Depth of precipitation for 500-year storm for 5-day duration in Texas. 


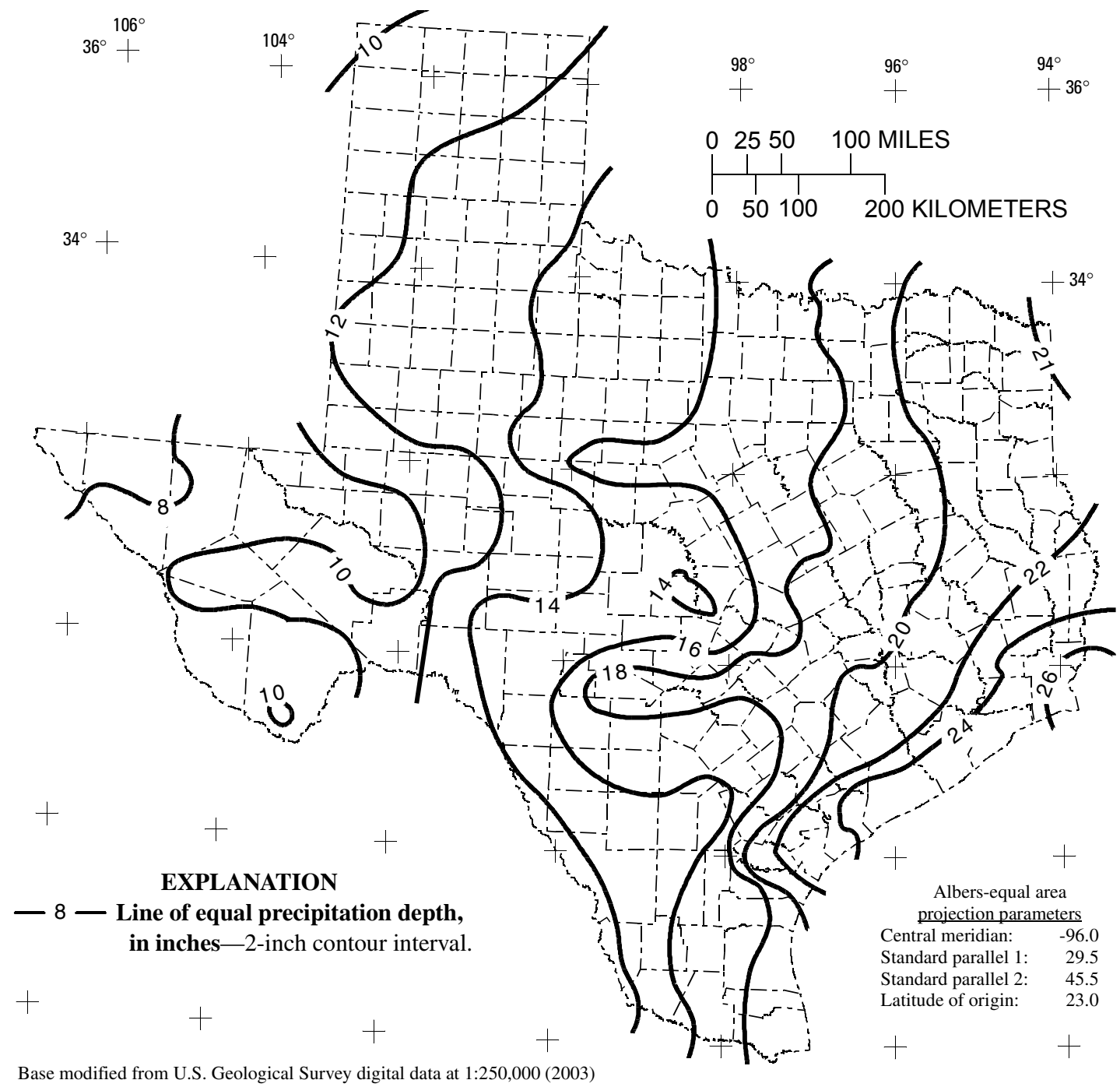

Figure 99. Depth of precipitation for 500-year storm for 7-day duration in Texas. 
Prepared by the Texas District office:

U.S. Geological Survey

8027 Exchange Drive

Austin, TX 78754-4733

Information regarding water resources in Texas is available at URL http://tx.usgs.gov/ 